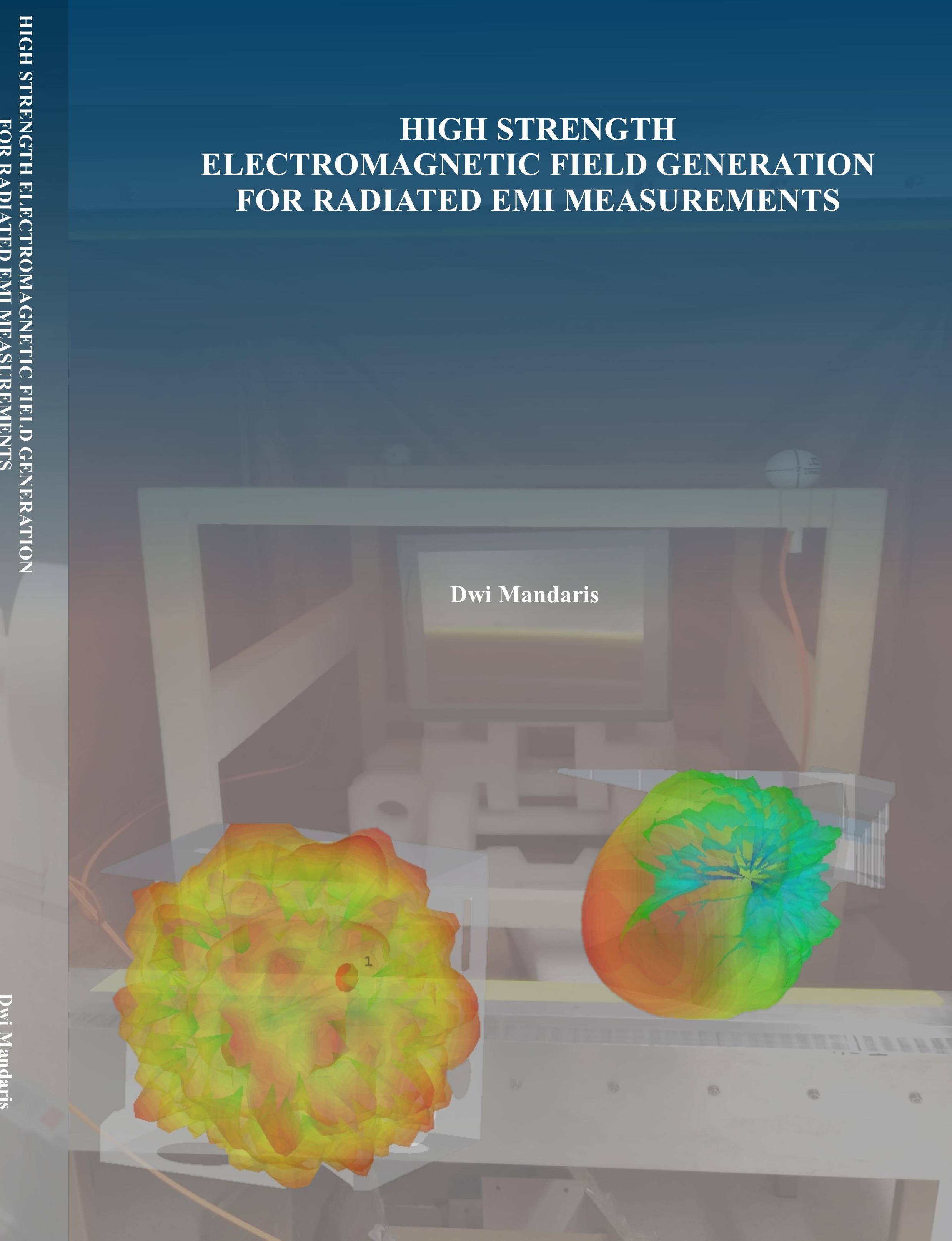




\title{
HIGH STRENGTH ELECTROMAGNETIC FIELD GENERATION FOR RADIATED EMI MEASUREMENTS
}

\author{
Dwi Mandaris
}


Members of the graduation committee:

Chairman \& Secretary:

Prof.dr. J.N. Kok

University of Twente

Promotor:

Prof.dr.ir. F.B.J. Leferink

University of Twente

Internal Members:

Prof.dr.ir. C.H. Slump

University of Twente

Dr. A. Alayón Glazunov

University of Twente

External Members:

Prof.dr. V. Mariani Primiani

Universitá Politecnica delle Marché

Prof.dr.ir. M.J. Bentum

Eindhoven University of Technology

Referee:

Dr.ir. G.S. van de Beek

ETB Energie

The research described in this thesis was carried out in the Telecommunication Engineering Group, which is part of the Faculty of Electrical Engineering, Mathematics and Computer Sciences at the University of Twente in Enschede, the Netherlands.

This research has received funding from Ministry of Research, Technology and Higher Education of the Republic Indonesia, through the Riset-PRO project and is supported by the University of Twente in the Netherlands and the Indonesian Institute of Sciences (LIPI) in Indonesia.

(C) 2020 by Dwi Mandaris

All right reserved. No part of this publication may be reproduced, stored in a retrieval system, or transmitted, in any form or by any means, electronic, mechanical, photocopying, recording, or otherwise, without the prior permission in writing from the proprietor.

Cover: designed by Dwi Mandaris

ISBN: 978-90-365-4972-1

URL: https://doi.org/10.3990/1.9789036549721

Printed by Ipskamp Printing - Enschede 


\section{HIGH STRENGTH \\ ELECTROMAGNETIC FIELD GENERATION \\ FOR RADIATED EMI MEASUREMENTS}

\section{DISSERTATION}

to obtain

the degree of doctor at the University of Twente, on the authority of the rector magnificus, prof.dr. T.T.M. Palstra,

on account of the decision of the graduation committee,

to be publicly defended

on Thursday the 30th of April 2020 at $14.45 \mathrm{hrs}$

by

\section{Dwi Mandaris}

born on the 1st of February 1977

in Bandung, Indonesia 
This dissertation has been approved by:

The Promotor : $\quad$ Prof.dr.ir. F.B.J. Leferink 
Batas langit adalah pikiran

Batas bumi adalah tubuh yang mati 


\section{SAMENVATTING}

Elektromagnetische compatibiliteit (EMC) beschrijft de stoorgevoeligheid en ongewenste emissie van elektrische apparaten. De koppelpaden tussen storend en stoorgevoelig is via geleiding of via elektromagnetische (EM) velden. De gevoeligheid van apparaten voor elektromagnetische velden, ook wel immuniteit of susceptibiliteit genoemd, wordt gemeten door het creëren van een hoge veldsterkte in een groot frequentiegebied. Die testen worden gebruikelijk in een elektromagnetisch anechoïsche kamer uitgevoerd, met grote antennes en kostbare breedband versterkers. Het onderwerp van deze thesis is het kosten- en tijdefficiënter maken van deze elektromagnetische susceptibiliteitstesten, terwijl de kwaliteit van de testen behouden moet blijven of verbeterd wordt.

Er bestaan verschillende technieken om hoge veldsterktes voor elektromagnetische susceptibiliteit op te wekken. In deze thesis worden twee methodes behandeld. In beide gevallen wordt er gebruik gemaakt van een antenne, maar het type kamer waarin de test plaats vindt zijn verschillend. De eerste is de, eerder genoemde, anechoïsche kamer (Anechoïc Chamber, AC), waarbij indirecte en ongewenste EM velden worden geabsorbeerd. De tweede kamer is de nagalm kamer (Reverberation Chamber, RC) waarin alle energie wordt gebruikt door ze bewust te laten reflecteren resulterend in een hogere veldsterkte.

Allereerst is een studie uitgevoerd naar het gebruik van verschillende antennes met de focus op het benodigde vermogen voor het creëren van constante veldsterkte met een uniforme veld verdeling. Door middel van numerieke simulaties en metingen is aangetoond dat de double-ridged guide horn (DRGH) vergelijkbare prestaties levert als de double log-periodic dipole array (LPDA), uit het oogpunt van vermogen. Maar de DRGH presteert een klein beetje beter in het maken van een uniform veld. Ook zijn twee verschillende test methoden uitgevoerd die aantonen dat de grootte van het te testen apparaat de veldsterkte beïnvloeden. Het onderzoek heeft er mede toe geleid dat in een meetstandaard de pre-kalibratie methode de voorkeur krijgt boven de klassiek gesloten-lus methode (closed-loop-leveling).

Een probleem van standaard elektrische veldsterkte meters is de meetsnelheid. De traagheid blijkt een belangrijke beperkende factor te zijn. Daarnaast is het aantal sensoren gelimiteerd omdat ze duur zijn. In sommige standaarden wordt de veldsterkte daarom gemeten met behulp van een enkele antenne met één polarisatie. In verschillende metingen die in dit proefschrift worden beschreven, worden nieuwe, snelle, driedimensionale sensoren gebruikt, die het mogelijk maken om tijdsefficiënte susceptibiliteitstesten uit te voeren. Bovendien is de snelle en zeer gevoelige veldsterktesensor geschikt voor de vibrerende intrinsieke nagalmkamer (VIRC) metingen, die een snel variërend en tijdsafhankelijk elektrisch veld (E-veld) gedrag in de kamer hebben. Om deze voordelen te bewijzen heeft een groot i 
automobielbedrijf de VIRC en het snelle multi-sensor systeem toegepast in een gesloten-lus EMC evaluatie van grote en complexe systemen. Deze meetmethode is nu voorgesteld als basis meetmethode in internationale standaarden.

Verder is de invloed van de testomgeving op de susceptibiliteit van een apparaat onderzocht. De AC is hierin vergeleken met de RC, aangezien de verschillende methodes anders met de richtingsgevoeligheid van het apparaat omgaan. Een fictief apparaat is nagebootst door een metalen doos. De metalen doos heeft gaten erin met verschillende vormen, die een zeer onvoorspelbaar maar gericht stralingspatroon veroorzaken. Voor uitgebreide testen van susceptibiliteit zijn dure breedband versterkers nodig. Door middel van reciprociteit zouden de resultaten van een susceptibiliteitstest vergelijkbaar moeten zijn met een emissie test, en daarom is in de doos een breedbandige zender geplaats, en zijn emissie metingen uitgevoerd in plaats van susceptibiliteitsmetingen. Daarmee is aangetoond dat een RC een veel betere testomgeving is dan een $\mathrm{AC}$, aangezien bij een $\mathrm{RC}$ de velden van alle kanten komen. Bij een AC zou een te testen apparaat vanuit alle richtingen belicht moeten worden door antennes te verplaatsen en bij sommige objecten is dat niet mogelijk.

Tot slot is de susceptibiliteitstest met de veldsterktesensor in de doos uitgevoerd in de AC en de VIRC om het gedrag van de apparaten te analyseren en de gevoeligheid voor het hoge E-veld dat uit verschillende richtingen komt vast te stellen. De resultaten toonden aan dat bij hogere frequenties de sensor in de doos een hogere veldsterkte kreeg dan verwacht. Dit betekent dat er een grote kans is dat in dit frequentiegebied de slechtst denkbare interferentie in de box wordt gekoppeld, en daarna in het meest gevoelige deel van het apparaat. In de VIRC, gebruikmakend van een lager vermogen en een snellere meettijd, worden dezelfde resultaten verkregen als in de AC.

Concluderend kan worden gesteld dat de klassieke antennetechniek in de AC methode duur is, vooral vanwege de benodigde veld absorberende materialen en dure breedbandversterkers. Bovendien heeft de huidige AC methode een beperkte robuustheid, omdat maar enkele invallende richtingen en veldpolarisaties worden getest en dus niet lijken op datgene wat gebeurt in de werkelijke leef- en werkomgevingen. De (VI)RC-methoden hebben veel lagere kosten voor apparatuur en belicht een apparaat vanuit alle richtingen.

Verder onderzoek zou zich kunnen richten op het gedrag van apparaten voor velden vanuit verschillende richtingen en tijdsvariërende EM velden. De richtingsgevoeligheid wordt belangrijk bij hogere frequenties. Tijdafhankelijke velden spelen een rol in de belichtingstijd, met andere woorden de tijd dat een apparaat door een EM veld wordt belicht. 


\section{SUMMARY}

Electro-magnetic compatibility (EMC) is an important parameter to guarantee that electronic and electrical products are electronically compatible with their environments.

Radiated immunity (RI) testing, also called radiated susceptibility (RS) testing, requires a high field strength to illuminate the equipment under test (EUT). The crucial and important components of a susceptibility test system are the indispensable and high-cost power amplifier, an anechoic chamber (AC) and a proper antenna. The challenge and topic of this thesis is to make the RS test more effective to lower the cost of equipment, and more efficient by saving test time, while maintaining or improving the quality of the test results.

There are three major techniques for creating high field strength for RS testing: an antenna inside the $\mathrm{AC}$, an enclosed coaxial structure like the transverse electromagnetic (TEM) cell, or the reverberation chamber (RC). This thesis studies two methods: the antenna structure as a transmitting transducer inside the $\mathrm{AC}$ and the RC structure for creating high field strength for EMI testing.

First, the antenna technique has been investigated by exploring and improving our understanding of the power required by the antennas and resulting field obtained in the uniform field area (UFA). By means of measurements (empirical) and numerical simulation it is shown that a double-ridged guide horn (DRGH) is comparable to a double log-periodic dipole array (LPDA) antenna in terms of power-to-field-strength and is slightly better in creating good field uniformity (FU). Additionally, two different RS test methods have been studied showing that the size of the EUT affects the field strength. This research result supported the change in some standards where pre-calibration (or substitution) is now preferred above closed-loop-levelling when testing large EUT.

Radiated electromagnetic (EM) field measurements in different environments, using the AC antenna technique, the TEM method, and the RC method have been investigated to analyze the relationship between the receive- radiation-pattern of an EUT and the test technique. Focusing on RS, this research could have been using an EUT with indication of the perceived field strength. In this work, such a fictitious EUT was replaced by a field strength sensor. By adding a box with different holes and hole patterns, a real-life EUT could be replicated. Although using this validation approach is very valid, it is cumbersome and costly, as high-power amplifiers are needed for all test environments. By using the reciprocity concept, the validity of comparing test environments is performed using radiated emission (RE) measurements where a broadband emitter was used as source.

One major issue in applying the $\mathrm{RC}$ technique is the slow readout of electric field strength probes, and a key limiting factor in a widespread use of RCs. Furthermore, the number of sensors is often limited. In some standards, the field strength is monitored and/or measured using a single antenna (polarization). In various 
measurements described in this thesis fast three-dimensional (3D) sensors which allows time-efficient RS testing are used. Moreover, the fast and very sensitive field probe are best suited for vibrating intrinsic reverberation chamber (VIRC) measurements, which have rapid and time-varying electric field (E-field) behavior inside the chamber. To prove these advantages, a major automotive company has applied the VIRC and the fast multi-probe system that allows closed-loop EMC evaluation of large and complex systems.

Finally, the RS test inside AC and VIRC with the box with field probe inside to represent EUTs were investigated to analyze the EUTs behavior and its susceptibility to the high E-field coming from various directions. The results showed that at higher frequencies, with thirty-six points in rotation increments, the probe inside the box received higher E-field strength than the target field. This implies that there is a high probability that in this frequency range the worst-case interference is coupled into the box and hitting the most susceptible part of the EUT. In the VIRC, with lower power and faster measurement time, the same results are also obtained.

In conclusion, the classic antenna technique in the AC method is expensive mainly due to the necessary EM absorbers and expensive power amplifiers. Furthermore, the current AC method has limited robustness, since a few incident directions and field polarizations are tested, and thus does not resemble actual living and working environments. The (VI)RC has much lower costs for equipment, and illuminates an EUT from all directions, thus resembling actual living and working environments.

Further research is suggested and could be focused on the behavior of EUT for directivity and in time-varying fields. The directivity becomes important at higher frequencies. Time-varying fields play a role in the dwell time, which is the time an EUT is illuminated. 


\section{TABLE OF CONTENTS}

SAMENVATTING ............................................................................. i

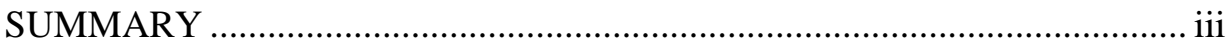

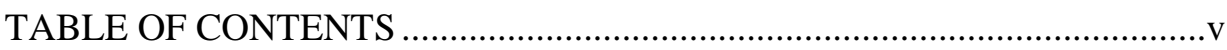

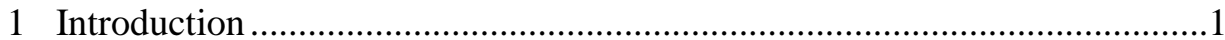

1.1 Background and Motivation..................................................

1.1.1 Generating High Field Strength ........................................2

1.1.2 The Required Power and Electric Field ..............................3

1.1.3 The Size of Equipment Under Test (EUT)..........................5

1.1.4 The Frequency Range ................................................ 7

1.2 Problem Formulation ..................................................................

1.3 Research Objectives ....................................................................

1.4 Thesis Structure ..................................................................

2 Antennas for Generating High E-Field Strength ...................................... 11

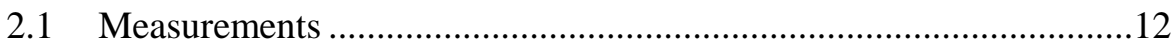

2.1.1 Measurement Setups ............................................... 14

2.1.2 Experimental Results ...............................................16

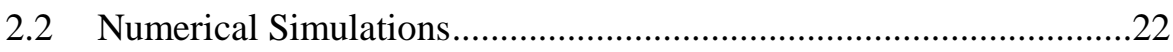

2.2.1 Antenna Models ............................................................24

2.2.2 Simulation Results .....................................................26

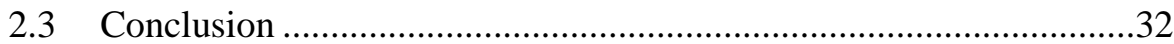

3 Generating E-field Strength in Active Leveling and Pre-Calibration ..........33

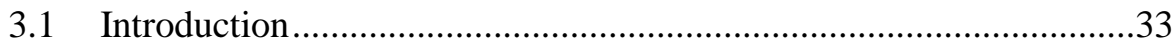

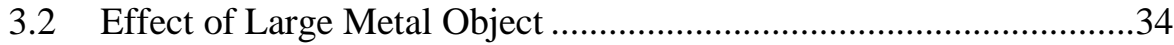

3.3 Influence of Vertical Grounded Wire .............................................37

3.4 Active Leveling and Pre-Calibration ..........................................41

3.4.1 Active Leveling..........................................................41

3.4.2 Pre-Calibration / Substitution Method ...............................44

3.4.3 Theoretical Calculable Method ........................................43

3.4.4 Experiment Setup .......................................................43 


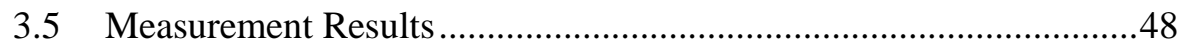

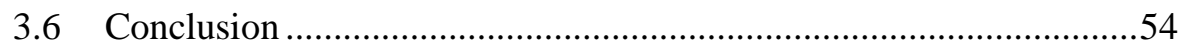

4 Generating High E-Field Strength: Reverberation Chamber .......................56

4.1 Reverberation Chamber: Overview ………………........................56

4.2 Simultaneous Multi-Probe System for the Rapid Evaluation of RC .57

4.2.1 Setup Description of the Reverberation Chambers................59

4.2.2 Results and Discussion ......................................................62

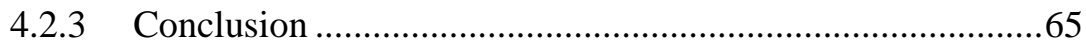

4.3 Time-Efficient Reverberation Chamber Performance Analysis ........65

4.3.1 Stirrer Evaluation Methodology.............................................66

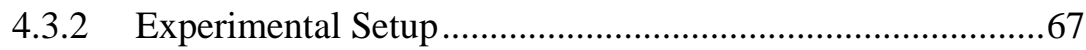

4.3.3 Result and Discussion .......................................................69

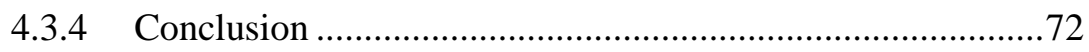

5 Radiated Electromagnetic Fields in Different Test Environments...............74

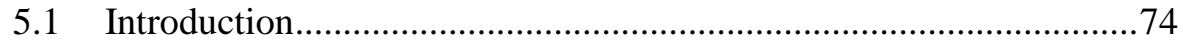

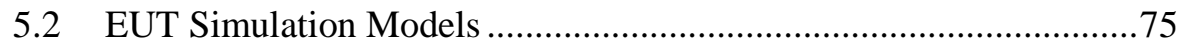

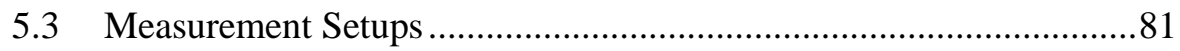

5.3.1 Fully Anechoic Room (FAR) .............................................. 81

5.3.2 Semi Anechoic Chamber (SAC) .......................................... 83

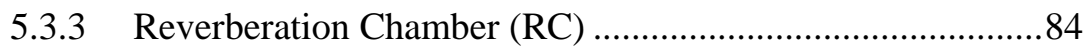

5.3.4 Vibrating Intrinsic Reverberation Chamber (VIRC).............85

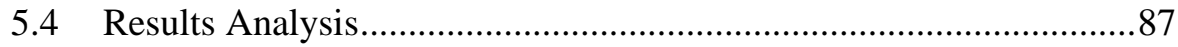

5.4.1 Comparison: Simulation vs FAR ………………………..... 87

5.4.2 Comparison: EUTs at the Different Test Sites......................91

5.4.3 Comparison: RC vs VIRC ................................................94

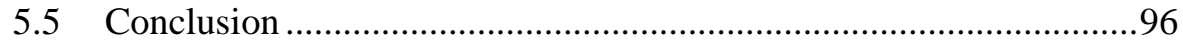

6 Generating High Field Strength for RS Measurement .................................98

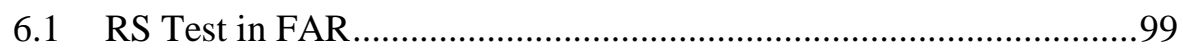

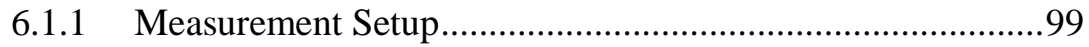

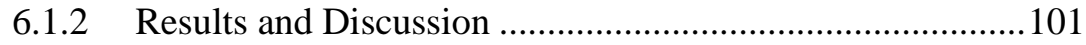

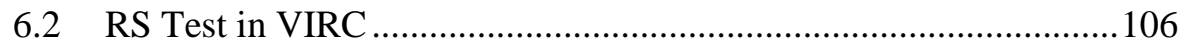

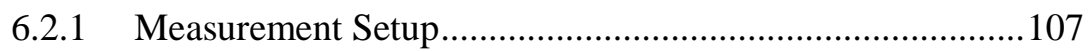


6.2.2 Results and Discussion......................................................108

6.3 FAR vs VIRC Test Comparison ................................................111

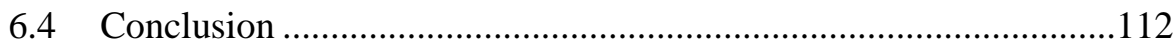

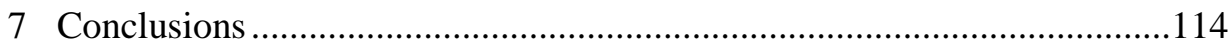

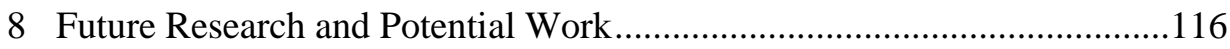

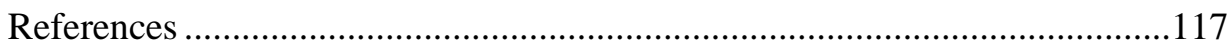

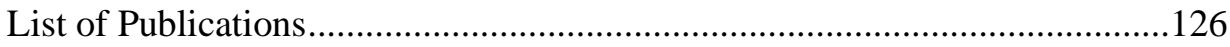

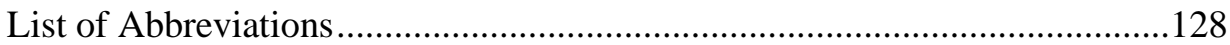

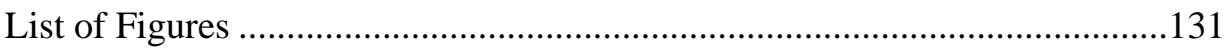

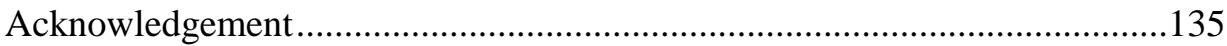

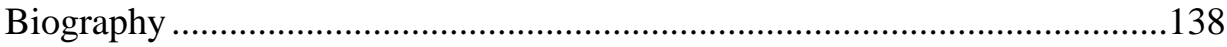




\section{Introduction}

\subsection{Background and Motivation}

The deployment of electronic products in everyday life is significantly increasing the number of electromagnetic emission sources due to the improvement of telecommunication technology, for example, the amount of wireless communication is growing rapidly (e.g. Wi-Fi, Bluetooth, $4 \mathrm{G}$ and $5 \mathrm{G}$ technologies, wireless sensor networks (WSN), radar, smart cities concept and more). These sources are becoming more compound and in many cases, these products emit a lot of unwanted signals to one another. Moreover, the increasing complexity of the electromagnetic environment is also caused by electronic devices that are evolving towards higher frequencies, smaller designs with limited electromagnetic compatibility (EMC) measurements and lower power levels of operation. Electromagnetic emissions in such environments can easily be the cause of much electromagnetic interference (EMI). EMC is defined as "the ability of the equipment, subsystem or system to share the electromagnetic spectrum and perform at the same time its desired function without unacceptable degradation from or to the environment in which it exists." [1]

Today's electronic devices must be designed to be acceptably compatible with other electronic products. A key aspect of proper electronic design and optimization is EMC testing ${ }^{1}$. The different existing test methods have been developed from classic concepts and techniques, such as free space radiation, and are polluted by metrology concepts which are different from the objectives of EMC. Many EMC test laboratories are still applying these conventional EMC tests (and relying on them) inside a semi-anechoic chamber (SAC), which are mimicking open area test sites (OATS), both for radiated emission (RE) and radiated susceptibility (RS) testing.

There are some noticeable drawbacks of the conventional SAC EMC technique:

- It requires expensive facilities, like an anechoic chamber, absorbers, and high-power, expensive amplifiers used in RS testing

- It is time-consuming for EMC radiated testing. In order to be able to capture all EM emissions in any direction and for all possible test setups, one has to turn a turntable, change the antenna height, and measure in two polarizations

For radiated susceptibility (RS) EMC testing, a high field strength has to be generated, making RS testing one of the most expensive aspects of an EMC assessment. This is mainly due to the high cost of the range of high-power broadband radio frequency (RF) amplifiers needed to drive the variety of antennas

\footnotetext{
${ }^{1}$ Actually we should call it EMI testing, but in common language people talk about EMC testing
} 
used to cover frequencies from $10 \mathrm{kHz}$ (military) or $80 \mathrm{MHz}$ (civilian) up to $1 \mathrm{GHz}$ or $6 \mathrm{GHz}$ (civilian) [2] and $18 \mathrm{GHz}$ or $40 \mathrm{GHz}$ (military) [3][4]. Additionally, the screened room or anechoic chamber (AC) and the radio absorbing material are also costly items and increase the capital investment which must be made by the test laboratory if the RS testing is to be performed [5]. Furthermore, all the measurement equipment also has to follow requirements defined by the CISPR 16-1 standard [6].

Moreover, especially in developing countries like Indonesia, cost and test time are big problems when we want to build and develop a decent EMC testing facility. That is the focus of this thesis: identifying more cost-effective and more timeefficient EMC techniques.

Some techniques for producing high field strength have been compared before, and these techniques have been investigated in further detail to acquire the optimum power-to-field-strength $(\mathrm{P} 2 \mathrm{E})$ ratio and applicability for EMC testing. The approach followed addresses the transmitting transducer for producing the high field strength, which falls into three classes. First is free wave field generation, which means that an antenna is utilized inside an AC. The chamber is needed to prevent any leakage of the generated field into the external environment and vice versa. The second method is a bounded wave-field, which means that the source of the generating signal is bounded into a stripline or micro-strip, such as a TEM cell-like generating structure [5]. The last technique of generating high field strength is utilizing a reverberation chamber (RC) structure [7][8][9][10]. These three test techniques, including variations like fully anechoic room (FAR), were studied in order to improve understanding and provide insight into creating high E-field strength with moderate power, working in a wide frequency range, investigating the field homogeneity (uniformity) in the chamber, determining the influence of large EUT on the E-field reading, and determining the ability of a test technique to reproduce real (semi-enclosed) environments like houses, offices, trains, cars, etc.

\subsubsection{Generating High Field Strength}

According to the standardization scheme recognition, the common and conventional way to perform the RS EMC test is to use an antenna inside the AC [2][3][4]. The level of the field needed depends on the product categories, as stated in the related standard. Other techniques are also allowed as an alternative test, such as a TEM cell and RC. Figure 1.1 (a) and (b) show two facilities for creating a high field strength inside the chamber. 


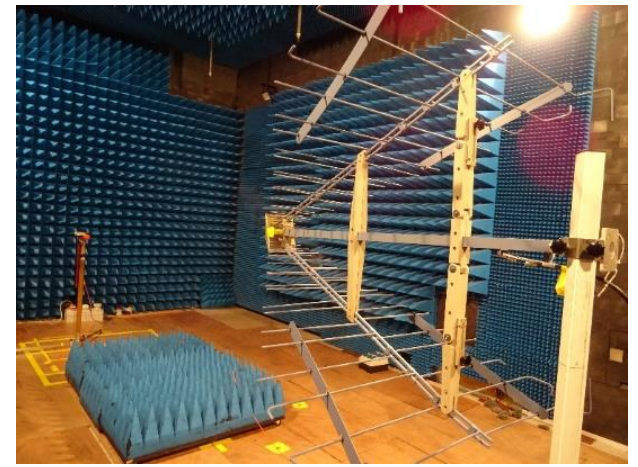

(a)

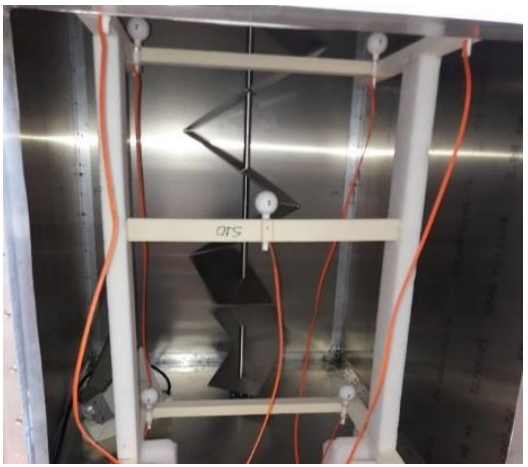

(b)

Figure 1.1 Generating high field strength (a) inside a fully anechoic chamber and (b) inside a reverberation chamber

All techniques have their advantages and disadvantages for generating high field strength. In order to determine the optimum choice in creating high field strength, three different key aspects which might give better knowledge and understanding have been investigated. These key aspects are as follows:

- The P2E

- The size of EUT and thus the required uniform field area (UFA)

- The frequency range

\subsubsection{The Required Power and Electric Field}

The log-periodic dipole array (LPDA) and the double-ridged guide horn (DRGH) antenna are very popular transducers to produce high field strength in AC. The schematic diagram for creating a high field with an LPDA is depicted in Figure 1.2. As illustrated - with respect to the required power - in order to achieve E-field $10 \mathrm{~V} / \mathrm{m}$ in the probe side, the system need the amplification of $47 \mathrm{~dB}$, for example.

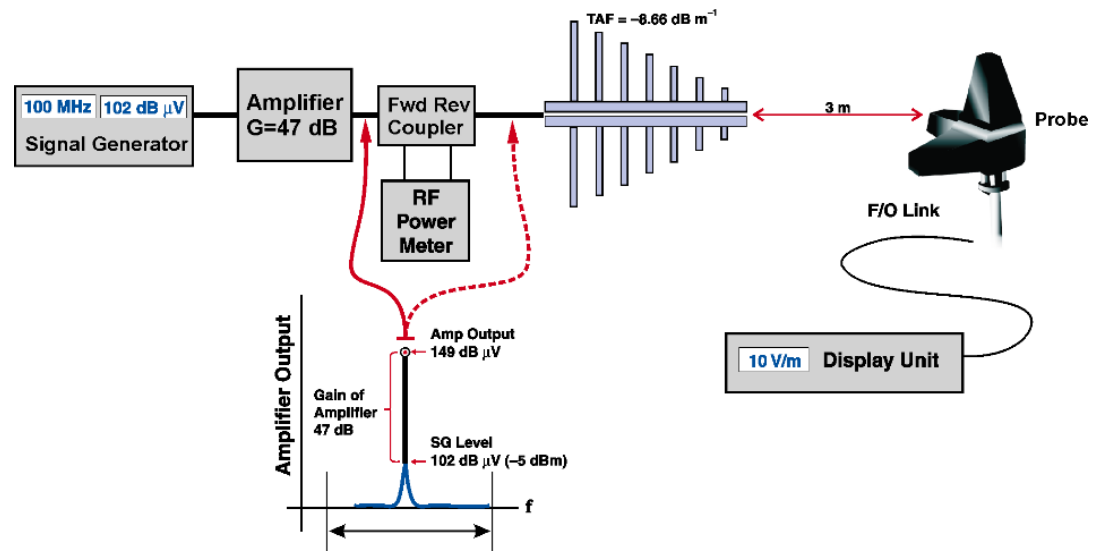

Figure 1.2 An example of a diagram in generating high E-field strength 
This is for $10 \mathrm{~V} / \mathrm{m}$ E-field strength, but the required level depends on the operational environment. For instance, automotive and military equipment require up to $600 \mathrm{~V} / \mathrm{m}$ and up to $200 \mathrm{~V} / \mathrm{m}$, respectively [3]. Although this is a common issue in the EMC world, very little literature exists. It is quite obvious that the key element is the antenna, which should give sufficient directivity in both planes (horizontal and vertical). On the other hand, the directivity should not be too much, as it will decrease the UFA. In order to improve our understanding and gain insight into the underlying properties of the antennas, a lot of measurements have been performed and supplemented with simulations. By analyzing both measurement and simulation results, the power needed by the antenna and the UFA were investigated [11][12], [13].

However, this does not help to avoid the existing costly AC facilities with field absorbers. Another disadvantage when using antennas is the long test time, as an EUT has to be illuminated from all directions. A further essential problem is the size of the antenna. Theoretically, the antenna length is proportional to the longest wavelength, or lowest frequency of the band. In order to reach a minimum frequency of as low as $80 \mathrm{MHz}$, which is the default starting frequency for IEC-based standards, more than $1 \mathrm{~m}$ antenna size is required to make sure that the far-field region is reached [14]. Another issue is the vertical polarization when employing LPDA antennas [11], as the tip of the dipole array is near to the metal floor, which causes coupling.

The second technique to develop a high E-field is the stripline or TEM cell-like structure [15]. The stripline TEM-like antenna technique was developed in 1971 and the rectangular, so-called Crawford cell was built for calibration purposes by the National Bureau of Standard (NBS) [16]. After that, many kinds of TEM cell improvements were made and a comprehensive review of these TEM cell techniques can be found in [15]. This paper also proposes applying the new concept of the balanced stripline antenna and the results showed that, compared to the conventional antenna technique, the stripline required less power, gives better field uniformity (FU) and operates in a larger frequency range. The current state-of-theart technique, well known and widely applied [17], is GTEM as an alternative EMC test method. In terms of P2E, this is an interesting technique to develop a high Efield with moderate power. As mentioned in [15], the power needed for the antenna to achieve $10 \mathrm{~V} / \mathrm{m}$ is below $1 \mathrm{~W}$. As a comparison, in a normal anechoic shielded enclosure, at least $100 \mathrm{~W}$ is needed to generate a field strength of $10 \mathrm{~V} / \mathrm{m}$ over an area of $1.5 \mathrm{~m} \times 1.5 \mathrm{~m}$ [5][15]. However, the TEM cell technique is not within the scope of this thesis.

The last one is the $\mathrm{RC}$ technique. $\mathrm{RC}$ is an alternative test technique capable of creating high field strengths. The RC was introduced for the first time in MIL-STD 1377. An RC is an electrically large, multimode and highly reflective cavity or environment. Many publications on the RC can be found in the literature, for instance [9] [10] [18] [19]. Some advantages of using the RC technique include: 
- A considerably large working volume compared to the total volume in the chamber [20]

- There are no disruptive ambient signals because RCs work in a screened environment

- $\mathrm{RCs}$ work in a relatively wide frequency range [21]

- When performing RE or susceptibility tests, the EUT directivity, position and/or orientation is irrelevant

- Particularly for RS testing, the RC technique requires much less power for generating a high field strength compared to the $\mathrm{AC}$ technique

The RC technique has attracted many researchers for several decades. A lot of effort has been put into improving the technique for many applications [22][23][24][25], reviewed different types of RC and stirring strategies [26] and performance characteristic for different purposes [27]. Currently, as an alternative method, the RC standard has been developed as a guide to carry out RE or susceptibility EMC testing [8]. With respect to P2E, RC is the best. It is possible to generate very high E-field strength with a small amount of input power, for instance for RCs with $1.2 \mathrm{~m}^{3}, 1 \mathrm{~W}$ gives $100 \mathrm{~V} / \mathrm{m}$. Furthermore, the RC also does not require expensive absorbers on the ceiling and walls of the chamber. The RC is a very promising technique because of its $\mathrm{P} 2 \mathrm{E}$ ratio, and therefore a main part of this thesis is devoted to the study of this technique.

\subsubsection{The Size of Equipment Under Test (EUT)}

Antennas are the default transducer inside an AC that illuminates any EUT size. As long as the AC and its UFA are big enough for a very large EUT, the test can be done appropriately. However, as mentioned before, this sophisticated testing facility is very costly. Large EUTs, such as very large industrial equipment, large radar equipment, airplanes, and so on, need a very large capacity chamber. Transport to the EMC laboratory is also an issue. If this is not possible, testing has to be done on-site. Additionally, when testing large EUTs, the conductive metal plates of the EUT will disturb the E-field level, which results in over-stressing (testing) or understressing the EUT susceptibility level [28].

The size of the EUT is the main problem of the TEM cell technique. The geometry of the TEM or GTEM cells has the limitation of having a small test volume, as approximately one-third can be occupied as a working volume. The TEM and GTEM dimensions are also limited at higher frequencies due to multi-mode resonances. 


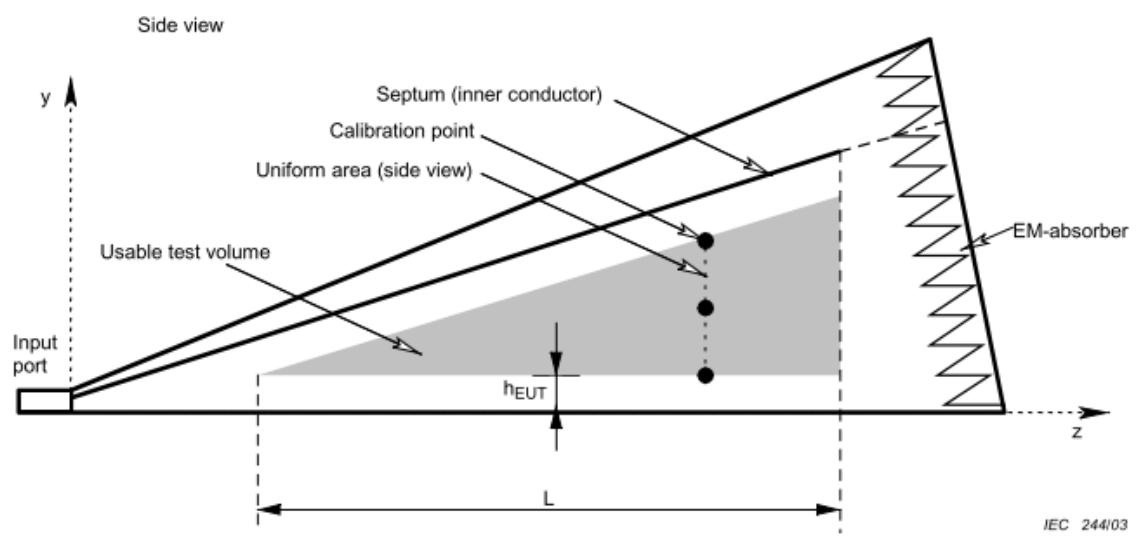

Figure 1.3 Side view of GTEM working volume points [17]

For instance, as can be seen in Figure 1.3, due to the geometry of the GTEM, the working volume is relatively small compared to the GTEM dimension. Of course, we could extend the size of the GTEM cell, but this would affect the need for input power [5], while the GTEM would also be less usable at higher frequencies due to the presence of resonances.

Another type of screened room which varies between the TEM cell concept and the classical chamber is called dual-polarized broadband field generator (BFG), as described in [29]. The idea was to use the existing chamber and place a stripline at both the horizontal and vertical polarization. This BFG and the balanced stripline antenna [15] seem to be the best TEM cell-like structure so far, as it uses moderate power, has considerably good uniformity, and covers a broad frequency range. It can also be used to test large-size EUTs. However, this TEM version still has to be operated inside a big and costly AC.

Large EUTs can, however, be tested easily inside an RC. However, a larger EUT also means a bigger RC, which creates higher costs, especially when the RC is a big metallic box, like the classical one. However, there is another type of RC which is made from conductive fabrics: The vibrating intrinsic reverberation chamber (VIRC) [9]. It is simpler, lighter, and does not need extra space inside the laboratory; it can be folded and put away fast. Moreover, the most important advantage of the flexible structure of the VIRC is that it can be installed in-situ [30]. The VIRC is operated by moving the walls, while a classical RC makes use of a stirrer or tuner. If the stirrer is rotated continuously, we call it a mode stirred chamber. In this case, the field variation over time is fast. The mode tuned technique makes use of discrete steps of a motor for rotating the tuner. In this case, the field is stable until the stirrer is moved to the next position. The mode stirred technique is much faster at measuring than the mode tuned technique, but for some applications where the equipment under test has a long dwell time, mode tuned is preferred. In this case, the tunable intrinsic reverberation chamber (TIRC) can be used [31]. This is a VIRC, 
but the walls are not moving or vibrating continuously. The walls can be moved using a stepper motor, or the modes can be changed using a conventional paddlewheel driven by a stepper motor. The fields can therefore be mode-tuned in a TIRC, instead of mode-stirred in a VIRC.

\subsubsection{The Frequency Range}

When we look at the operating frequency range, especially for the antenna technique, the lower frequency is a problem due to the near field effects and absorbers, which do not work very effectively. But the main problem at lower frequencies is that the size of the antenna is small with respect to the wavelength and therefore has very low efficiency. In general, the lower the frequency, the bigger the antenna. At high frequencies, above a few $\mathrm{GHz}$, the radiation pattern is much more complex, which makes it more difficult to achieve a good UFA.

The TEM cell can be used until the height of the septum becomes a half wavelength. The GTEM extended this range, although for higher frequencies multiple resonances occur due to coupling of the EUT with the septum, higher order modes and resonance, and in general the GTEM is limited to a few GHz.

The RC has a relatively wide test frequency range, starting from the lowest usable frequency defined by the point where statistical FU can be achieved. Using the VIRC is even better, as it also works at lower frequencies than classic modestirred RCs [9] [21]. An RC starts when approximately 60 modes can be generated. The $\mathrm{RC}$ is an EMC test technique which creates a P2E ratio and a large statistically uniform area of illumination and is much faster because of its isotropy. [32][33].

This is why one of the focal points in this thesis is investigating the applicability of the RC in generating high field strength for EMC testing.

\subsection{Problem Formulation}

Based on the background and motivation, in order to create the high field strength for EMC testing, there are three basic techniques for creating high field strength. These can be used for RS EMC testing: Antenna technique inside an AC, TEM cell technique, and RC technique.

The required power to produce similar E-field strength, P2E, the UFA and the test technique comparison are the main focus of this research. In this thesis, the techniques for generating high field strength are studied and evaluated: the antenna technique as a basic generating transducer, and the RC technique.

The first focal point of this thesis is to research the capability of the basic antennas inside the AC by means of measurements and numerical simulation to create high field strength. Three basic antennas have been examined and some issues 
were revealed. Additionally, this thesis also explored the effect of large EUTs on the UFA with respect to the pre-calibration and leveling RS method.

The experiment using RC with simultaneous multiprobe-system was also studied to analyze the behavior of the field inside RC and statistically UFA using different stirring technique. What are the benefits of using RC technique?

When comparing the different test techniques, some interesting issues arose about the correlation between different test techniques. What are the possibilities for using $\mathrm{RC}$ and what are the benefits of using the RC structure compared to another technique in generating high E-field strength for EMC testing with respect to the power, E-field produced, and also by investigating the behavior of different EUT as well as the testing time.

\subsection{Research Objectives}

Based on the background stated previously, the research objectives are:

- Understand the high strength E-field generation technique for EMI measurements by studying and analyzing the conventional antennas technique inside $\mathrm{AC}$ with respect to the required power and produced $\mathrm{E}$ field strength. Additionally, investigate the FU and find the limitation of antenna technique in the lower frequency band.

- Understand the E-field behavior regarding the conventional RS EMC testing inside $\mathrm{AC}$ using pre-calibration method and leveling method.

- Understand the high strength E-field generation techniques in RCs by investigating the environment using a simultaneous multi-probe system.

- Provide information and investigate the correlation of radiated field measurements using antennas in FAR, AC and RCs by using dummy EUTs as radiators contained in metal boxes with holes and tubes, representing real equipment, and showing the radiated E-field behavior of these EUTs in different test techniques.

- Give recommendations and discuss the possibility of creating high strength E-field for cost-effective RS EMC measurements.

\subsection{Thesis Structure}

The outline of the thesis is in line with the research goals stated in the previous chapter. Chapter 1 provides background information and motivation for why this research was carried out.

Chapter 2 gives a description and analysis of three different antennas for generating the E-field. The investigation is based on the required power, the produced E-field, FU and the working frequency band. Antenna design and simulation were done by 3-D full-wave simulation software and many 
measurements were performed in order to confirm the results. From these measurements, we can compare the results of those antennas with respect to P2E and UFA. With respect to the size of the EUT and the test method, the RS EMC measurement was carried out as an additional test. This chapter explains and further investigates the RS measurement with respect to the different test methods (i.e. distances, EUT sizes, and different standard tests). This experiment was carried out to analyze the influence of the field inside the UFA, which can be seen on the Efield probes level during the test.

Chapter 4 describes the $\mathrm{RC}$ technique used to generate high field strength and obtain an EMC test field with efficient power and statistically good uniformity. A multi-probe system was used to quickly measure the field in three orthogonal directions at nine positions in an RC. This technique reduces the measurement time and also generates twenty-seven (9 $\mathrm{x} 3$ in $x-y-z$ direction) samples. By comparing these samples, the statistical FU can be evaluated much faster and more precisely. Some cases with mode stirred RC were taken by applying different stirrer shape and statistically FU and number of independent samples were investigated.

In Chapter 5, the radiated electromagnetic field is investigated using the different EMC test technique. This research step is the key point to compare different test techniques. Some dummy EUTs were used, including a basic monopole, a monopole in a metal box with a hole, a monopole in a metal box with a tube, and a monopole in a metal box with random slots. A model was created and the radiated fields were simulated, the radiation patterns were derived as were the E-fields for the EUTs. Measurements were carried out using FAR, SAC and RC and compared with the simulation results.

The next step was to investigate and explore the applicability of RC or VIRC for producing high field strength for EMC testing. By using the simple EUT, 3D fast and sensitive field probe and placed inside some different boxes, the RS measurement was done in FAR and RC. Correlation between FAR (AC) and RC radiated susceptibility results were addressed in this section. The results show that following the conventional RS methods using a FAR can result in under-testing of an EUT, and missing susceptibility problems. And the VIRC method is a potential and promising technique for RE as well as RS test, particularly for generating high field strength. This is described in Chapter 6.

The thesis ends with Chapter 7 and Chapter 8, which offer a conclusion of the work and suggestions for future research. 
In summary, the thesis structure follows the work published at the following conferences:

\begin{tabular}{|c|l|}
\hline Chapters & \multicolumn{1}{|c|}{ Place of publication or short description } \\
\hline 1 & Introduction - background and motivation - research goals \\
\hline 2 & APEMC 2017 and EMC Europe 2017 \\
\hline 3 & EMC Europe 2016 \\
\hline 4 & APEMC 2018 and EMC Europe 2018 \\
\hline 5 & Not published yet \\
\hline 6 & Not published yet \\
\hline 7 & Conclusions \\
\hline 8 & Future Research \\
\hline
\end{tabular}




\section{Antennas for Generating High E-Field Strength}

This chapter describes and reviews measurement results of the basic conventional antenna, the theory and important parameters of antennas, design, and simulation for generating high field strength for EMC testing and fundamental P2E evaluation. This chapter is based on the papers published at the International Symposium on EMC, APEMC 2017 [13] and the International Symposium on EMC, EMC EUROPE 2017 [12].

Broadband antennas are very important transducers for detecting or radiating electromagnetic fields, specifically in EMC measurements. A dipole-like array antenna or LPDA is widely used in civilian RS EMC standards [2] because the antenna pattern can be calculated precisely using the equations for electrically small dipoles and resonant dipoles.

A conventional LPDA usually ranges from $300 \mathrm{MHz}$ to $1 \mathrm{GHz}$, but a modern adapted LPDA starts at $150 \mathrm{MHz}$. In order to get better FU, the single LPDA was improved and the double LPDA antenna was introduced. Basically, this is a set of two LPDAs arranged together at a certain angle. This solution allows for increased gain compared to a single LPDA. Nowadays, the double LPDA is popular for RS testing; however, it was recently removed from the AECTP 501 [4] because of large deviations compared to measurements using a DRGH antenna. The DRGH is a wellknown broadband antenna in the range of $200 \mathrm{MHz}$ to $1 \mathrm{GHz}$ that has many advantages, such as fewer side-lobes, higher gain, and minimal influence from the chamber floor and walls. As the basic DRG horn antenna starts at $200 \mathrm{MHz}$, an extended double-ridged guide horn (Ext-DRGH) was developed which starts at 80 $\mathrm{MHz}$ [11], which is the starting frequency for civilian standards.

LPDA and DRG horn antennas have been researched for decades to create high field strength, either for measurements or from a design and simulation point of view in many applications. For example, In [33] designed an LPDA antenna that ranges from $300 \mathrm{MHz}$ to $1 \mathrm{GHz}$ and $\mathrm{B}$. Audone and I. Marziali [34] used the antenna to define a uniform field (UF) factor to calculate the uncertainty of the precalibration field for the repeatability of radiated immunity testing. The DRG horn antenna was studied mostly between $200 \mathrm{MHz}$ and $2 \mathrm{GHz}$ [34] and above $1 \mathrm{GHz}$ [34][35][36]. In addition, in [37], three models of DRG were designed and simulated from $100 \mathrm{MHz}$ to $1 \mathrm{GHz}$. The gain and radiation patterns were compared; however, 
none of them covered $80 \mathrm{MHz}$ to $1 \mathrm{GHz}$ and in particular for EMC application for generating high field strength. In [9] field homogeneity was researched in the presence of a ground plane or floor absorbers, wall reflection, test distance, and height of transmit antenna and polarization. Previous research [13] has found that an Ext-DRGH has excellent homogeneity and power efficiency, and that it is comparable to high-gain double LPDA based on the manufacturing specifications, which state that this antenna type has 2-3 dB more gain than a single LPDA. A single LPDA is not as good due to its low performance in broadband applications and polarization.

Although these phenomena appear to be relatively common, no publications discuss these issues or analyze the differences or benefits.

The LPDA was a popular antenna because it was thought to yield predictable results (calculated from basic equations). This most likely explains the general preference for this type of antenna for susceptibility testing and other types of tests. The double LPDA should improve FU, but no published results are available to corroborate this. The extended DRGH also has better properties compared to the LPDA [11].

Several papers have been published on antennas for RE testing, but no papers are devoted to RS testing. In [11] a theoretical and practical study on generating high field strength in large volumes using different antennas at a standard distance is presented. This study shows that Ext-DRGH has better performance than biconical and single log-periodic antennas in terms of FU, as also described in [38]. Some researchers also worked on finding an alternative test method and proposed a new concept of RE and RS testing [39], in addition to improving the repeatability and reproducibility of RS tests [40][41]. However, no analyses or measurement comparisons were carried out for the UFA calibration, nor was the power determined for the different antennas (e.g. ordinary biconical, LPDA, double LPDA, and Ext-DRGH).

In this section, a comparison was made for the 16 UFA points and the power efficiency using four different transmitting antennas, which can provide sufficient information for comparing them in terms of power efficiency and generated E-field and the FU.

\subsection{Measurements}

\section{Log Periodic Dipole Array (LPDA) Antenna}

A single LPDA antenna which consists of an array of dipoles is often used to cover a wide frequency band in many applications. This type of antenna provides good directivity and low VSWR [14]. The LPDA is a frequency-dependent antenna that utilizes many dipole elements of various lengths. The distances between the 
dipoles increase in proportion to the distance from the feed-point. This gives the LPDA antenna a wide frequency range and moderate directivity.

An improvement of the ordinary LPDA is a double V-shape LPDA or double LPDA. Figure 2.1 The radiation pattern of a double LPDA (HL 046) at $500 \mathrm{MHz}$, which is a typical field pattern for a double LPDA. The double design helps to focus the directional pattern of the H-Plane, resulting in a typical gain improvement of 2$3 \mathrm{~dB}$ compared to an ordinary single LPDA.

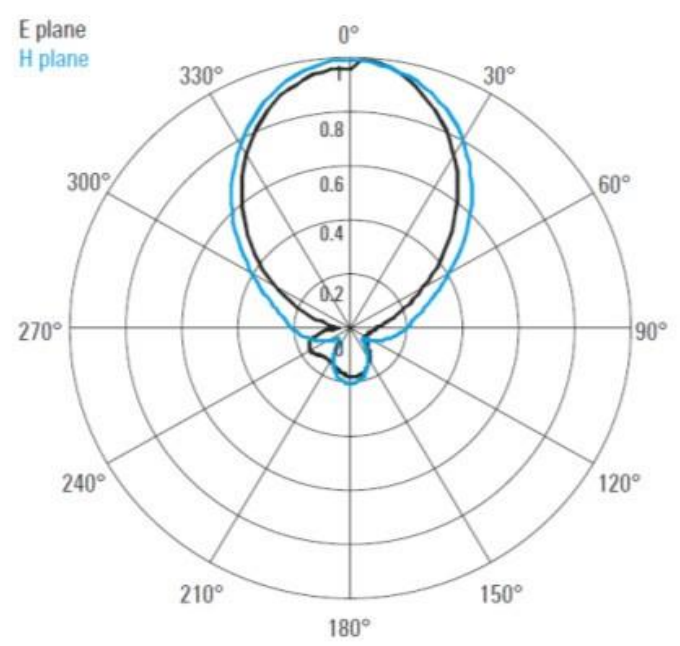

Figure 2.1 The radiation pattern of a double LPDA (HL 046) at $500 \mathrm{MHz}$ [42]

This is especially important for susceptibility testing, which requires maximum field strength and good FU. The beam-widths in the E-plane and the H-plane are nearly identical, providing an optimized illumination of the EUT with minimal ground reflection difference.

\section{Double-Ridged Guide Horn (DRGH) Antenna}

The DRGH antenna might be considered an impedance match or RF transformer between the waveguide feeder and free-space, which has an impedance of $120 \pi \Omega$ [14]. A DRGH antenna is basically a horn antenna with a ridge. In order to achieve a lower cut-off frequency, a rectangular waveguide is loaded by a centrally doubleridged guide [11]. By continuing the double-ridged from a waveguide into a pyramidal horn, the useful bandwidth of the horn can be increased. As the biconical antenna was quite problematic, especially in the near field, an Ext-DRG horn as shown in Figure 2.2 was developed and designed to operate between $80 \mathrm{MHz}$ and 1 $\mathrm{GHz}$. 


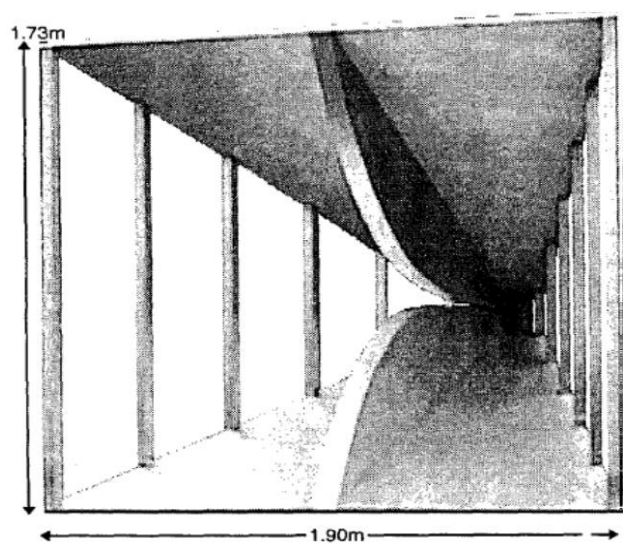

Figure 2.2 Extended double-ridged guide horn (Ext-DRGH) antenna [43]

Assuming that the height $(h)$ and the width $(w)$ are both at least one wavelength $(\lambda)$, then the gain $(G)$ is determined by the dimensions of the horn [11] as shown in equation (2.1):

$$
G=10 * \log (7.5 * h * w)
$$

The gain level of the horn antenna might be up to $20 \mathrm{~dB}$ for some instances. Additionally, it provides both a significant level of directivity, gain, and low sidelobe and back-lobe radiation. Therefore, regarding these characteristics, the DRGH could also be suitable for EMC measurements, even with amplifiers with a lower output power.

This study used two approaches: An experimental method and a simple calculated (or calculable) method. Measurements were conducted for four different types of antennas at a standard distance of $3 \mathrm{~m}$. In order to verify the results, the calculable method was used based on a theoretical calculation.

\subsubsection{Measurement Setups}

UFA measurements were carried out in a fully anechoic chamber using the methods described in [2]. In order to achieve the desired objectives, measurements were carried out using the following antennas:

- Bi-conical antenna $(80 \mathrm{MHz}-200 \mathrm{MHz})$

- Single LPDA (150 MHz - $1 \mathrm{GHz})$

- Double LPDA or HL046E (80 MHz - $1 \mathrm{GHz})$

- Ext-DRGH antenna $(80 \mathrm{MHz}-1 \mathrm{GHz})$

The LPDA test setup can be seen in Figure 2.3 and Figure 2.4 and the ExtDRGH test setup can be seen in Figure 2.5. Similar conditions were applied in both test setups in order to ensure comparable results. 


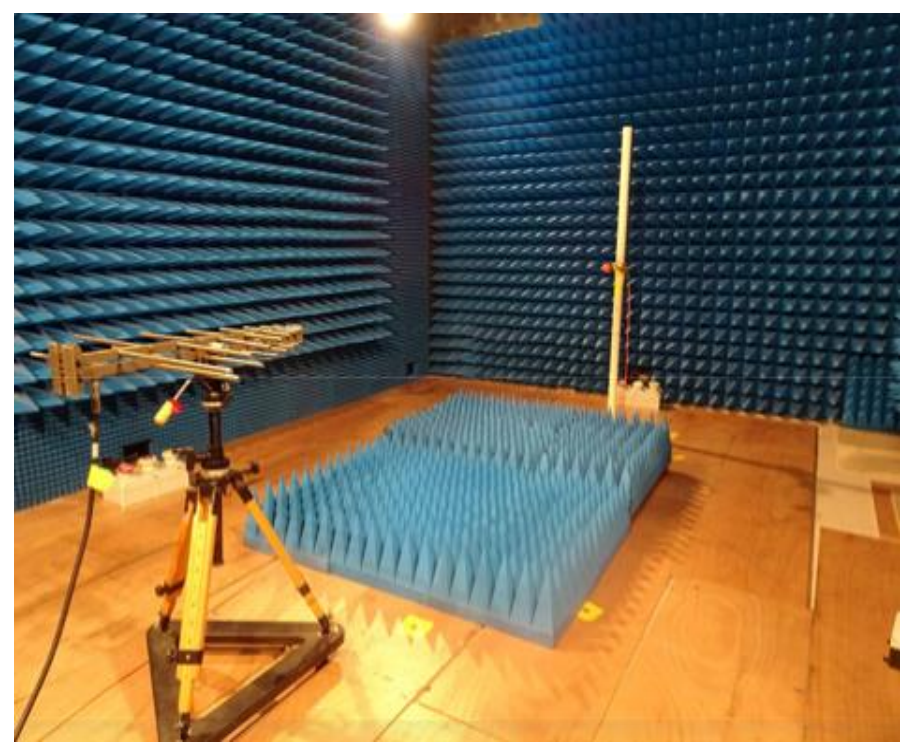

Figure 2.3 Test setup with single LPDA

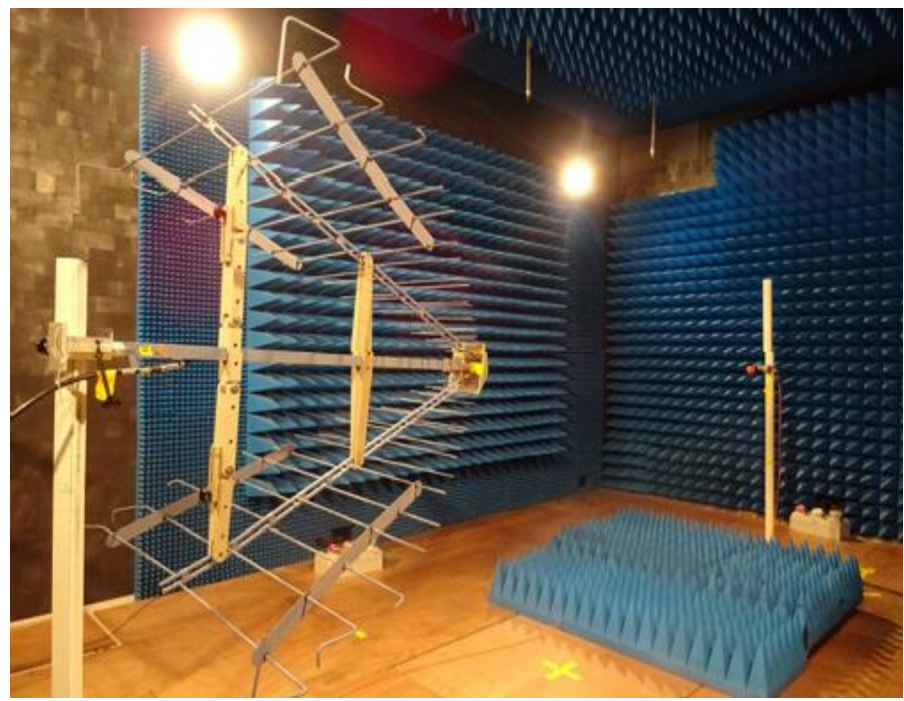

Figure 2.4 Test setup with double LPDA 


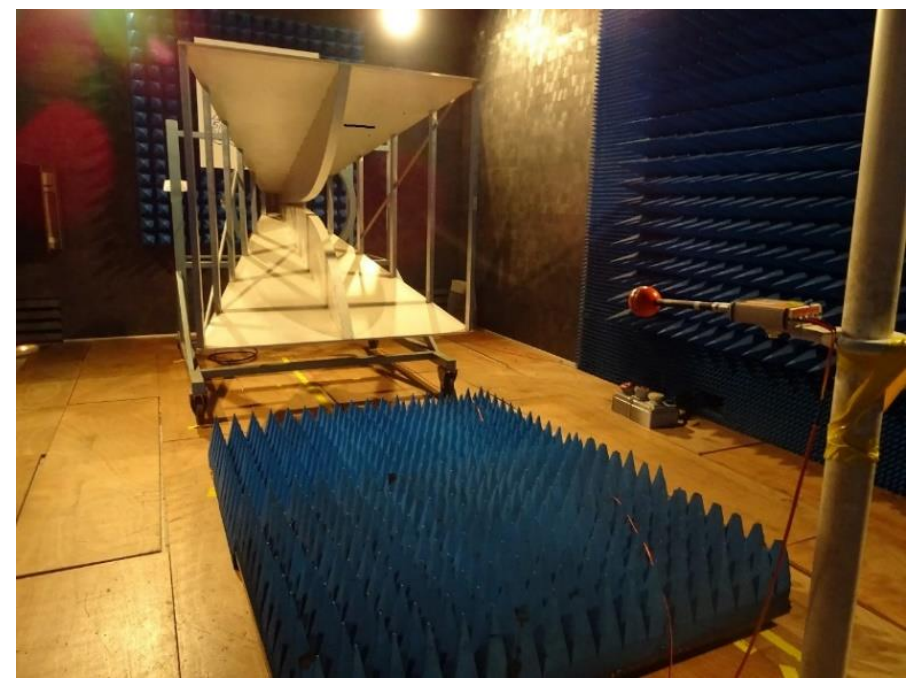

Figure 2.5 Test setup with Ext-DRGH

The relationship between the power injected into the antenna - or forward power - and the E-field in the far-field in the linear domain, can be calculated with

$$
E\left(\frac{V}{m}\right)=\frac{\sqrt{30 P G}}{R}
$$

where $P$ is power, $G$ is the gain of the antenna, and $R$ is the distance between the phase center of the antenna and the UFA (here assumed to be $3 \mathrm{~m}$ ). Determining the forward power from the generator or amplifier and using the $G$-value from the antenna calibration specification allows us to obtain the E-field value for each frequency point.

\subsubsection{Experimental Results}

Several measurements were conducted, starting with UFA calibration. The field strength was first applied at 16 points over an area of $1.5 \mathrm{~m} \times 1.5 \mathrm{~m}$ to achieve 10 $\mathrm{V} / \mathrm{m}$ according to [2] and was then measured along the centerline of the antenna at a $3 \mathrm{~m}$ distances with constant power transmitted to the antenna using standard EMC test equipment and Rohde and Schwarz EMS32 software. The results are depicted in Figure 2.6 to Figure 2.10, respectively.

Figure 2.6 shows the power needed for each antenna to achieved $10 \mathrm{~V} / \mathrm{m}$ at all frequencies from $80 \mathrm{MHz}$ to $1 \mathrm{GHz}$, at a distance of $3 \mathrm{~m}$. It is important to note that the floor of the anechoic chamber is lined with ferrite and additional carbon-loaded foam absorbers, and thus the field should not be influenced by ground reflection. 

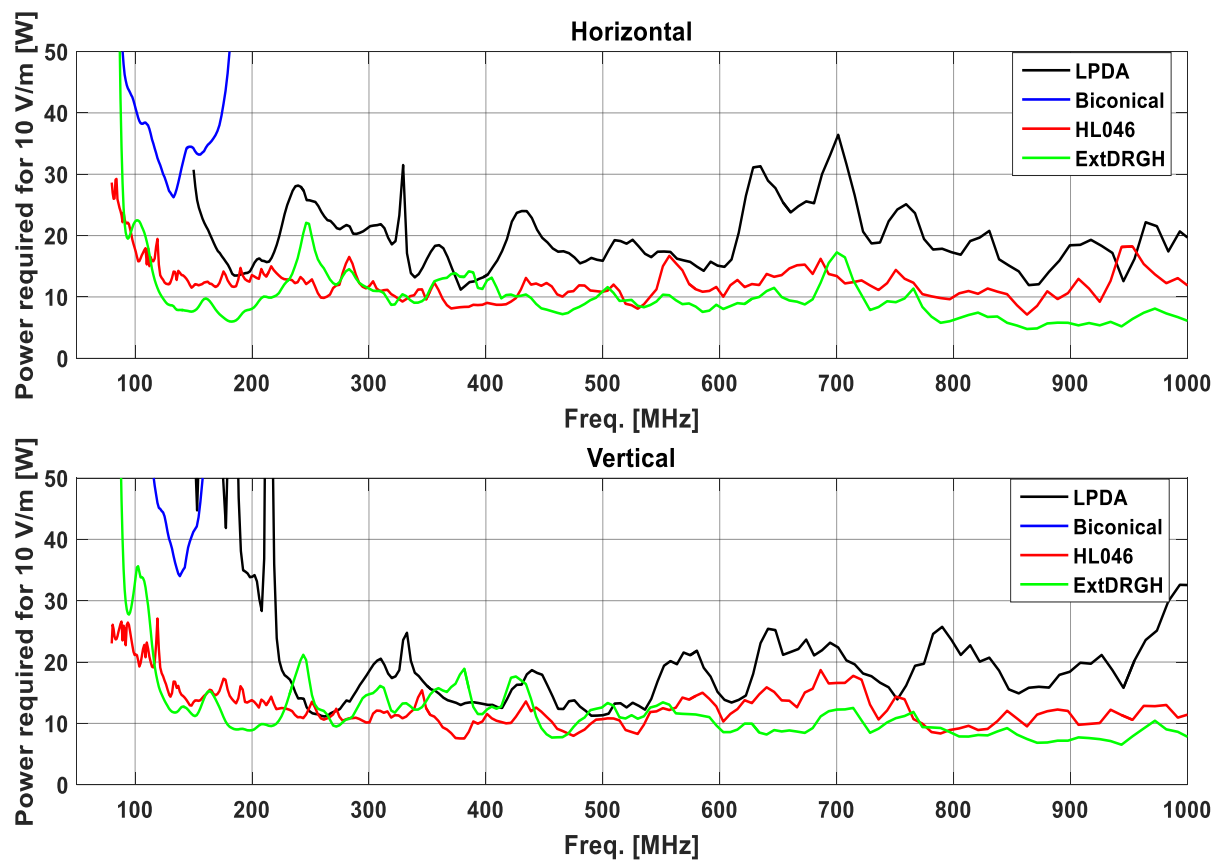

Figure 2.6 Power required for 10V/m, biconical, single LPDA, double LPDA (HLO46) and Ext$D R G H$, horizontal and vertical polarization, at $3 \mathrm{~m}$

The power required to establish this field strength should ideally be the same for both horizontal and vertical polarization. But the measurement results confirm what was already mentioned in [11]: The dipole-like antennas are influenced by near field effects (e.g. the floor), particularly for biconical antennas with longer arms. As can be seen in Figure 2.6, regarding the forward power needed to achieve the required $10 \mathrm{~V} / \mathrm{m}$ E-field for both horizontal and vertical polarizations, both biconical and single LPDA require higher power over all frequency bands ( $80 \mathrm{MHz}$ to $1 \mathrm{GHz}$ ).

The other two antennas, double LPDA (or HL046) and Ext-DRGH constantly use power approximately in the same range between $10 \mathrm{~W}$ to $15 \mathrm{~W}$, except for frequencies under $150 \mathrm{MHz}$. Due to a problem with the feed connection between 80 and $90 \mathrm{MHz}$, the Ext-DRGH requires high power in this range. Above $100 \mathrm{MHz}$, the Ext-DRGH established very efficient and comparable results with the double LPDA (HL04E). Those results are strongly related to the characteristics of the biconical (dipole-like) antenna and the single LPDA, which has less directivity and gain compared to the double LPDA and the Ext-DRGH. Therefore, with higher gain, the double LPDA and the Ext-DRGH will require less power to obtain the same level of E-field strength at a specific distance from the antenna. 

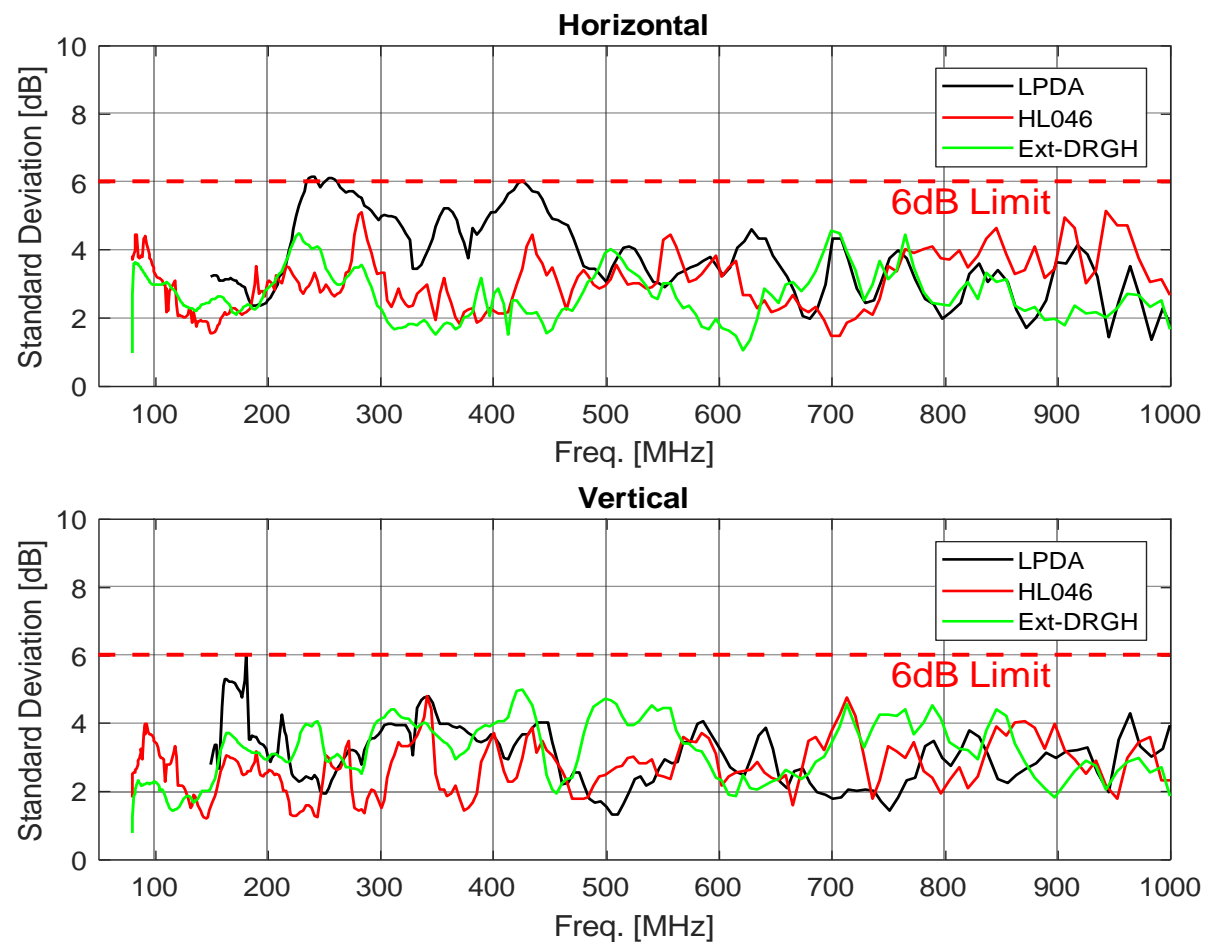

Figure 2.7 FU generated by single LPDA, double LPDA and Ext-DRGH Antenna, horizontal and vertical polarization, $3 \mathrm{~m}$

Figure 2.7 shows the FU for all of the antennas, for both horizontal and vertical polarizations with respect to the different power differences being transmitted. In the horizontal polarization, the black line (LPDA) nearly reach the $6 \mathrm{~dB}$ limit up to $500 \mathrm{MHz}$, while the other two, double LPDA (HL046) and Ext-DRGH are far from the limit. Better uniformity is obtained for the vertical polarization and the results indicate a similar pattern with double LPDA (HL046) and Ext-DRG, except for frequency between 150 to $200 \mathrm{MHz}$, which almost exceeds the $6 \mathrm{~dB}$ limit. 


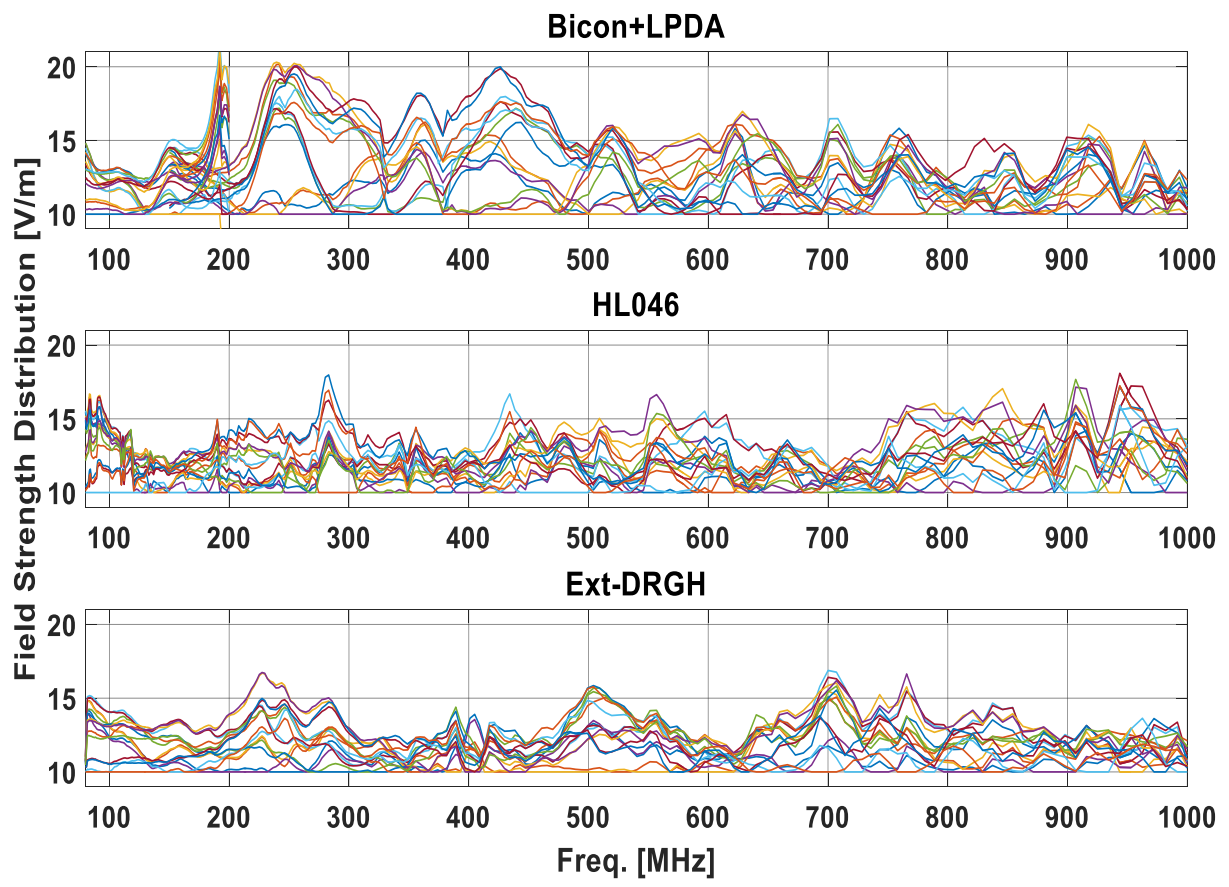

Figure 2.8 Measured field strength distribution, biconical and single LPDA, double LPDA and ExtDRGH antenna, horizontal polarization

Generally speaking, the biconical and single LPDA antennas are not bad; however, the major drawback is in the lower frequency range, particularly around $200 \mathrm{MHz}$. On the other hand, double LPDA and Ext-DRGH antennas have better uniformity in both polarizations and require less power. For the double LPDA, the dual-stacked elements which not only help increase the gain, they also to create a better radiation pattern in both directions.

The field strength distribution for horizontal polarization is plotted in Figure 2.8. As depicted in this figure, the biconical and single LPDA antennas have slightly bigger field distribution variations than the double LPDA and Ext-DRGH antennas (especially under $500 \mathrm{MHz}$ ), while the rest have a relatively similar distribution. 

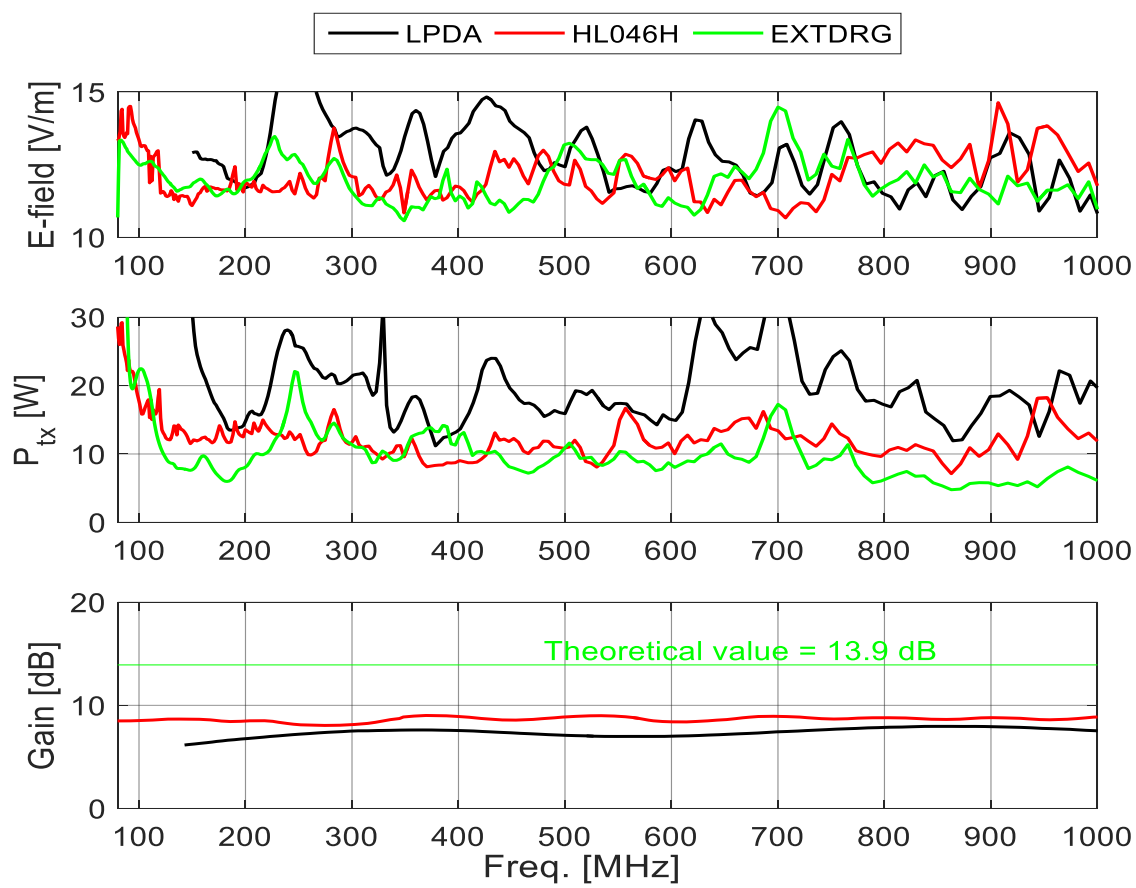

Figure 2.9 Calculated E-field strength, forward power and theoretical/manufactured gain of single LPDA, double LPDA, Ext-DRGH antenna, horizontal and vertical polarization

Figure 2.9 shows the calculated E-field based on forward power and the theoretical (and datasheet) gains of different antennas. In this figure, the E-field curves are relatively similar for all antennas, with only slightly larger variation occurring for the single LPDA. Gain is antenna-dependent and, as can be seen on the black curves, the LPDA has less gain and therefore requires more power to generate the required field strength. The Ext-DRGH needs the least power from 500 $\mathrm{MHz}$ to $1 \mathrm{GHz}$. As the antenna gain is almost $10 \mathrm{~dB}$ higher than LPDA, the required amplifier gain is 10 times lower than in case of the LPDA . 

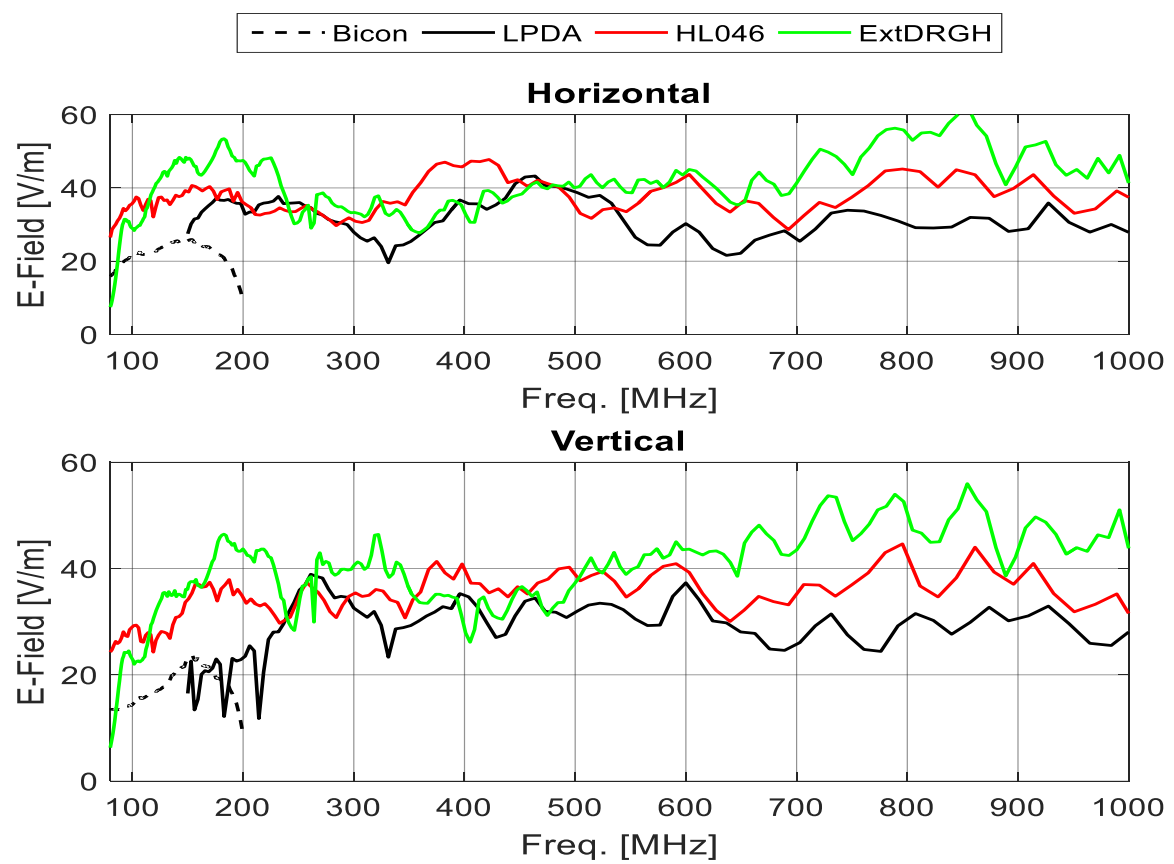

Figure 2.10 Measured field strength generated by biconical, single LPDA, double LPDA and ExtDRGH antennas at constant power $(100 \mathrm{~W})$, vertical and horizontal polarization, $3 \mathrm{~m}$

Figure 2.10 serves to verify the previous results and shows that different E-field values are obtained despite the constant power $(100 \mathrm{~W})$ injected into each antenna. The single LPDA, which has the smallest gain, produces the lowest E-field strength over almost the entire frequency range. However, the Ext-DRGH generates a larger E-field for both horizontal and vertical polarization. Although the E-field is lower than the LPDA in some frequency points, they are higher in most cases. The results confirm that the Ext-DRGH antenna is the most efficient in terms of P2E and yields comparable results as the double LPDA with regard to FU.

Experiments were conducted to compare four types of antenna for generating high field strength based on IEC 61000-4-3. With respect to power efficiency, the results show that the biconical and LPDA (or dipole-like) antenna require more power to achieve a uniform $10 \mathrm{~V} / \mathrm{m}$ E-field than the double LPDA or Ext-DRGH antenna. Moreover, using better antennas like the double LPDA and Ext-DRGH antenna can help obtain better FU. Both antennas show comparable results for all points from $80 \mathrm{MHz}$ to $1 \mathrm{GHz}$, none of which exceed the $6 \mathrm{~dB}$ limit. It must be stated that a bigger antenna is needed to reach the lower frequency, which is associated with issues such as the near field effect and reflection from the chamber. 


\subsection{Numerical Simulations}

Basic models of the LPDA and Ext-DRGH antennas were made and simulated and the results were compared with the measurements. The objective was to achieve optimized field uniformity with the lowest input power, as power is a key cost driver for the test laboratories being set up in developing countries. The first step was to analyze the simulated parameters $S_{11}$ and the gain over the desired frequency band. It must be stressed that the objective of this study was not to conduct a classic simulation-measurement-validation study, but to evaluate antenna designs used to generate high field strength and uniformity relative to the required power.

The theoretical equation for designing an LPDA can be found in [14][1]. An LPDA consists of dipole elements of different sizes, arranged in an array shape depending on the required frequency range. This type of antenna was first developed by Isbell and was later optimized by Carrel [44]. The basic concept is that a gradually expanding periodic structure array radiates most effectively when the array elements (dipoles) are near resonance so that a change in frequency will move the active (radiating) region along the array. Expanding structure arrays differ from uniform arrays. Figure 2.11 illustrates the schematic diagram of an LPDA.

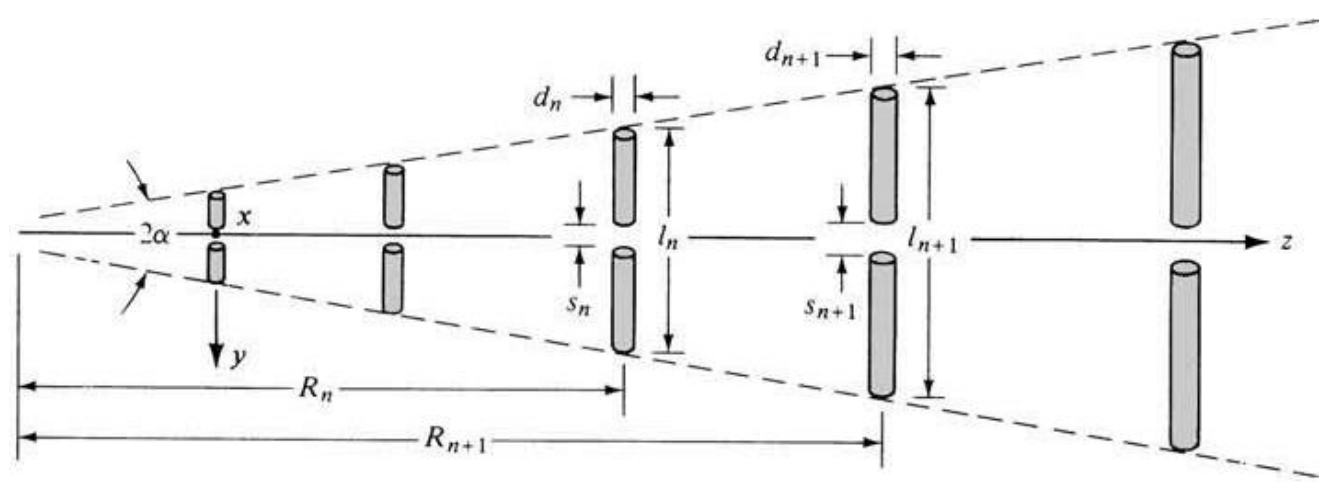

Figure 2.11 The schematic diagram of LPDA [14]

At a given frequency, when the current travels along the feeder and it reaches a section of the structure, the relation between the electrical lengths and the phase of the element caused radiation. As frequency is varied, the position of the resonant element is moved smoothly from one element to the next. The upper and lower frequency limits will then be determined by the lengths of the shortest and longest elements. Alternatively, half-elements can be used to satisfy the bandwidth requirement. The longest half-element must be about $1 / 4$ wavelength at the lowest bandwidth frequency and the shortest half-element must be about $1 / 4$ wavelength at the highest frequency in the desired operating bandwidth [14].

This antenna shares the properties of all log-periodic structures in that the element distances, lengths and separations are connected by a constant, such as [1]: 


$$
\tau=\frac{l_{n}}{l_{n+1}}=\frac{R_{n}}{R_{n+1}}
$$

Now, let us define the parameters $\tau, \alpha^{\prime}$ and $\sigma$ to describe the geometry of the LPDA. The relationships between $\tau$ and $\alpha^{\prime}$, the element dipole lengths $\left(L_{n}\right)$ and distance $\left(R_{n}\right)$ to the apex are determined by geometry and expressed as:

$$
\frac{L_{1}}{R_{1}}=\frac{L_{n}}{R_{n}}=2 \tan \alpha^{\prime}
$$

Where

$R_{n}=$ distance from apex to the $n^{\text {th }}$ element

$L_{n}=$ total length of the $n^{\text {th }}$ element

$\alpha^{\prime}=$ half-angle subtended by the ends of radiating elements

In addition, the ratios of $\frac{d_{n+1}}{d_{n}}$ and $\frac{R_{n+1}}{R_{n}}$ are equal to $\tau$, which is usually a number less than 1.0. That is:

$$
\frac{d_{n+1}}{d_{n}}=\frac{R_{n+1}(1-\tau)}{R_{n}(1-\tau)}=\frac{R_{n+1}}{R_{n}}=\tau
$$

Where $d_{n}$ is the distance between the $n^{\text {th }}$ and $(n+1)^{t h}$ elements

It is often convenient to think of the element spacing $\left(d_{n}\right)$ in terms of wavelength. The free-space wavelength $\left(\lambda_{1}\right)$ of a signal that resonates the first largest element $\left(l_{1}\right)$ is approximately four times $l_{1}$, thus $\lambda_{1} \approx 4 l_{1}$.

Similarly:

$$
\lambda_{2} \approx 4 l_{2} ; \lambda_{3}=4 l_{3} ; \lambda_{n}=4 l_{n}
$$

For any value of $n$, the ratio $\frac{d_{n}}{4 l_{n}}$ is a useful quantity. It is called a spacing factor $(\sigma)$ and can be expressed in terms of $\tau$ and $\alpha^{\prime}$ as follows:

$$
\sigma=\frac{d_{1}}{4 l_{1}}=\frac{d_{n}}{4 l_{n}}=\frac{R_{n}(1-\tau)}{4\left(R_{n} \tan \alpha^{\prime}\right)}=\frac{1-\tau}{4 \tan \alpha^{\prime}}
$$

The $\sigma$ and $\tau$ are important parameters when creating models and designs using simulation software. By varying these parameters, it is possible to define the frequency band.

Based on the theoretical calculation, the following simple and basic broadband antennas for EMC applications were designed using 3D full-wave simulation CST software: 
- Single LPDA antenna

- Double LPDA antenna

- Double-Ridged Guided Horn (DRGH) antenna

\subsubsection{Antenna Models}

\section{A. Log-Periodic Dipole Array (LPDA) Antenna}

Two basic models of the log-periodic dipole array antenna were designed and simulated. The antennas working in a broad frequency range, and its simulation results are used to compare with the measurement results. The first was an LPDA antenna, which works from $150 \mathrm{MHz}$ to $1 \mathrm{GHz}$; the second was a double LPDA, which works from $80 \mathrm{MHz}$ to $1 \mathrm{GHz}$. Figure 2.12 and Figure 2.13 show the models of both antennas created using CST Microwave Studio.

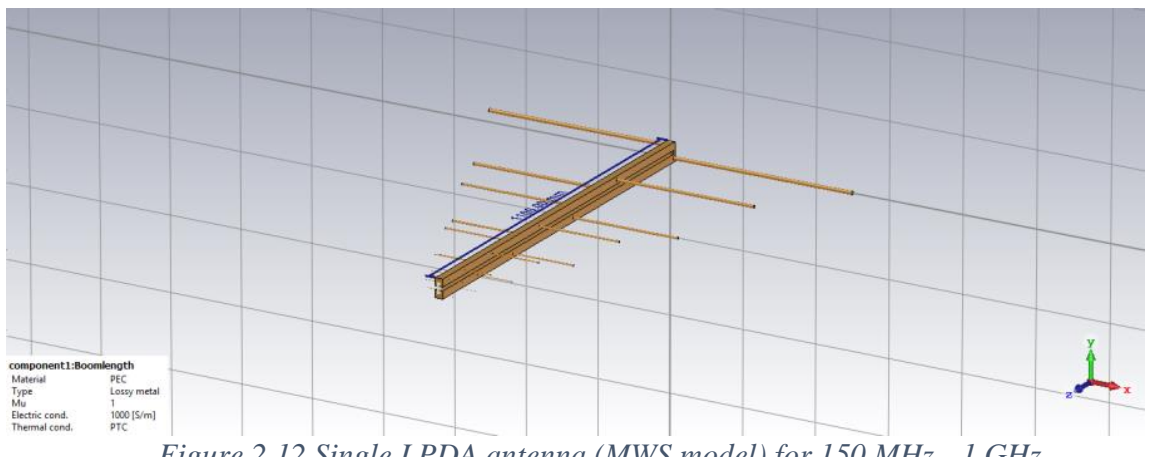

Figure 2.12 Single LPDA antenna (MWS model) for $150 \mathrm{MHz}-1 \mathrm{GHz}$

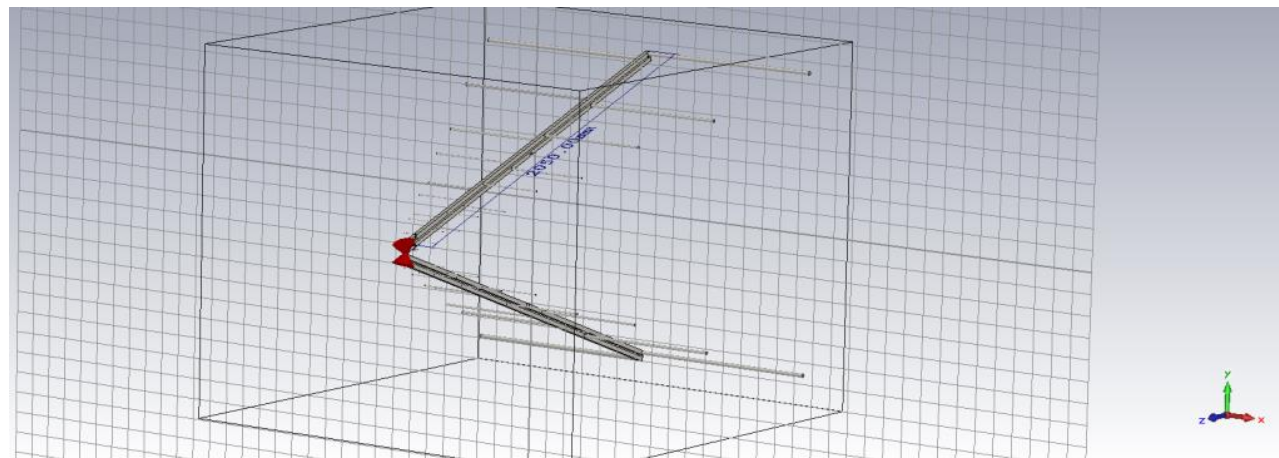

Figure 2.13 Double LPDA antenna (MWS model) for $80 \mathrm{MHz}-1 \mathrm{GHz}$

The single LPDA consist of 13 pairs of dipole elements with a boom length of $1096 \mathrm{~mm}$. Every single LPDA in the double LPDA has $2050 \mathrm{~mm}$ boom length and consists of 15 elements. The antenna models were then simulated for the entire frequency band. In order to obtain the E-field values at a distance, the monitoring probe was placed in the $z$-plane, see Figure 2.14. The probe can evaluate three 
electric field components in $x-y-z$, as well as the total E-field value. The probe was positioned $3 \mathrm{~m}$ from the antenna in the 16 points of the UFA in the frequency range $80 \mathrm{MHz}$ to $1 \mathrm{GHz}$. In order to simplify the environment, the surrounding space is defined as an open space boundary condition for all directions.

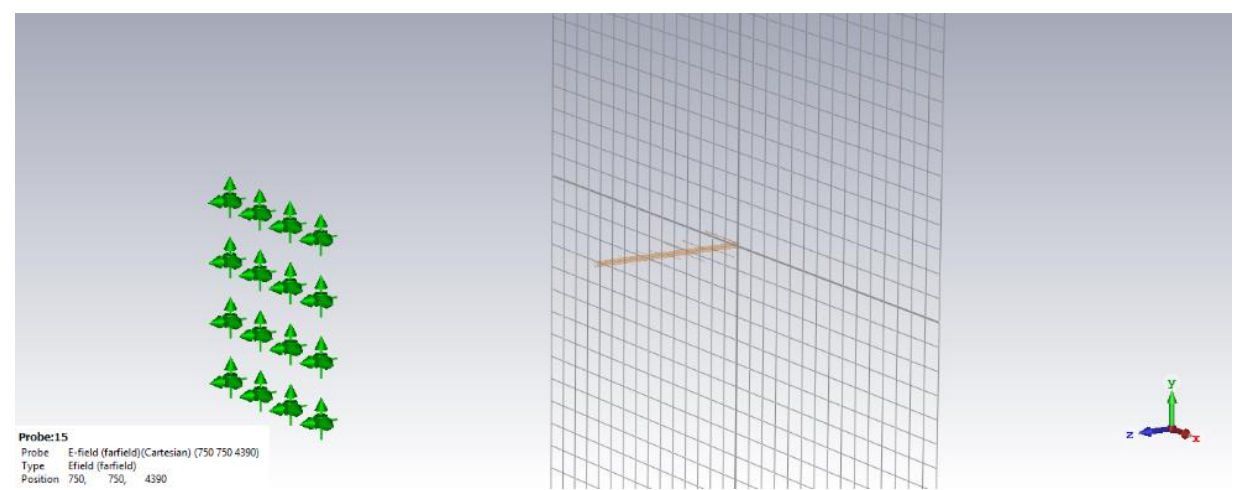

Figure 2.14 Model of E-field measurement at a distance of $3 \mathrm{~m}$ in CST

\section{B. Double-Ridged Guide Horn Antenna}

The Ext-DRGH antenna was actually designed and manufactured some time ago, however, no simulation results were available to verify and optimize its electromagnetic characteristics. The dimensions are $1.73 \mathrm{~m} \mathrm{x} 1.90 \mathrm{~m} \times 2.16 \mathrm{~m}(h \mathrm{x}$ $w \times l)$ on the horn flare section. The ridged flare is actually the extension of a waveguide. The Ext-DRG model is shown in Figure 2.15. The antenna consists of a cavity, two lower and two upper H-plane flares, and two exponentially shaped ridges, as mentioned in [34][37]. The back cavity is actually a rectangular waveguide with a double ridge. By continuing the double-ridge structure into the pyramidal horn, the bandwidth was extended [11].

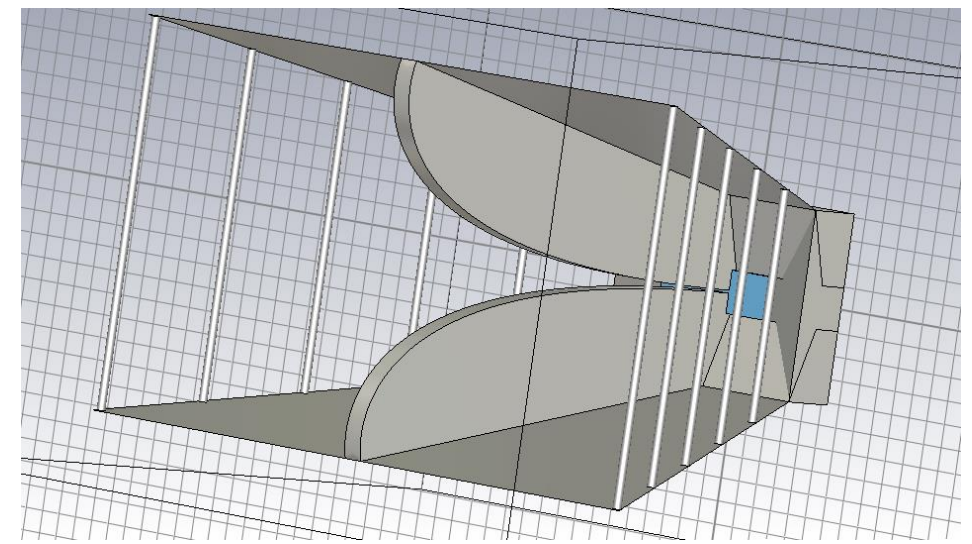

Figure 2.15 The Ext-DRGH antenna (MWS model) for $80 \mathrm{MHz}-1 \mathrm{GHz}$ 
Due to a different design of the Ext-DRGH antenna, slightly different boundary conditions were applied to the model. Although it was set to open space in both EField and H-field for all directions $(x-y-z)$, an additional $x-z$ magnetic symmetry plane was applied. While a discrete excitation port was used for the single and double LPDA, a waveguide excitation port to coaxial feed was used for the ExtDRGH model.

\subsubsection{Simulation Results}

The simulated scattering parameter for the LPDA is shown in Figure 2.16. The $S_{11}$ is under $-10 \mathrm{~dB}$, which indicates that the LPDA model works well in the range of $150 \mathrm{MHz}$ to $1 \mathrm{GHz}$.

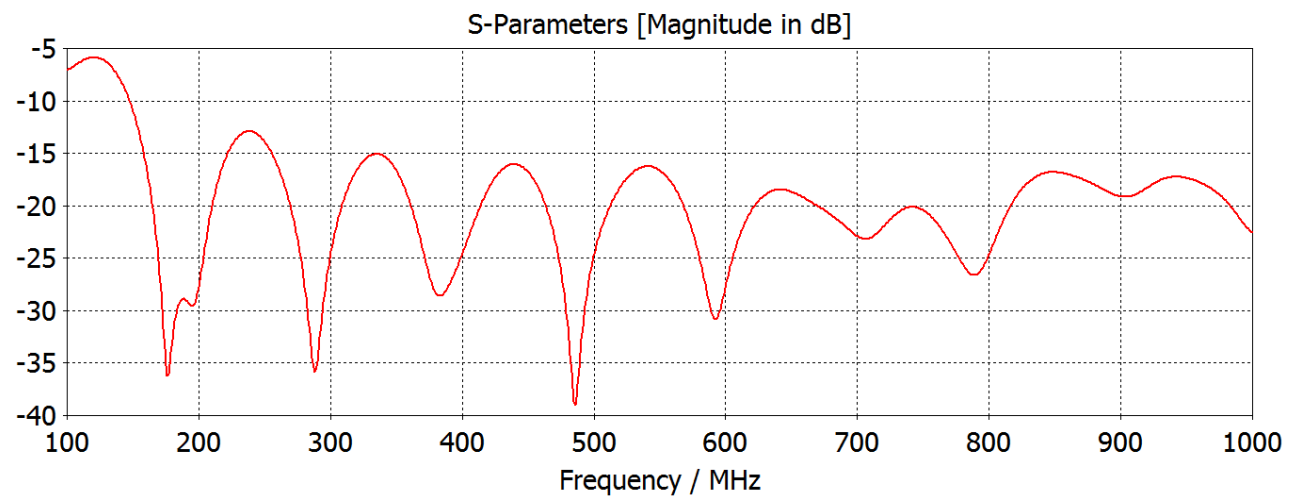

Figure 2.16 Simulated $S_{11}$ of single LPDA $150 \mathrm{MHz}-1 \mathrm{GHz}$

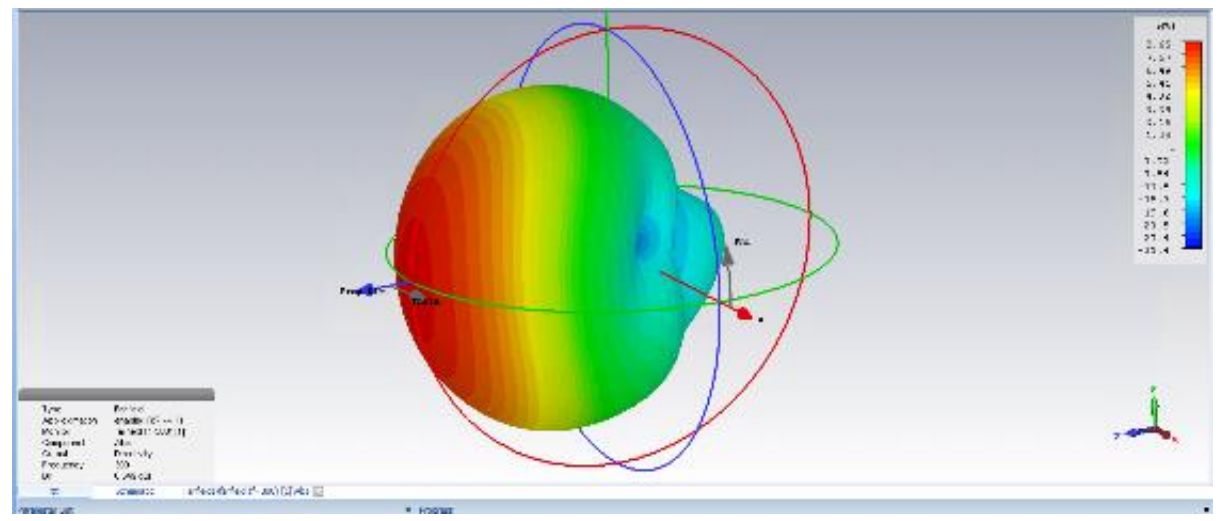

Figure 2.17 The radiation pattern of the LPDA at $300 \mathrm{MHz}$ 
Farfield Directivity Abs (Phi $=0)$

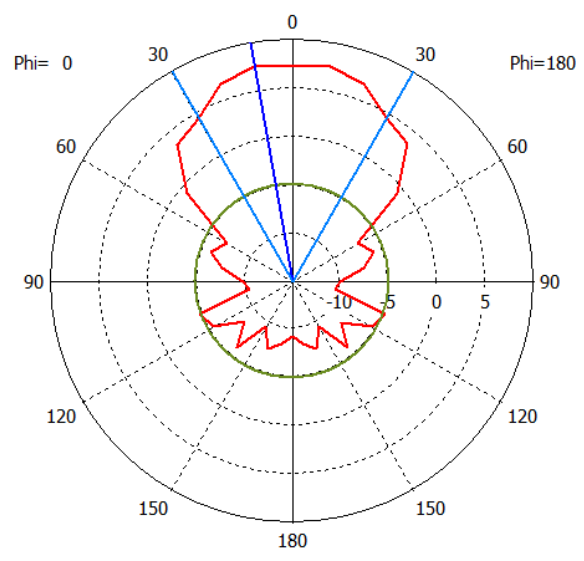

Theta / Degree vs. dBi
Frequency $=1000 \mathrm{MHz}$

Main lobe magnitude $=7.45 \mathrm{dBi}$

Main lobe direction $=10.0 \mathrm{deg}$.

Angular width $(3 \mathrm{~dB})=59.8 \mathrm{deg}$.

Side lobe level $=-12.3 \mathrm{~dB}$

Figure 2.18 The polar plot of radiation pattern for the LPDA at $1 \mathrm{GHz}$

Figure 2.17 and Figure 2.18 show the radiation pattern of the LPDA at $300 \mathrm{MHz}$ and the polar plot at $1 \mathrm{GHz}$. The simulated E-field of the single LPDA at $3 \mathrm{~m}$ is depicted in Figure 2.19. The E-field distribution of 16 points at $3 \mathrm{~m}$ fluctuates between $16 \mathrm{~V} / \mathrm{m}$ and $30 \mathrm{~V} / \mathrm{m}$, with a power of $100 \mathrm{~W}$ in the excitation port. This result is slightly higher than the initial measurement due to the ideal assumption of the model and the boundary (space), and the exclusion of system losses.

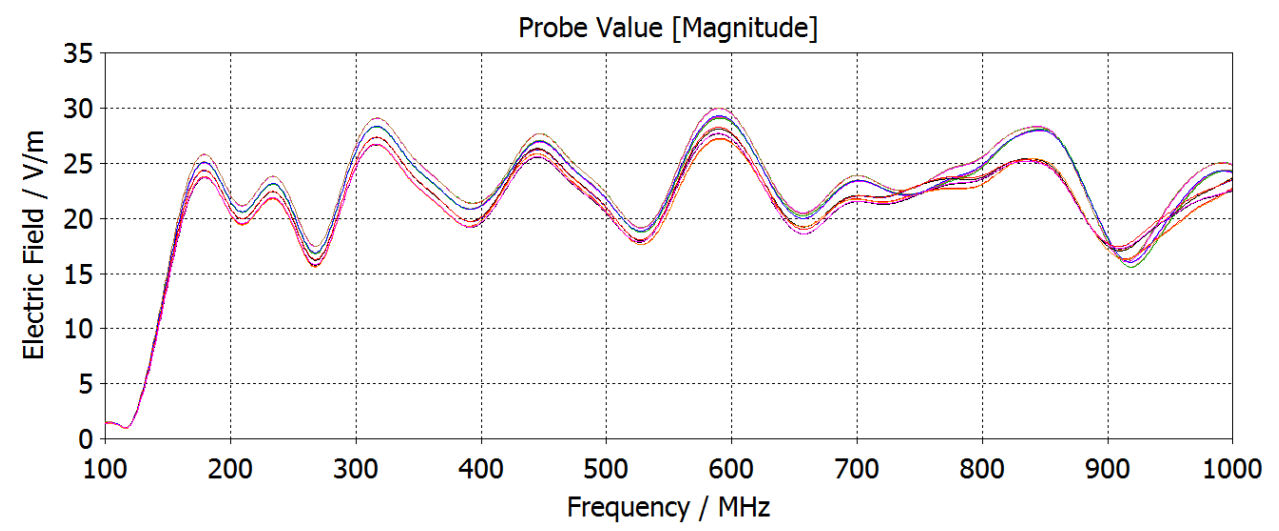

Figure 2.19 Simulated E-field probe value of a single LPDA, 16 points, at $3 \mathrm{~m}$ 


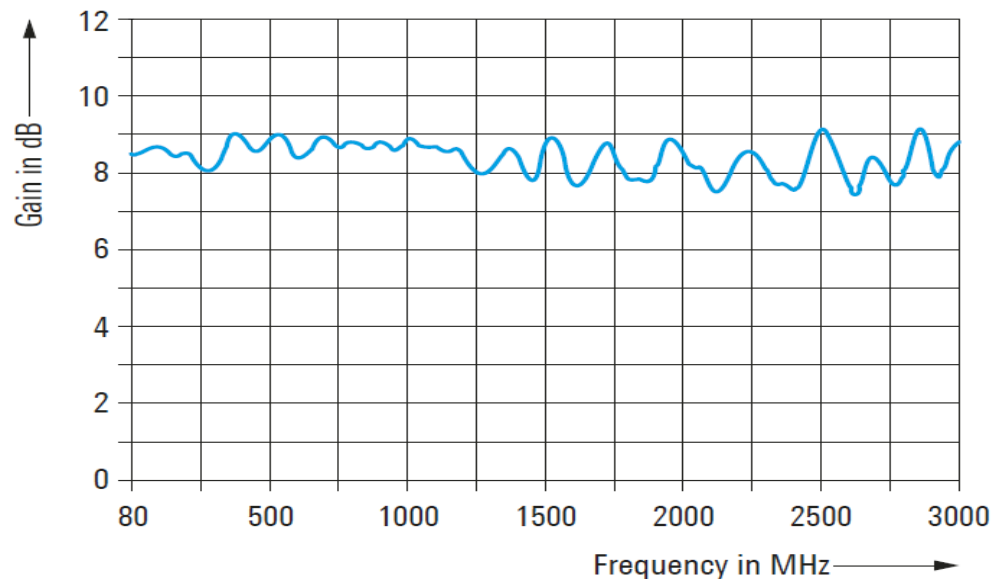

Figure 2.20 The typical gain of a double LPDA $0.8-1 \mathrm{GHz}$ (manual specification)

The gain of the double LPDA is shown in Figure 2.20 for the measured antenna and in Figure 2.21 for the simulated antenna. The gain is not very similar due in part to the simplification of the design or the model and to the computation time. Minor differences can be seen on the two graphs. For $80 \mathrm{MHz}$ to $1 \mathrm{GHz}$, the gain is between 8 to $9 \mathrm{~dB}$ in the specification (Figure 2.20) and $8 \mathrm{~dB}$ in the simulation at a middle frequency, only reaching $9 \mathrm{~dB}$ for some frequency points (Figure 2.21). The average simulated gain is $1 \mathrm{~dB}$ higher than the single LPDA.

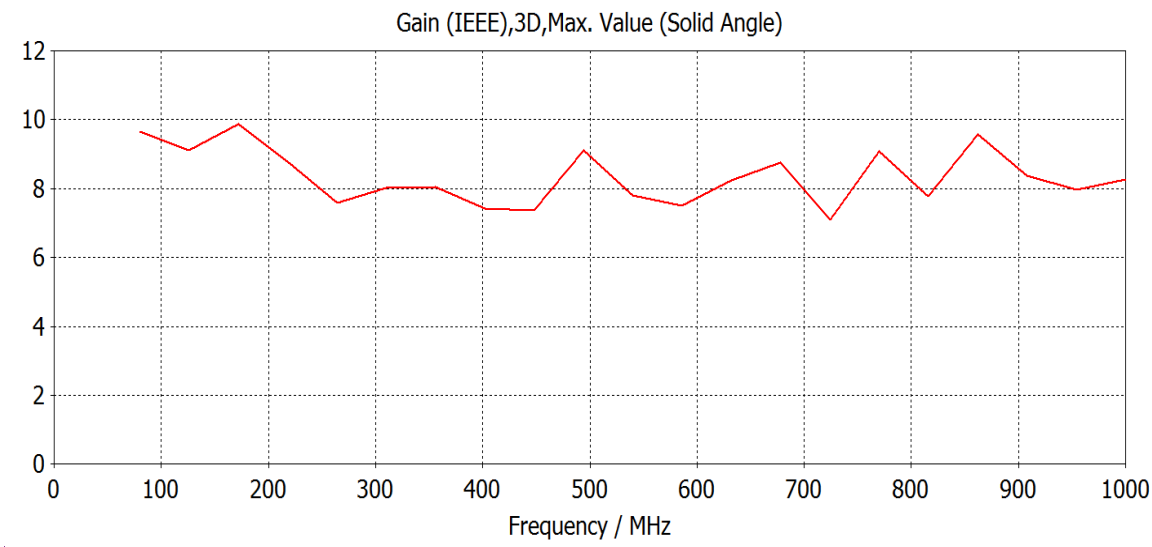

Figure 2.21 Simulated Gain of double LPDA $80 \mathrm{MHz}-1 \mathrm{GHz}$

Figure 2.22 shows the simulated $S_{11}$ of the double LPDA. The line does not exceed $10 \mathrm{~dB}$ for the entire frequency band (except under $150 \mathrm{MHz}$ ). This $S_{11}$ curve is quite similar and slightly better than that of the single LPDA, indicating that the double LPDA would have similar properties, but with a higher gain. There are no specific requirements for $S_{11}$ for antennas being used for EMC, but the common rule of thumb is $S_{11}<-10 \mathrm{~dB}$. 


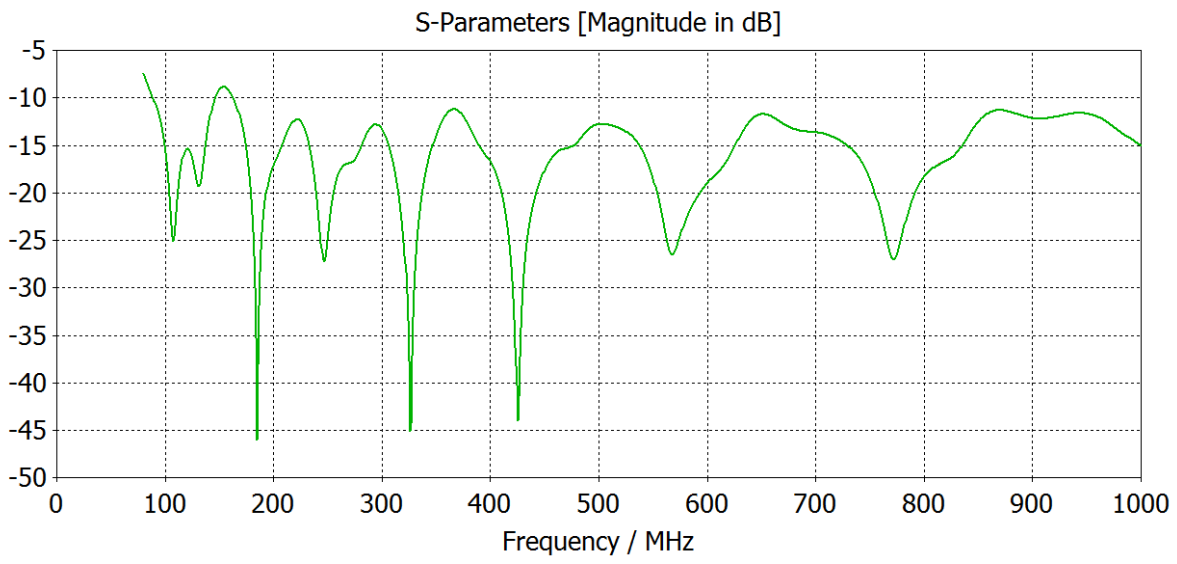

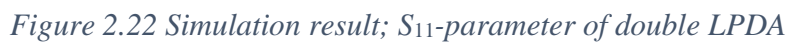

Figure 2.23 shows the E-field distribution value of the double LPDA in the sixteen probe points at $3 \mathrm{~m}$. This figure shows that the double LPDA has a wider distribution. The range distribution value is 20 to $53 \mathrm{~V} / \mathrm{m}$, even more at certain frequencies and at some points. On average, this value higher than the single LPDA, which has a peak value of $32 \mathrm{~V} / \mathrm{m}$ and a lowest point of $17 \mathrm{~V} / \mathrm{m}$ in some frequency bands. Under $100 \mathrm{MHz}$, the field value is very small, as confirmed by the $S_{11}$ result.

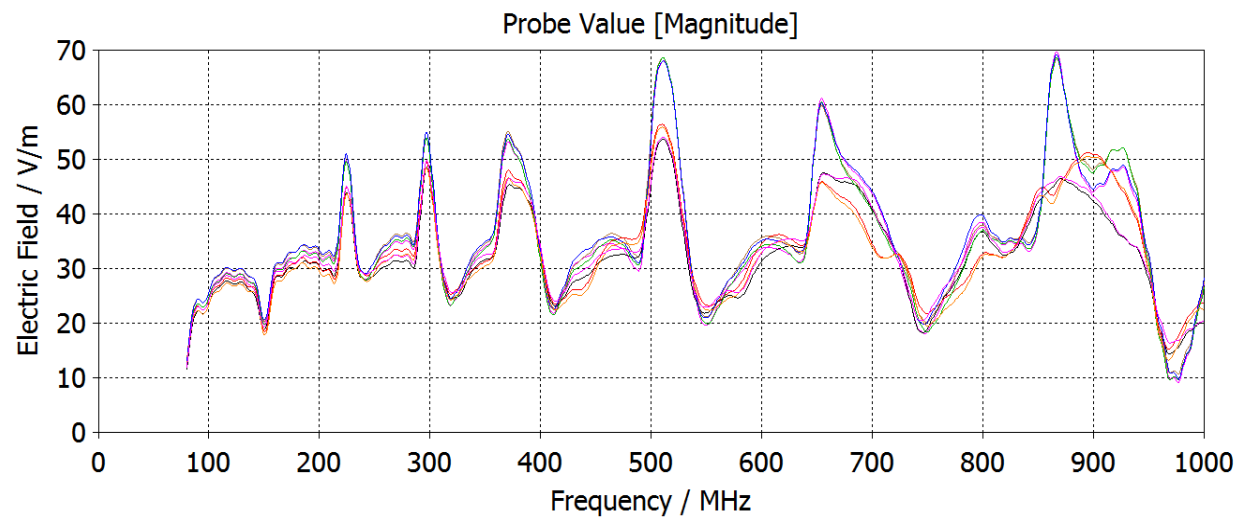

Figure 2.23 Simulated E-field distribution of double LPDA, 16 points at $3 \mathrm{~m}$

The FU for both LPDAs is plotted in Figure 2.24. The simulation result illustrates that the single LPDA continues to produce better uniformity with only $1 \mathrm{~dB}$ of variation compared to $2 \mathrm{~dB}$ from the double LPDA. The basic parameters of the double LPDA are similar to those of the single LPDA, but due to simplification, the double LPDA experienced some problems. The gain of the double LPDA is slightly higher than that of the single LPDA. The distance and angle between the two LPDAs are important issues that could be causing mutual coupling, resulting a poor radiation pattern and a higher variation of FU. 


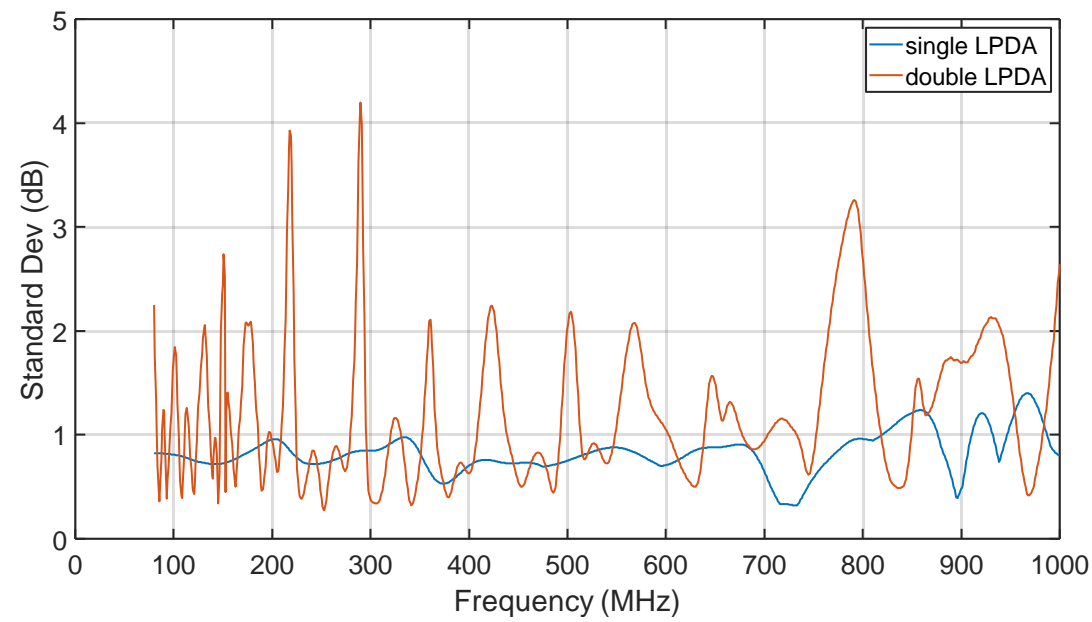

Figure 2.24 Simulated FU of E-field for single LPDA and double LPDA

The final model is the Ext-DRGH antenna. This result is important for verifying the measurement result and confirming that this antenna has its own advantages compared to the other antennas. Figure 2.25 shows the $S_{11}$ parameter of the ExtDRGH antenna.

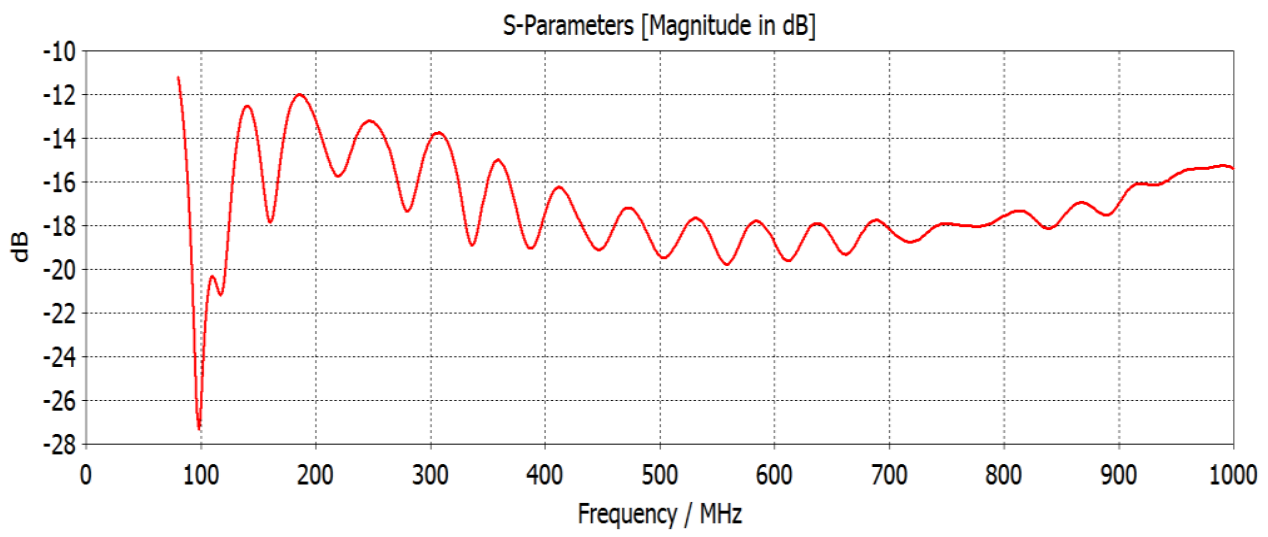

Figure 2.25 Simulated result: S-parameter of Ext-DRGH antenna

As shown in Figure 2.25, the $S_{11}$ curve has a much better result than the single and double LPDAs. In the frequency range $100 \mathrm{MHz}$ to $1 \mathrm{GHz}$, the line does not exceed $12 \mathrm{~dB}$. This simulation result supports the assumption that the Ext-DRGH antenna has good characteristics compared to LPDA-type antennas. 


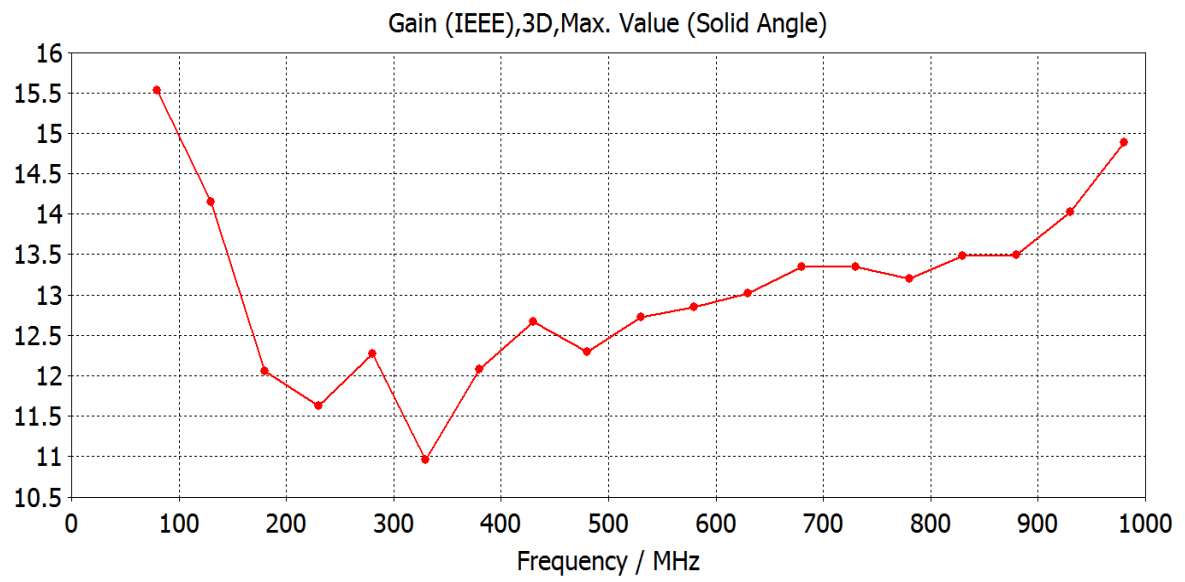

Figure 2.26 Simulation result: Gain of Ext-DRGH antenna

The gain of the simulated Ext-DRGH antenna is shown in Figure 2.26. It starts from $11 \mathrm{~dB}$ at the lower frequency and reaches $15 \mathrm{~dB}$ at $1 \mathrm{GHz}$. With a higher gain, better $S_{11}$ and a good radiation pattern, the Ext-DRG produces a higher electrical field at a distance of $3 \mathrm{~m}$, as confirmed by the E-field distribution shown in Figure 2.27. The field distribution and uniformity are shown in Figure 2.27 and Figure 2.28 , respectively.

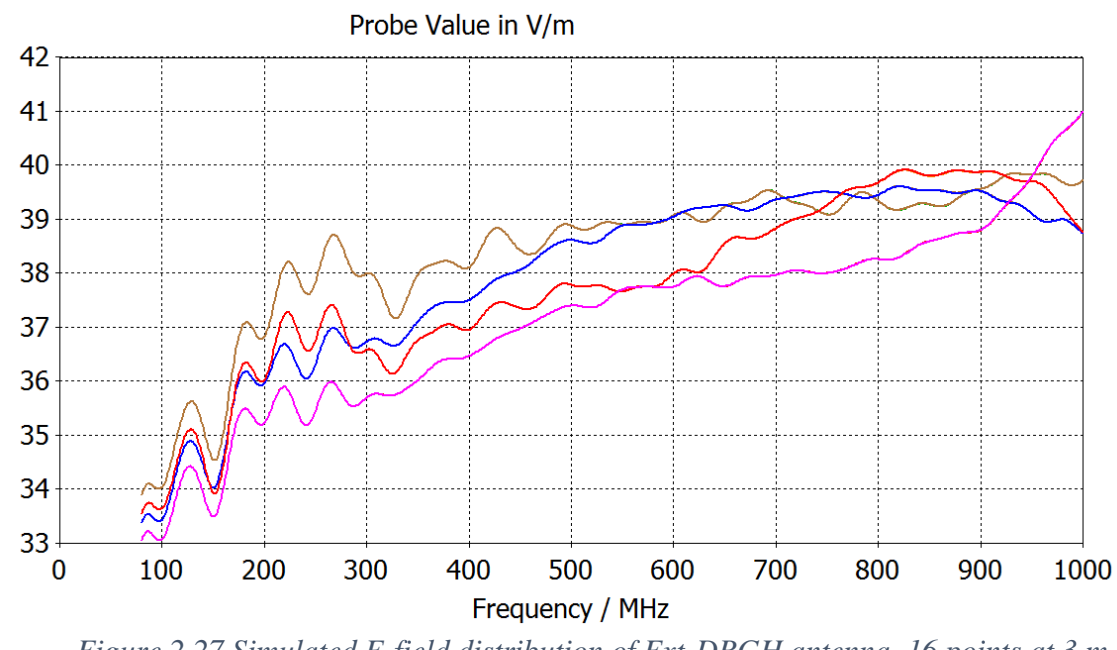

Figure 2.27 Simulated E-field distribution of Ext-DRGH antenna, 16 points at $3 \mathrm{~m}$

The E-field distribution result as depicted in Figure 2.27 shows fields starting from $33 \mathrm{~V} / \mathrm{m}$ to $41 \mathrm{~V} / \mathrm{m}$ at $1 \mathrm{GHz}$, within 16 points. These values are much higher than the LPDA (Figure 2.23), with a difference of 1 to $7 \mathrm{~V} / \mathrm{m}$. With respect to the P2E Ext-DRGH antenna, this result simply confirms that with the same power, this antenna creates a stronger field at the probe location. 


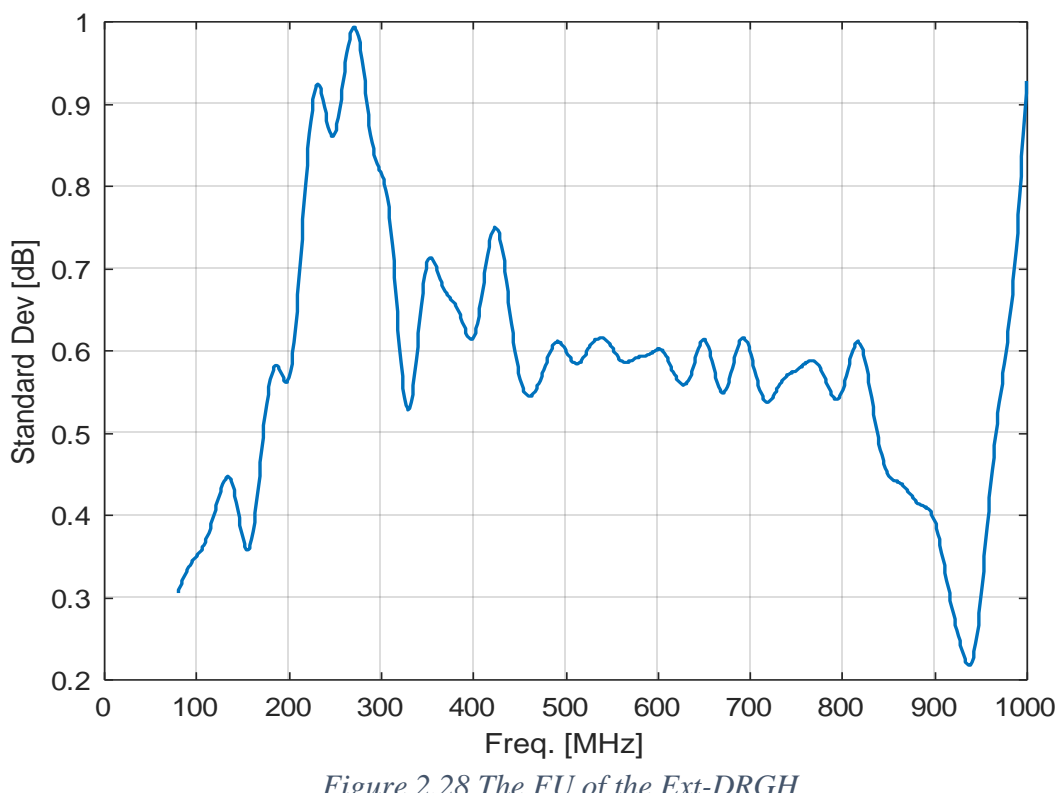

The FU of the Ext-DRG yielded good results: under $1 \mathrm{~dB}$ for the entire frequency band and better than the LPDA, as illustrated in Figure 2.28. This simulation result also validates the measurement results: Despite its larger size, the Ext-DRGH antenna is the best option in terms of uniformity and power efficiency.

\subsection{Conclusion}

The single log-periodic dipole antenna (LPDA), Double LPDA and Ext-DRG horn antennas which are used for electric field generation have been investigated. The FU based on IEC 61000-4-3 has been analyzed via measurements and simulations. Important parameters of the simulation results are compared with the antennas used in the measurement to validate the model.

The three antenna types analyzed in this chapter can be used as a transducer for generating high intensity field. Measurements show that the Ext-DRGH is resulting in the most efficient and best uniformity compared to single and double LPDA. The simulation gain of the double LPDA shows a slightly higher gain than the single LPDA, as expected, as well as better S parameters. However, FU is worse than the single LPDA due to design issue and mutual coupling between them.

With respect to the required power (P2E) and FU, the Ext-DRGH comes out as the best choice. The Ext-DRGH antenna requires lower power than the other two, and shows comparable FU with the double LPDA. The disadvantage of Ext-DRGH antenna is its weight and the big size. 


\section{Generating E-field Strength in Active Leveling and Pre-Calibration}

This chapter is based on the paper published at the International Conference on EMC, EMC Europe 2016, as well as some additional results that could not be included in the paper. The work was carried out in close collaboration with Tubitak (Turkey), INTA (Spain) and CMI (Czech Republic).

This section discusses radiated susceptibility testing in SAC, particularly large equipment, which influences the E-field reading of the probe and can cause errors in the EUT susceptibility level estimation and power level required by the transmitting antenna. This work provides the foundation for allowing the precalibration (or substitution) methods in STANAG 4370 AECTP 501, Edition E, Test Method NRS02 [45].

\subsection{Introduction}

RS tests for EMI assessments to achieve EMC were developed many decades ago. The most well-known standard is MIL-STD 461G [46], which is based on MILSTD 461 [47]. Other standards for professional equipment are often a (national) derivative [4][48]. For instance, RTCA/DO-160 [49] for airborne equipment is based on MIL-STD. For civilian equipment, the standard method is IEC 61000-4-3 [2], developed around 1990. It was based on IEC 801-3 [50] and was stimulated by the introduction of European EMC Directive 89/336/EEC [51]. Historically, EMC has been an important concern for the military [1]. EMI requirements were driven by military usage and EMC efforts were conducted by the military and a few industries.

Before 1970, the factual review of available radio-frequency (RF) technologies shows that during this time the majority of electronics were developed by and for the military (with an exception for AM/FM radio and TV), largely due to the limited application and high costs of this equipment [52]. This is now completely reversed. For the past four decades, starting with the emergence of the microprocessor in the mid-1970s, commercial applications began to take the lead over technological developments and the consumer market grew rapidly. As a result, EMI problems emerged in the civilian environment for which EMC standards were developed, resulting in the European EMC Directive 89/336/EEC, now 2014/30/EU [53], and the IEC 61000 series of standards. MIL-STD uses the leveling technique in the RS103 test up to $40 \mathrm{GHz}$, and alternatively the pre-calibration (or substitution) 
method above $1 \mathrm{GHz}$ for radiated susceptibility tests. There is no difference between large or small equipment. IEC 61000-4-3 [6] uses the pre-calibration method for an area of $1.5 \mathrm{~m}$ by $1.5 \mathrm{~m}$. Large industrial installations, however, could be even bigger. The main difference between the pre-calibration method and levelling method is that for the pre-calibration the P2E is determined without any EUT placed, while the levelling methods is carried out with a field strength sensor place in front, or on top of the EUT. That means that the EUT can influence the reading of the field strength sensor.

Research has been carried out for the uncertainty of radiated susceptibility, sensor calibration and the effect of sensor position on the RS103 method [54], but not on the effect of large reflecting equipment on measured field strength. Unusual or strange effects and large variations were observed, particularly when using the leveling method for large equipment. In the development of IEC 61000-4-39, we recognize similar discussions, where national committees comment on the setup based on estimation and engineering judgments.

On the other hand, when discussing leveling against pre-calibration, people feel confident with the technique they use. In the latest version of the NATO AECTP 500 standard, both techniques have been allowed for testing, although the technique used for qualification will be described in the test report [4]. To evaluate and provide suggestions for best practices, we performed measurements and compared the results of the leveling method and the pre-calibration (or substitution) method for large and small equipment. Active leveling and pre-calibration tests were performed when the forward power, reflected power, and electric field strengths were measured. The objective was to gain a better understanding of why, when and under which conditions the methods differed, with a focus on the size of the equipment under test (EUT). As an additional measurement, we also included the calculated method in the research, which is sometimes used in the industry as an alternative method.

\subsection{Effect of Large Metal Object}

If an electromagnetic field is radiating towards an infinitely large metallic plane, a current will flow at the air-metal boundary. Due to the continuity relation, a current will also flow in the opposite direction, which will generate a field. This field will reduce the incident field from the antenna, creating a net effect called quasi active shielding (QAS) [55]. Consider the electric field generated by a short currentcarrying segment at a distance $r_{l}$ :

$$
\hat{E}_{1}=j \frac{\hat{I} d l}{4 \pi} \eta \beta \frac{e^{-j \beta r_{1}}}{r_{1}}
$$

Where: 
$\hat{E}_{1}$ is the electric field strength vector in specific position, in the infinite metal plane $\hat{I}$ is the current vector flows in the specific length $d l$

$r_{l}$ is the distance between the source to the probe

$\eta$ is wave constant

$\beta$ is intrinsic impedance

In Figure 3.1, due to the metal plane, a current will be induced, resulting in a similar field $\hat{E}_{2}$, in the opposite direction. The sum of the fields at some distance is then $\hat{E}_{\text {net }}=\hat{E}_{1}-\hat{E}_{2}$

$$
\hat{E}_{n e t}=j \frac{\hat{I} d l}{4 \pi} \eta \beta\left(\frac{e^{-j \beta r_{1}}}{r_{1}}-\frac{e^{-j \beta r_{2}}}{r_{2}}\right)
$$

With $r_{1}=r-d$ and $r_{2}=r+d$ with $d / 2$ being the distance between the current-carrying segment and the metal plane, as shown in Figure 3.2. If $r>>d$ then the net field strength becomes:

$$
\hat{E}_{n e t}=j \frac{\hat{I} d l}{4 \pi} \eta \beta \frac{e^{-j \beta r}}{r}\left(e^{-j \beta d}-e^{-j \beta d}\right)
$$

And the QAS becomes:

$$
Q A S=\left|\frac{E_{1}}{E_{n e t}}\right|=\left|\frac{1}{e^{j \beta d}-e^{-j \beta d}}\right|=\left|\frac{1}{2 j \sin (\beta d)}\right|
$$

So, if the EUT is near the sensor, it will affect the electric field strength reading in the sensor due to the coupling between them, as shown in Figure 3.1 and Figure 3.2 .
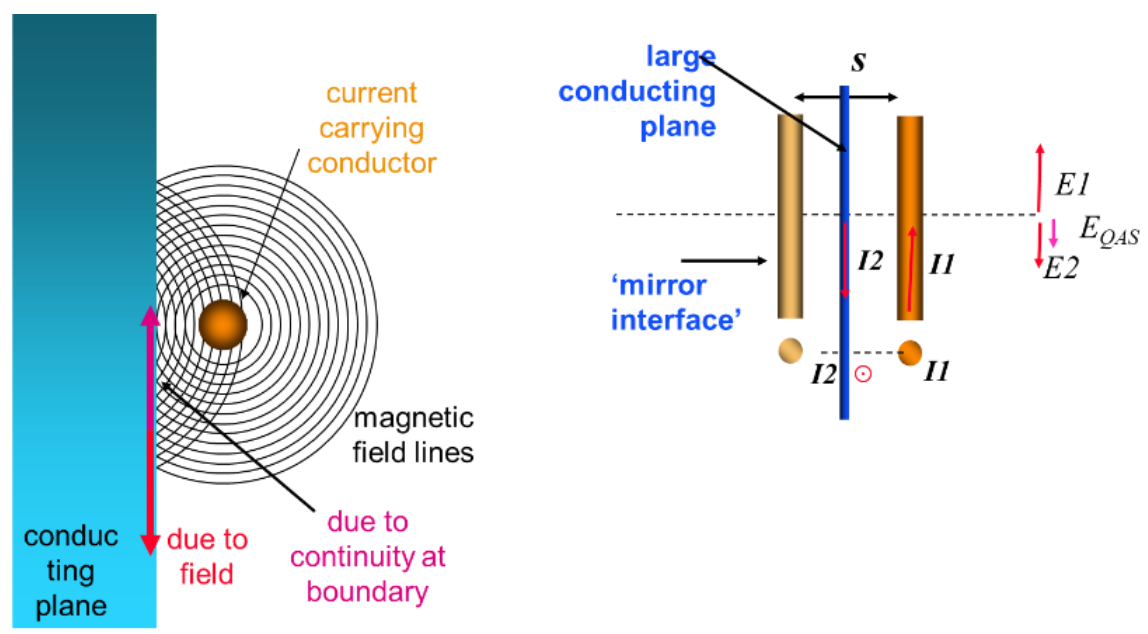

Figure 3.1 QAS effect due to nearby conducting plane [56] 


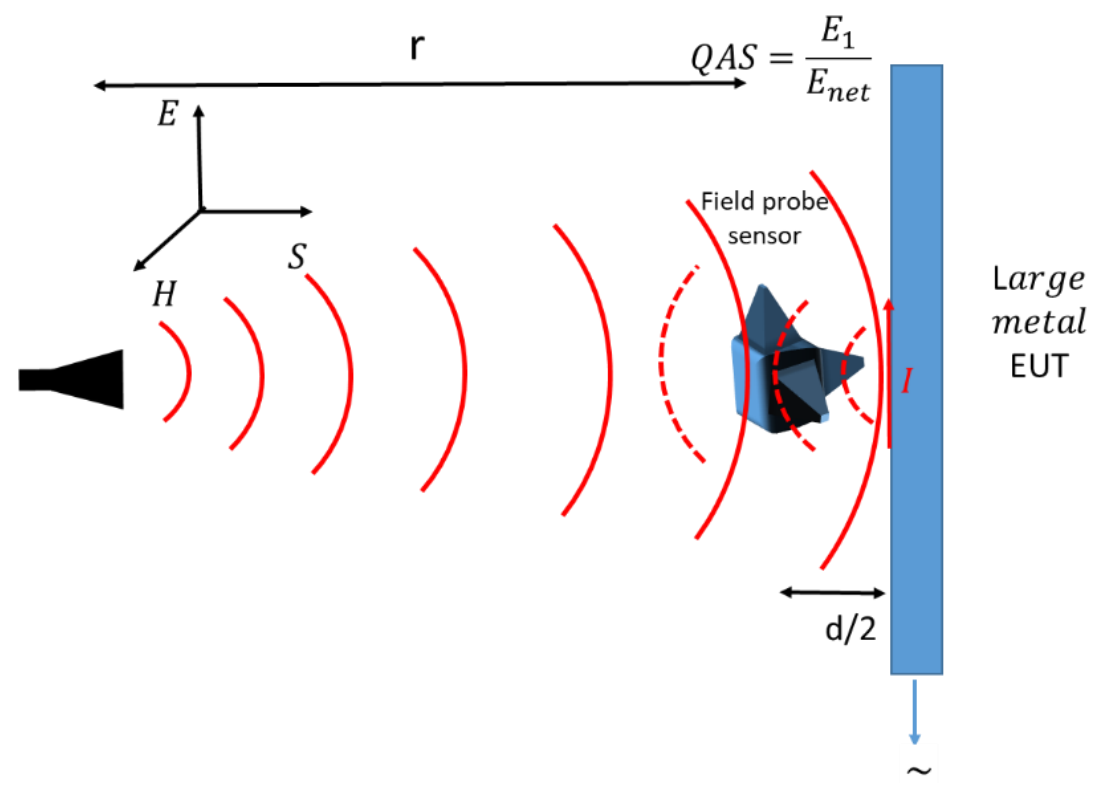

Figure 3.2 Coupling caused by induced current on the large metal plane

In Figure 3.3, the theoretical reduction in field strength for the $x$ and $y$ directed antennas of the sensor is shown as a function of the frequency. If a sensor is placed on top of a metal EUT, as shown in Figure 3.4, this effect will not occur, although the $y$ directed antenna of the sensor will be influenced by the enlarged virtual ground plane formed by the EUT.

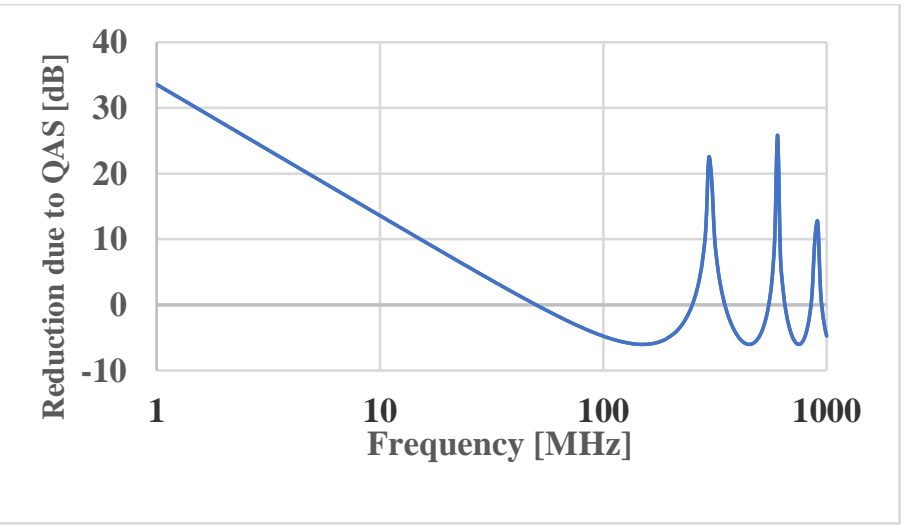

Figure 3.3 Reduction of E-field strength as a function of frequency 


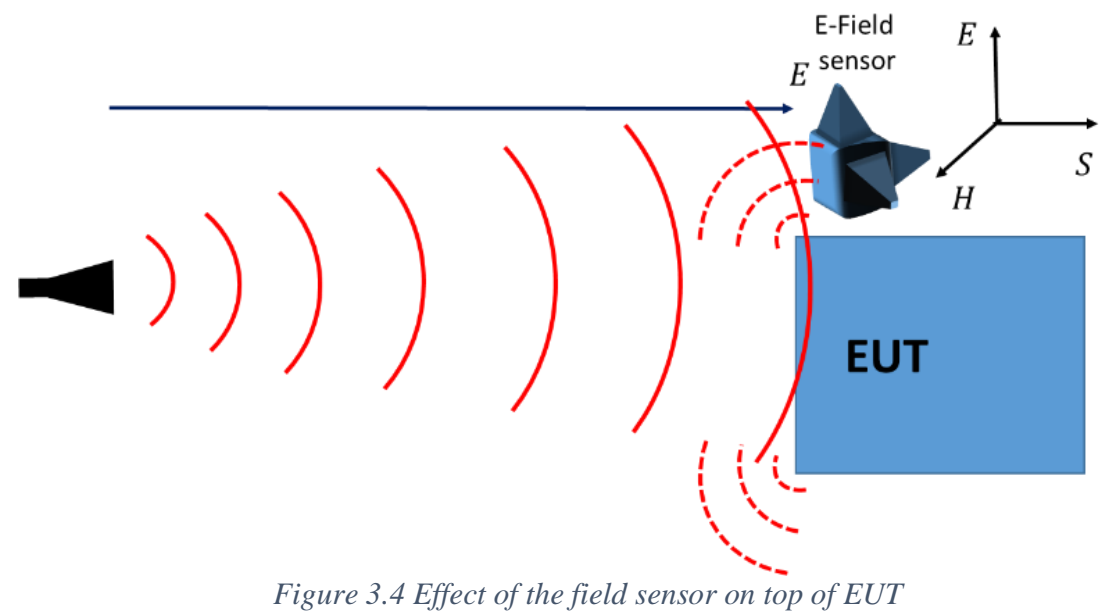

\subsection{Influence of Vertical Grounded Wire}

If a large metal plate has an additional vertical grounded wire, the occurring effect will be worse, as shown in the measurement and simulation results in Figure 3.6 and Figure 3.7, respectively. In the pre-calibration method, the presence of a vertical grounded wire above a conducting plane may cause a significant increase in electric field intensity when a vertically polarized electric field is applied. This test setup may have the highest effect in the frequency range under $80 \mathrm{MHz}$, which is not often used for testing according to 61000-4-3, but this range is required in some product standards (e.g. OIML R 49-2). This also confirms that a large vertical metal plate or wire will influence the reading of the E-field sensor if placed nearby.

The influence of a vertical wire was studied in the test setup shown in Figure 3.5. The antenna was vertically polarized and positioned at a height of $1.55 \mathrm{~m}$ to produce a required FU between $0.8 \mathrm{~m}$ and $2.3 \mathrm{~m}$. The vertical wire with a length of $1.65 \mathrm{~m}$ was placed $1.5 \mathrm{~m}$ from the antenna. The isotropic field probe was placed $0.1 \mathrm{~m}$ away from the wire at different heights from $0.5 \mathrm{~m}$ to $1.8 \mathrm{~m}$ above the ground plane.

Those measurements were done at the $10 \mathrm{~m}$ EMC chamber which meets the CISPR 16-1-4, $10 \mathrm{~m}$ normalised site attenuation (NSA) requirement. It is the precondition for $\mathrm{RE}$ measurement between $30 \mathrm{MHz}$ to $1 \mathrm{GHz}$, so the exact dimension is not important anymore. Above $1 \mathrm{GHz}$, the sVSWR must applied and the requirements are not similar. 


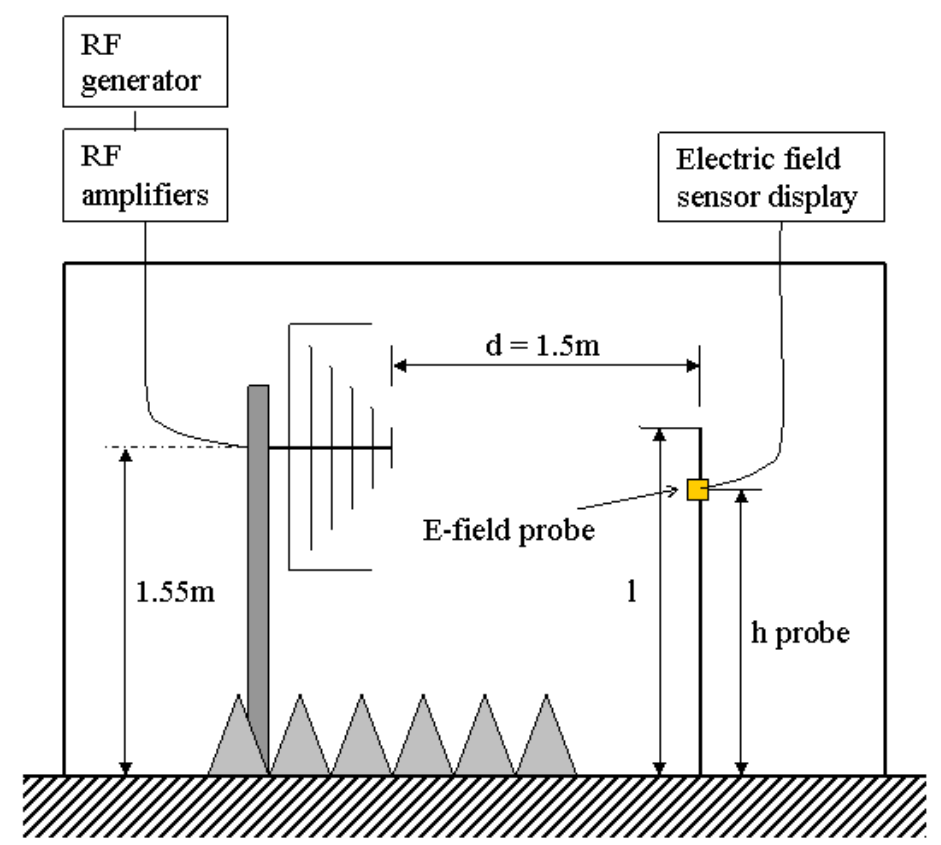

Figure 3.5 Test setup with vertical grounded wire measurement

For the measurement, the pre-calibration with target electric field level $10 \mathrm{~V} / \mathrm{m}$ was used. As the calibration was done at sixteen discrete points, the electric field intensity was measured at every probe position without the presence of the wire to obtain the reference values. Then the vertical grounded wire was installed and the electric field intensity was measured at the same points. The measured results were normalized to compensate for the difference in measured reference values and target level $10 \mathrm{~V} / \mathrm{m}$. Figure 3.6 shows the influence of the inserted vertical wire for the ideal calibration on $10 \mathrm{~V} / \mathrm{m}$. The next two figures used logarithmic scale on the $x$ axis, because these figures have been produced by our partner.

Figure 3.6 shows the increase of electric field intensity up to $140 \mathrm{~V} / \mathrm{m}$ and 60 $\mathrm{V} / \mathrm{m}$ on frequencies $42 \mathrm{MHz}$ and $132 \mathrm{MHz}$. This results in a $23 \mathrm{~dB}$ increase in the first peak at a distance of $100 \mathrm{~mm}$ from the wire. This significant increase of the electric field is caused by the behaviour of the grounded wire as a monopole antenna in resonance. The first peak is a product of the $\lambda / 4$ resonance and the second of the $\lambda * 3 / 4$ resonance. Resonances at higher frequencies $(\lambda * 5 / 4 ; \lambda * 7 / 4 ; \ldots)$ can be identified as well, but their magnitude is low. 


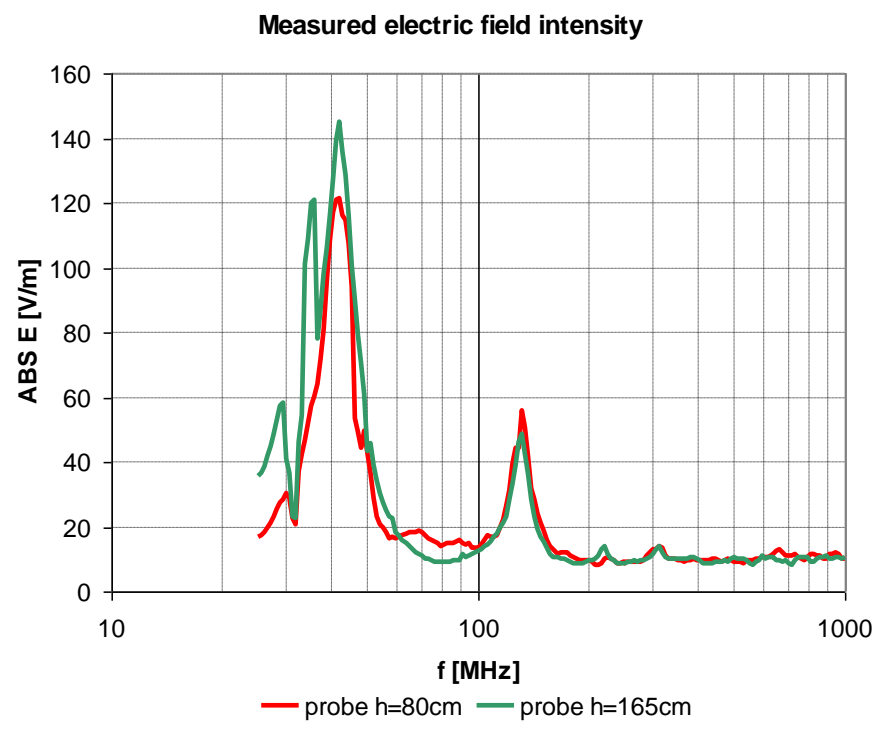

Figure 3.6 Measured electric field intensity at the vertical grounded wire

A set of simulations were performed to validate the measurement. Figure 3.7 shows the results for the simulations, which were performed using the same setup as used for the actual measurement. The results of the simulations are consistent with those of the actual measurement.

\section{Electric field intensity simulated in FEKO}

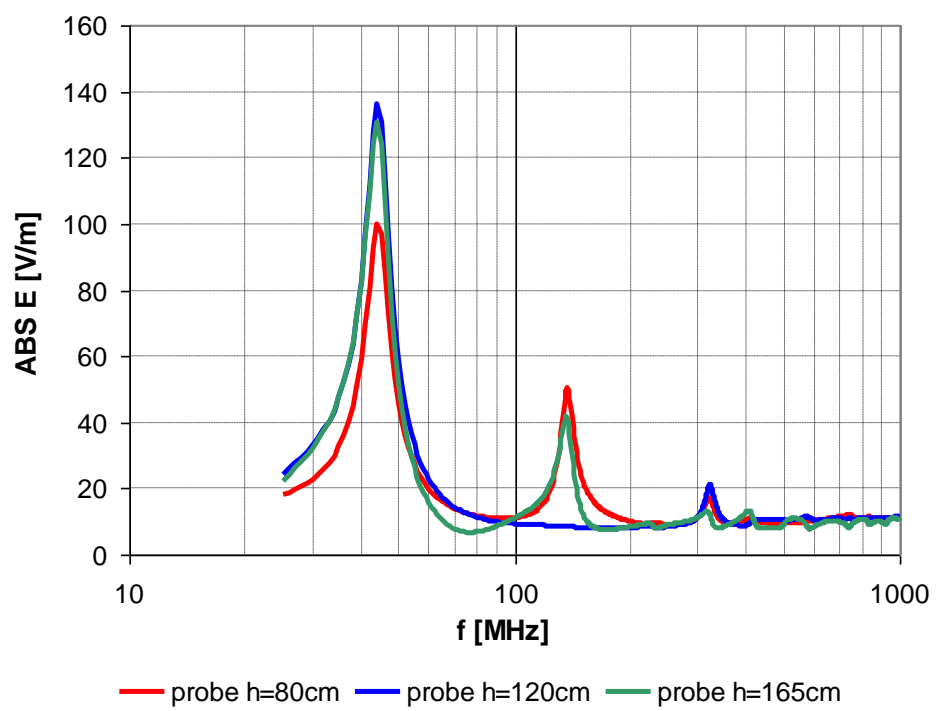

Figure 3.7 Simulated electric field intensity at the vertical grounded wire 
The E-field distribution along the wire was measured and simulated. Figure 3.8 shows that the maximum of the E-field on the first resonance frequency is close to the end of the wire. In the second resonance there are two peaks at the end, at approximately $1 / 3$ of the length.

The simulation also showed that the value of the E-field is highly dependent on the distance from the wire. As the current distribution on the wire in resonance is the dominant source of the field in the area near the end of the wire, the equipment under test may be exposed to very high electric field intensity.

Electric field distribution along the wire

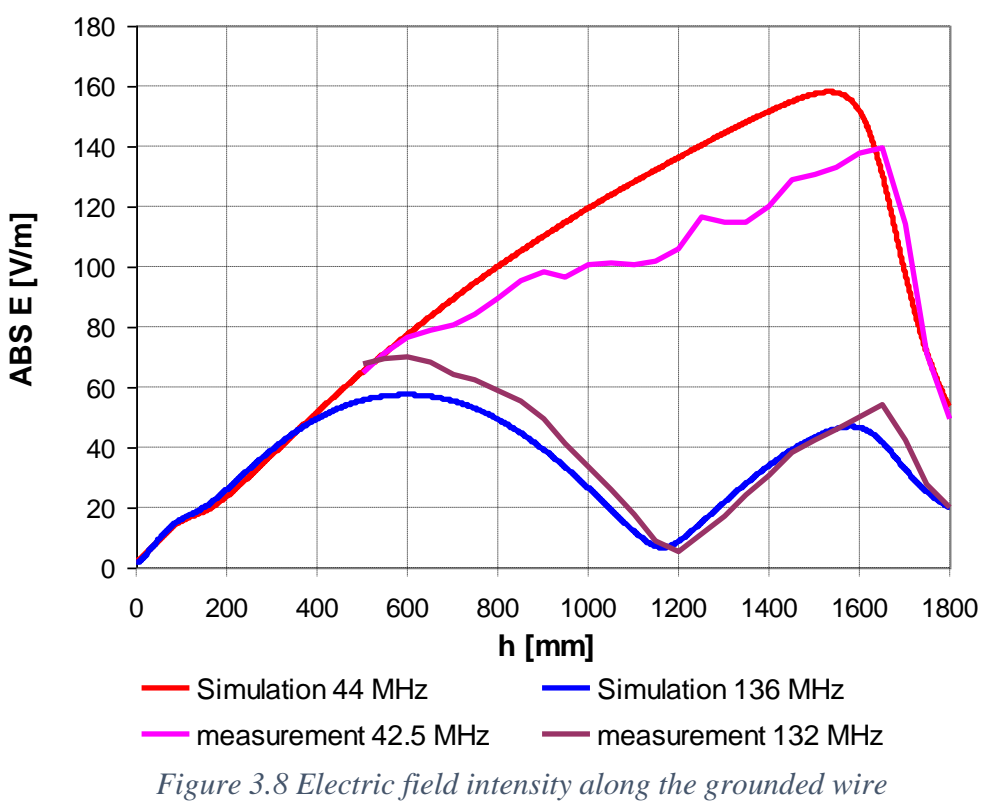

The effect described in this part may influence the electromagnetic susceptibility test results of a different kind of equipment requiring grounding during the test. Efield intensity may increase by $20 \mathrm{~dB}$ due to the presence of a grounded wire. It also can explain some probable differences that may occur between the pre-calibration and leveling method using a field probe to set the target immunity level. As there is no EUT in the pre-calibration method during the calibration phase, the grounded wire of the EUT will not affect the test results, but it will be very effective in the active leveling method as the grounded wire maybe present to the field sensor during the leveling stage. This demonstrates the possible difference between precalibration and leveling methods using a field probe to set the target immunity level. 


\subsection{Active Leveling and Pre-Calibration}

\subsubsection{Active Leveling}

EMC testing for RI or RS in the transmitting sides (i.e. antennas, signal generators and amplifiers) is always related to the amount of power injected into the antenna and how much power is transmitted by the antenna despite the efficiency and matching factor of the antennas. The RS or immunity test method based on leveling uses a generating antenna typically positioned $1 \mathrm{~m}$ or $3 \mathrm{~m}$ in front of the EUT, as shown in Figure 3.9. The test is performed at a frequency range starting at $10 \mathrm{kHz}$, but more often at $2 \mathrm{MHz}$ and up to $40 \mathrm{GHz}$. Despite critiques on measurements performed in the near field [14], this test setup replicates the EMI case: In military environments, antennas or sources are positioned very close to other equipment, and the test setup resembles this situation. Near field tests have been used for many decades and have been proven to be a valid method of evaluating the risk of electromagnetic interference in many applications, such as ground-based, land-based mobile, naval and aerospace applications.

Test levels are around $10 \mathrm{~V} / \mathrm{m}$ for sheltered environments, $50 \mathrm{~V} / \mathrm{m}$ for exposed land-based environments, $200 \mathrm{~V} / \mathrm{m}$ for exposed naval environments, and up to 600 $\mathrm{V} / \mathrm{m}$ for aerospace environments. The last two $(200$ and $600 \mathrm{~V} / \mathrm{m})$ are field strengths almost close to high-power, high-frequency (HF) and ultra-high and super-high frequency (VHF, SHF) transmit antennas and in the main beam of radar systems. As can be seen in Figure 3.9, the field sensor was placed in front of the antenna and both were centered between the edges of the test setup under $200 \mathrm{MHz}$. On the other hand, above $200 \mathrm{MHz}$ up to $1 \mathrm{GHz}$, the antenna and the field sensor are placed in a sufficient number of positions such that entire width of each EUT enclosure and the first $35 \mathrm{~cm}$ of cable within the $3 \mathrm{~dB}$ lobe of the antenna. For frequency above $1 \mathrm{GHz}$ and the EUT test setup boundaries are less or equal than $3 \mathrm{~m}$, the field sensor are placed $7 \mathrm{~cm}$ of the cable. The signal source was amplified to drive sufficient energy to the antenna. The electric field sensor received and measured the signal until it reached the required level stated in the standard. The display reading shows the electric field value based on the electric field sensor, placed within the EUT test boundary. 


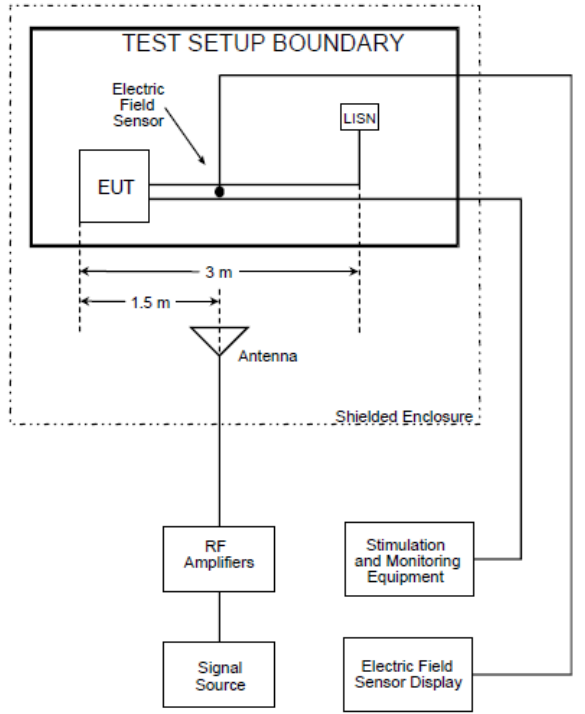

(a)

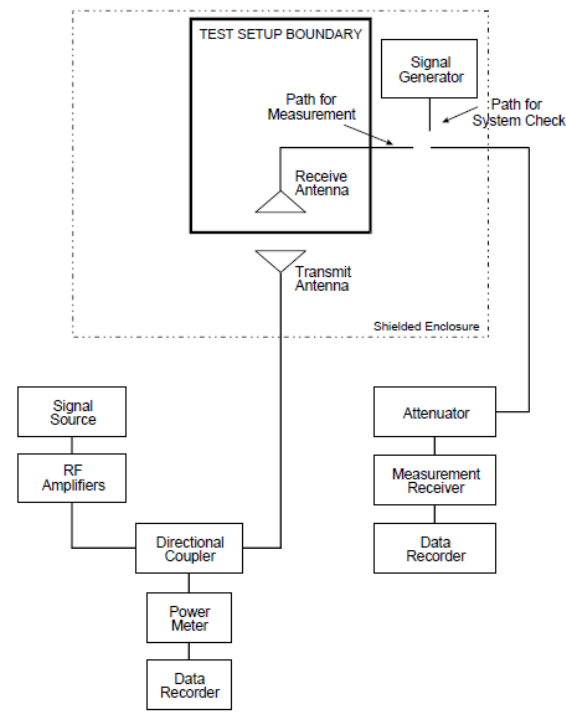

(b)

Figure 3.9 (a) AECTP 500 NRSO2 test equipment configuration (b) Pre-calibration procedure (1 to $40 \mathrm{GHz})[4]$

\subsubsection{Pre-Calibration / Substitution Method}

The pre-calibration method may only be used as an alternative to the active leveling method above $1 \mathrm{GHz}$. Therefore one field strength sensor or a receiving antenna is positioned where the EUT will be placed and the power needed to generate the field strength is measured and stored, as shown in Figure 3.9b. The electric field level is gradually increased until it reaches the applicable limit and the power needed to generate this field strength is registered.

Testing large equipment influences the field strength reading of the electric field probe. Therefore it is recommended to use the aforementioned pre-calibration (or substitution) method also for frequencies under $1 \mathrm{GHz}$. To prove the validity of this approach, several measurements have been performed and analyzed in the next section.

Another important parameter is electric field strength in the uniform area on the test, in particular during the EUT test. Other standards have been explored and investigated for small, middle and large EUTs to determine in which condition the E-field reading on the field probe changes and is disturbed by the size of the EUT. For commercial products, RS tests are based on the pre-calibration method as described in IEC 61000-4-3 [2]. It is usually performed from $80 \mathrm{MHz}$ to $1 \mathrm{GHz}$, although it can be extended up to $6 \mathrm{GHz}$. The electric field strength is 3 to $20 \mathrm{~V} / \mathrm{m}$, depending on the product application and environment. In this pre-calibration procedure, the field strength has to be measured without the EUT being present. The 
IEC method requires a UFA of $1.5 \mathrm{~m}$ by $1.5 \mathrm{~m}$, placed on a vertical measurement plane $3 \mathrm{~m}$ from the phase center of the transmitting antenna. The field strength is measured at 16 points and at least 12 points must fulfil the criteria. No clear description is given for large EUTs with bigger dimensions.

\subsubsection{Theoretical Calculable Method}

A third method is often denoted as the calculable method. Suppliers of test systems often calculate the E-field using this method [14] by taking:

$$
E=\frac{\sqrt{30 P G}}{R}
$$

Here, $R$ is the distance (often assumed to be $3 \mathrm{~m}$ ), 120/ $\Omega$ is the air impedance in the far field region, $P$ is the forward power and $G$ is the gain. However, the gain is generally undefined for $3 \mathrm{~m}$ and must be specifically measured at $3 \mathrm{~m}$ for this purpose. For a popular high-power biconical antenna the power needed to generate $200 \mathrm{~V} / \mathrm{m}$ at a distance of $3 \mathrm{~m}$ in the frequency range 50 to $100 \mathrm{MHz}$ would be approximately $1100 \mathrm{~W}$. For a popular bicon-log-periodic antenna, for frequency 80 MHz it is stated that $10-15 \mathrm{~W}$ is needed at $3 \mathrm{~m}$ for $10 \mathrm{~V} / \mathrm{m}$. In practice, these power levels appear to be underestimated.

\subsubsection{Experiment Setup}

Pre-calibration and active leveling tests were performed in three different laboratories: TUBITAK in Turkey, INTA in Spain, and THALES in the Netherlands, as part of the EMRP project Industry-60 funded by the European Commission (EC). In addition to these methods, the calculable method was also studied at TUBITAK. The primary target of these measurements was to determine which method was more consistent with the standard method and more applicable to the industrial environment. Several measurement results were taken into account and the graph format was adjusted accordingly in order to show the effects of different EUTs and metallic surfaces on the E-field level. The $3 \mathrm{~m}$ chamber was used and dummy EUTs were tested here. The dimensions of the $3 \mathrm{~m}$ chamber is length $8.72 \mathrm{~m}$, width $5.38 \mathrm{~m}$ and height $3.53 \mathrm{~m}$. The walls, the ceiling, and the floor are covered with hybrid absorbers (ferrite tile with foam absorbers). The chamber meets IEC61000-4-3 FU requirements, $0-6 \mathrm{~dB}$ and MIL-STD 461 absorber requirements.

Firstly three different RS methods were investigated. The standard FU method (pre-calibration method), the active leveling method, and the calculable method. We then compared these based on the applied forward power and the effects created by a dummy EUT on the E-field probe reading. As mentioned earlier, active leveling is the method by which the electrical field is actively established on the EUT by 
means of an electrical field sensor close to the EUT, as seen in Figure 3.12 and Figure 3.14 without pre-calibration or an established UFA. The pre-calibration method relies on the field strength calibration without an EUT in place and on registering the power levels needed to generate the required field strength. The calculable method relies on the theoretical calculation utilizing the equation, the antenna gain and the antenna-EUT distance in order to calculate the electrical field value at the EUT.

The measurements were performed in the frequency range $80 \mathrm{MHz}$ to $1 \mathrm{GHz}$ by means of a bi-log antenna (Schaffner Model: CBL6112B). The sixteen-point FU as stipulated by [2] in the horizontal polarization of the antenna at $3 \mathrm{~m}$ antenna distance was measured and recorded in the final calibration file, which includes the final forward power values and corresponding target field levels to be used in further measurements. The target was $5 \mathrm{~V} / \mathrm{m}$ to stay in the safe region and to stay away from the saturation region of the amplifier. The first measurements were performed at a distance of $3 \mathrm{~m}$ in free space with a monitor field sensor exactly at the center of the FU area, but without using the dummy EUT as seen in Figure 3.12. The first measurement in free space was performed by using a FU with the electrical target 5 $\mathrm{V} / \mathrm{m}$ as a reference. Thereafter the active leveling method with exactly the same setup and with the same electrical target level $(5 \mathrm{~V} / \mathrm{m})$ was applied. In the active leveling method, as mentioned, the electrical field on the sensor was actively established with feedback from the sensor without any pre-calibration file for each frequency. Then, in order to calculate the required power that theoretically establishes the target electrical field $(5 \mathrm{~V} / \mathrm{m}$, in our case) on the EUT, the calculable method for free space is applied by using ( 3.5 ).

The EUT was then placed inside this FU area and a pre-calibrated field was applied to the EUT. In this standard (pre-calibration) method [2], while the field sensor was used in the calibration of the FU area, it was only used for monitoring purposes in the test stage. Metal boxes with receiving elements to simulate typical EUTs were used. The dummy EUT had an internal receiving small antenna which received radiation through slits. The other radiating element was a set of cables coming out of the slits and laid over the surface of the dummy EUT to simulate the external cables of a typical EUT. The internal antenna and external cable configuration were connected to the same feeding point ( $\mathrm{N}$ connector) at the bottom of the metallic boxes. The internal antenna and external cables were connected to this $\mathrm{N}$ connector in parallel without any splitter or other components. One of the external cables was connected to the live point of the $\mathrm{N}$ connector and the other was connected to the metal case of the EUT (grounded) to simulate the earth cable of an actual EUT. The dummy EUT can be seen in Figure 3.10 and Figure 3.11. 


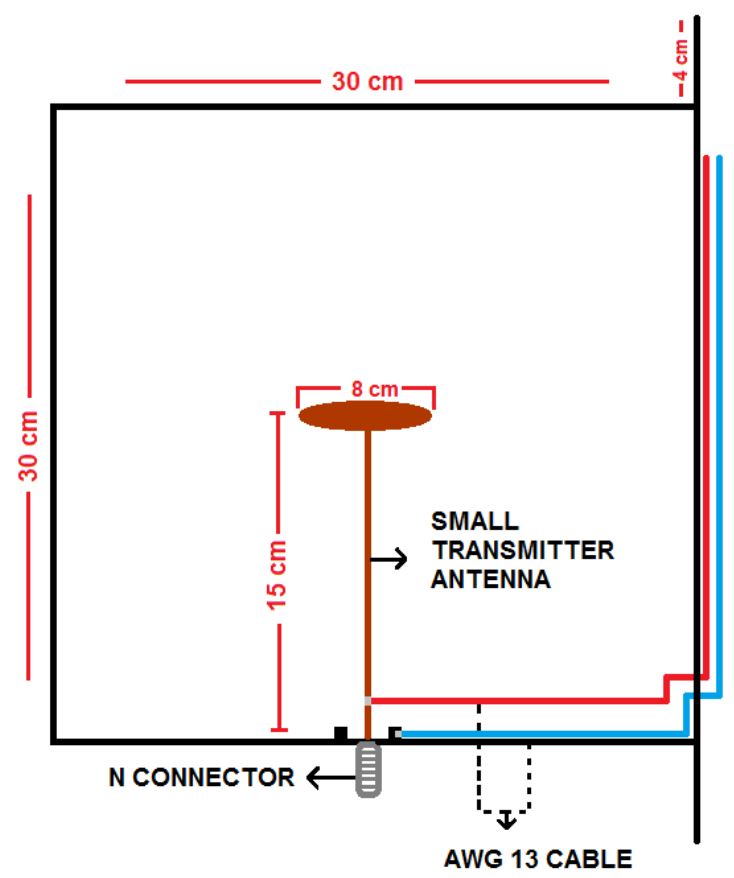

Figure 3.10 Dummy EUT (inside view and side view)

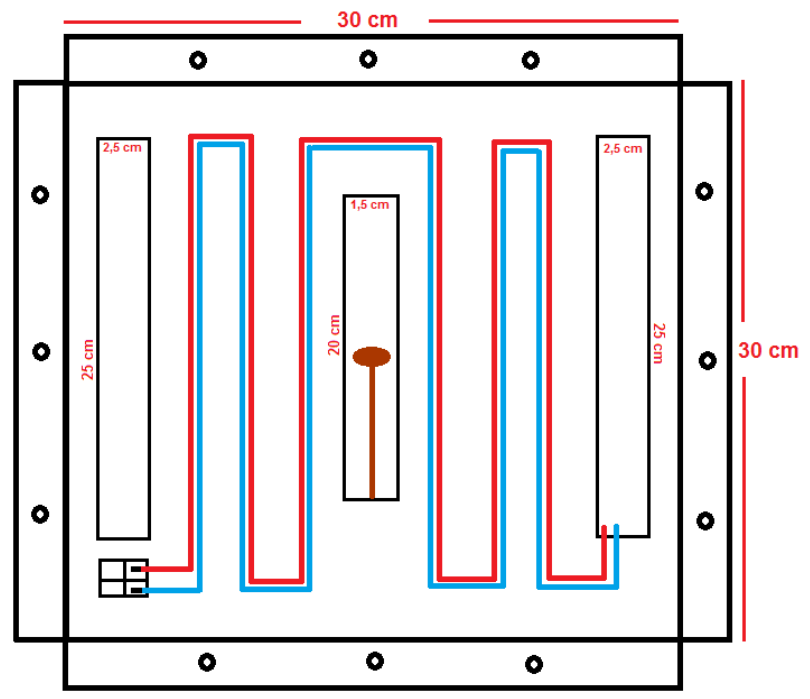

Figure 3.11 Dummy EUT (front view) 


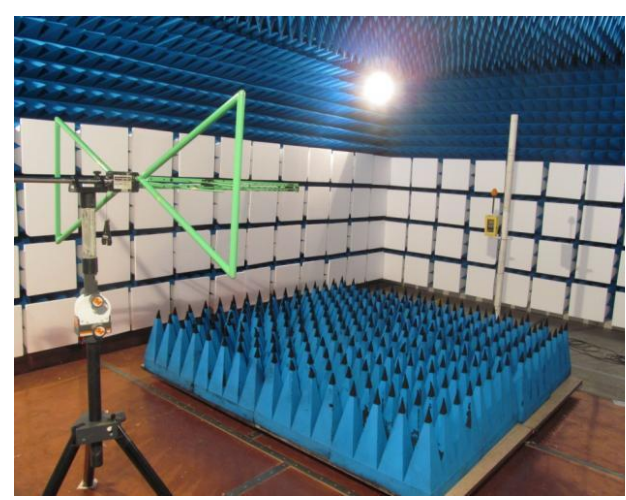

(a)

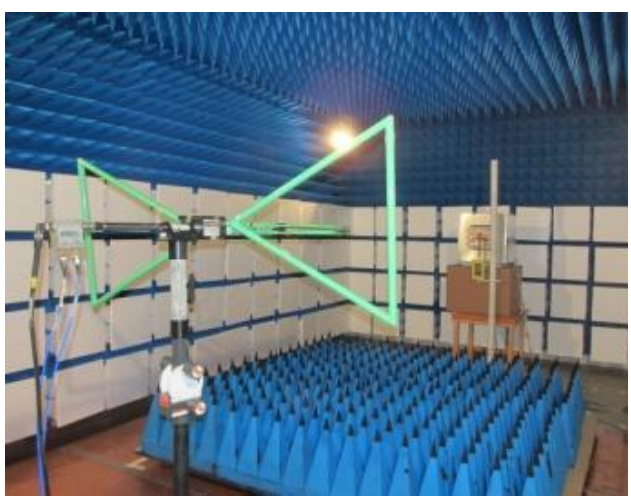

(b)

Figure 3.12 Measurement at $3 \mathrm{~m}$ (a) free space (b) with dummy EUT

During the research, two EUTs with different dimensions were used. In the measurements, the antennas were kept at a fixed height of $1.7 \mathrm{~m}$ at standard and non-standard measurement distances. As the spatial FU area was more uniform in horizontal polarization in the anechoic chamber, all the investigations were performed in the horizontal polarization. In each configuration, the forward power injected into the antenna, the displayed electrical field by the monitor sensor and the signal induced inside the EUT via the small receiving antenna and external receiving cables were recorded. Given that all three methods aim to produce the same electrical field value on the EUT, the investigation of differences in forward power injected into the antenna, the displayed electrical field values on the electrical field sensor, and the induced voltages inside the EUTs were the best ways to compare the results of the three methods and to clearly show that the methods may yield different results.

A second measurement setup was installed at non-standard and standard distances with the use of different EUT sizes at INTA. All measurements were performed in a $10 \mathrm{~m}$ EMC chamber and also meets the FU pre-condition for field susceptibility test at $3 \mathrm{~m}$ as per IEC 61000-4-3 These measurements were also performed in order to compare the pre-calibration method based on IEC 61000-4-3 with the leveling method at $1 \mathrm{~m}$ on small equipment $(18 \mathrm{~cm} \times 20 \mathrm{~cm} \times 8 \mathrm{~cm})$, medium equipment $(18 \mathrm{~cm} \times 40 \mathrm{~cm} \times 36 \mathrm{~cm})$ and large equipment $(80 \mathrm{~cm} \times 60 \mathrm{~cm}$ $\mathrm{x} 135 \mathrm{~cm}$ ) in the frequency range $80 \mathrm{MHz}-1 \mathrm{GHz}$. Thereafter, the data was analyzed, showing the results for the power injected into the antenna and the electric field strength on the sensor inside the EUT. The result and target level were recorded for both the horizontal and vertical polarization. The test setup can be seen in Figure 3.15 . 

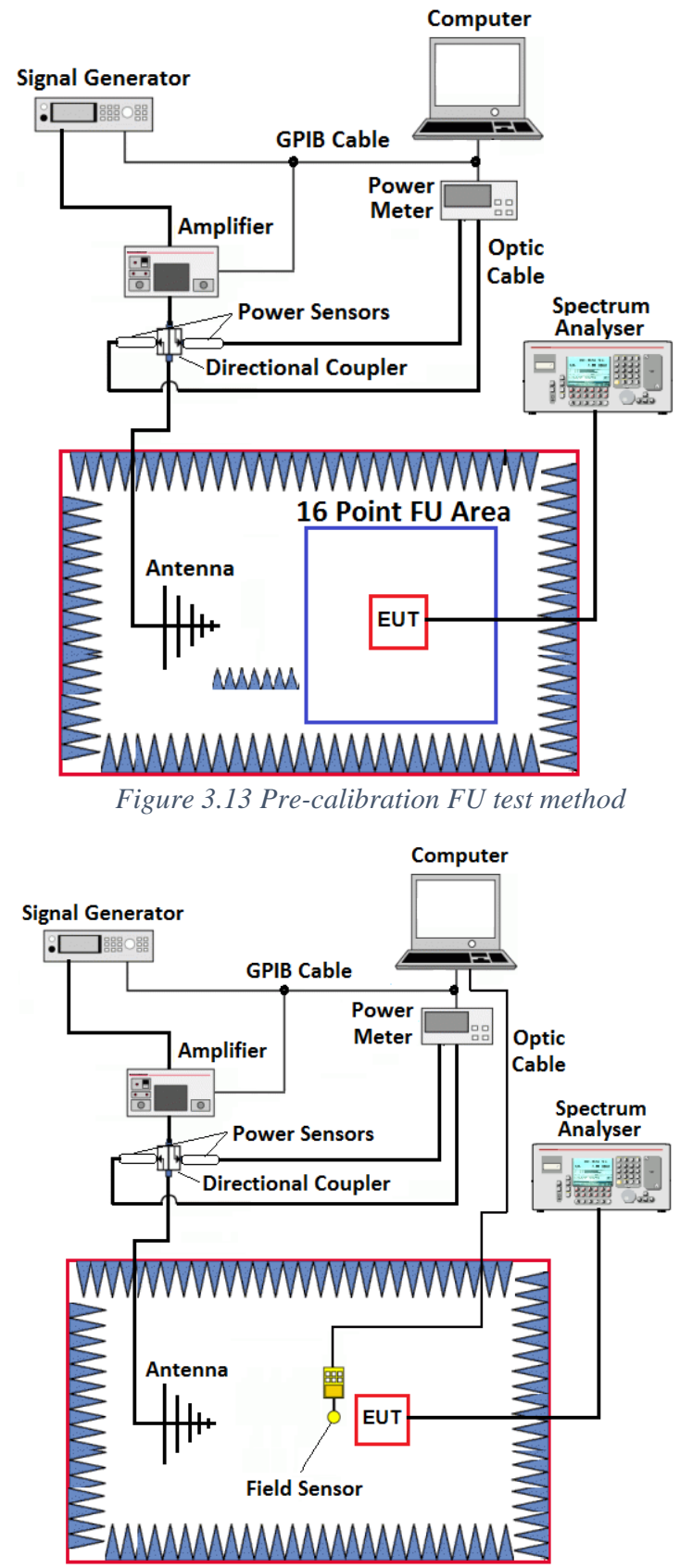

Figure 3.14 Active leveling test method

The last setup was installed with the small and medium EUTs and the measurements were performed with the pre-calibrated electric field. During testing, 
the forward (input) power as (which was also used during pre-calibration) was applied and the electric field reading was recorded.

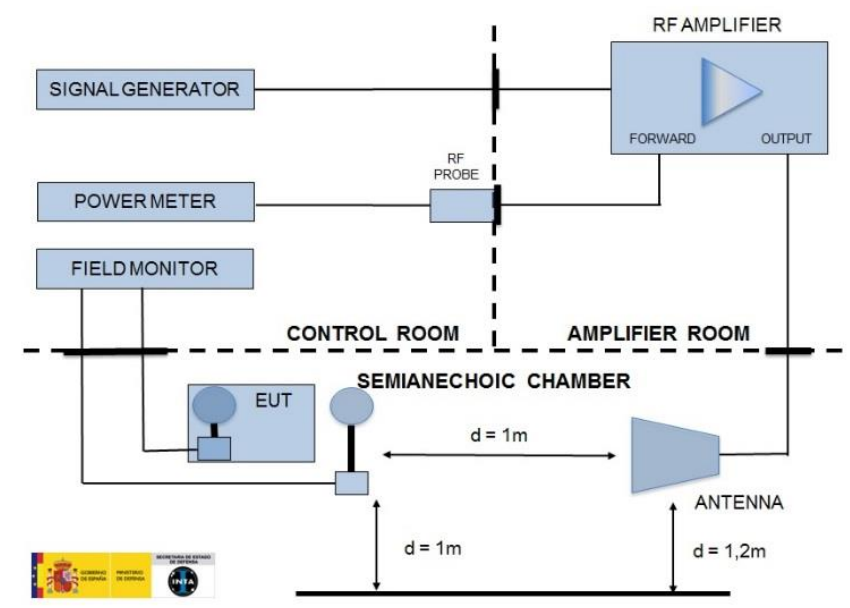

Figure 3.15 Test setup for active leveling method (INTA)

\subsection{Measurement Results}

The comparative results of the standard (pre-calibration) method, the active leveling method, and the calculable method at $3 \mathrm{~m}$ (obtained at TUBITAK) are presented in Figure 3.16 (a) to (e). In Figure 3.16 (b) clearly shows that, in the situation with the big dummy EUT $(0.125 \mathrm{~m} 3)$, the required injected power to the antenna in the active leveling method exceeds the power required in the standard (pre-calibration) method at several lower frequencies. This is due to the EUT presence, despite the fact that the antenna is $3 \mathrm{~m}$ away from the EUT in the precalibration method and $1 \mathrm{~m}$ away in the other methods.

The electrical fields on the field sensor change dramatically due to the EUT presence for the pre-calibration and calculable methods. The curves in Figure 3.16 (c) also reveal that the results of the pre-calibration and calculable methods are reasonably consistent, but the active leveling method causes over-testing in lower frequencies and under-testing in higher frequencies compared to the pre-calibration method. 


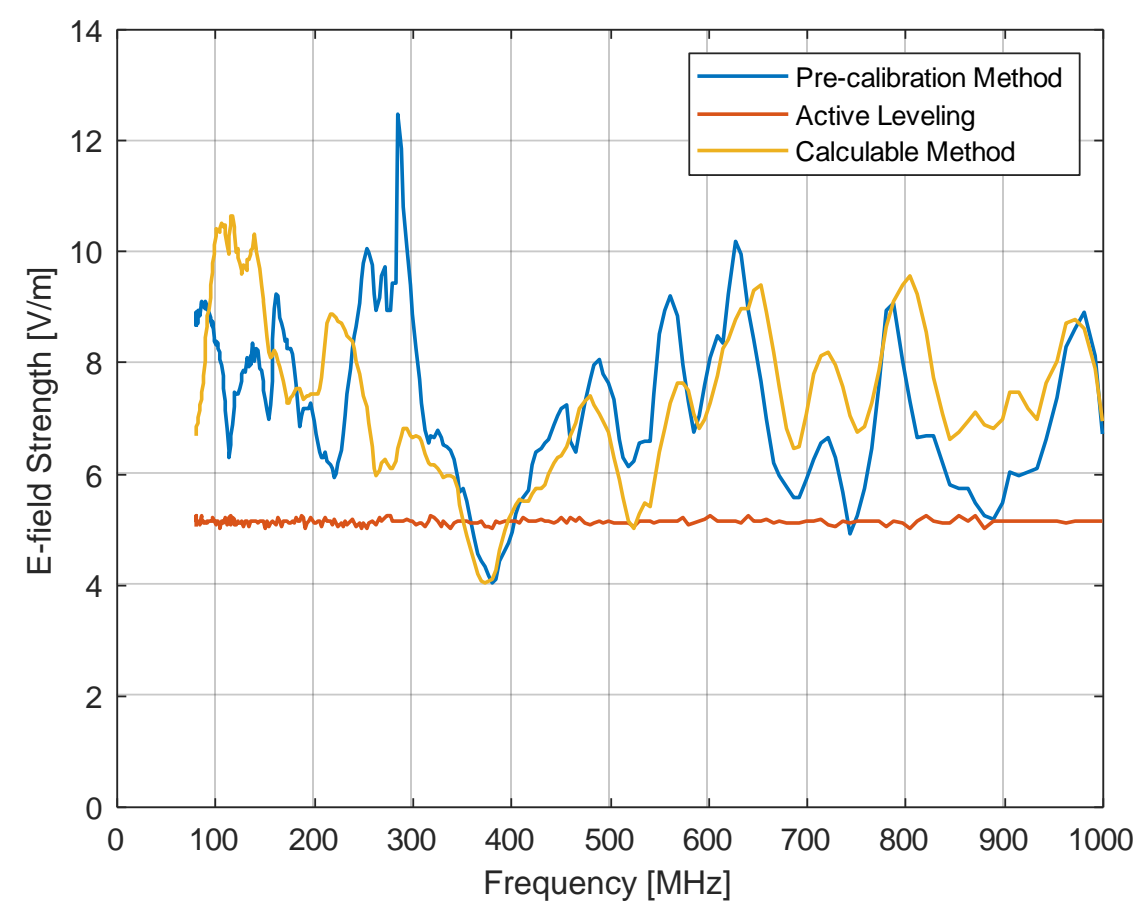

(a)

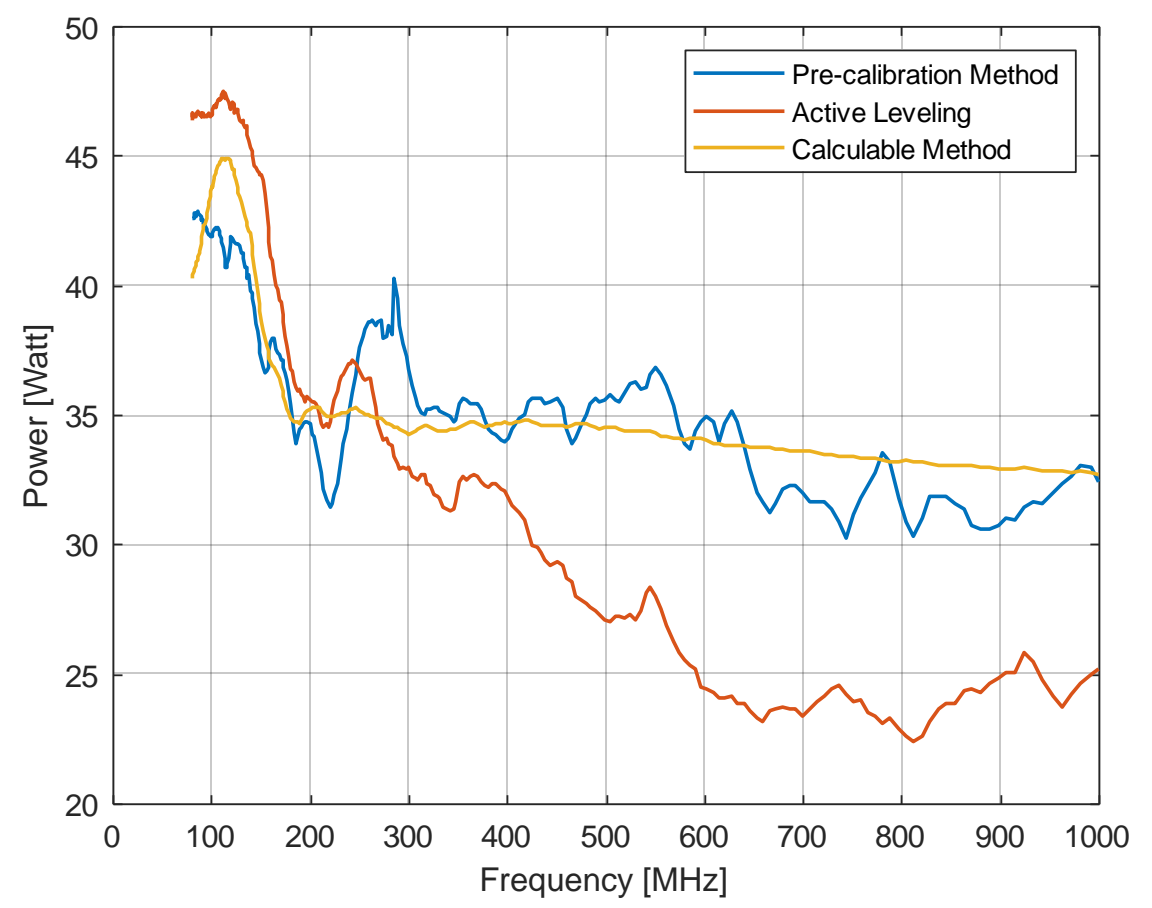

(b) 
CHAPTER III. GENERATING E-FIELD STRENGTH IN ACTIVE LEVELING AND PRE-CALIBRATION METHOD

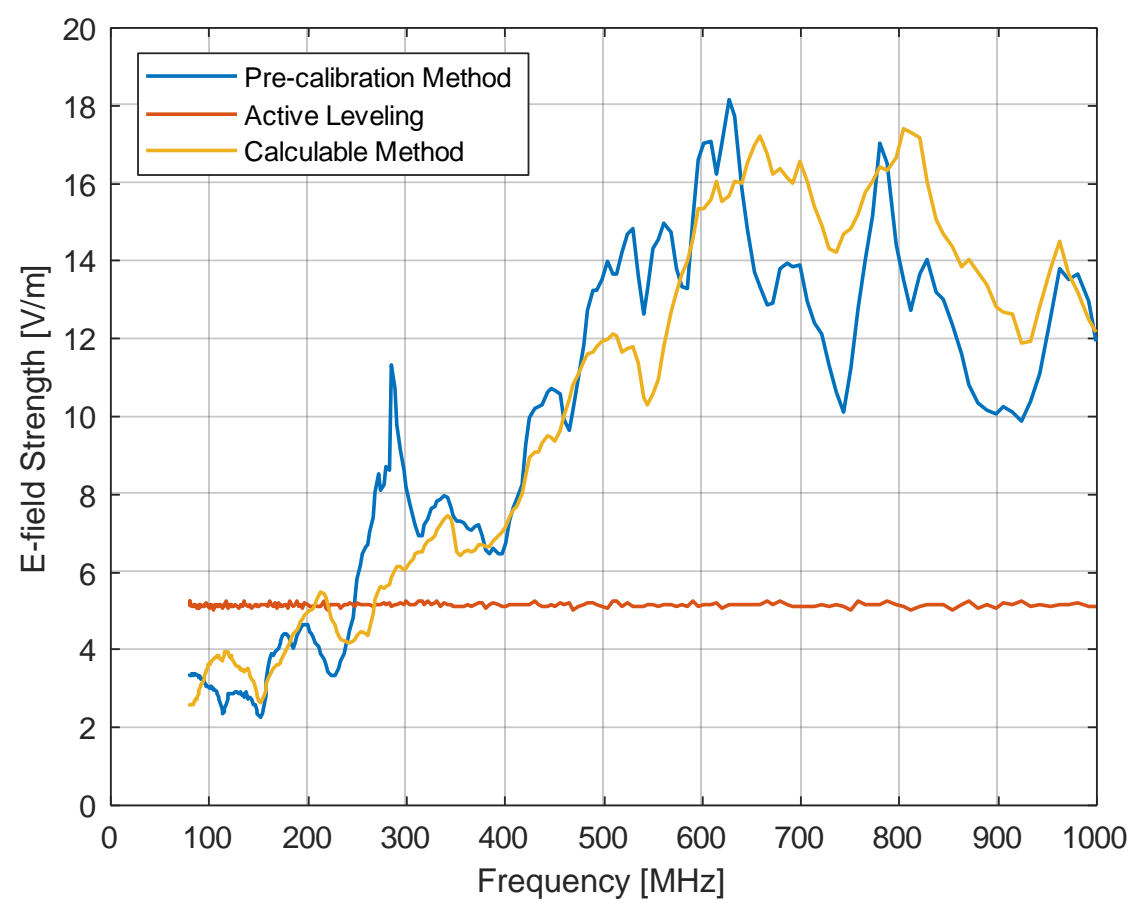

(c)

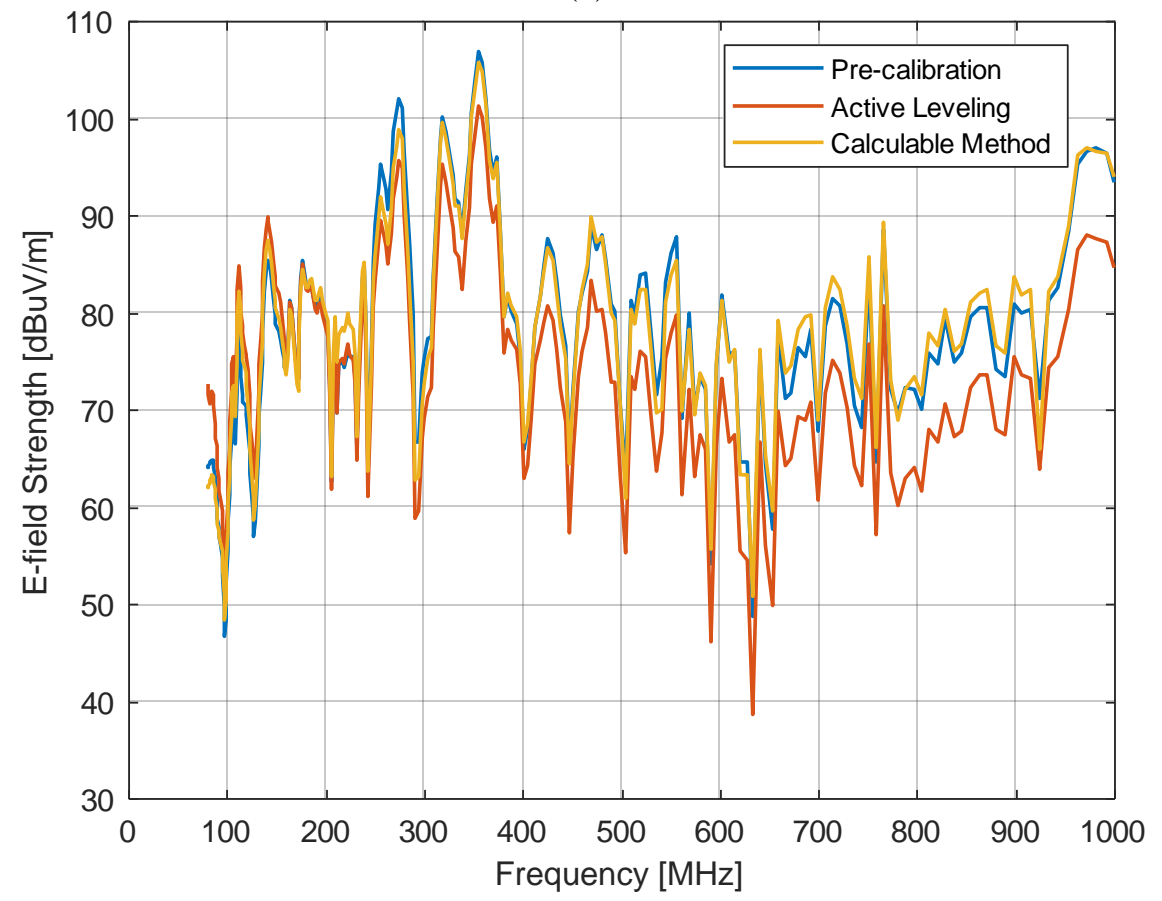

(d) 


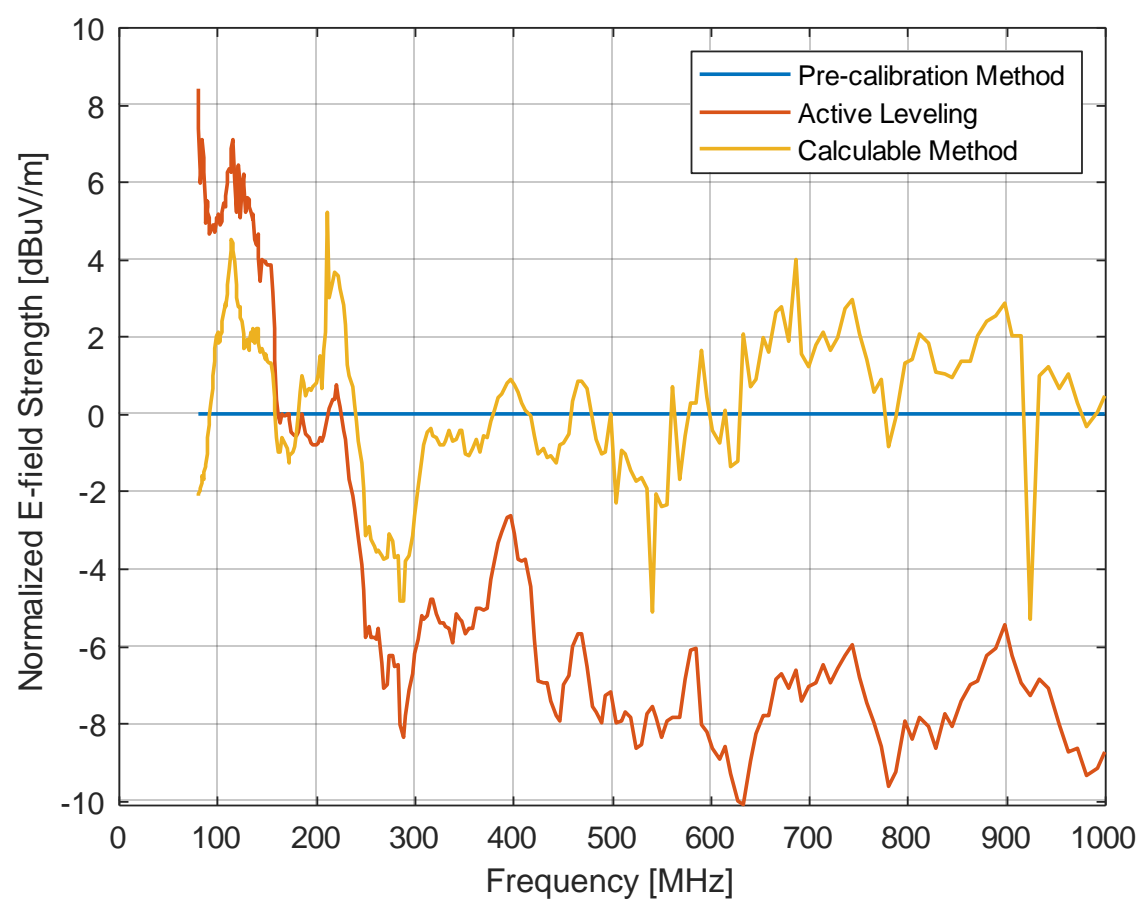

(e)

Figure 3.16 Comparison of RS test methods at $3 \mathrm{~m}$ with the standard method (pre-calibration) at $3 m$ (with large EUTs) (a) E-field calibration, (b) forward power, (c) E-field outside EUT, (d) induced E-field (e) normalized induced E-field

The second set of measurement results obtained at INTA are shown in Figure 3.17 to Figure 3.19. Because the raw data is not available anymore, the $x$-axis of those 3 graphs are shown in logarithmic scale. These graphs show the external electric field and incident power on the antenna for the small, medium and large EUTs and for both of the polarizations with the pre-calibration method according to EN 61000-4-3 at a distance of $1 \mathrm{~m}$ and the active levelling method at the same distance. The graphs are the result of the pre-calibrated $30 \mathrm{~V} / \mathrm{m} \mathrm{E}$-field and the external E-fields under the presence of the three EUTs. The graph clearly shows a high level of discrepancy. The curve for the small EUT (EUT1) does not change as much as for medium-sized EUTs. Obviously, it occurred due to the coupling between the E-field sensor and the large metal plate nearby. Those results are depicted in Figure 3.17 and Figure 3.18. 


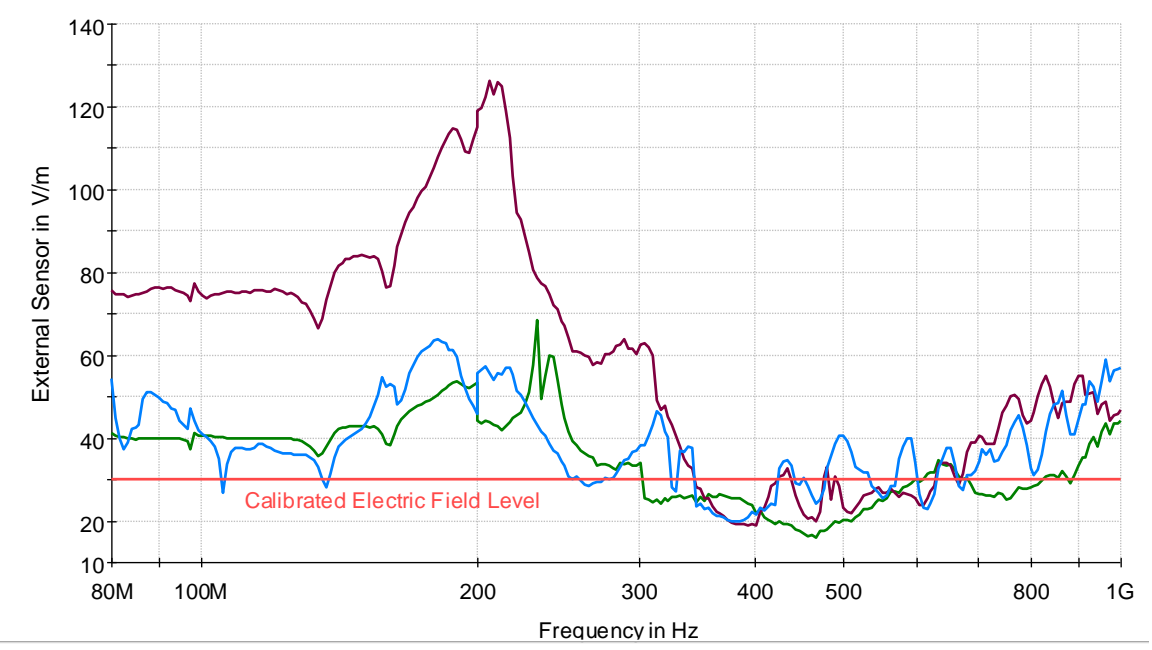

External Electric Field Level EUT1 External Electric Field Level EUT3

External Electric Field Level EUT2 Calibrated Electric Field Level $30 \mathrm{~V} / \mathrm{m}$

Figure 3.17 External E-field @ 30 V/m for different sized EUTs, horizontal polarization

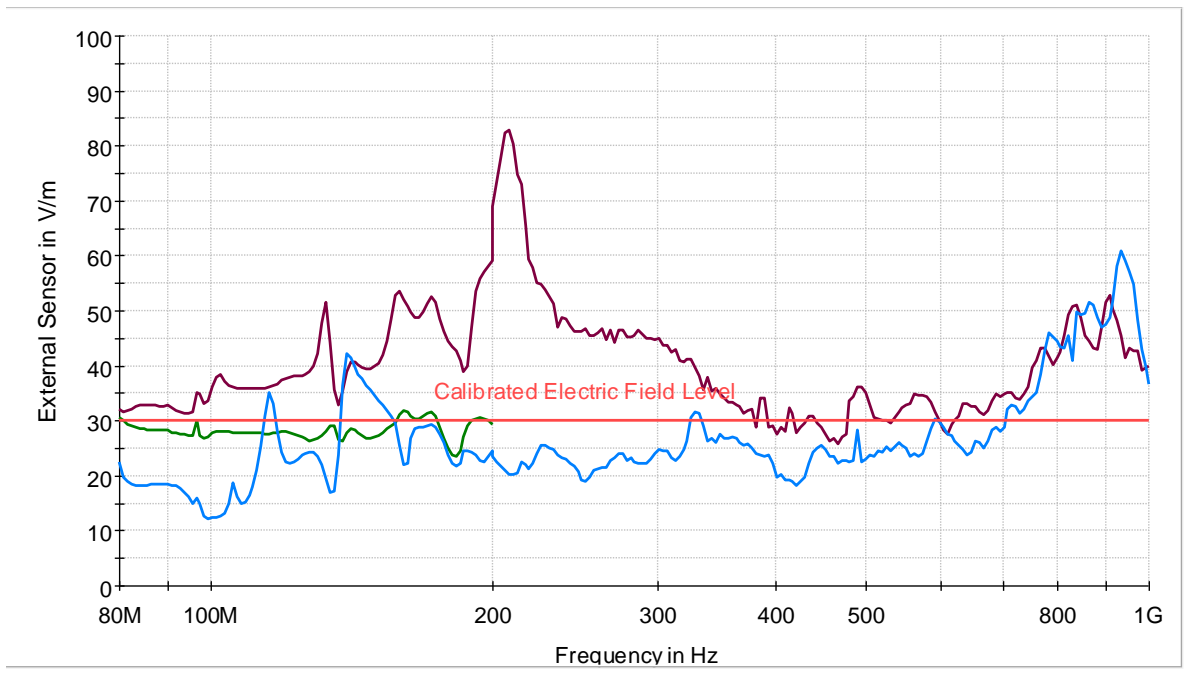

External Electric Field Level EUT1 External Electric Field Level EUT3

Figure 3.18 External E-Field @ 30 V/m for different size of EUT, vertical polarization

Figure 3.19 shows the incident power on the antenna. There are many fluctuations, especially in the lower frequencies, which means the E-field strength was significantly influenced by reflections, thereby requiring more power to maintain it. In the end, this will result in over-testing or under-testing due to induced currents along the metal conductive surface that act as Quasi Active Shielding. 
Subsequently, this phenomenon causes the return of electric fields and affects the reading of the field sensor.

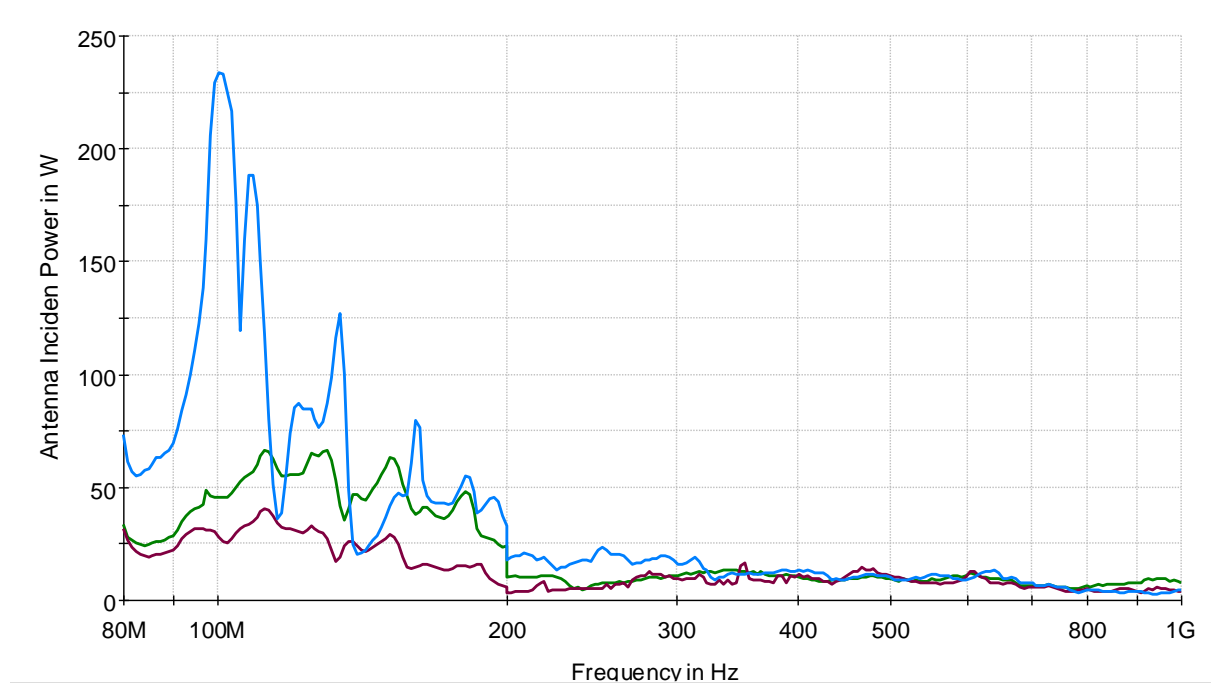

- Antenna Incident Power EUT1

Antenna Incident Power EUT2

Antenna Incident Power EUT3

Figure 3.19 Input power antenna for leveling for different EUTs

As seen in Figure 3.17 to Figure 3.19, in some frequency bands and polarizations there is a certain correlation between the leveling method $(1 \mathrm{~m})$ and pre-calibration method. However, none of them are results that can be perfectly correlated for both the polarizations and any frequency range.

The final results are shown in Figure 3.20 and Figure 3.21. In Figure 3.20, the pre-calibration result is shown for the relatively small EUT. The field strength was kept constant at the pre-calibration level of $100 \mathrm{~V} / \mathrm{m}$ and the forward power and the field strength in front of the EUT were measured. 


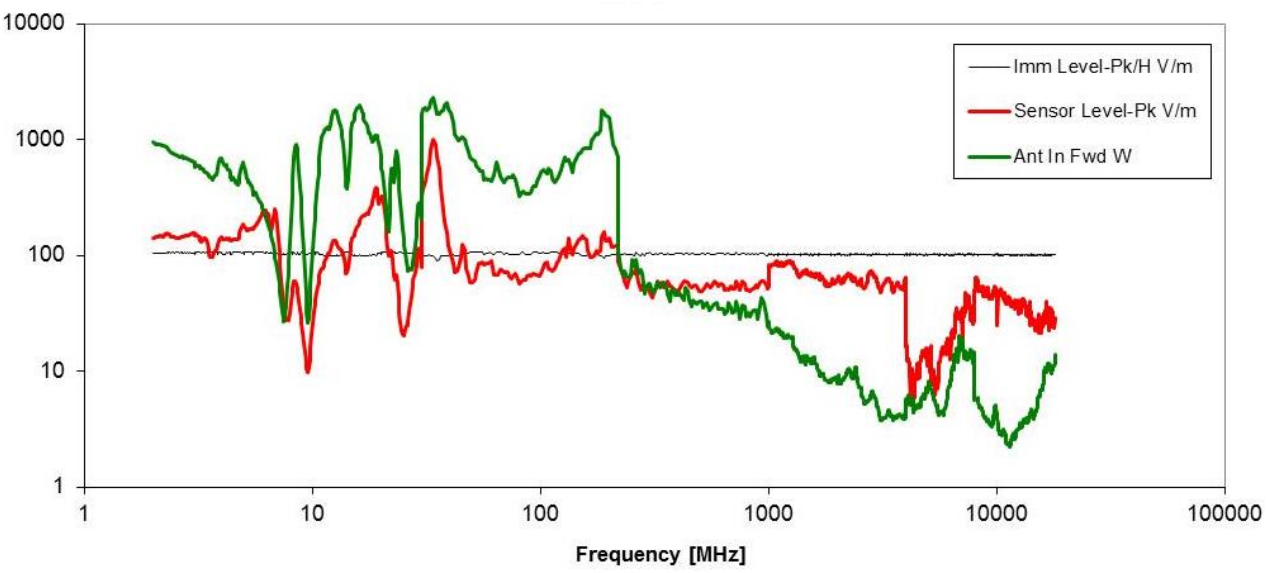

Figure 3.20 The E-field reading, antenna input power and susceptibility level for $100 \mathrm{~V} / \mathrm{m}$ for a medium-size EUT

Figure 3.21 shows the pre-calibration result for the large EUT for $200 \mathrm{~V} / \mathrm{m}$. The shape of the necessary forward power is comparable but not the same because the test setups and - therefore the pre-calibration setups - were different. The influence of the EUT on the recorded field strength is obvious.

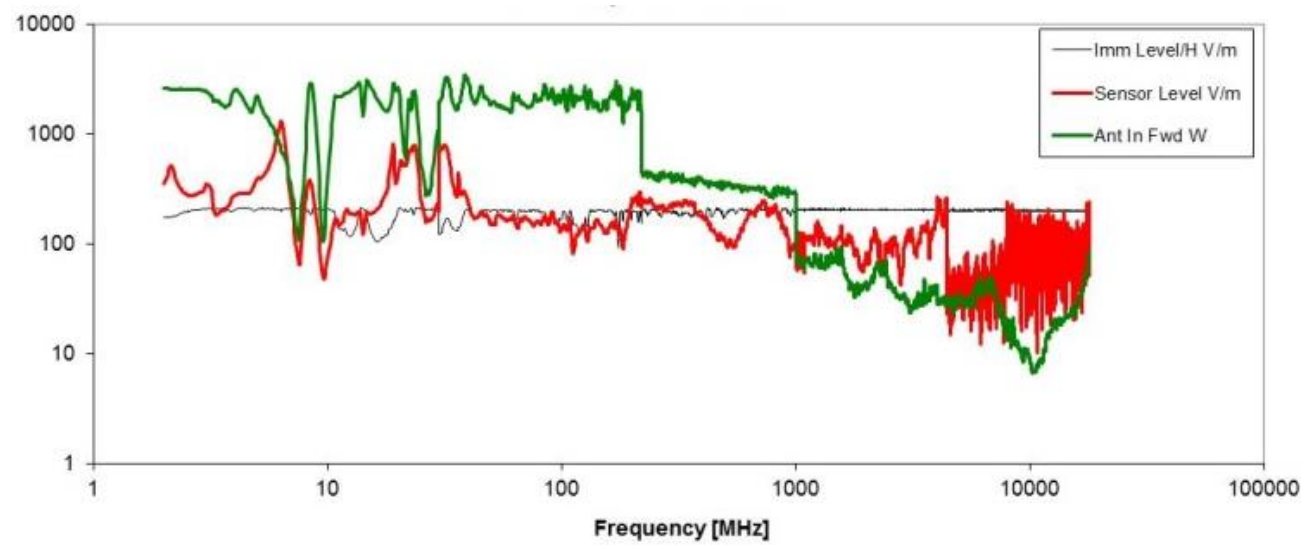

Figure 3.21 The E-field reading, antenna input power, susceptibility level for $200 \mathrm{~V} / \mathrm{m}$ for large EUTs (radar)

\subsection{Conclusion}

A comparison between active leveling techniques and pre-calibration field strength measurement techniques has been analyzed and it is found that each of these methods has its own advantages and disadvantages for different conditions. Both the pre-calibration method and levelling method for RS EMC testing should 
be done inside an $\mathrm{AC}$, which is costly. Both methods are not very robust, with many uncertainty parameters, and the methods should be applied carefully.

The advantage of the leveling method is that it does not need pre-calibration of the FU because only the sensor is placed at a certain position near the EUT and the generated field is measured using the sensor at a close distance to achieve a certain targeted E-field strength. However, this method is suitable only for small EUTs because the method is influenced by the level of the electric field near the EUT, causing a large variation due to the interaction with the EUT. This effect becomes more prominent for large EUTs.

The advantage of the pre-calibration technique is beneficial to small and large EUTs. The pre-condition of the FU before EUTs presence is the key factor. The power delivered to the EUTs will not be changed during illumination of the EUT, and thus the EUT will be exposed to the same amount of energy emitted by the antenna. 


\section{Generating High E-Field Strength: Reverberation Chamber}

This chapter is based on the papers published at the joint IEEE and 2018 AsiaPacific International Symposium on EMC, APEMC 2018 [32] and the International Symposium on EMC, EMC Europe 2018 [33].

\subsection{Reverberation Chamber: Overview}

Reverberation rooms have been used in acoustics for nearly a century. RC are electrically large, complex cavities with spatially- and time-varying field distributions. The details of the cavity geometry and loading objects are not expected to be precisely known. In this case, the deterministic mode theory is not appropriate for predicting the field distribution properties, but the statistical approach is useful, as shown in [57]. Modern equipment, especially equipment with large dimensions with respect to the wavelength of the signals in and around them, shows more directive radiation patterns than electrically small equipment. If the equipment is being used in semi-enclosed environments such as houses, offices, cars and trains, then the radiated field pattern is no longer deterministic. A statistical approach to the emission of electromagnetic fields, and the susceptibility due to electromagnetic fields, is necessary. This statistical approach cannot be performed in conventional measurement environments, such as OATS, SAC or FAR, as this is extremely time-consuming. The main reason is the spatial dependence of the fields. In a well-calibrated RC, the dominant source of error is the spatial dependence of the fields. To ensure a low uncertainty in EM measurements, it is important to have spatially uniform field distribution statistics throughout the chamber (i.e. the energy density in the chamber should be statistically as uniform as possible). This will ensure that the measurement results are independent of the exact measurement location within the working volume of the RC. Classical RCs use mechanically rotating stirrers, which can operate in a tune-set-tune mode or a continuous stirring mode. The tuned stirrer is used for susceptibility measurements when some longer dwell time is needed for EUTs to react, while the continuous stirrer can be used for fast-reacting EUTs and for emission measurements.

A fundamental mathematical principle applied to many statistical models is the Central Limit Theorem (CLT). This implies that the sum of many independent and identically distributed (i.i.d.) random samples or variables tends to become Gaussian (or normal) distributed [58]. In RCs, the field measured at a certain point within its 
volume is the result of the superposition of several waves. The real and imaginary parts of the electric field are both Gaussian distributed with zero mean in a wellstirred reverberation chamber. In this case, the magnitude of the electric field becomes Rayleigh distributed when measured over time and at various points within the RC volume. The Rayleigh distribution is a special case of the Rician distribution when there is no deterministic component present [57][10][59]. This deterministic component is associated with the energy coupling between the transmitter and the receiver without any additional interaction with the stirrer. In this case, the Rician probability density function (PDF) for the electric field in the RC is expressed as:

$$
f\left(\left|E_{x}\right|\right)=\frac{\left|E_{x}\right|}{\sigma^{2}} e^{-\frac{\left|E_{x}\right|^{2}+\left|E_{d x}\right|^{2}}{2 \sigma^{2}}} I_{0}\left(\frac{\left|E_{x}\right|}{\sigma^{2}}\right)\left|E_{d x}\right|
$$

where $I_{0}$ is the modified Bessel function of the zeroth order, $\left|E_{x}\right|$ is the amplitude of the complex electric field from the modes that interact with the changing environment of the RC, $\left|E_{d x}\right|$ is the amplitude of the complex unstirred field component and $\sigma$ is the standard deviation of the magnitude of the real or imaginary parts of the stirred electric field. A Rician distribution is characterized by the Rician $K$-factor, which is defined as the ratio of the signal power in the unstirred components over the stirred power. For the $K=0$ equation ( 4.1 ) reduces to the Rayleigh distribution.

A straightforward method to characterize the spatial uniformity is by graphical inspection/comparison. In other words, the PDF of the measured data and the theoretical Rayleigh PDF (see ( 4.1) with $\left|E_{d x}\right|=0$ ) are plotted on the same graph. While this technique is relatively easy to carry out, one must be careful when interpreting the results. The measured PDF of a field probe or antenna placed in a single position may look somewhat like the theoretical PDF; however, it will still be necessary to take these measurements in multiple locations within the chamber and compare the PDFs for each position. In doing so, we need to ensure that they are not only of the correct type, but that there is little variation in their respective magnitudes and shapes relative to each other. This research is focused on evaluating the best technique for developing a high field strength with low RF input power from the perspective of cost (P2E), by applying simultaneous multi-probe system in mode-stirred RC and analyzing the behavior fast field inside RC, statistical FU and the number of independent samples.

\subsection{Simultaneous Multi-Probe System for the Rapid Evaluation of RC}

In modern life, semi-enclosed electromagnetic environments (EME) like houses, offices, industries and cars will generate many reflections and thereby become multi-path environments. In this case, the fields do not behave as they do in the freespace environment, but more like they do in a reverberant environment [60]. 
Therefore, it would be better to perform tests in a nature-like EME equivalent in which the EUT is exposed in many possible angles. This can be achieved in RCs. Nowadays RCs are widely used, as can be seen in many standards [3], [4] and also in the International Electrotechnical Standard (IEC), IEC 61000-4-21 [8] for emission and immunity testing. The RC technique has become increasingly popular since many EMC researchers have committed themselves to finding better, faster, more cost-effective, more reliable and more repeatable test methods. However, before using it for EMC testing, RCs have to be calibrated, which can be very timeconsuming, as shown in [61], for instance. When using mode stirring or other fastvarying stirring techniques, the fast behavior of the fields requires an advanced fast field detector, not the normal slow response field probes for AC measurements [62], [63]. Basic probes often use shielded cables which can affect the field around the probe as well as the field distribution inside the RC [64]. Coating the cable with absorbers reduces this effect, but these absorbers also absorb the electromagnetic field in the RC [65]. Because of this, optically-fed electromagnetic field probes are required to reduce unwanted coupling with cables and interference with the EM field distribution inside an RC [66]. The technique described in [66] was implemented with the probes used in this research.

In [67] it was suggested that stirred-mode operation of the RC (i.e. continuous stirring) is more cost-effective and robust compared to stepped tuner operation, although this is applicable only for fast-reacting EUTs with a short dwell time. However, as conventional E-field probes are slow and have a limited sampling rate, the stirring technique for the RC is often replaced with an antenna and focuses on $S_{11}$ and $S_{21}$ measurements [68]. However, an antenna performs measurements in only one polarization (1D), while an E-field probe measures simultaneously in three polarizations (3D).

A vibrating intrinsic reverberation chamber (VIRC) uses mode stirring through the vibrating walls with fast-changing fields, resulting in many independent samples compared to mode-tuned chambers [60]. Several studies have been performed using numerical simulations based on FDTD for VIRC [69] as well as method of moments (MoM) for RC [18][20][70], which show very good statistically FU and good field distribution of well-stirred RCs. VIRC is being used in applications such as shielding effectiveness [25], the radiation and total efficiency antennas measurements [24][71] and in-situ EMC testing [72][73]. The effect of different chamber sizes and loading factors was also investigated [74]. Because of the large number of independent samples in a VIRC, it also allows for a better prediction of extreme field strengths than mode-tuned chambers, which can be used to estimate the risk of EMI in semi-enclosed environments [60][75].

To validate a reverberation chamber, field strength measurements have to be performed at eight, preferably nine, locations inside the RC [8]. The technique using a multi-probe system for VIRC was reported in [76]. In this paper, the field behavior of the VIRC was intensively investigated. Due to the fast-changing field inside the 
VIRC, fast E-field probes were used with non-optical cable. Measurement results were processed statistically to determine FU and to obtain initial observations of the field distribution near a cavity wall. The result showed very good FU and some noticeable E-field disturbance near the walls. [76].

The multi-probe system with very fast optically-fed 3D probes generates much more data in shorter measuring time. This technique is very appropriate for analyzing the field strength and field distribution inside a VIRC. It is also a timesaving and effective technique for conventional mode-stirring (instead of modetuning) RCs. In [77] and [78] it is mentioned that the calibration of an RC with conventional probes takes one week. In the standard [8] a 1D antenna is used, simply because conventional probes are too slow. With a simultaneous probe system it takes only a few hours. Furthermore, these probes can also be used during the actual EUT testing (if testing both outside and inside for large equipment that requires the simultaneous analysis of field strength).

\subsubsection{Setup Description of the Reverberation Chambers}

\section{A. Classical Reverberation Chamber}

As a reference, a classical $\mathrm{RC}$ was used with the following physical dimensions: $1 \mathrm{~m}$ by $1.3 \mathrm{~m}$ by $1.5 \mathrm{~m}$. All sides were made of fixed metal plates and three stirrer types, which can rotate and are controlled by a stepper motor. The tuned and stirred steps, the rotation speed, and the angle of rotation could be easily configured via software.

\section{B. Vibrating Intrinsic Reverberation Chamber}

The VIRC used for the experiments had nearly identical dimensions as the conventional RC, namely, $1 \mathrm{~m}$ by $1.2 \mathrm{~m}$ by $1.5 \mathrm{~m}$. Two sides of the VIRC were connected by a rope which was connected to two DC motors. The motor could be operated using two different settings, random and regular movement, and produced wall movements with no periodic pattern. The random behavior of the flexible walls is causing a non-repetitive pattern, inherently complexity and the independence of field distribution which easily generate a large number of uncorrelated data samples [16]. This means that, under the right conditions, the electrical field inside the RC could show considerable variation in a short amount of time. This unique characteristic might not happen in conventional metallic RCs, but it requires fast electric field probes.

The measurement was carried out in both the conventional RC and the VIRC. Four different measurements were performed, all using the same transmitting DRGH antenna and nine small and fast 3D E-field probes. This probe is essentially built from electrically small dipole antennas mounted on three axis directions $(x-y$ $z$ ), as shown in Figure 4.1. The probe is laser-powered to allow for continuous operation with no recharging or battery replacement required. 


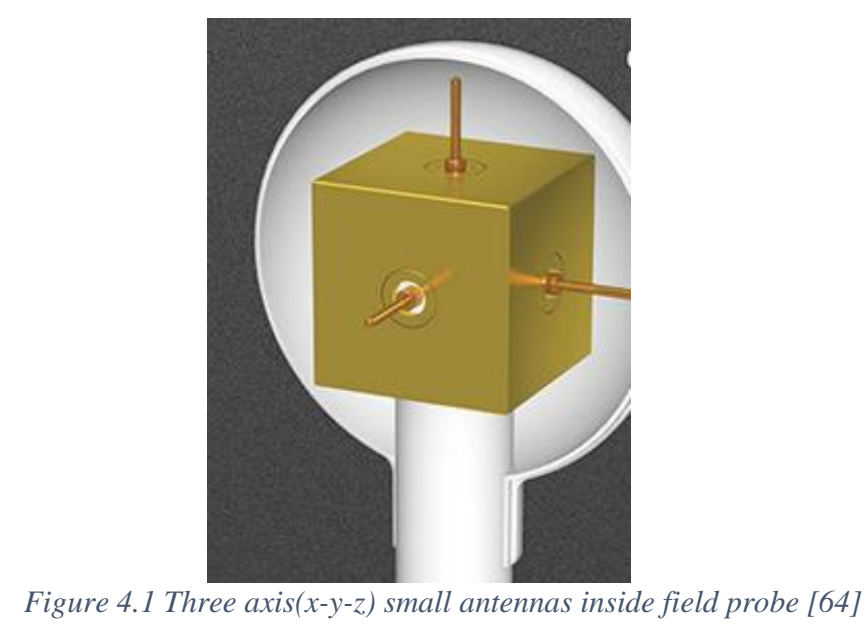

A programmable signal generator (PSG) was used to feed a signal to the DRGH antenna. A directional DRGH antenna was used to avoid line of sight (LOS) during the measurement process, which could create Rice-distributed fields instead of the Rayleigh distributions. Measurements were performed according to the frequency steps shown in Table 4.1.

Table 4.1 Step frequency setup

\begin{tabular}{|c|c|c|}
\hline \multirow{2}{*}{ No. } & \multicolumn{2}{|c|}{ Setup } \\
\cline { 2 - 3 } & Frequency Band (MHz) & $\begin{array}{c}\text { Frequency } \\
\text { Steps (MHz) }\end{array}$ \\
\hline 1 & $300-500$ & 5 \\
\hline 2 & $500-1000$ & 50 \\
\hline 3 & $1000-2000$ & 100 \\
\hline 4 & 2500 & \\
\hline
\end{tabular}

The position of the probes both inside the classic RC and the VIRC, including the test setup, can be seen in Figure 4.2 and Figure 4.3. Eight probes were placed at the corner of each rectangle angle and one probe in the center of the chamber. The working volume was approximately $0.78 \mathrm{~m}^{3}$. Due to the small size of the RC, the symmetric rectangle positions were chosen and the nine probes were placed approximately in the center volume. The probes used the sampling rate of $0.5 \mathrm{MS} / \mathrm{s}$. In each frequency step, 30 seconds of data was recorded, amounting to 15 MS per frequency point. Although this is a large oversampling, the data was reduced in the post-processing phase. 


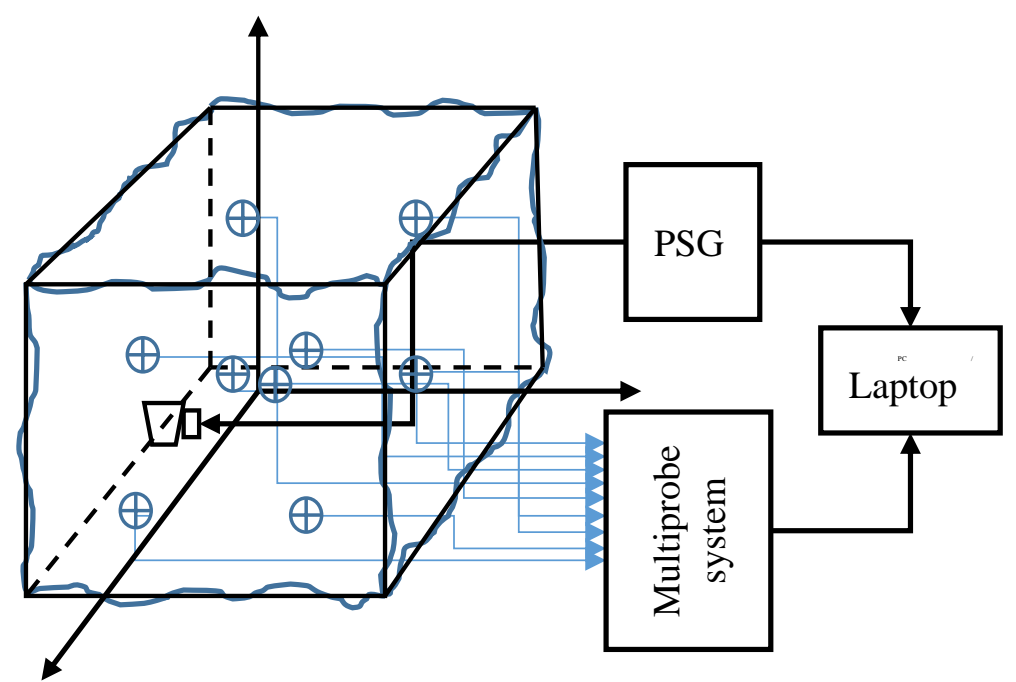

Figure 4.2 Schematic diagram of multi-probe system on classical RC / VIRC

Figure 4.2 shows a schematic diagram. The nine probes inside the chamber were connected to the multi-probe system device and the measurement results were displayed on the laptop. This laptop also controlled the PSG sending a signal to the antenna. The nine probes installed inside the $\mathrm{RC}$ were connected to the multi-probe Lumiloop measurement system [8].

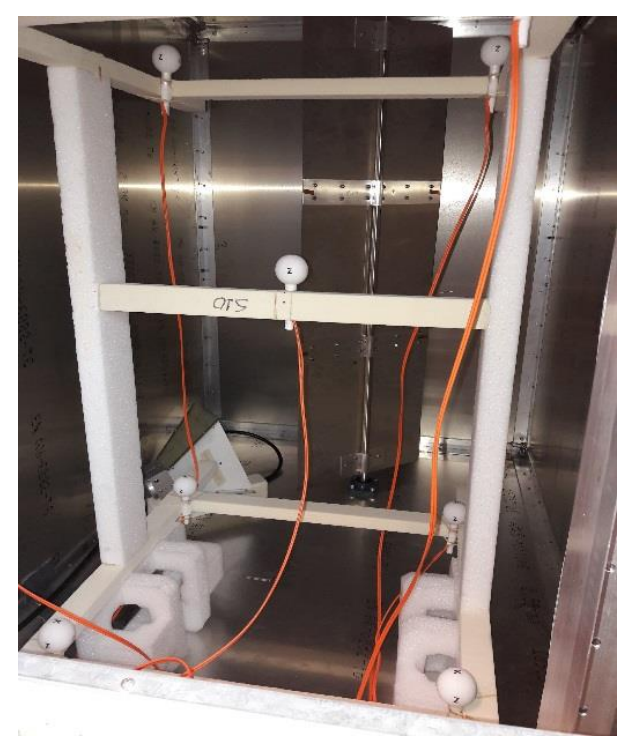

Figure 4.3 Multi-probe setup in classical RC 
The measurement setup in the classical RC can be seen in Figure 4.3. The same measurement method was carried out in the VIRC, as seen in Figure 4.4. The DRGH antenna was facing one of the walls to make sure there was no LOS to the probes. In addition, all probes were placed in the working space, which started at least $\lambda / 4$ away from the walls.

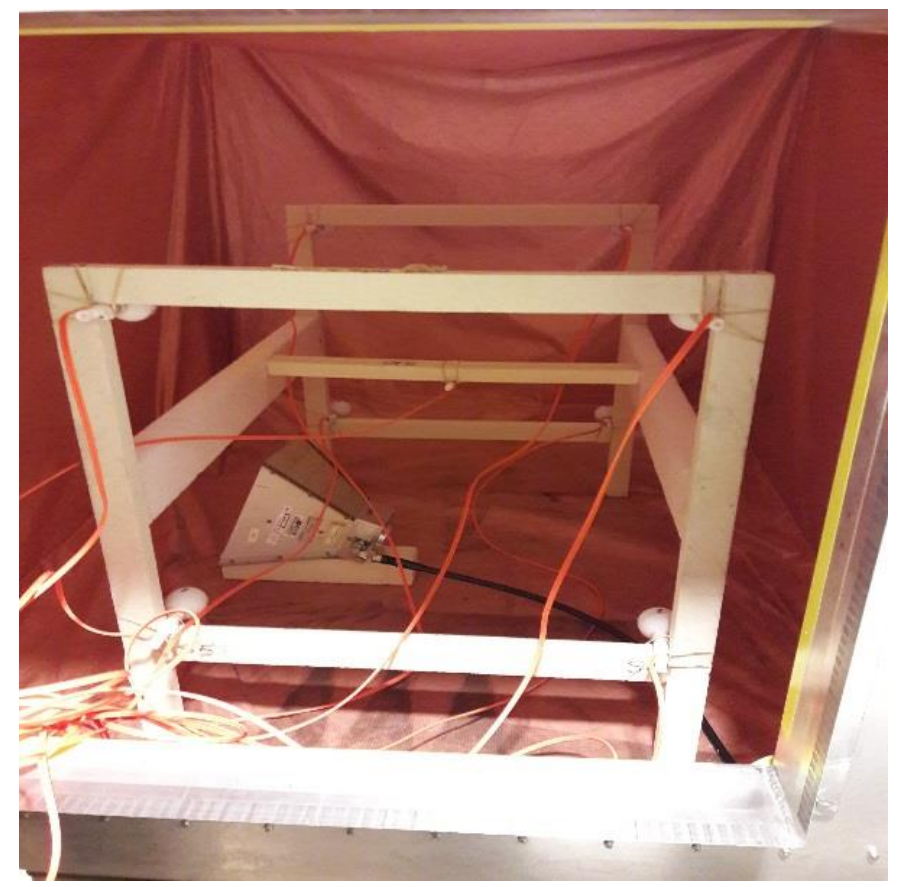

Figure 4.4 Multi-probe setup in VIRC

\subsubsection{Results and Discussion}

At low frequencies, the $\mathrm{RC}$ does not function properly due to a limited number of excited modes. On the other hand, at high frequencies, the RCs are electrically large enough that the field becomes statistically uniform and isotropic because many modes are excited and the CLT is easily satisfied. Thirty-second time series E-field values were recorded for each of the twenty-seven frequency points: nine probe positions and three polarizations. As mentioned before, the sampling rate was very high - much higher than required to capture the change rate of the field envelope while shaking the VIRC. To evaluate the data, they were under-sampled and processed at a sampling rate of $1 \mathrm{kHz}$ for both measurements results in the classical $\mathrm{RC}$ and the VIRC. Based on previous research [60], a sampling rate of $100 \mathrm{~Hz}$ is sufficient for an accurate analysis. 
While the classical approach (mode-tuned operation) is to perform a measurement at a specific stirrer position and then move the stirrer and perform the next measurement, the mode-stirred operation used here generates measurement samples as function of time. Example measurement results obtained in the classical $\mathrm{RC}$ and the VIRC at $1500 \mathrm{MHz}$, from the center of the working volume, are depicted in Figure 4.5 and Figure 4.6. For each frequency point, 5,000 data samples were obtained for the classical RC and 30,000 data samples for the VIRC. Figure 4.5 shows the field behavior inside the classical RC within $0.25 \mathrm{~s}$ and Figure 4.6 shows the results for the VIRC. The average E-field strengths are approximately $10 \mathrm{~V} / \mathrm{m}$ and $15 \mathrm{~V} / \mathrm{m}$ for RC and VIRC, respectively. The Q-factor for both chambers affect the field results. At $1500 \mathrm{MHz}$, VIRC has slightly higher Q-factor than classical RC, as previously confirmed by [60].

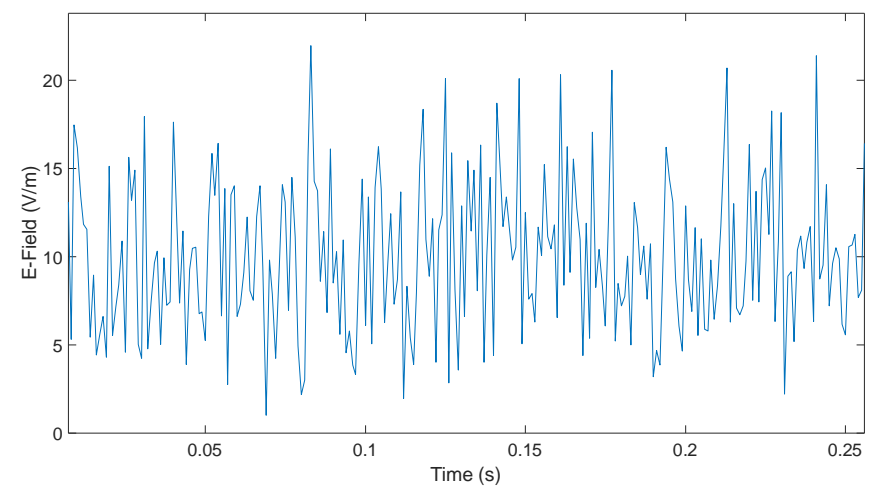

Figure 4.5 Field behavior over time inside classical RC

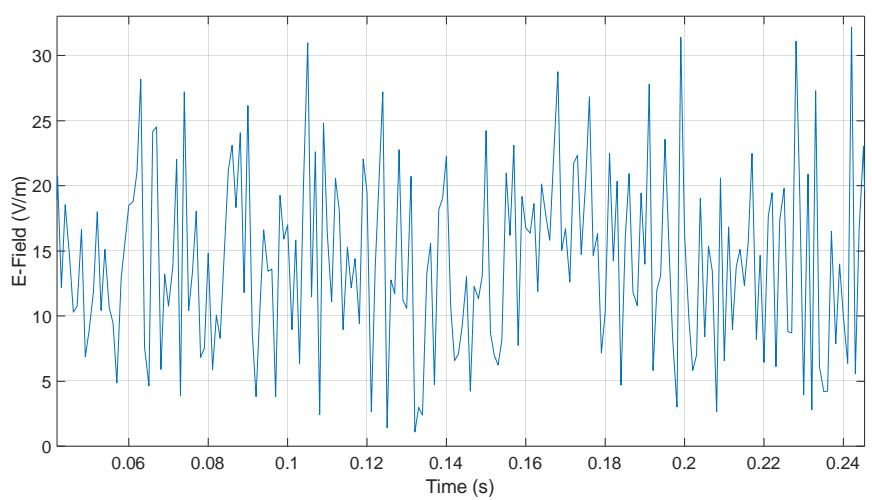

Figure 4.6 Field behavior over time inside VIRC

As can be seen in Figure 4.5 and Figure 4.6, the shape and the behavior of the fields changed quickly as the fields mixed; however, the fast E-field probe was able to detect this signal. 
The next figures show a normalized average field for all of the positions where simultaneous measurements were performed in nine different positions.

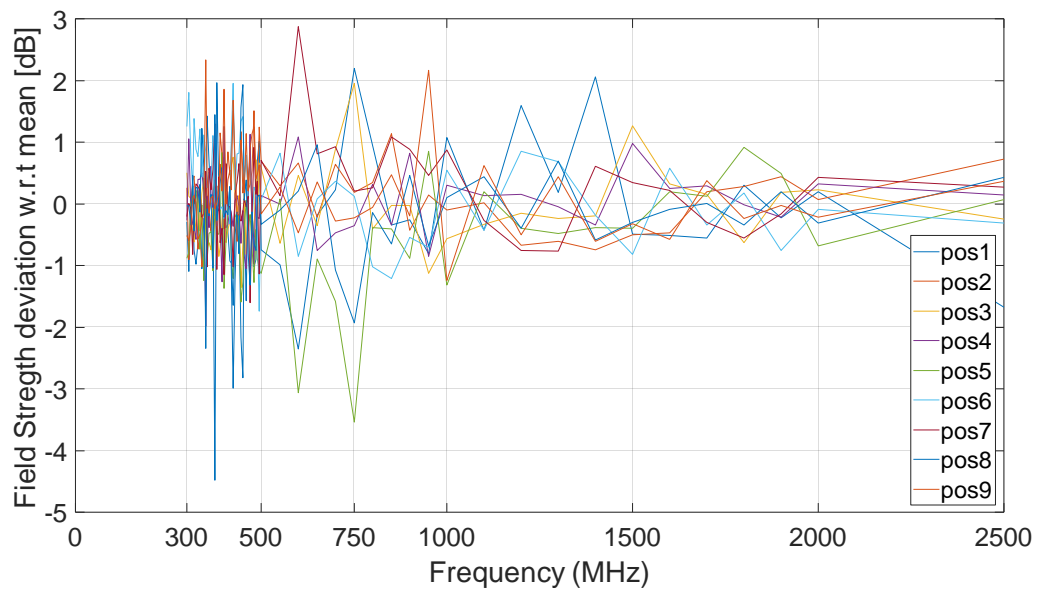

Figure 4.7 Normalized field strength deviation to the mean at 9 positions, classical RC with regular Z-folded stirrer

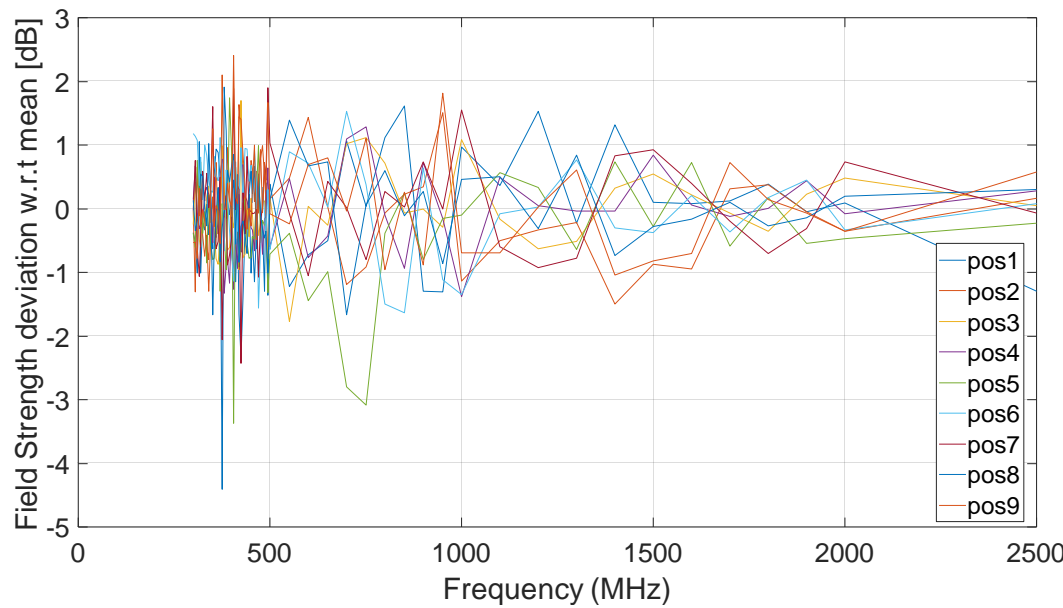

Figure 4.8 Normalized field strength deviation to the mean at 9 positions, classical RC with irregular Z-folded stirrer

Figure 4.7 and Figure 4.8 show the field strength deviation with respect to the overall mean for the classical RC with different stirrers. Figure 4.9 shows the similar analysis performed inside the VIRC. From this figure, we can conclude that the field strength is within the limit of $\pm 6 \mathrm{~dB}$ or $\pm 4 \mathrm{~dB}$ in the case of the RC standard [8] for frequencies above $370 \mathrm{MHz}$, although the minor deviation around $360 \mathrm{MHz}$ is only slightly above the limit. 


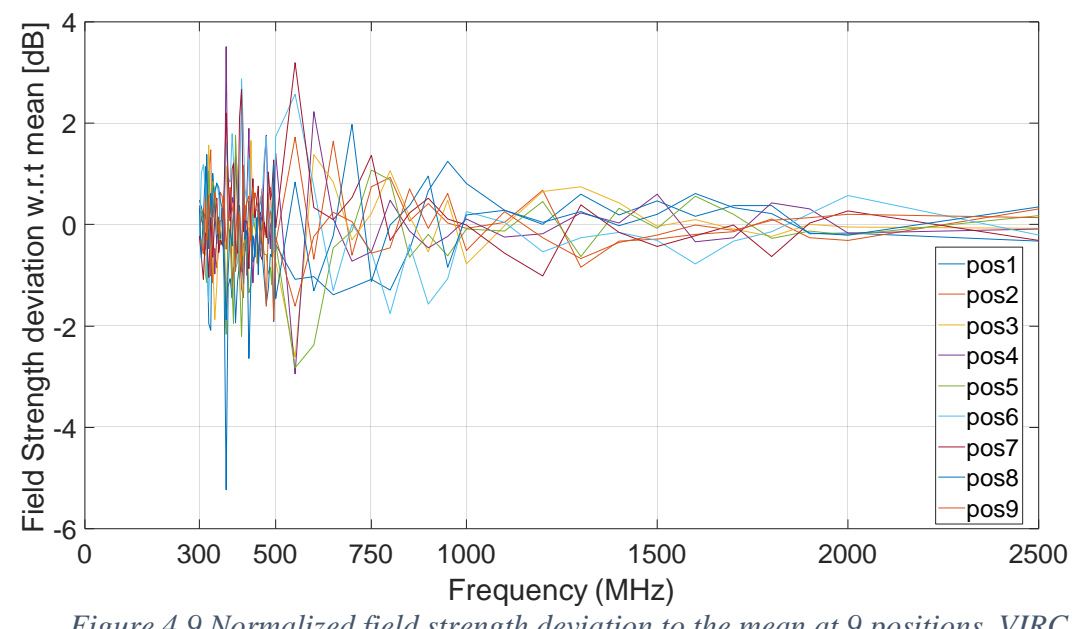

These results are an important parameter since they show the uniformity of the maximum or average values of the E-field in the chamber as a function of spatial position and frequency. This means the method is a suitable tool to validate the proper working of a classical RC as well as a VIRC, with the benefit of faster measurement time. Furthermore, in applications like EMC testing, antenna measurement, etc., this technique allows for more efficient testing time.

\subsubsection{Conclusion}

The dream of reverberation engineers is to have access to a system of multiple and very fast optically-fed 3D probes. This allows for much faster calibration of an $\mathrm{RC}$ and measurements with much more independent samples, and could result in more accurate susceptibility measurements on EUTs in an RC. We carried out measurements with such a multi-probe system in both a conventional RC and a VIRC, proving that this technique is indeed faster and more effective than the conventional mode-tuned $\mathrm{RC}$ technique and moving the probes after every measurement. Good uniformity was found in the field behavior and the average field in the spatial working volume, within $\pm 6 \mathrm{~dB}$. The multi-probe system is also suitable for a conventional $\mathrm{RC}$ allowing mode-stirring and a much shorter measuring time, thereby decreasing the total measurement time.

\subsection{Time-Efficient Reverberation Chamber Performance Analysis}

The capabilities of the used multi-probe system can be used to quickly analyze the FU. One of the applications, described below, involves evaluating the performance of stirrers used in classical RCs. Typically, such an analysis would 
require a lengthy measurement campaign due to the need to move the field probe to eight different positions within the working volume of the chamber and to run the measurement in each of them separately. However, utilizing a set of eight probes sigificantly increases the measurement time because the field is received simultaneously in all of the positions. The results allow for a quick evaluation of the performance of the stirrers in terms of $\mathrm{FU}$ and the number of generated i.i.d. samples.

Based on [79], RC simulation was investigated, which generated interesting results. Classical $\mathrm{RC}$ and the stirrers were simulated using $3 \mathrm{D}$ full-wave simulation software. Three different stirrer designs were made and the UFA was analyzed. The results showed that the irregular Z-shaped stirrer generated the best UFA [79]. However, in [79], the irregular Z-shaped stirrer had a larger volume than the other two stirrers. In this thesis, an experimental evaluation was performed using a smaller version of the irregular Z-shaped stirrer, which had the same volume as the other two to ensure a fair comparison.

\subsubsection{Stirrer Evaluation Methodology}

\section{Standard Method}

FU is determined by measuring the maximum field in the three-axis component among all stirrer steps, at eight corners of the working volume. After the maximum field is obtained at each frequency and each point, the standard deviation of each component $(x, y, z)$ is calculated according to [8]. The correlation coefficient $r$ is a measure of the statistical dependency of the variables. In RC application, this value is used to determine the stirrer efficiency inside the chamber and to estimate the number of i.i.d. samples that can be generated in the given setup.

\section{General Method}

The general method is discussed and explained detail in [80]. It is based on the Pearson Correlation Coefficient (PCC) used to determine the relationship between two vectors or matrices with a linear correlation. The spatial correlation coefficient is obtained using [80][81]

$$
r_{i j}=\frac{\operatorname{Cov}\left(X_{i}, X_{j}\right)}{\sqrt{\operatorname{Var} X_{i} \operatorname{Var} X_{j}}}
$$

where $r_{i j}$ is the PCC for the $i, j$ position, $X_{i}$ is the field distribution in the $i$ stirrer position, and $X_{j}$ is the field distribution in the $j$ stirrer position. This $r_{i j}$ value is then compared to a threshold value $r_{s}$ to assess the correlation. Then the values from the different frequency points and positions are evaluated in the specific algorithm, as described in [80], to obtain the total number of i.i.d. samples. 


\subsubsection{Experimental Setup}

The measurements were carried out in a conventional $\mathrm{RC}$ with three different stirrers. The chamber size was $1 \mathrm{~m}$ by $1.3 \mathrm{~m}$ by $1.5 \mathrm{~m}$, as can be seen in Figure 4.10 . Three different types of stirrers were used. Stirrer 1 had six wide plates in a irregular folded configuration, arranged in different folding angles (irregular Z-folded). Stirrer 2 consisted of one flat plate ( $1.20 \mathrm{~m}$ high and $0.40 \mathrm{~m}$ wide). Stirrer 3 consisted of seven continuously connected plates oriented in various folding and slanting angles (asymmetrical irregular Z-folded stirrer). With respect to [79], stirrer 1 was a bit smaller to ensure that the volumes of all stirrers were the same.

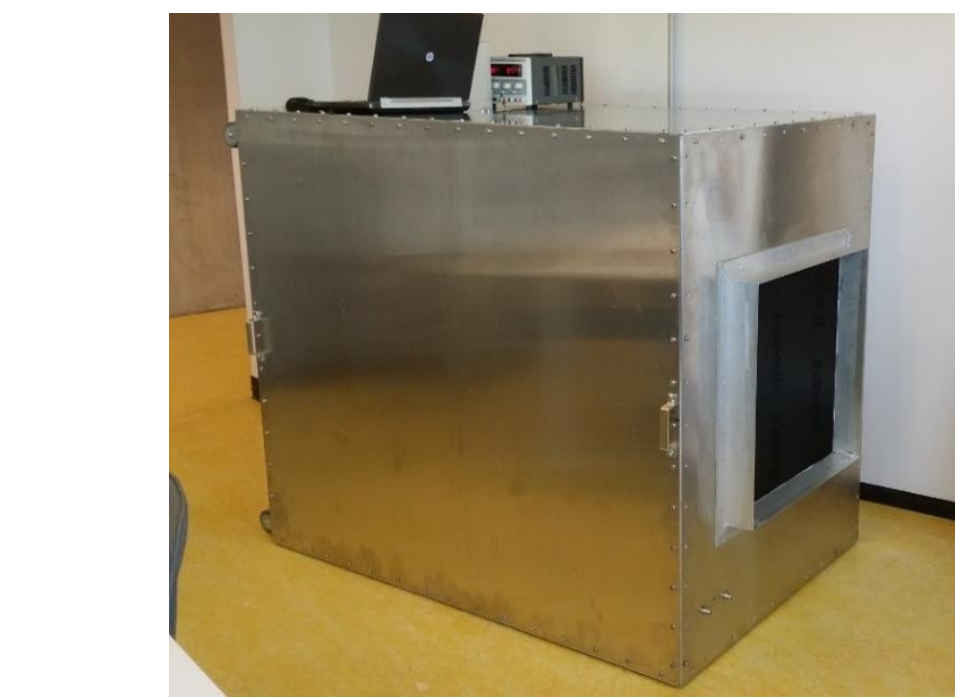

Figure 4.10 Small classical RC, dimension $1.5 \mathrm{~m} \times 1.3 \mathrm{~m} \times 1 \mathrm{~m}$, the motor is connected to the stirrer inside the $R C$

All of the stirrers shape are shown in Figure 4.11. A DRGH antenna was used as the transmitting antenna to generate a signal in the cavity, aimed at the stirrer. The nine very fast small field probes were placed at nine positions inside the RC, spread out over the working volume of the chamber. This setup is depicted in Figure 4.12. The working volume was approximately $0.7 \mathrm{~m}^{3}$. Due to the small size of the RC, the symmetric rectangle position was chosen and we maintained a $\lambda / 4$ distance from the walls for the eight field probes. One more probe was placed in the center of the space. The measurement setup and position of the probe is similar in the classical $\mathrm{RC}$, since it was a scaled version of the one described in the standard [8].

The fast optical laser-powered probes used in this experiment were able to capture the E-field with $0.5 \mathrm{kS} / \mathrm{s}$ in streaming mode. The amplitude accuracy ranged from $1 \mathrm{~dB}$ to $1.3 \mathrm{~dB}$, depending on the frequency and the E-field strength value, with a dynamic range of $70 \mathrm{~dB}$ to $80 \mathrm{~dB}$. The small size of the sensors as well as the 
optical fiber connection allowed us to place many of them without distorting or significantly influencing the field distribution inside the chamber.

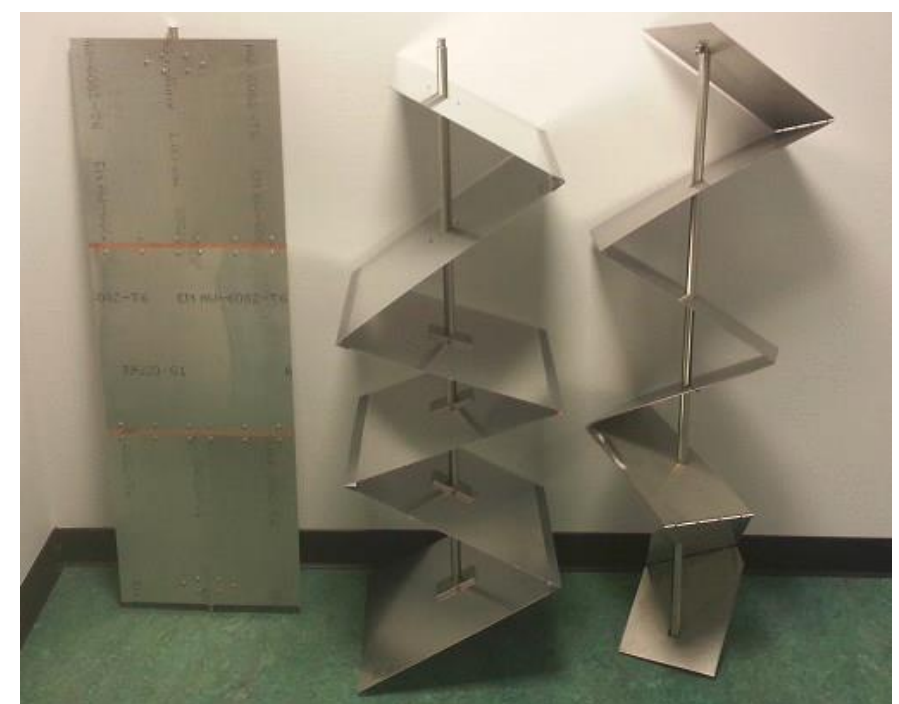

Figure 4.11 Three different shapes of stirrers. Stirrer 1 (irregular Z-folded) in the middle, stirrer 2 (flat panel) on the left side, stirrer 3 (asymmetrical irregular folded) on the right side

The measurement was carried out from $400 \mathrm{MHz}$ to $1 \mathrm{GHz}$ in increments of 50 $\mathrm{MHz}$, and from $1 \mathrm{GHz}$ to $2 \mathrm{GHz}$ in increments of $100 \mathrm{MHz}$. The E-field values were sampled with $2 \mathrm{kS} / \mathrm{s}$ at each frequency point. During the measurement, the stirrers were used as mode-stirrers with a rotation speed of approximately one second per rotation. 


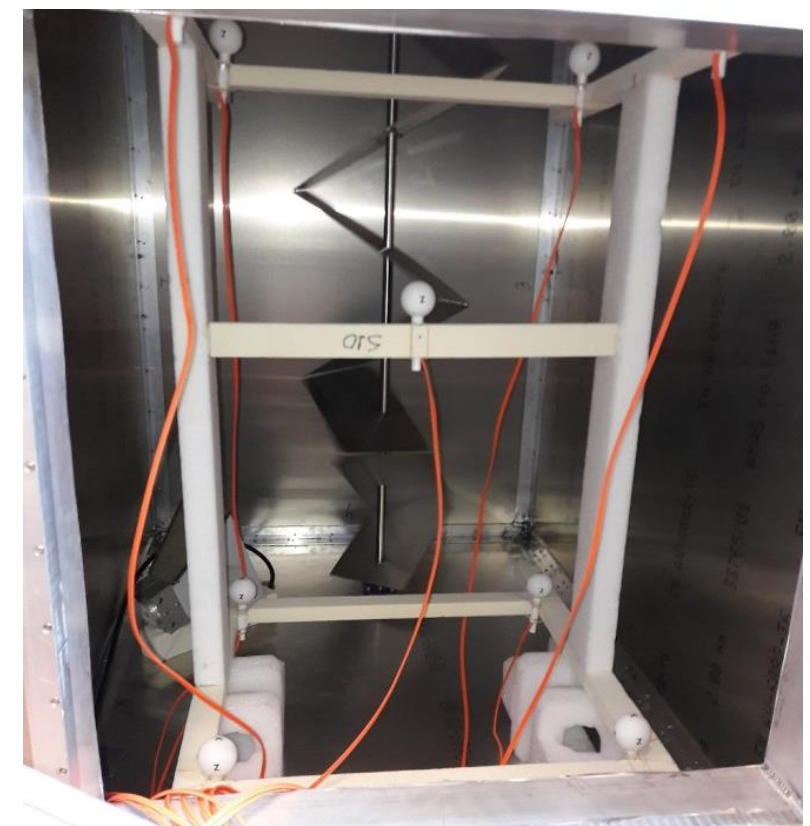

Figure 4.12 Test setup of nine multi-probe system in classical $R C$

\subsubsection{Result and Discussion}

\section{Standard Methods}

The FU was analyzed for a three-axis component in nine positions, as depicted in Figure 4.13, Figure 4.14 and Figure 4.15 for stirrer 1, stirrer 2 and stirrer 3, respectively. The chamber was deemed to have passed the $\mathrm{FU}$ requirements if for both three axis component; $\mathrm{E}_{\mathrm{x}}, \mathrm{E}_{\mathrm{y}}, \mathrm{E}_{\mathrm{z}}$ and the total data set $\mathrm{E}_{\mathrm{abs}}$ were within $3 \mathrm{~dB}$ for frequency range above $400 \mathrm{MHz}$.

Figure 4.13 shows the evaluation for stirrer 1 (irregular Z-folded). As can be seen, the rms field (black line) is under the $3 \mathrm{~dB}$ threshold for all frequency ranges. One component $\left(E_{z}\right)$ is slightly above the threshold at $600 \mathrm{MHz}$. 


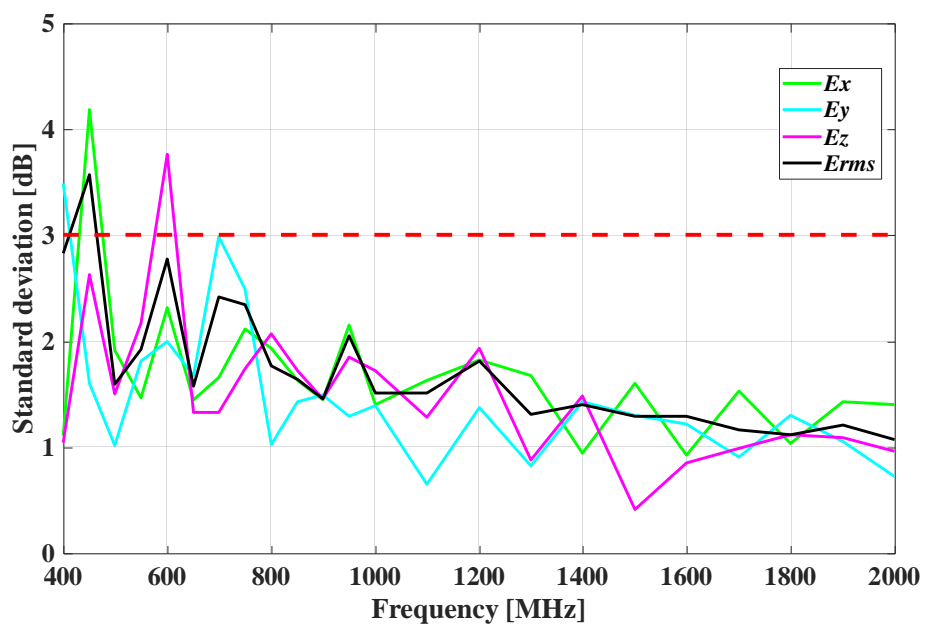

Figure $4.13 \mathrm{FU}$ inside RC with stirrer 1 (irregular Z-folded)

Figure 4.14 is for stirrer 2 (flat panel). In this figure, all points of the E-field are under the IEC limit [1], which shows very good performance in terms of statistical FU. The field within the chamber is considered uniform if the standard deviation is within $3 \mathrm{~dB}$. A similar result was obtained for stirrer 3, with some lower frequency points that are slightly out of the limit, as depicted in Figure 4.15. This comparison shows that stirrer 2 has the best performance in term of FU. In the higher frequency range, many more modes are excited and the mode stirring becomes more effective, therefore the field isotropy and statistical field uniformities are similar for all stirrers.

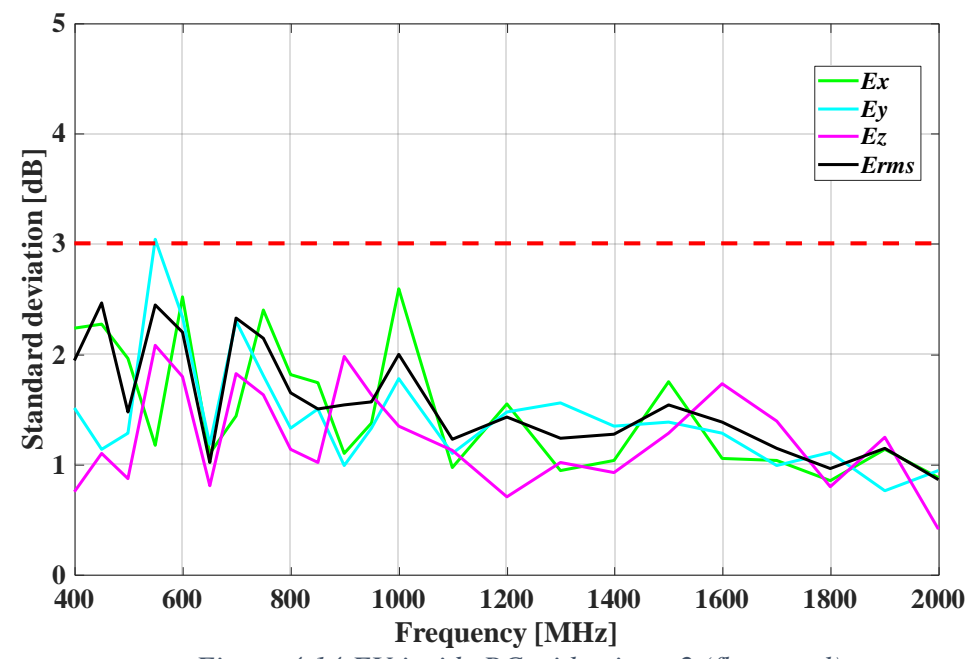

Figure $4.14 \mathrm{FU}$ inside $R C$ with stirrer 2 (flat panel) 


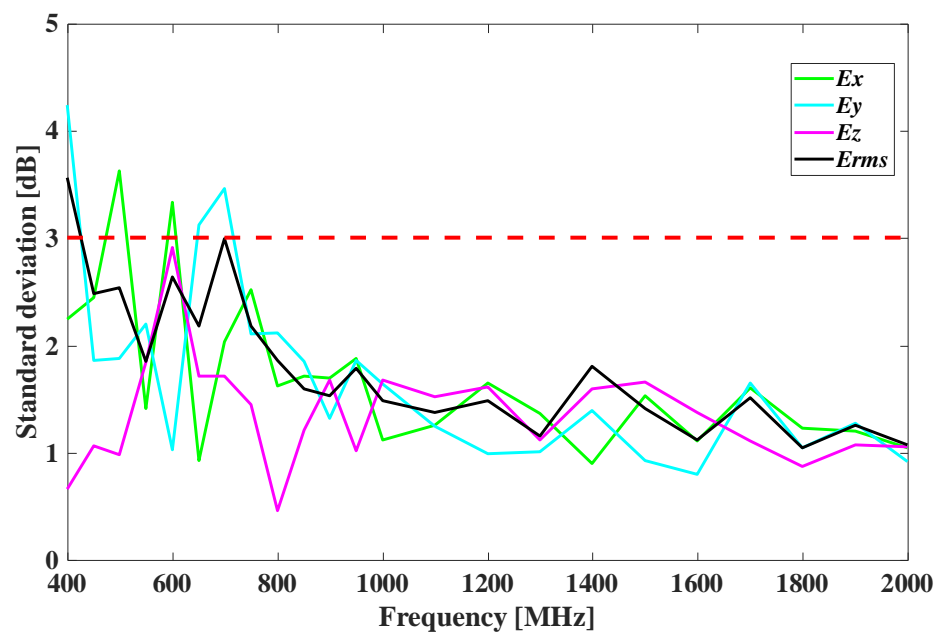

Figure 4.15 FU inside RC with stirrer 3 (asymmetric irregular folded)

The second parameter influenced by the stirring performance is the number of independent samples. This calculation was conducted according to the standard [8]. The results are presented in Figure 4.16. It can be observed from the graphs that stirrer 2 produced more independent samples than the folded stirrers. These two stirrers had similar results, with stirrer 1 being slightly better than stirrer 3 .

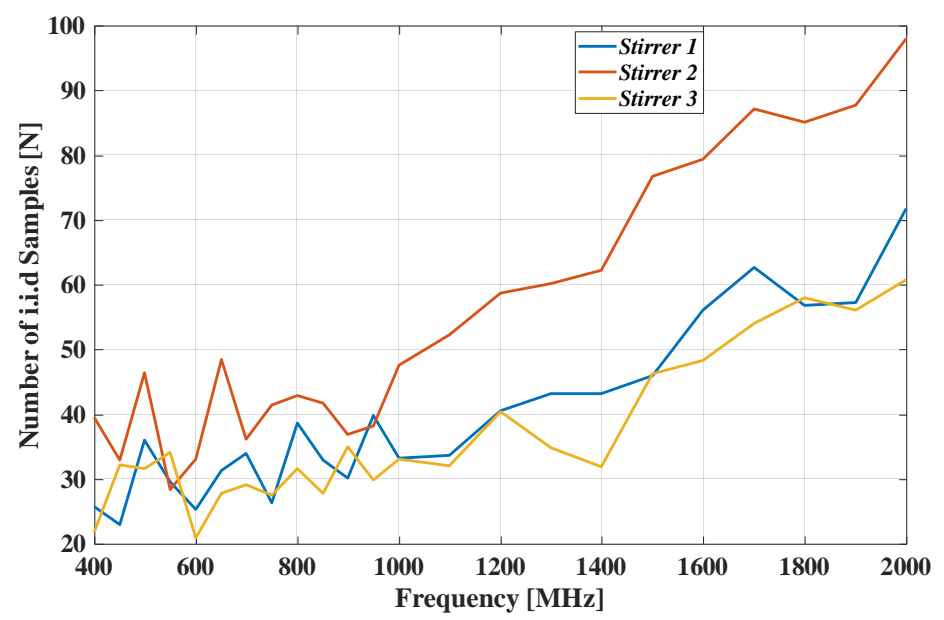

Figure 4.16 Number of independent samples for three different stirrers based on standard method [8]

The multi-probe system allows many simultaneous samples, which means the general method can be used to investigate the performance in nine spatial positions (27 datasets) more deeply. Figure 4.17 shows the number of independent samples 
as a function of frequency for the general method. As can be observed, the number of independent samples is always lower than the number obtained by the standard method as presented in Figure 4.16. However, similar to the standard method results, it is also clear that stirrer 2 generated more independent samples than the other two. This is a very interesting observation and implies that although a flat stirrer is expected to cause high correlation after a 180-degree rotation, the rate of change of the boundary conditions with the rotation angle is the highest, which is especially important in the low frequency range. It can be deduced that this is because the fields with large wavelengths are affected more by the large flat surface of stirrer 2 than the complex but smaller pieces of stirrers 1 and 3 .

The same threshold values $\left(\mathrm{r}_{\mathrm{s}} \approx 0.37(1 / \mathrm{e})\right)$ were used to compare the standard and general methods. As can be seen in Figure 4.16 and Figure 4.17, the standard method led to a significant overestimation, as confirmed by [82]. A factor of approximately 1.5 to 2 can be given for the average of the nine positions (27 components). Aside from that, both methods showed a linear increase as a function of the frequency. On the other hand, Figure 4.16 shows small deviations at the beginning of the $400 \mathrm{MHz}$ to $600 \mathrm{MHz}$ range, where the number of independent samples, determined by the standard method, decreased slightly.

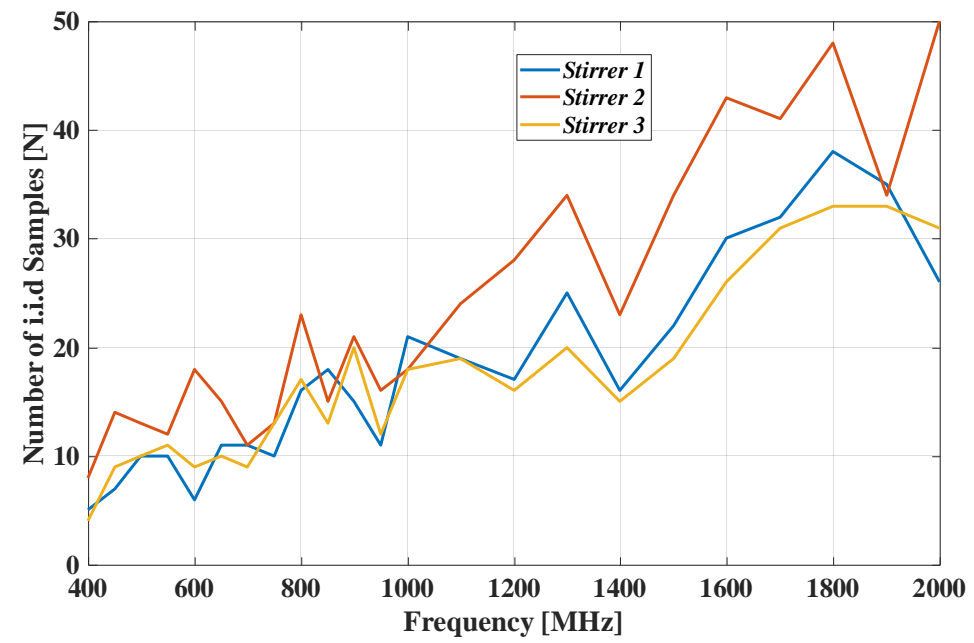

Figure 4.17 Number of independent samples for three different stirrers with general method

\subsubsection{Conclusion}

A simultaneous fast sampling 3D multi-probe system was used to conduct electric field measurements at nine spatial positions in a RC. This system allows more techniques to evaluate the quality of the electromagnetic field in a RC. Two important parameters were evaluated - FU and the number of independent samples 
- using a standard method and a general method. The system proved to be very useful for the performance analysis of RCs under different conditions (much faster and much more effective). The multi-probe technique is now being used in EMC tests on large and complex systems, and the effectiveness of the technique for actual EMC tests is a subject for further research. 


\section{Radiated Electromagnetic Fields in Different Test Environments}

This chapter is based on a paper that will be submitted to the IEEE Transactions on EMC. This paper aims to investigates and compares the radiated electromagnetic fields in different test environments.

\subsection{Introduction}

Conventional AC has been used for many decades. It is the most popular and the most established technique for testing the compliance of equipment. On the other hand, RC has also been generating interest among researchers and engineers over the past decade as an alternative test method, as it reduces testing time and is more cost-efficient [33]. However, further research is required to confirm and validate the applicability of different test techniques for different EUTs and to increase their interchangeability, so test results from different sites can be correlated.

Other studies have compared RE test results between different test sites [83][84][85][86] with the aim of examining the applicability of different sites for performing EM measurements with the same quality results. In [87][3] they used a two-wire transmission line as a device under test (DUT) and investigated the current induced on the line by the external fields as a possible susceptibility profile. In [88] and [89] they studied and compared test results in AC and RC with respect to the error bias and uncertainty as a function of the directivity of maximum received power. More studies about directivity and its effect on testing in RC and AC can be found in [90]. Furthermore, a study done in [91] focuses on radiated immunity on $\mathrm{PC}$ main boards in those two environments.

This chapter focuses on radiated electromagnetic field measurements of dummy EUTs, monopole antennas and simple metal boxes with holes and slits using different test sites. The boxes were designed and built in order to have different radiation pattern behaviors, representing various cases of real EUTs. The results were investigated to study the EUT behavior and to gain insight into different test sites.

Based on the background, this study aimed to:

- Analyze the correlation between different test techniques (SAC, FAR, RC and VIRC) for RE tests using dummy EUTs 
- Investigate the reciprocity concept validity in the different test sites

- Demonstrate the behavior of the EUTs in different sites by examining the radiation pattern

\subsection{EUT Simulation Models}

The analysis described in this chapter was carried out using four different types of EUT:

\section{Monopole antenna}

Dimension: length: $15 \mathrm{~cm}$, ground plane: $20 \mathrm{~cm}$ x $20 \mathrm{~cm}$.

This is the simplest EUT. It was used as a reference to show the correlation between the different facilities and has a well-known radiation pattern, as seen in Figure 5.1.

\section{Box with one hole}

Dimension of the box: $20 \mathrm{~cm} \times 20 \mathrm{~cm} \times 20 \mathrm{~cm}$. A hole was made at the top of the box, $2 \mathrm{~cm}$ off-center, with a diameter of $7.5 \mathrm{~cm}$. The monopole antenna was positioned inside the box. This is a strange EUT, comparable to a real EUT. It has quite a strange radiation pattern and it is more directive in higher frequencies (maximum directivity pointing up) than in lower frequencies, as shown in Figure 5.3.

\section{Box with tube}

Dimension: same box as before, but with a tube of $3 \mathrm{~cm}$ long and $7.5 \mathrm{~cm}$ in diameter placed on top of the hole. The monopole antenna is inside the box.

It has the same purpose as the box with the hole, but the addition of the tube makes the radiation even more directive, since the tube function is actually a cylinder waveguide as shown in Figure 5.4.

\section{Generic box}

Dimension: $20 \mathrm{~cm} \times 20 \mathrm{~cm} \times 20 \mathrm{~cm}$ with many random holes and slits of varying sizes on all sides. The monopole antenna is inside the box, which was adapted from [92] but with a smaller size.

This is an example of a radiator with a complex and unknown radiation pattern that mimics a real EUT. In [92] this model was used to analyze the unintentional radiator principle. The radiation pattern result is shown in Figure 5.5.

In order to find the correlation between different test techniques, the first step is to create simulation model by making a simple monopole antenna model, as a simple radiator. This model was designed and simulated in the $3 \mathrm{D}$ full wave simulation software, CST. 
Simulation settings:

- Accuracy: $-30 \mathrm{~dB}$

- Input power: $0 \mathrm{dBm}$

- Setup Solver: Time Domain Solver

- Port: discrete

- Signal: Gaussian

The model and radiation pattern of the monopole antenna for the three resonant frequencies are shown in Figure 5.1.

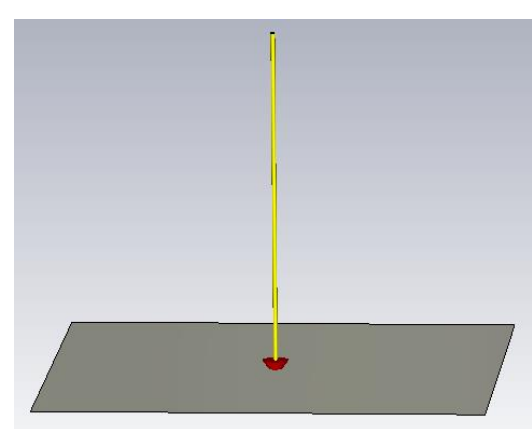

(a)

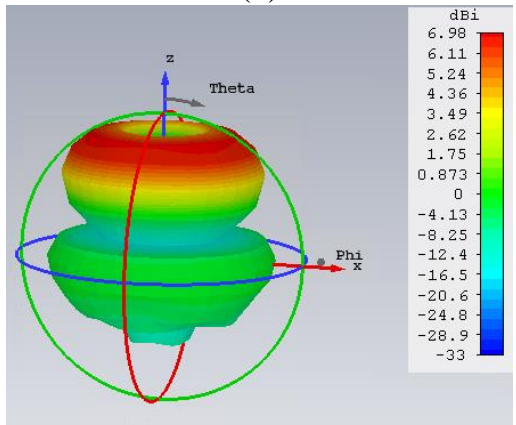

(c)

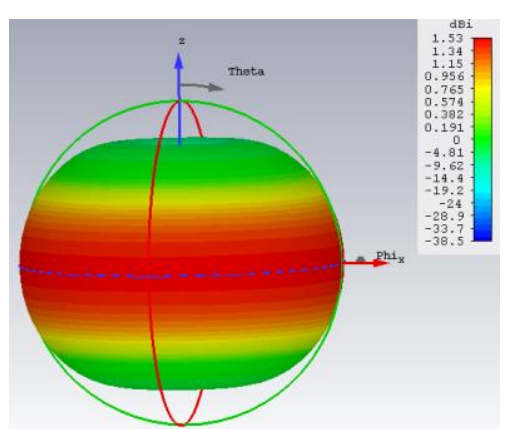

(b)

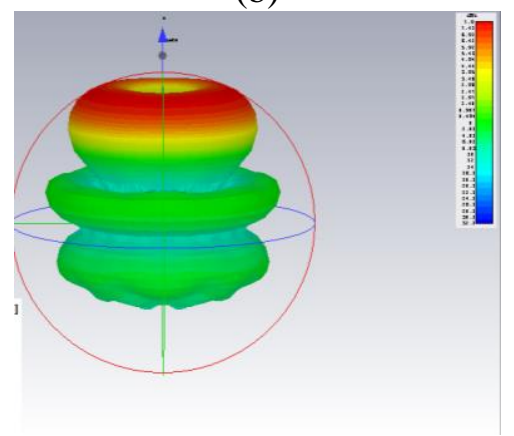

(d)

Figure 5.1 The monopole antenna model in CST (a) and radiation pattern at (b) $500 \mathrm{MHz}$, (c) 2.5 $\mathrm{GHz}$, and (d) $3.5 \mathrm{GHz}$

Since the length of the monopole is $15 \mathrm{~cm}$, the resonant first frequency should be at the frequency where this length is a quarter of the wavelength, meaning the resonance is approximately:

$$
F_{\text {resonant }}=\frac{c}{0.15 * 4} \approx 500 \mathrm{MHz}
$$

The next resonant frequencies will be approximately at $1.5 \mathrm{GHz}, 2.5 \mathrm{GHz}, 3.5$ $\mathrm{GHz}$, and so on, while the anti-resonant frequencies will be at $1 \mathrm{GHz}, 2 \mathrm{GHz}, 3$ 
$\mathrm{GHz}$, and so on. These can be also seen in Figure 5.2, which shows the $S_{11}$ parameter of the monopole.

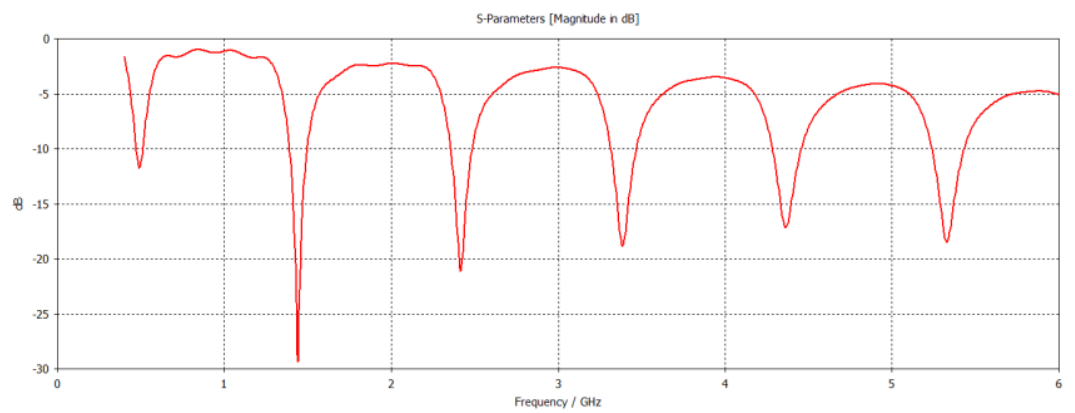

Figure 5.2 The coefficient reflection of monopole antenna

The three other EUTs consist of the same monopole covered with three types of boxes. The models and the 3D radiation pattern of the box with one hole, the box with the tube and the box with the random holes are shown in Figure 5.3, Figure 5.4 and Figure 5.5, respectively.

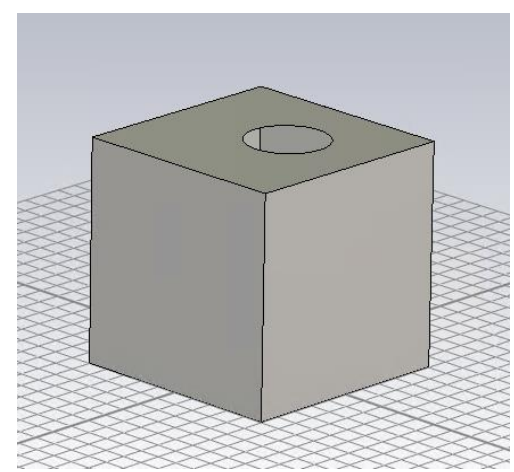

(a)

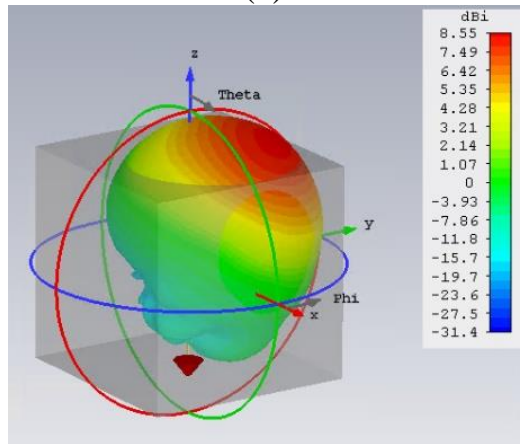

(c)

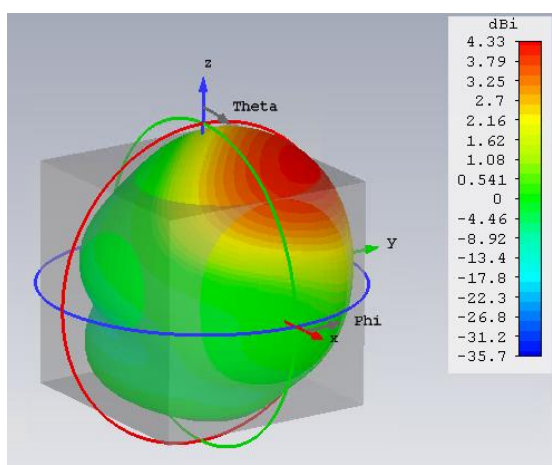

(b)

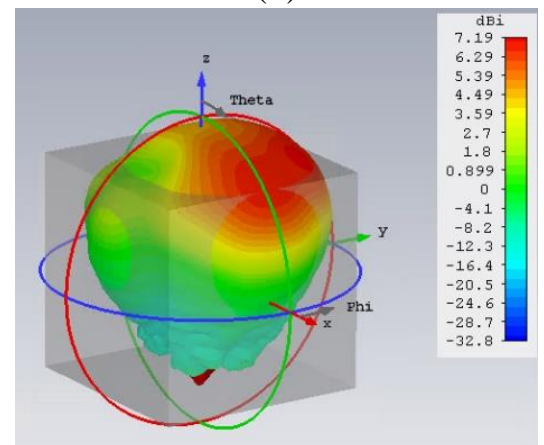

(d)

Figure 5.3 (a) The box with hole model and radiation pattern at (b) $1 \mathrm{GHz}$, (c) $2.5 \mathrm{GHz}$, (d) $3.5 \mathrm{GHz}$ 


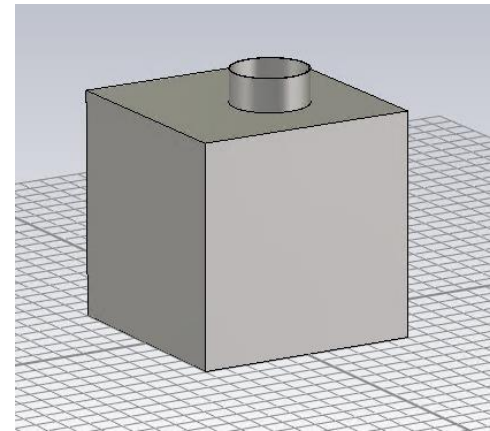

(a)

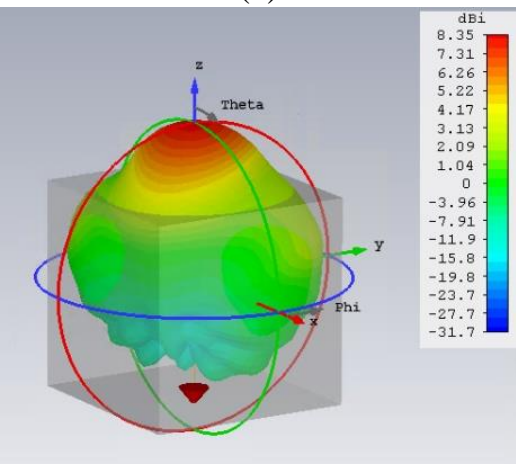

(c)

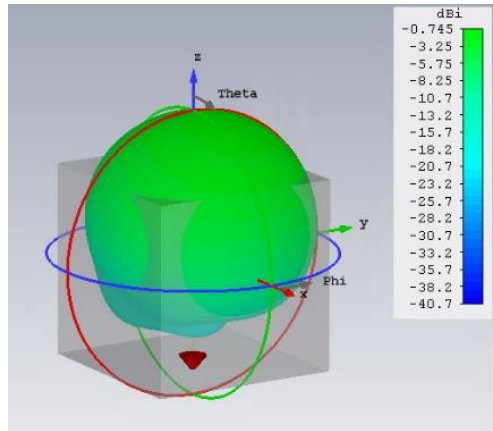

(b)

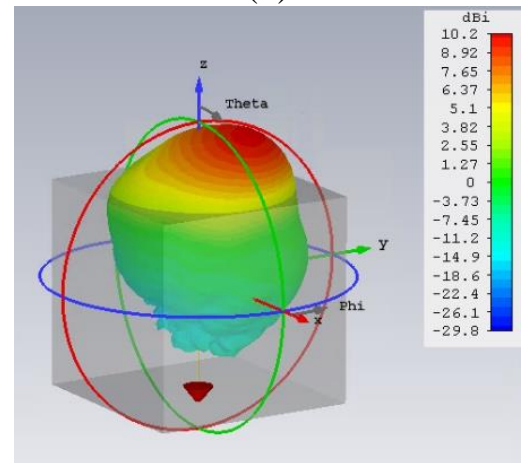

(d)

Figure 5.4 (a) The box with tube model and radiation pattern at (b) $500 \mathrm{MHz}$, (c) $2.5 \mathrm{GHz}$, (d) 3.5 $\mathrm{GHz}$

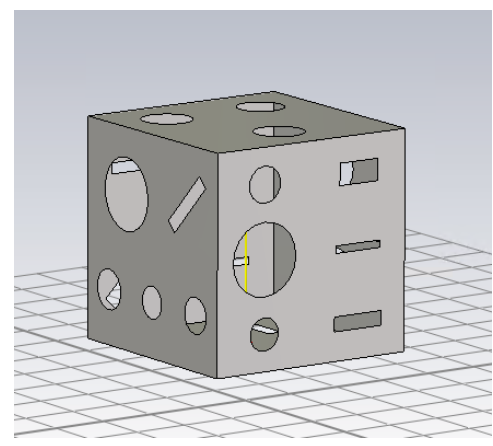

(a)

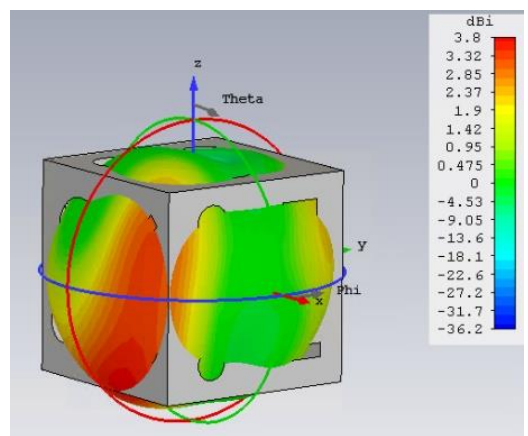

(b) 


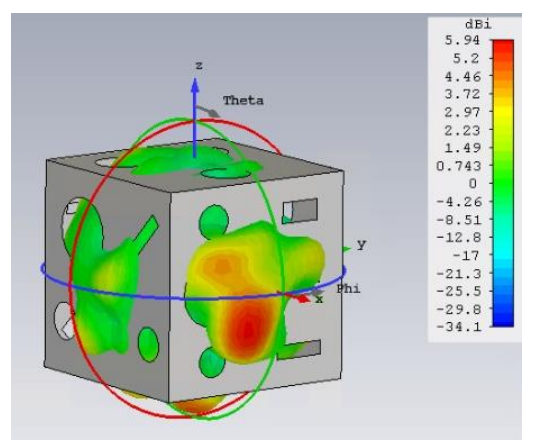

(c)

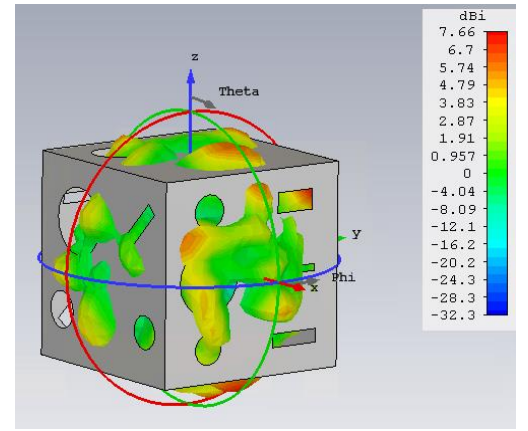

(d)

Figure 5.5 (a) The box with random holes model and radiation pattern at (b) $500 \mathrm{MHz}$, (c) $2.5 \mathrm{GHz}$, (d) $3.5 \mathrm{GHz}$

As shown in the simulation results, the box with one hole focuses the energy radiation of the entire EUT towards the direction of the hole. This effect is strengthened when a tube is mounted on the hole, creating a short waveguide. For low frequencies, the waveguide operates under the cutoff frequency, blocking the emission of the field outside. However, at higher frequencies, the gain of this EUT reaches over $10 \mathrm{dBi}$. Lastly, the generic box with random holes creates a very unpredictable radiation pattern that changes significantly changing with frequency.

The simulated E-field strength, probed at a $3 \mathrm{~m}$ distance around the EUT in the $\mathrm{x}-\mathrm{y}$ plane versus frequency in shown Figure 5.6. At a lower frequency under 1.5 $\mathrm{GHz}$, which covers most of the frequency range, the E-field strength generated by the box with one hole is lower than the monopole's, which is expected since the box operates as a shield between the monopole and the receiver and the energy is radiated upwards, never reaching the field probe. However, in some frequencies (e.g. around $2 \mathrm{GHz}$ ) the E-field strength is higher than the monopole's. This is because the monopole is in the anti-resonance and its radiation pattern is low in this direction, while the box modifies the pattern and directs some of the energy towards the field probe, possibly due to the reflections inside or the diffraction effects on the edge of the aperture. 


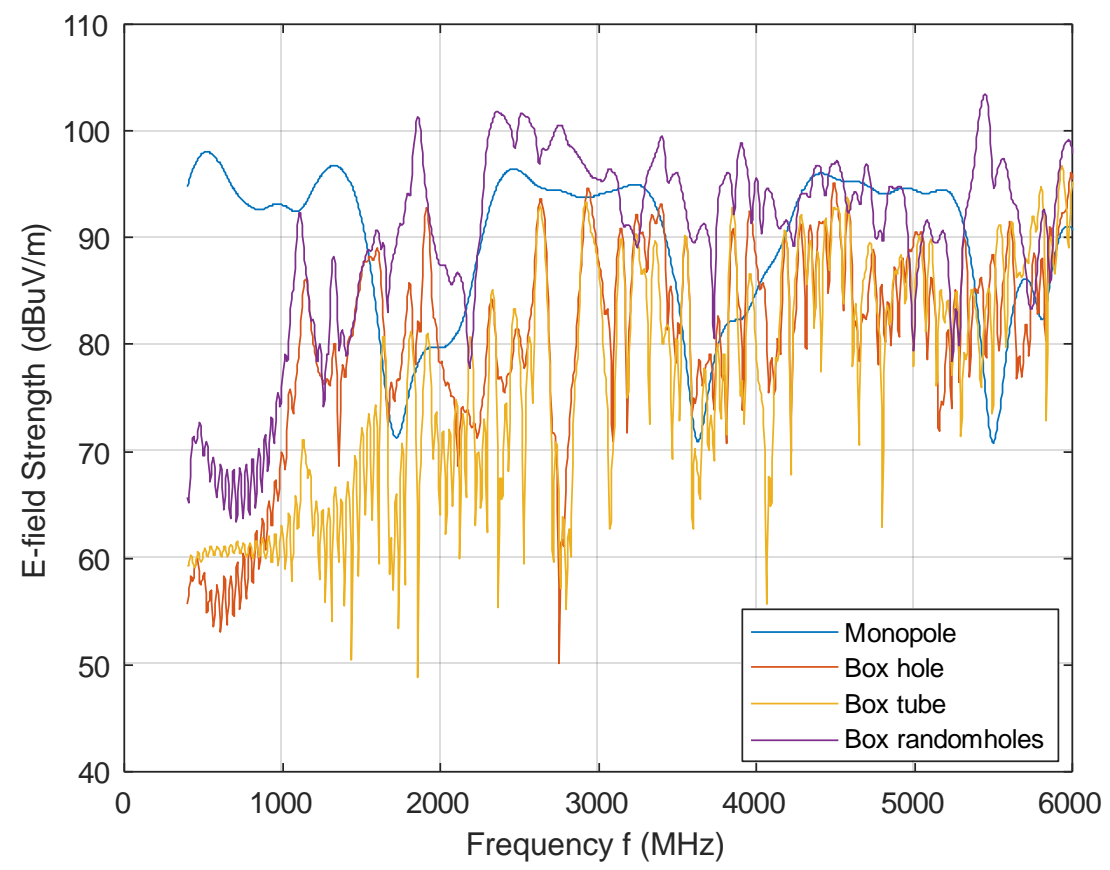

Figure 5.6 The simulated E-field results of the EUTs

The same thing that happened to the box with the hole applies to the box with the tube. The difference is that the radiation leaves the box at a higher frequency than in the box with the hole, since the tube blocks the low frequencies better. However, at higher frequencies ( $3.5 \mathrm{GHz}$ and higher), the tube acts as a waveguide and the directivity is even higher. As can be observed in Figure 5.6, this EUT functions as a shield up to $1 \mathrm{GHz}$ due to the small dimensions of the apertures and holes, while in the remaining frequency range the received field strength is mostly higher than the monopoles. Due to the geometry of the box and the higher frequency, which causes the coupling and reflections, the directivity of this box does not follow the directivity of the monopole; instead, it radiates everywhere unpredictably and with moderate gain, like unintentional radiator [92][93]. Finally, it should be noted that at low frequencies (under $1 \mathrm{GHz}$ ), the curves oscillate because the power received by the probe is very low, making the simulation result less accurate.

By following the standard procedure for measuring the RE of the EUTs, the maximum radiation was measured for a specific number of sampling points, which was sufficient for lower frequencies. At higher frequencies the maximum radiation is harder to detect by the receiving antenna due to the complexity of the radiation pattern. The specified amount of sampling points is therefore not sufficient to determine the maximum electric field strength [94] unless a height scan and a very small degree of table rotation are also performed, which is very time-consuming. 
On the other hand, if this EUT model is going to be tested in a RC (RC or VIRC), it is more likely that the maximum radiation will be detected despite the angle that it is pointing. This is because of the way RCs operate, since they measure the total radiated power and do not depend on any plane scanning [58].

\subsection{Measurement Setups}

The EUT models described in the previous section were manufactured in order to perform an experimental analysis comparing the different test sites. The measurement equipment was the same in each test setup and consisted of:

a. Receiver: A small LPDA antenna (see Figure 5.7) connected to the spectrum analyzer by a coaxial cable.

b. Transmitter: A $15 \mathrm{~cm}$ monopole (copper wire $2 \mathrm{~mm}$ in diameter) on a ground plane of $20 \mathrm{~cm}$ by $20 \mathrm{~cm}$, as can be seen in Figure 5.7. The monopole was connected to the spectrum analyzer (SPA) with an optical RF link to minimize the influence of this connection on the measurement results.

c. SPA with tracking generator (Anritsu MS2712E): This was configured in the two-port transmission measurement mode, so the transmitted signal was generated by tracking generator. The tracking generator's output power was approximately $0 \mathrm{dBm}$. The frequency range under test was from $400 \mathrm{MHz}$ to 4 $\mathrm{GHz}$ with 551 frequency points.

d. The four test sites, FAR, SAC, RC, and VIRC are described in the following subsections.

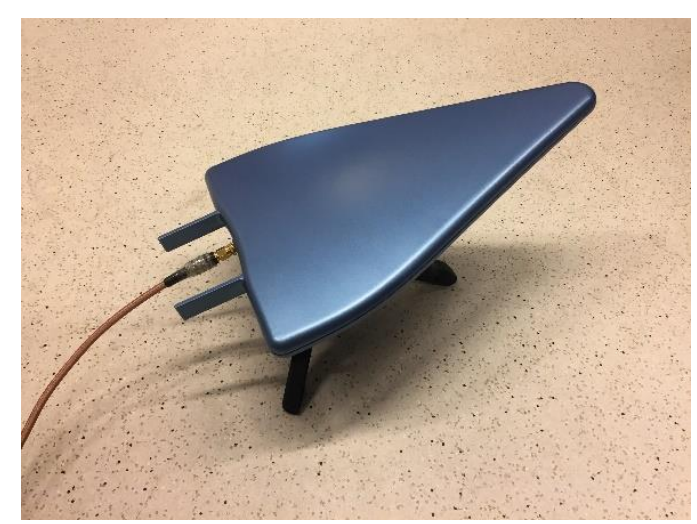

(a)

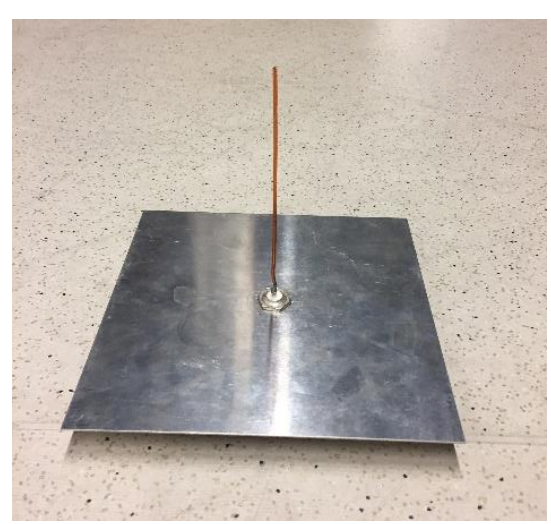

(b)

Figure 5.7 (a) The small LPDA and (b) the monopole antenna

\subsubsection{Fully Anechoic Room (FAR)}

A fully anechoic room (FAR) is a shielded enclosure where the walls, ceiling and floor are covered with an absorbent material, thereby creating a free space environment. The geometry of a FAR can be seen in Figure 5.8. The test setup in a 
FAR is comparable to that of open area test site (OATS) and SAC, except that a FAR has no reflective ground and the height scan is not performed. The radiated electric field strength of the test object was measured at a distance of $3 \mathrm{~m}$ at a height of $1 \mathrm{~m}$ (both test object and test antenna). The EUTs were placed in a turntable and rotated from 0 to 350 degrees at increments of 10 degrees. Then the data was collected on the receiving side. This measurement was carried out for two polarizations of the receiving antenna (vertical and horizontal). The E-field was calculated using the antenna factor (AF) of the receiving antenna. The measurements were carried out in two different FARs, one located at the Technical University of Wroclaw and one at the University of Nottingham. The actual setups and pictures can be seen in Figure 5.9.

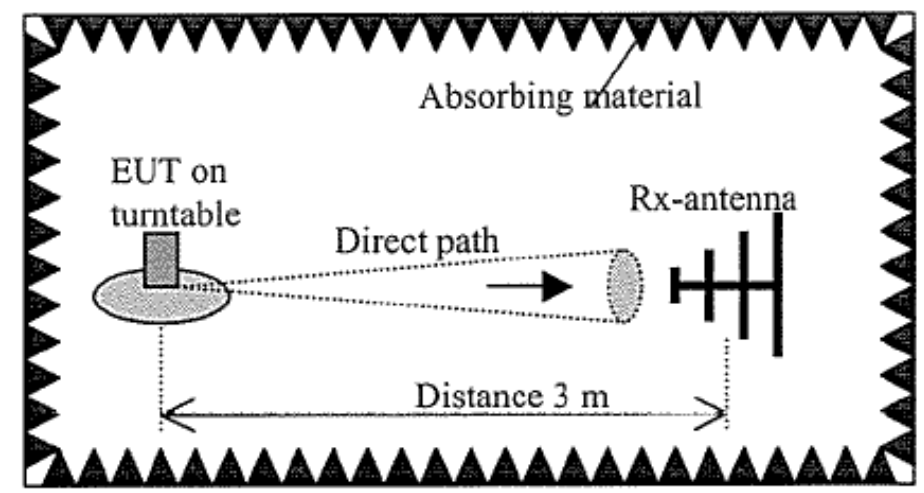

Figure 5.8 Measurement setup diagram inside FAR [82]

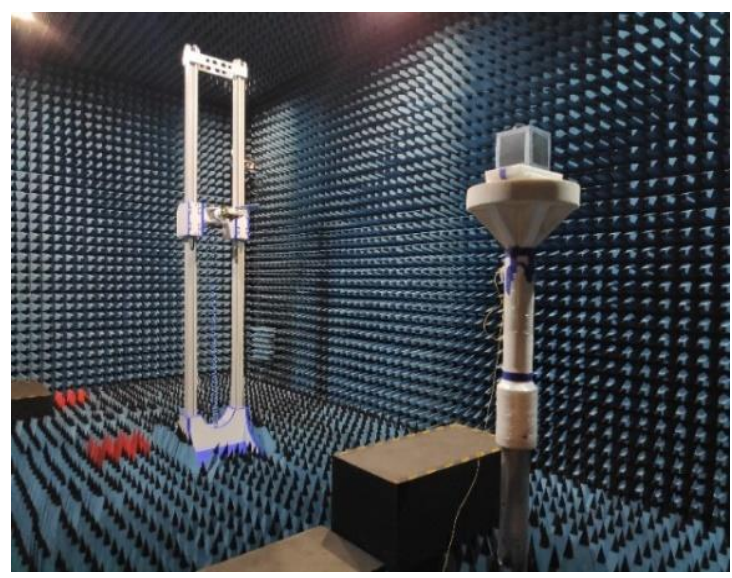

(a)

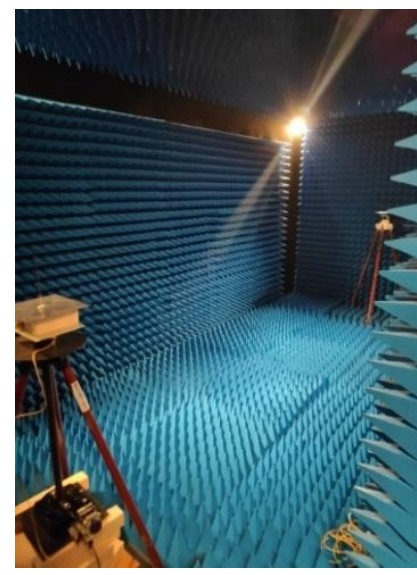

(b)

Figure 5.9 Measurement setup inside a FAR 


\subsubsection{Semi Anechoic Chamber (SAC)}

A SAC is a shielded enclosure with absorbers mounted on the walls and ceiling. Because a SAC has also a reflecting floor as a reference plane, it is comparable to an OATS. However, the typical disadvantages of an OATS (the influence of the weather and ambient signals) are not applicable for a SAC. The geometry of a SAC is shown in Figure 5.10.

The EUTs were placed in a turntable $1 \mathrm{~m}$ from the ground floor and $3 \mathrm{~m}$ from the receiving antenna at the same height. The EUTs were placed on a turntable and rotated 0 to 350 degrees at 10-degree increments and the height scan was performed 1 to $4 \mathrm{~m}$ from the ground, at increments of $0.5 \mathrm{~m}$. The data was collected on the receiving side (power value). This measurement was carried out for two polarizations of the receiving antenna (vertical and horizontal).

The measurements were carried out at the Technical University of Wroclaw, Poland and the actual setup can be seen in Figure 5.11.

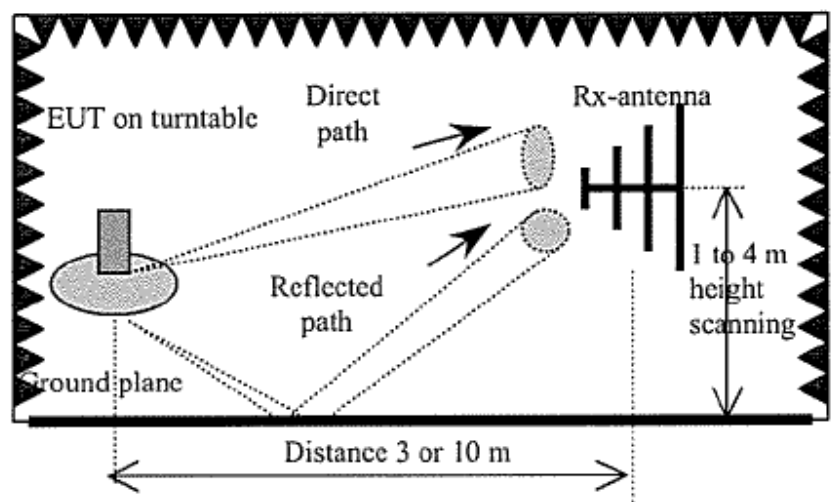

Figure 5.10 Measurement setup diagram inside SAC [82]

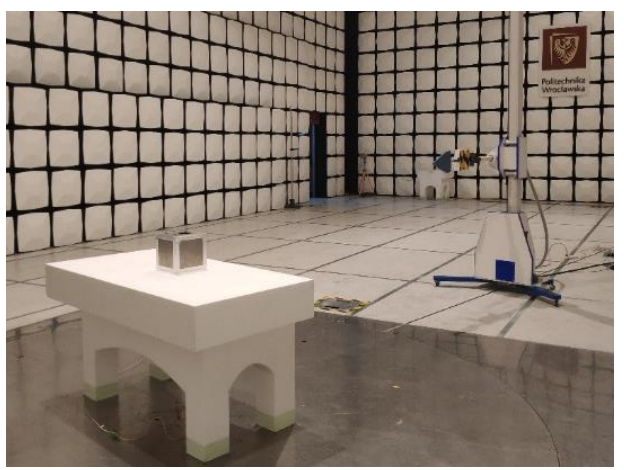

(a)

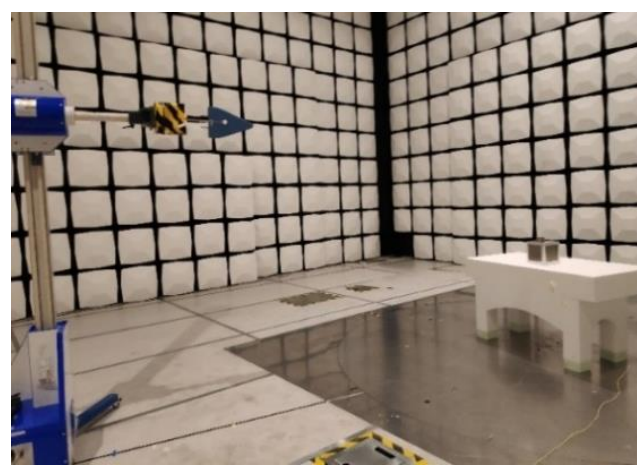

(b)

Figure 5.11 Measurement setup inside SAC 
Converting received power to E-field strength:

The data from the measurements was the transmitted power $P_{\mathrm{T}}(\mathrm{dBm})$.

The E-field strength was calculated as follows:

$$
\begin{gathered}
\text { E-field }(\mathrm{dB} \mu \mathrm{V} / \mathrm{m})=\text { Voltage }(\mathrm{dB} \mu \mathrm{V})+\mathrm{AF}(\mathrm{dB} / \mathrm{m}) \\
\text { Voltage }(\mathrm{dB} \mu \mathrm{V})=P_{\mathrm{T}}(\mathrm{dBm})+10 * \log _{10} * Z+90
\end{gathered}
$$

Where $Z=\eta_{0}=50 \Omega$ and AF, antenna factor, is provided by the manufacturer of the receiving antenna (LPDA HyperLog 60100).

\subsubsection{Reverberation Chamber (RC)}

An RC is an electrically large, highly conductive enclosed cavity or chamber. The objective of a RC is to create an isotropic and uniform test environment. This is conventionally accomplished by introducing a mechanical tuner into a shielded room. By rotating the tuner, the boundary conditions within the chamber are changed and many modes are created inside the chamber [58]. Once the tuner has been moved to a sufficient number of positions and given a sufficient number of independent samples, the field at any point becomes statistically uniform. The geometry of a classical RC is shown in Figure 5.12.

In this setup, the EUT is placed within the working volume of the chamber and the receiving antenna (LPDA) is not pointed directly at the EUT. The stirrer is set on a low rotation speed and many samples are captured by the SPA before one full rotation is completed. These test measurements were performed in three different RCs: At the Technical University of Wroclaw, at the University of Nottingham and at the University of Twente.

In the first test environment (Wroclaw), the EUTs were placed on top of a structure as seen in Figure 5.13(a) and were tested at two different heights from the ground $(1 \mathrm{~m}$ and $1.5 \mathrm{~m})$ or two different positions in the chamber. The stirrer was set at a low rotation speed (1 degree/second) and 160 samples per full rotation of the stirrer were taken by the SPA.

The setup of the second test environment (Nottingham) can be seen in Figure 5.13(b), where the EUTs were also placed in two different but random positions in the chamber. The stirrer was again set at a low rotation speed (1 degree/second) and 100 samples per full rotation of the stirrer were taken by the SPA.

In the third test environment, the EUTs were tested only in one position in the chamber, because of the smaller size of the chamber. The stirrer was set at a lower rotation speed (about 1 degree/2 seconds) and 100 samples were taken by the SPA. 


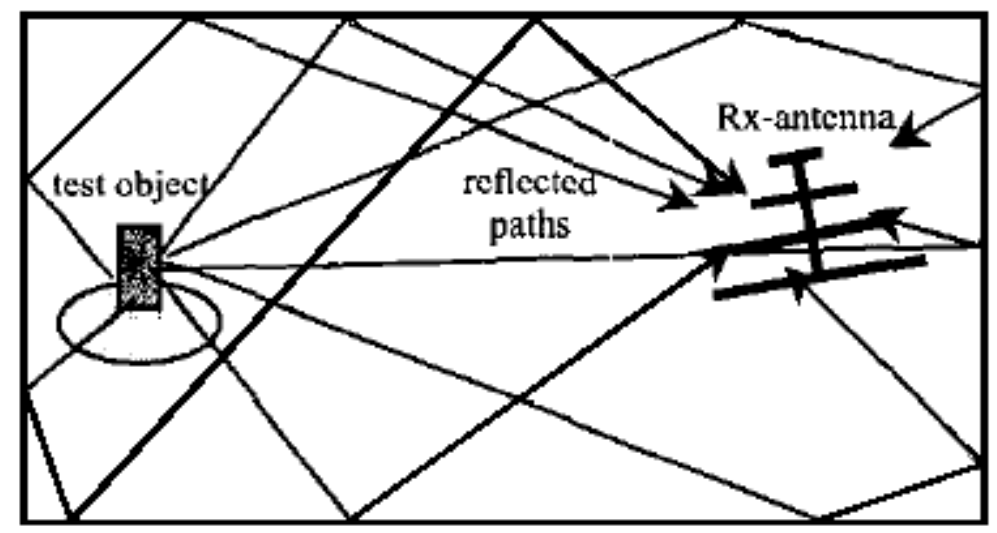

Figure 5.12 Measurement diagram inside the classical RC

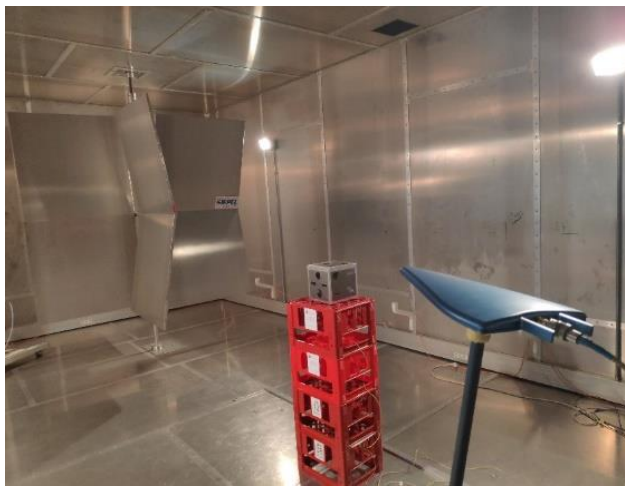

(a)

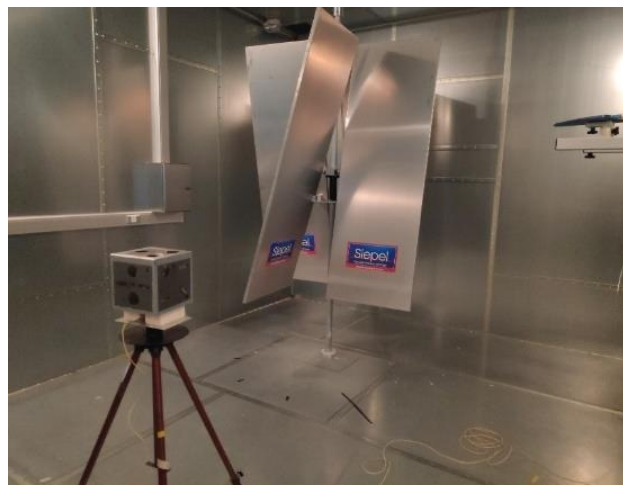

(b)

Figure 5.13 Measurement setup inside the classical RCs

\subsubsection{Vibrating Intrinsic Reverberation Chamber (VIRC)}

The VIRC is a different type of RC made from conductive fabric. By vibrating the walls inside a VIRC, a diffuse, statistically uniform electromagnetic field is created without the use of a mechanical, rotating mode stirrer. The measurement diagram inside a VIRC is depicted in Figure 5.14.

The EUT was placed inside the chamber in the center of the working volume and 100 samples were taken by the SPA as the walls vibrated. 


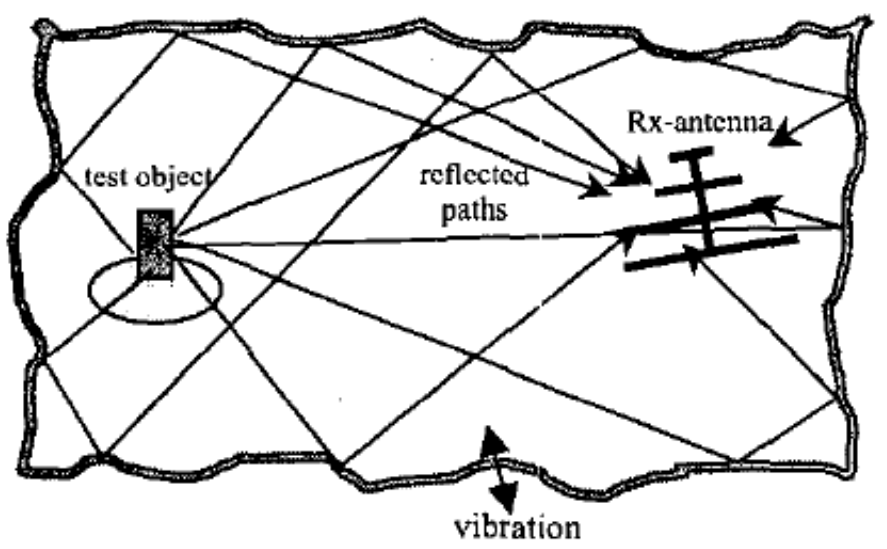

Figure 5.14 Measurement diagram inside VIRC

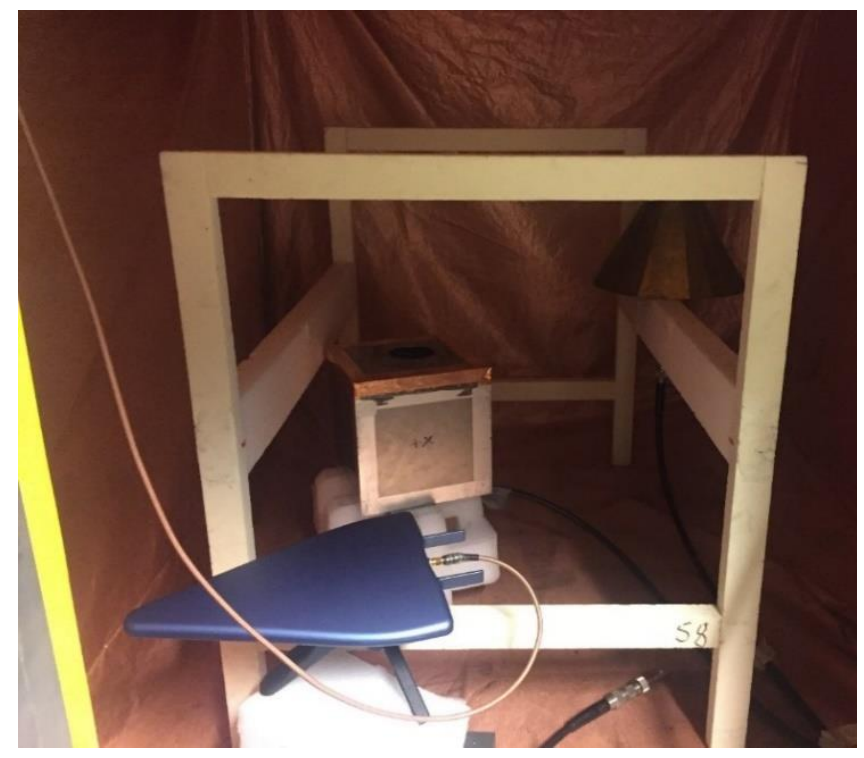

Figure 5.15 Measurement setup inside VIRC

Converting received power to E-field strength:

In order to convert, the received power needs to be converted to total radiated power according to the relevant standard [8], as described below:

$$
P_{\text {radiated }}=\frac{P_{\text {aveReceived }} \times \eta_{\mathrm{Tx}}}{\mathrm{CVF}}
$$

Where: 
- $\eta_{\mathrm{Tx}}$ is the antenna efficiency factor for the receiving antenna (for logperiodic antennas it is 0.75 )

- $P_{\text {aveReceived }}$ is the received power from the measurements (in watts)

- $\mathrm{CVF}$ is the chamber validation factor, the calculation of which is described in Appendix X [8]

The E-field strength is calculated from the transmitted power $P_{T}(\mathrm{dBm})$ :

$$
P(W)=10^{\frac{P(d B m)-30}{10}}
$$

And then,

$$
P_{\text {total }}(W)=\frac{\sum_{i=1}^{N} P_{i}}{N}
$$

The E-field strength is calculated:

$$
\text { E-field }(\mathrm{V} / \mathrm{m})=g_{\max } \sqrt{\frac{\eta_{o} D_{\max } P_{\text {total }}}{4 \pi}}
$$

- Where:

- $g_{\max }=\frac{2}{r}$ for comparison with SAC/OATS or $g_{\max }=\frac{1}{r}$ for comparison with a FAR.

- $D_{\text {max }}=\left\{\begin{array}{c}1.64, \text { for monopole } \\ 0.577+\ln (k a)+\frac{1}{2 k a}, \text { for unintentional radiator (boxes) }\end{array}\right.$,

- Where, $k a=\frac{2 \pi a f}{c}$, where $a=\sqrt{2} \cdot 10 \mathrm{~cm}$ is the radius of the minimum sphere that includes the EUT and $\mathrm{c}=3 * 108 \mathrm{~m} / \mathrm{s}$

\subsection{Results Analysis}

\subsubsection{Comparison: Simulation vs FAR}

As can be seen in Figure 5.16 to Figure 5.27, the simulation results were compared to the FAR result because both cases have absorbing boundary conditions and no reflections from the environment exist. 


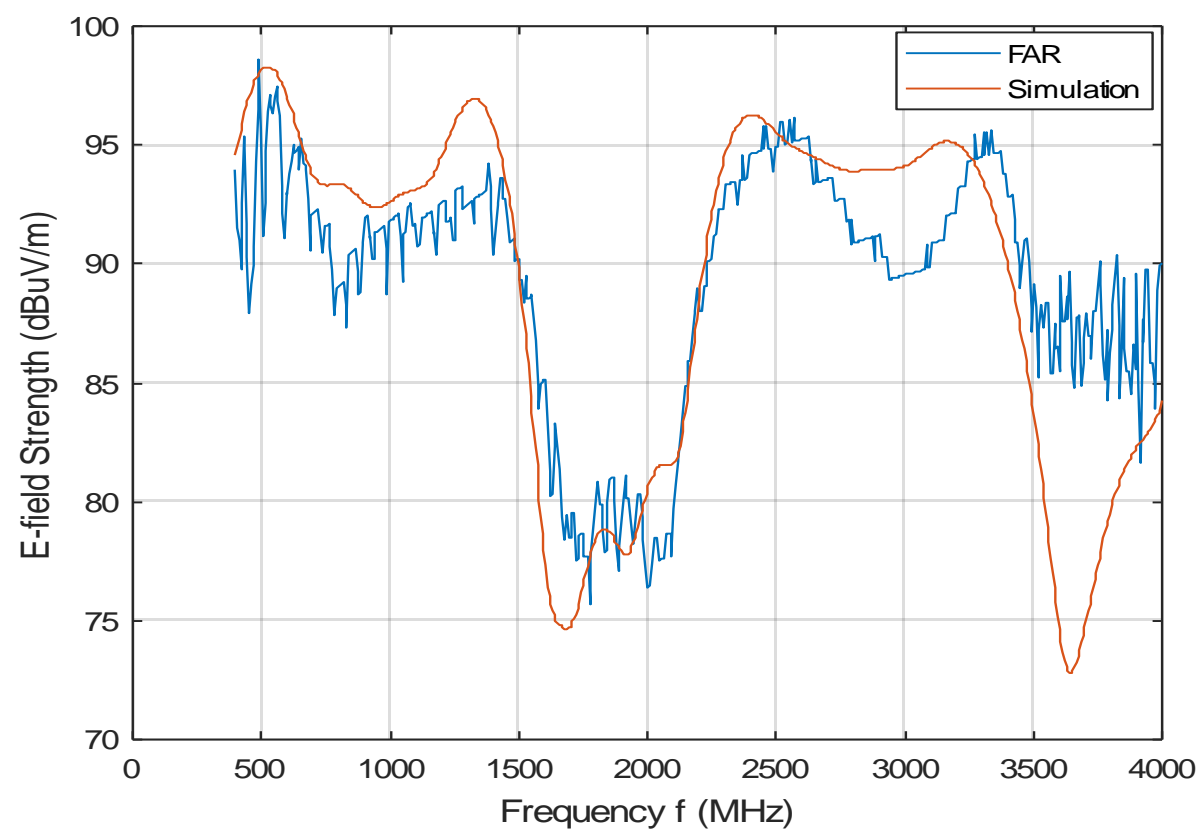

Figure 5.16 Simulation and measurement result in FAR: monopole antenna

Figure 5.16 shows the E-field magnitude of the monopole. The FAR result is the comparable test site as it represents a free space condition as a simulation. The two curves are quite similar and have a similar pattern. Simulated electric field strength was used as reference; however, the simulation curve is smoother since it represents the ideal situation of free space, while in the FAR it is not possible to have these perfect conditions due to the imperfection of the real chamber and its absorbers. It can also easily observe that the pattern appears to be noisier with relatively more discrepancies, especially at higher frequencies above $2.8 \mathrm{GHz}$. 


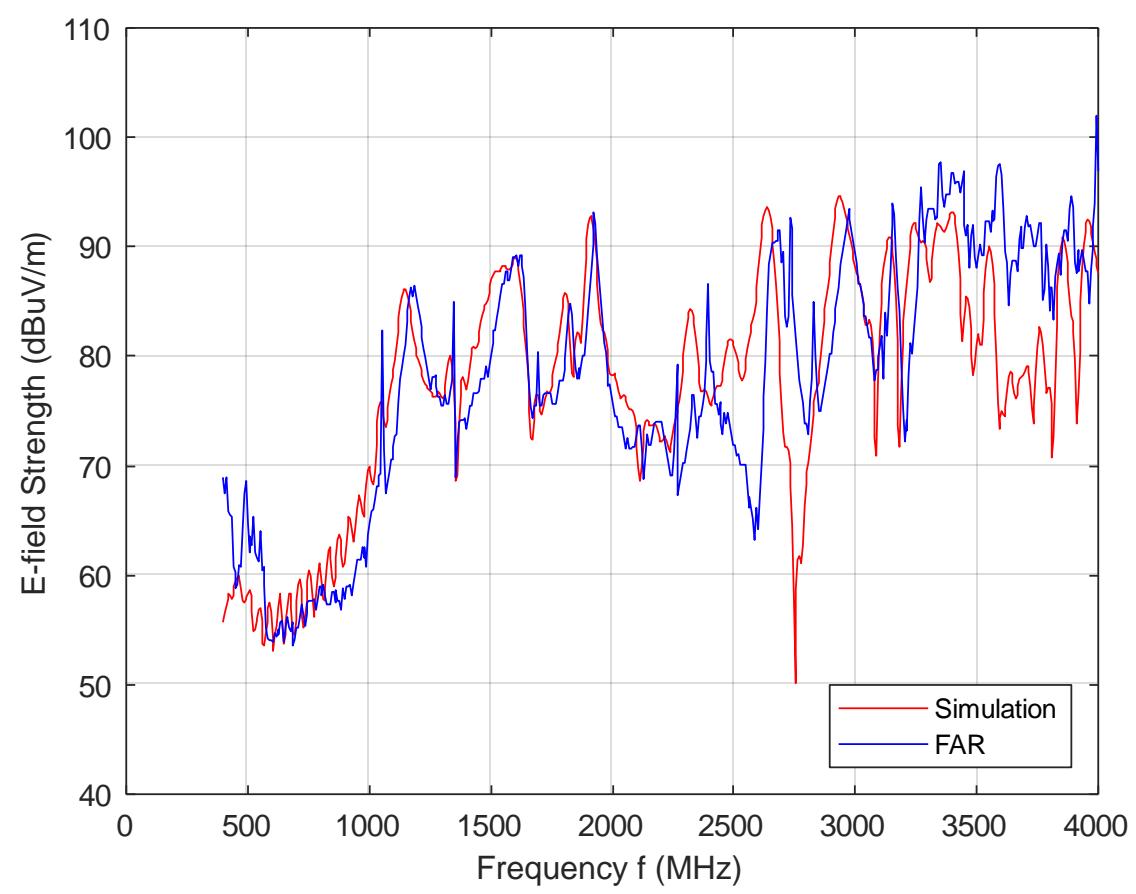

Figure 5.17 Comparison of simulation and FAR: Box with hole

In Figure 5.17 and Figure 5.18 (box with hole and tube), we can see that the graphs have a similar pattern, except for low frequencies below $1 \mathrm{GHz}$. In this frequency range the deviation is $\pm 10 \mathrm{~dB}$ compared to the simulation result for FAR 1. The power delivered to EUT caused the simulation result is not so accurate, as for box with tube the gain has less accuracy in this area (see Figure 5.4). Moreover, the simulation results mostly have less E-field magnitude in almost all frequency ranges.

Figure 5.19 shows the comparison between the simulation and FAR for the box with random holes. All of the results show a similar pattern, which confirms that the measurement results are comparable to the reference simulation (except for above $3 \mathrm{GHz}$ ). 


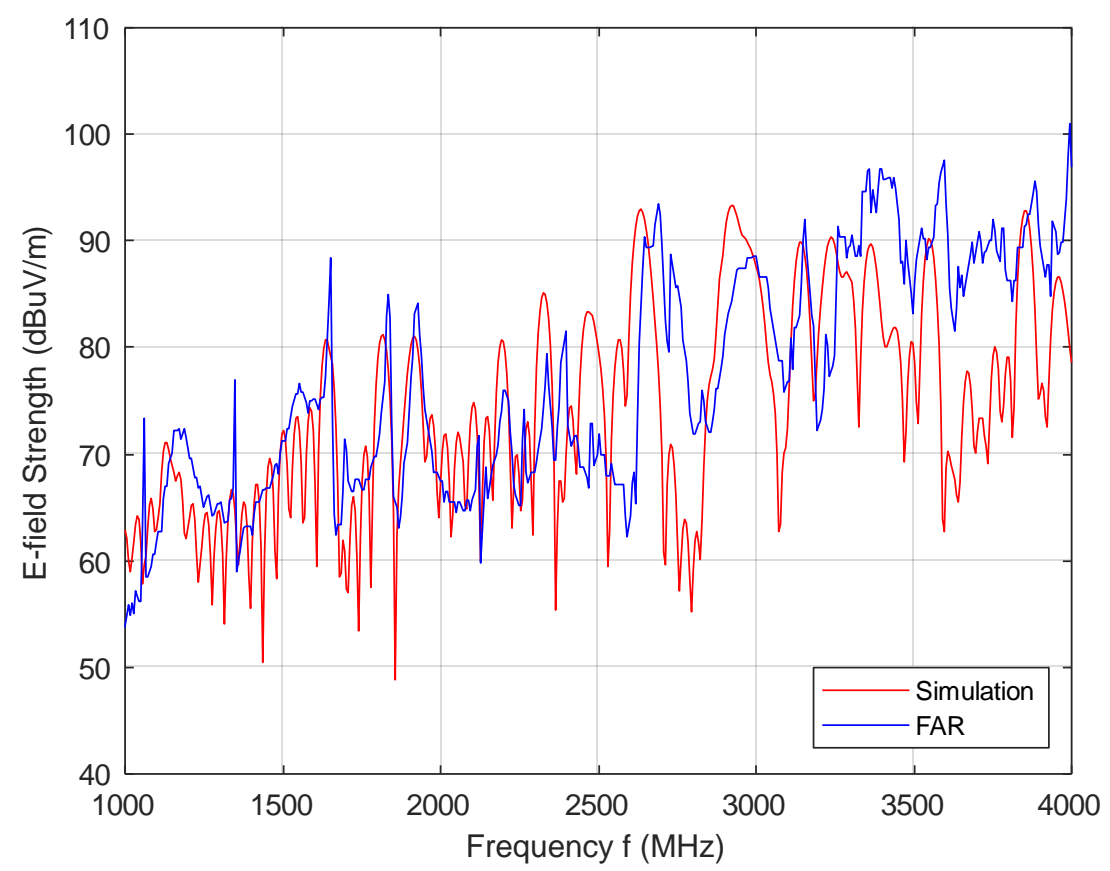

Figure 5.18 Comparison of simulation and FAR: Box with tube

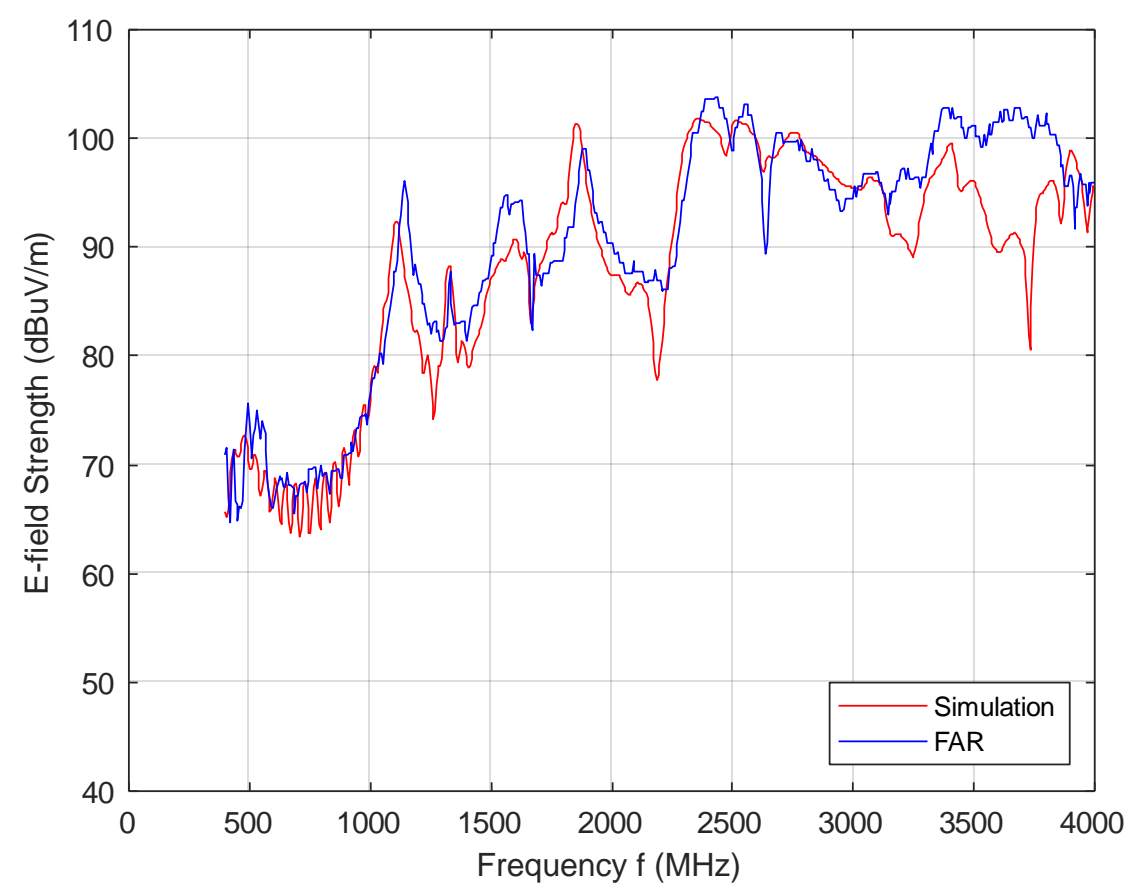

Figure 5.19 Comparison of simulation and FAR : Random box 


\subsubsection{Comparison: EUTs at the Different Test Sites}

The next analysis compares the E-field results for four different test sites, including the simulation. For the comparison of the monopole antenna, as depicted in Figure 5.20 in the frequency band 1.5 to $2 \mathrm{GHz}$, the discrepancies between the FAR and RC or VIRC are obvious (up to $15 \mathrm{~dB}$ ). This happens in cases where the monopole does not radiate well in that direction due to a zero in the radiation pattern. This range is actually where most probably the maximum emission occurred, which can't be detected inside the FAR. In case of an RC, VIRC and SAC - where additional reflections with a different angle exist, caused by the conductive walls in of the RC and VIRC or the floor of the SAC - this energy is successfully directed to the receiving antenna.

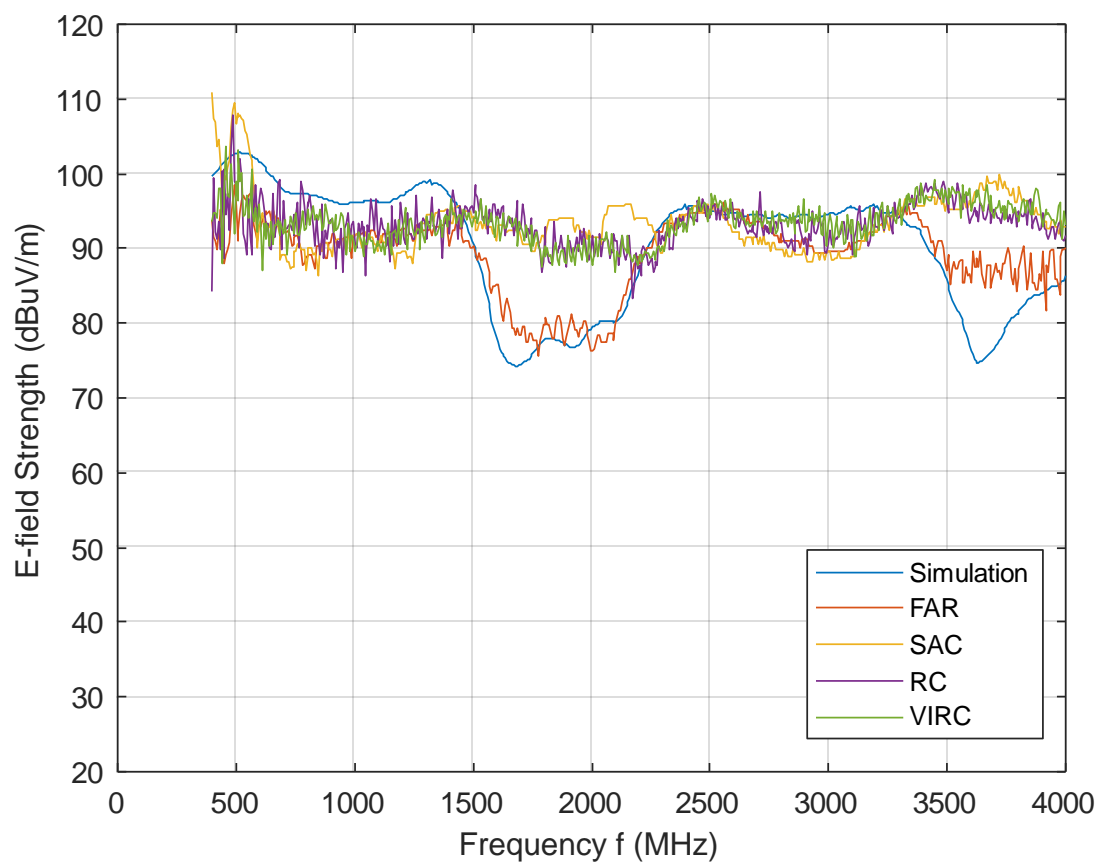

Figure 5.20 Simulated and measured E-field strength of a monopole antenna at different test sites (FAR, SAC, RC, VIRC)

For the other three boxes, in Figure 5.21 to Figure 5.23, the E-field results show quite a similar pattern for all of the sites as well as the simulation results. Using the simulation results as a reference, a deviation of up to $\pm 5 \mathrm{~dB}$ can only be seen between $2.4 \mathrm{GHz}$ to $3 \mathrm{GHz}$. This difference is relatively small compared to previous studies that have been performed to compare different test sites [83][84]. This study found that the deviation between test techniques could be between $20 \mathrm{~dB}$ and $40 \mathrm{~dB}$ when comparing the FAR and VIRC environments. 
As depicted in Figure 5.23 (in particular for the box with random holes), the results are also very similar. As the unintentional radiator (box with random holes) and the complexity is very similar to the real EUT, this EUT is often hard to compare and usually produces a large deviation for different sites [83]. However, according to Figure 5.23, the RC and VIRC results can be considered reasonably comparable to FAR and SAC.

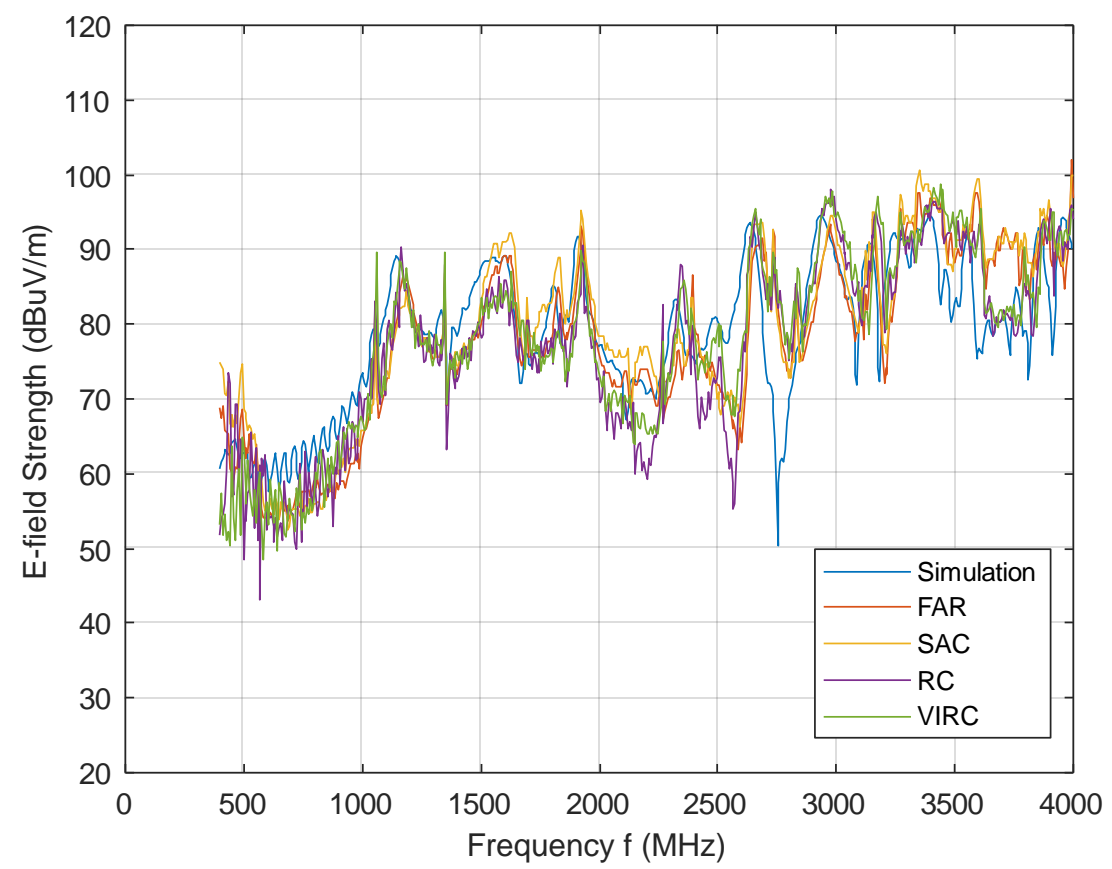

Figure 5.21 Simulated and measured E-field strength of a box with a hole at different test sites (FAR, SAC, RC, VIRC) 


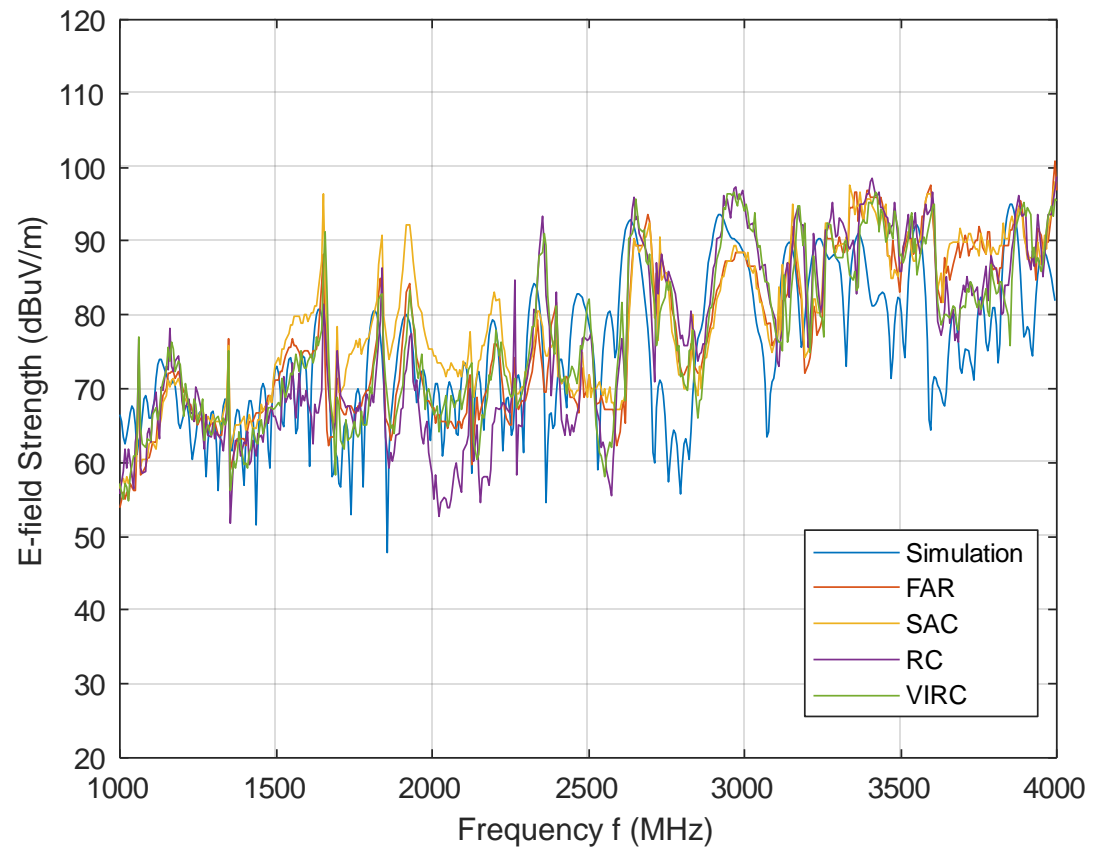

Figure 5.22 Simulated and measured E-field strength of a box with tube at different test sites (FAR, $S A C, R C, V I R C)$

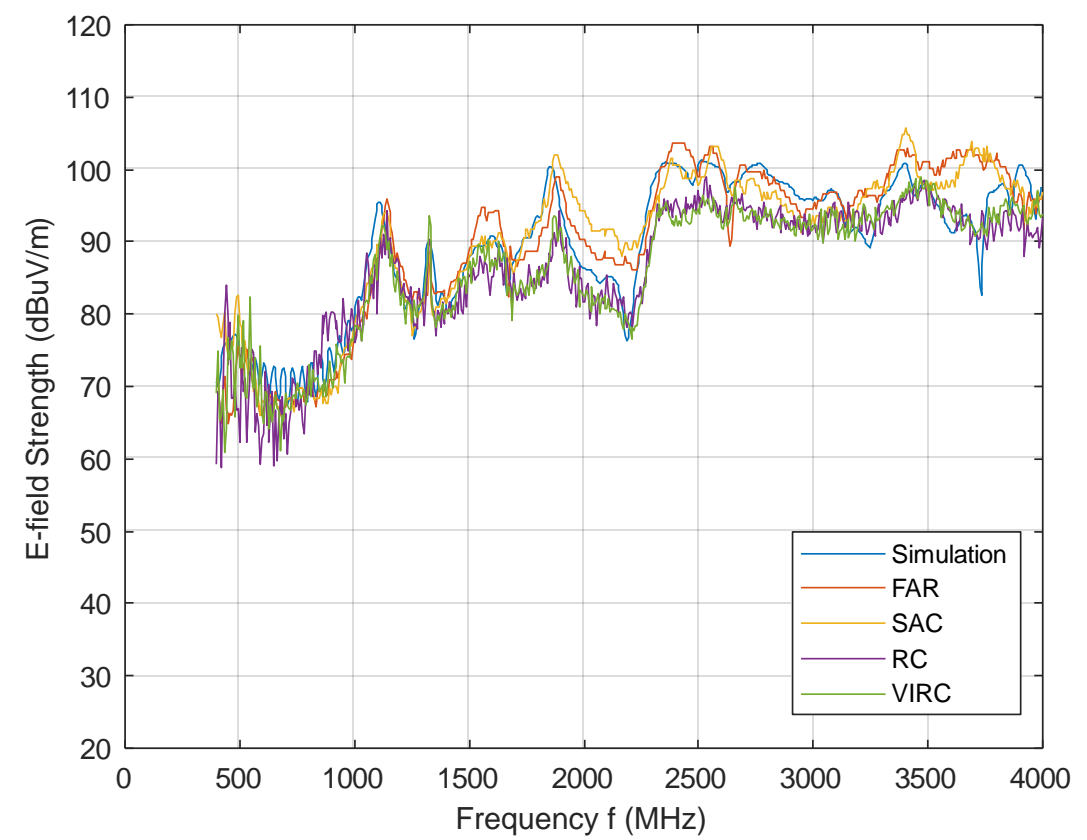

Figure 5.23 Simulated and measured E-field strength of a box with random holes at different test sites (FAR, SAC, RC, VIRC) 


\subsubsection{Comparison: RC vs VIRC}

$\mathrm{RC}$ or VIRC is regarded as an alternative technique to the FAR for RE testing. The advantage of this technique is that the direction or position of the EUT does not influence the results due to the statistical uniformity and isotropy inside the chamber [95]. Moreover, for further analysis, it's required only the total radiation power information after calibration of the chamber or chamber validation factor (CVF).

The next three figures, Figure 5.25 to Figure 5.27, compare RC and VIRC for the monopole and the three other EUTs (the boxes). As can be seen here, although different antenna references were used, all three E-field curves have a similar pattern with only 2 to $3 \mathrm{~dB}$ of deviation. This result proves that the RC or VIRC technique has minimal uncertainty, which could make it an easily repeatable and robust test technique for different EUTs.

In Figure 5.24, the E-field comparison of monopole antenna inside RC and VIRC is shown. As can be seen here, the curves are pretty similar except for the lower frequency range where the discrepancies are higher.

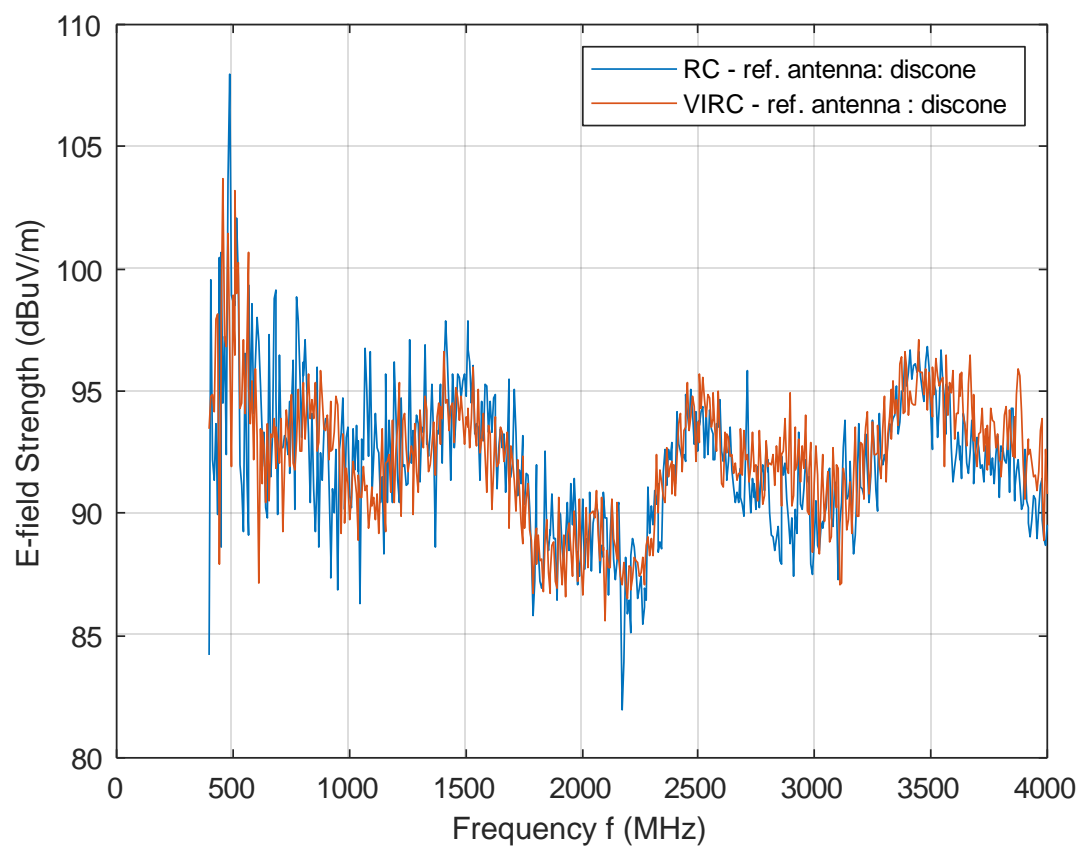

Figure 5.24 The E-field strength of monopole in the RC and VIRC

As can be seen in Figure 5.26 and Figure 5.26, the pattern and the shape are similar with small discrepancies, despite a different reference antenna being used. 


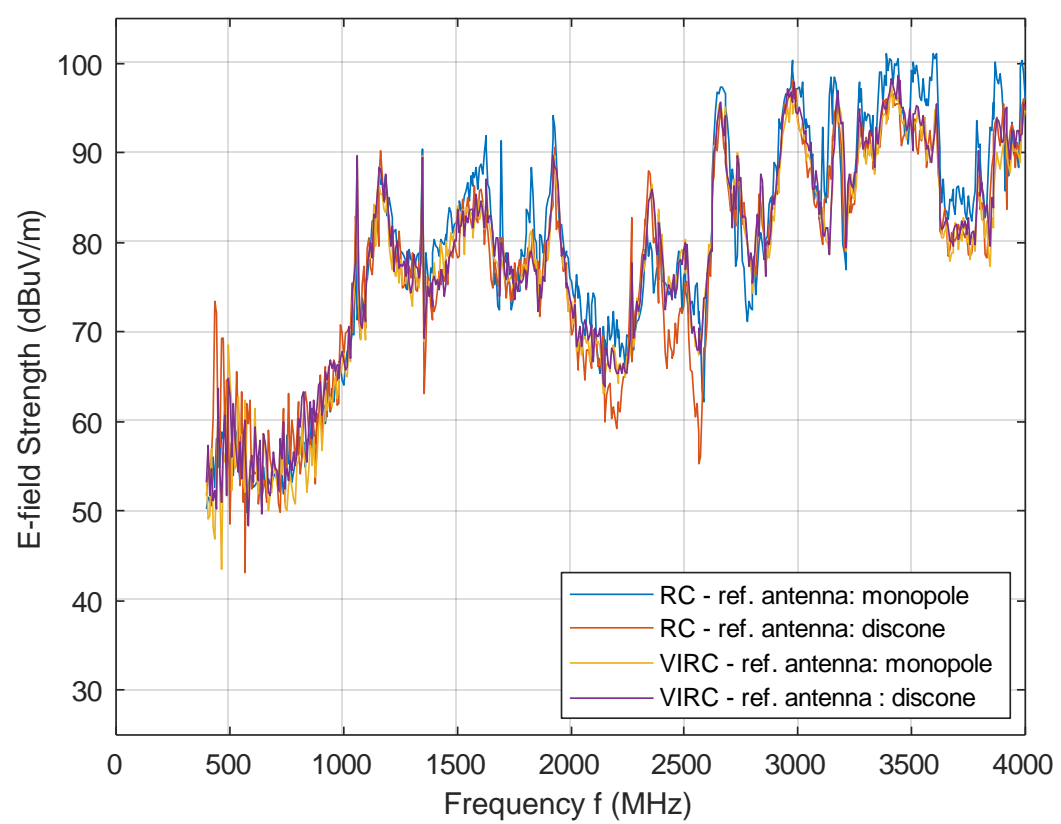

Figure 5.25 The E-field strength inside the box with hole in the RC and VIRC using different reference antenna

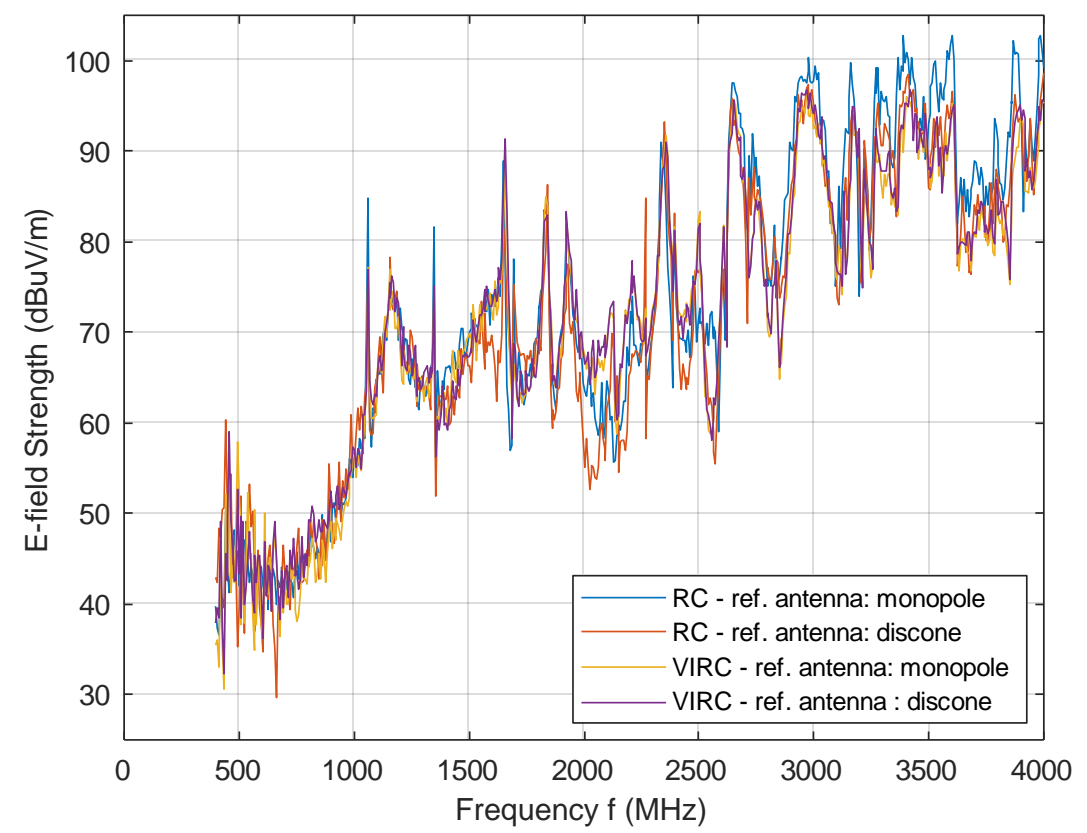

Figure 5.26 The E-field strength inside the box with tube in the RC and VIRC using different reference antenna 
The next figure, Figure 5.27, shows the result for the box with random holes. As expected, the result from RC and VIRC are in alignment. Moreover, the VIRC results with different reference antennas (discone and monopole) are very similar to one another.

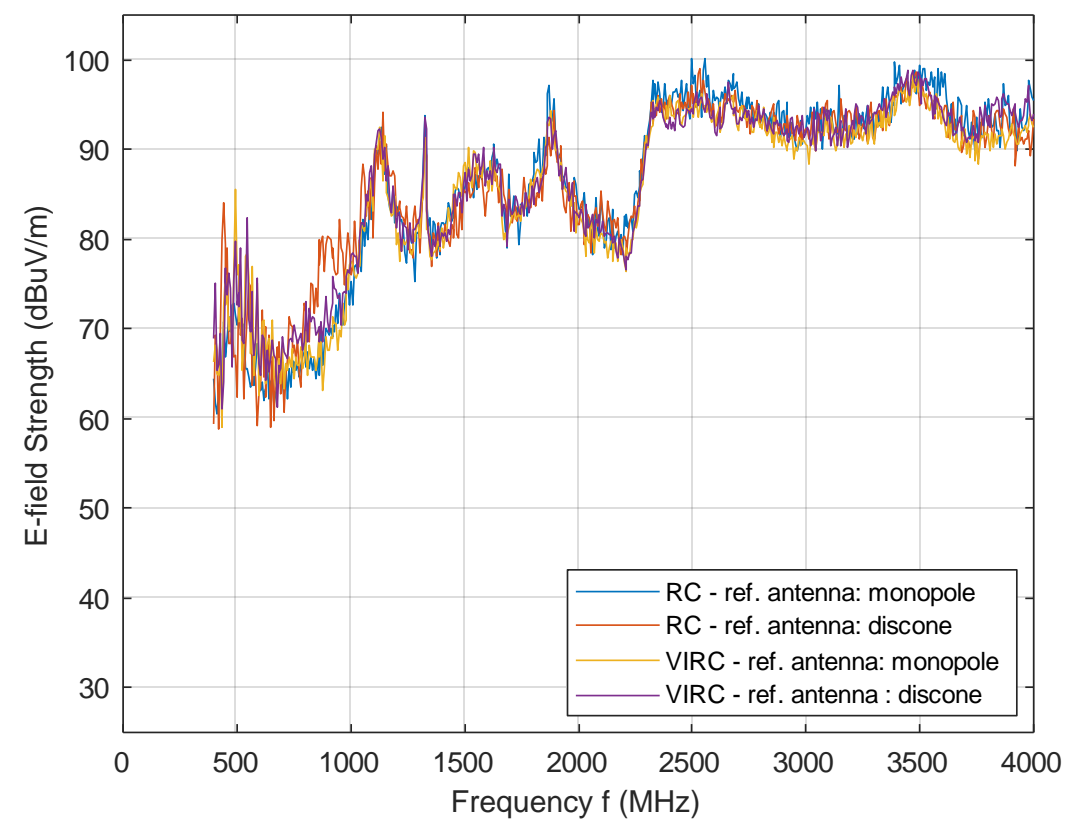

Figure 5.27 The E-field strength inside the box with random holes in the RC and VIRC using different reference antenna

\subsection{Conclusion}

An investigation and comparison was carried out at different test sites for four different EUTs: a monopole, a box with one hole and a monopole inside, a box with a tube with a monopole inside and a box with random holes with a monopole inside. The selected EUTs represent real equipment with various radiation characteristics: a monopole with a simple omnidirectional pattern with a deterministic occurrence of radiation zeros, two boxes with single apertures causing a strong directivity aimed upwards while limiting the radiation to the sides, and a generic box with highly unpredictable but moderate radiation lobes in every direction.

The simulated and measured electric field strengths of some EUTs were used to compare different sites. The first finding that the comparison between E-field strength simulated and measured (inside FAR) value of the monopole antenna as a simple source reference are relatively in a good agreement. However, due to the strong variation of the gain with the elevation angle at higher order resonances, the risk of missing a radiation peak is high and the $\mathrm{RC}$ or VIRC technique is preferred. 
The SAC result, although also fine, is more time-consuming due to the need to perform an additional antenna height scan in addition to the lengthy EUT rotation.

Another important result is that the E-field for maximum RE in RC or VIRC is comparable to the other test sites: FAR and SAC. For the monopole, RC and VIRC also revealed the maximum E-field, especially for an approximate frequency range between $1.5 \mathrm{GHz}$ and $2.2 \mathrm{GHz}$. Moreover, the boxes in FAR and SAC show roughly similar results with some minor deviations. Additionally, having the same quality results, the measurements with RC and VIRC could be carried out much faster than with FAR and SAC. This makes RC and VIRC very time-efficient. 


\section{Generating High Field Strength for RS Measurement}

Although the comparison of test techniques in Chapter 5 shows a decent similarity of the RE results, some advantages and disadvantages of the test sites exist. This chapter discusses the study on the generation of high-intensity electromagnetic fields for RS tests. A comparison of the simple RS EMC test was made in FAR using the antenna technique, as well as in a VIRC. Several papers have been published on carrying out an RS test using different test sites, and IEC 61000-4-21 shows the improvements that can be made. There is a need for more data to support the assumptions made in the standard; however, given that every test technique has its advantages and disadvantages, it bears questioning whether improvements can be made that easily. Several different EUTs were therefore used in the experiments described in this chapter.

In [91], the RS comparison analyses were done in FAR using the antenna technique and mode-stirred RC. By using a special device such as an EUT, they studied quantitative measures for susceptibility testing regarding their repeatability and reproducibility, as well as other advantages and disadvantages. In [96], an investigation based on the equivalence of the power received by the critical element of the EUTs was proposed as a new approach to unifying testing results inside an $\mathrm{AC}$ and an RC.

The experiments described in this chapter include applying the RS test technique inside a FAR using the antenna technique with a dummy EUT, as well as performing the same measurement in a VIRC. The test method is based on the substitution method or pre-calibration described in the standard [2]. We aimed for an E-field strength of $10 \mathrm{~V} / \mathrm{m}$ from $200 \mathrm{MHz}(300 \mathrm{MHz}$ in the VIRC) to $3 \mathrm{GHz}$. The objective of these experiments was to investigate the behavior of the EUT by analyzing the field coupled into the E-field probe inside different EUTs (boxes) for FAR and VIRC. This would allow for an estimation of the susceptibility level, which might be observed by the EUT based on the results and analysis of the applicability of the RS test techniques using antennas inside a FAR and an RC/VIRC. The four EUTs ascribed a symbol, which was defined in Table 6.1. 


\section{CHAPTER 6. GENERATING HIGH E-FIELD STRENGTH FOR RS MEASUREMENT}

Table 6.1 EUT symbols and meanings

\begin{tabular}{|l|l|}
\hline EUT's name / symbol & Meaning \\
\hline EUT P & The probe without a box \\
\hline EUT P-B & The box with one hole and probe inside \\
\hline EUT P-T & The box with a tube and probe inside \\
\hline EUT P-R & The box with random slots and probe inside \\
\hline
\end{tabular}

\subsection{RS Test in FAR}

The antenna technique, based on [2], requires that the RF field is first calibrated in an empty chamber. This was carried out using the E-field probe from lumiloop [66]. In the pre-calibration phase, for each frequency increment, the system was adjusted (as a feedback) to achieve the test level and the RF drive level was recorded. All measurements were conducted with continuous wave signals in order to insure proper levels and similar conditions as those in the standard. Then, the probe was placed in one of the boxes to mimic a real EUT. The field strength represents the field coupled onto the critical component inside the EUT that can lead to EMI issues. Most correction factors were also based on antennas-belowresonance, at resonance, or in the multi-resonance mode. By putting a broadband field strength sensor as the EUT in a metal box, It were better able to replicate an actual EUT. The susceptibility was not at a specific frequency, but over the entire band. The susceptibility threshold level was not just a threshold, but a continuous scale and this EUT displayed isotropic behavior.

\subsubsection{Measurement Setup}

The measurements were carried out in a FAR at the EMC Laboratory of THALES in the Netherlands, as seen in Figure 6.1 and Figure 6.2. The precalibration field was first performed at the standard distance of $3 \mathrm{~m}$, but only in the middle of the UFA. The one-point electric field calibration can be seen in Figure 6.1 , which is in line with the [45] procedure. The reason is that from experience and [13][12] it is known that the UFA is very stable in the FAR and uses the dual LPDA. The target field strength was $10 \mathrm{~V} / \mathrm{m}$ and the power required to establish the desired E-field was recorded and stored as a calibration file.

The measurements were performed with the EUT, which is a box with the Lumiloop probe inside. By utilizing the same power as that used during calibration, the RS test was performed from $200 \mathrm{MHz}$ to $3 \mathrm{GHz}$. The lowest usable frequency was determined by the available power amplifiers at the time of the experiments. The EUT was illuminated from 36 inspection angles, in 100 rotation increments, 
CHAPTER 6. GENERATING HIGH E-FIELD STRENGTH FOR RS MEASUREMENT

laying over one horizontal (X-Y) plane and two antenna polarizations (horizontal and vertical). The measurement equipment and test setup is shown in Table 6.2.

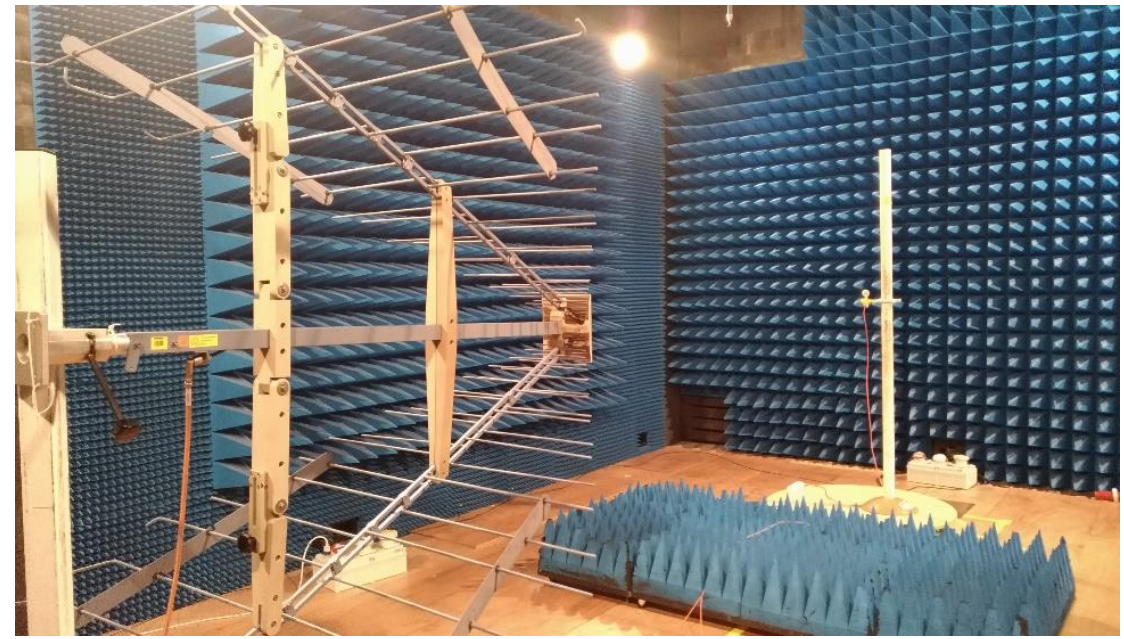

Figure 6.1 The E-field pre-calibration measurement inside the FAR using E-field targeted as EUT $P$ at $3 \mathrm{~V} / \mathrm{m}$ and $10 \mathrm{~V} / \mathrm{m}$

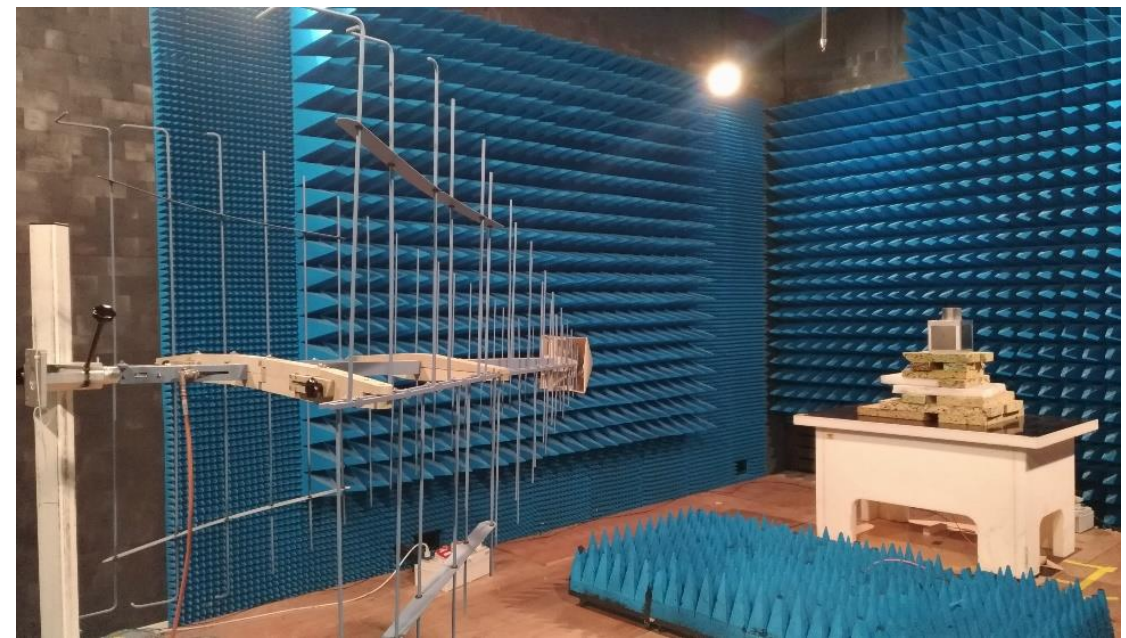

Figure 6.2 RS test setup inside FAR, E-field inside the box

Table 6.2 Test setup inside FAR

\begin{tabular}{|l|l|}
\hline Frequency range $(\mathrm{MHz})$ & $200 \mathrm{MHz}-3000 \mathrm{MHz}$ \\
\hline Transmitting transducer & Double LPDA HL4060 \\
\hline Measurement system & EMC 32 and the Lumiloop probe system \\
\hline EUTs & Four types of EUT, as described in Table 6.1 \\
\hline Moving table azimuth & Every $10^{\circ}$ rotation increments at X-Y plane \\
\hline
\end{tabular}




\subsubsection{Results and Discussion}

Two measurements were carried out in the FAR. The power needed to generate $10 \mathrm{~V} / \mathrm{m}$ at the probe, as functions of the frequency, is shown in Figure 6.3. As the experiments were performed in a FAR and the probe was isotropic, there should be no difference in the power needed to generate $10 \mathrm{~V} / \mathrm{m}$ of field strength for horizontal and vertical polarizations. The large effect, up to $3 \mathrm{~dB}$, already gives an indication of the lack of repeatability and consistency of the FAR antenna technique.

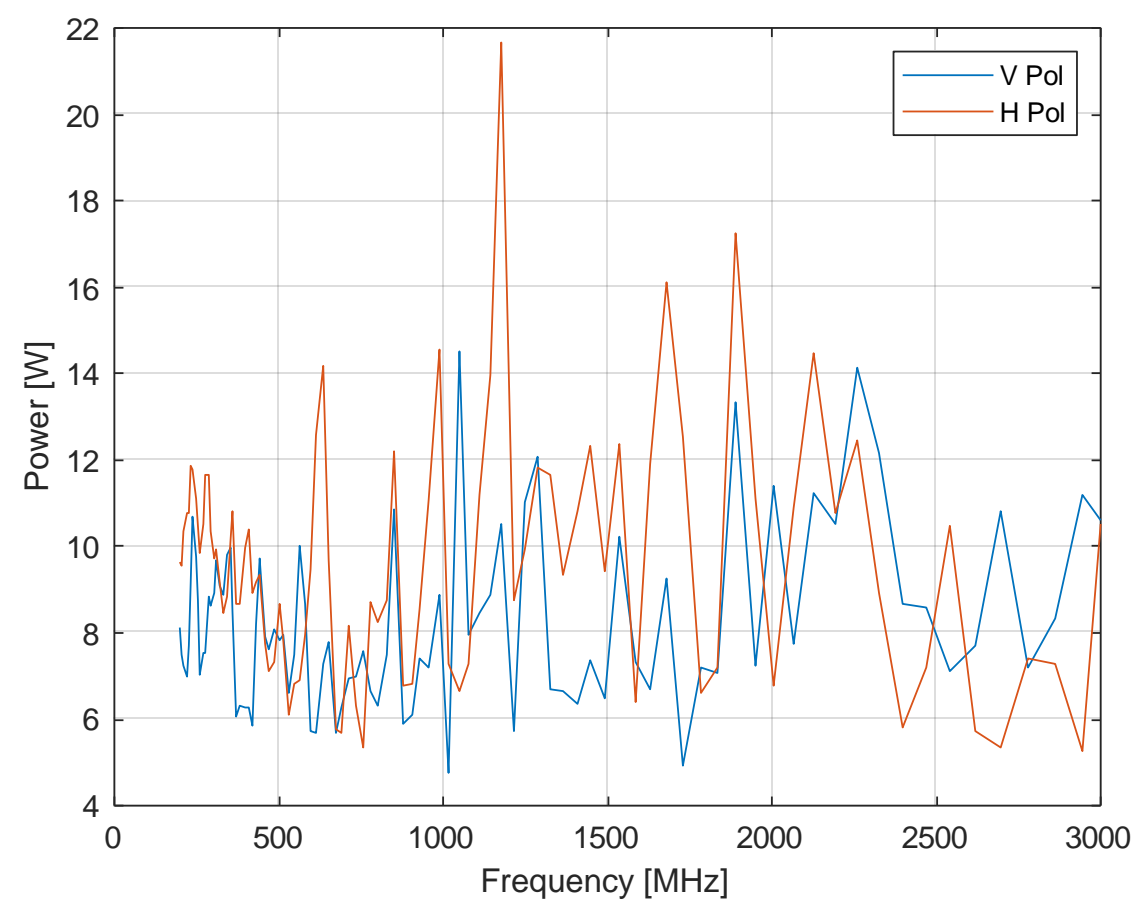

Figure 6.3 Power required for pre-calibration $10 \mathrm{~V} / \mathrm{m}$ E-field targeted

The reading value of the E-field magnitude by EUT P, EUT P-B, EUT P-T and EUT P-R are depicted in Figure 6.4 (a), (b), and (c), respectively. 


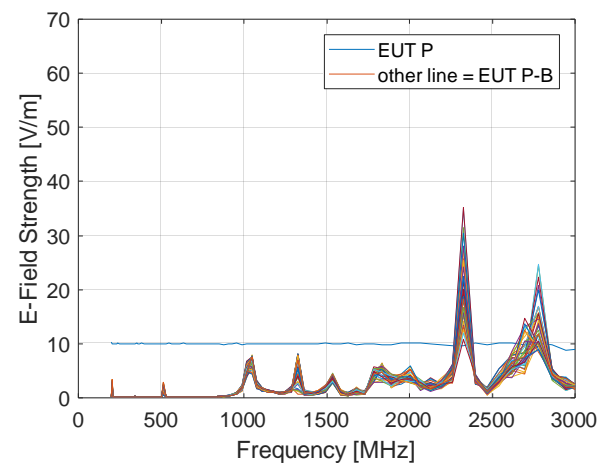

(a)

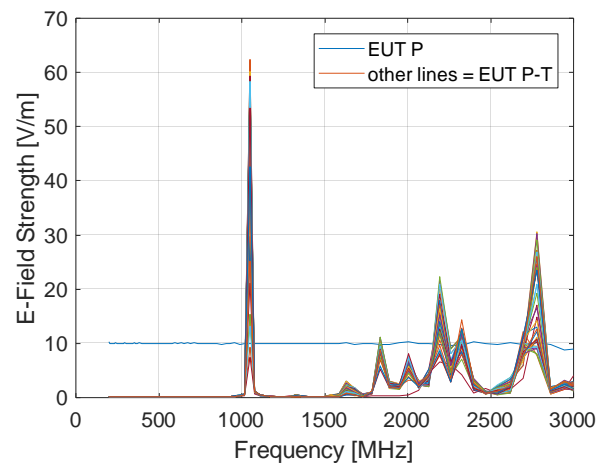

(b)

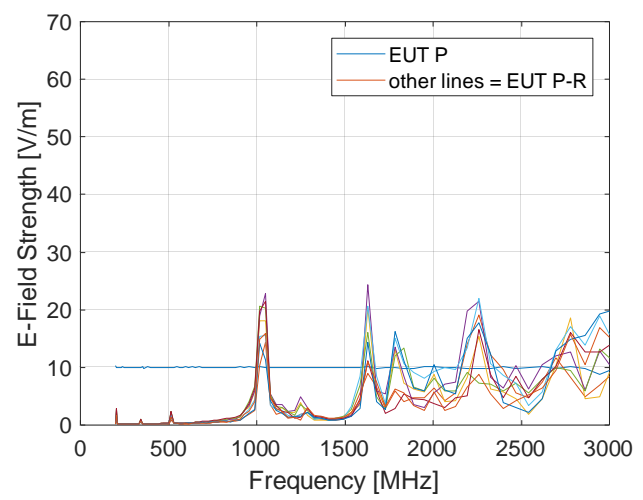

(c)

Figure 6.4 E-field received by EUT P (pre-calibration targeted E-field, $10 \mathrm{~V} / \mathrm{m}$ ), (a) EUT P-B and (b) EUT P-T, (c) EUT P-R with $10^{\circ}$ rotation increment for EUT P, EUT P-T and $45^{\circ}$ for EUT P-R

The various traces in Figure 6.4 show the E-field reading by the probe for every 100 rotation of the EUTs position in one axis of the horizontal (x-y) plane. The flat blue line is the calibration E-field for the $10 \mathrm{~V} / \mathrm{m}$ reading from the probe without the box, (EUT P). As can be observed, the field coupled onto the probe is very different for different angles. This means that the coupling paths vary quite significantly, depending on the geometry of the shielding chassis, in this case presented as boxes with different types of apertures. This effect is smaller for the more symmetrical EUT P-B and EUT P-T, but is very strong in the case of EUT P$\mathrm{R}$, where the location of slots and apertures is chaotic.

The higher the frequency, the more EM signals couple onto the probe. The size of the box $\left(20 \times 20 \mathrm{~cm}^{2}\right)$ is a cavity with its own resonance. The incoming field is modified both by the shielding chassis with apertures that can attenuate it as well as by the internal resonances that can strongly amplify its magnitude. Although on average the field is indeed lower than the calibrated $10 \mathrm{~V} / \mathrm{m}$, at $1 \mathrm{GHz}$ the first cavity resonance can be observed that strongly exceeds the FAR result. It is visible for both 


\section{CHAPTER 6. GENERATING HIGH E-FIELD STRENGTH FOR RS MEASUREMENT}

EUTs, EUT P-B (box with 1 hole) and EUT P-T (box with tube). But the second one (b), EUT P-T has a very sharp resonance. As depicted in Figure 6.5, when observing at the maximum value of the E-field in one full rotation scanning, for the EUT P-T (green line), around $1 \mathrm{GHz}$, the value can be up to 6 times higher than the target field at EUT-P $(10$ Volts $/ \mathrm{m})$. This implies that there is a high probability that in this frequency range the worst-case interference is coupled into the box. This is particularly true given that the size of the EUT and the tube diameter is $7 \mathrm{~cm}$ and its resonance at that particular frequency $\lambda / 2$ is around that region. When increasing to the higher frequency range, this happened more rapidly and at specific frequency points over the targeted field $10 \mathrm{~V} / \mathrm{m}$. The sensitivity of the EUT for different rotation increments also shows the directivity of this simple EUT. In other words, correction factors based on basic dipoles can be very tricky and very difficult.

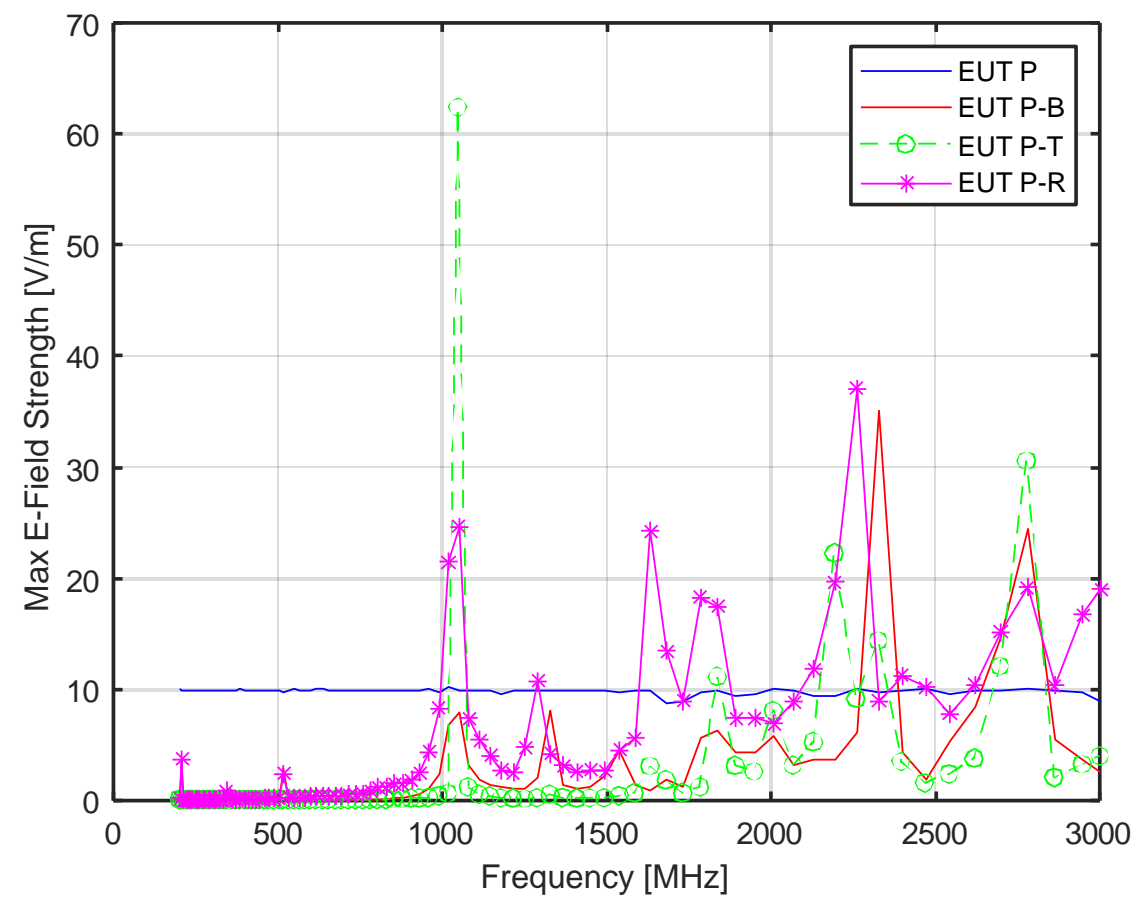

Figure 6.5 Comparison of maximum E-field received by the probe inside the box in EUT P-B, EUT P-T and EUT P-R. Targeted field, $10 \mathrm{~V} / \mathrm{m}$ at EUT P

A similar pattern can be seen in Figure 6.4 (c), however the resonances are less sharp and the penetration of the field is over a larger frequency range. As depicted here - most in the frequency range from $800 \mathrm{MHz}$ up to $3 \mathrm{GHz}$, due to many opening area in the EUT-R - it can be observed that the field coupled to the probe inside is obvious as the frequency goes up. 
Maximal E-field behavior inside the EUTs (boxes) are shown in Figure 6.5. As can be seen here, there are more field coupled into EUT P-R (more opening sides) in boarder frequency band. However, at certain frequency points - around $1 \mathrm{GHz}$, $2.2 \mathrm{GHz}$ and $2.8 \mathrm{GHz}$ - the box with the tube shows a very high E-field.

The following figures are the azimuth graph in a polar coordinate plot at specific frequency points between E-field strength versus azimuth steps in degree. At the low frequencies band below $1 \mathrm{GHz}$, as shown in the previous figures, almost nothing can be observed due to strong shielding effectiveness of the steel chassis and low transmission of the small apertures. The E-field inside the boxes is very low compared to the targeted E-field $10 \mathrm{~V} / \mathrm{m}$. This is based on the example of EUT P-T as plotted in Figure 6.6.

Figure 6.6 shows the behavior of E-field magnitude versus azimuth in the $\mathrm{X}-\mathrm{Y}$ plane.

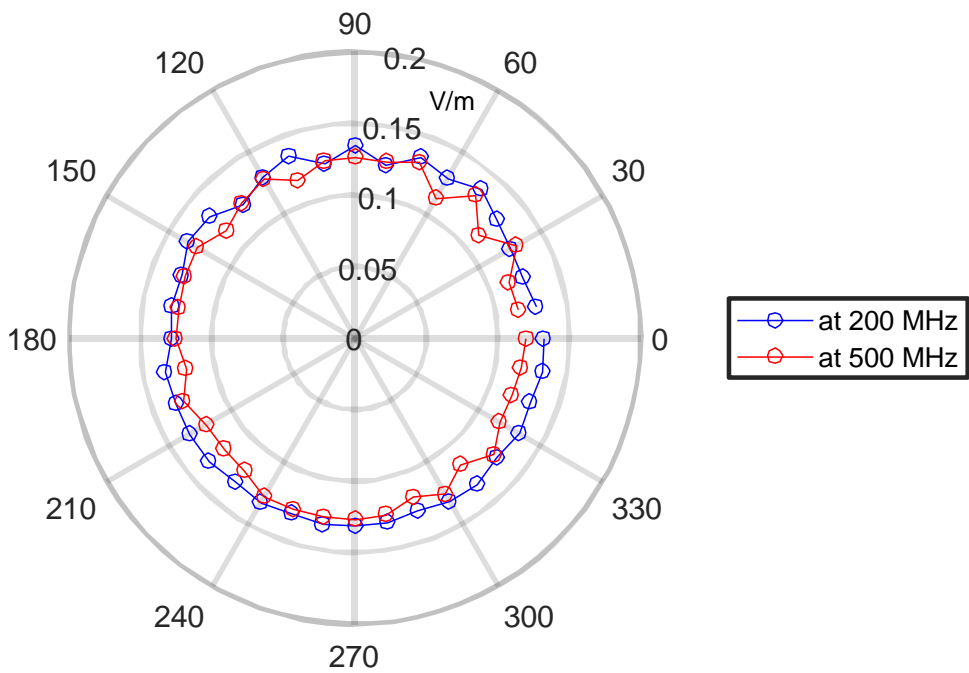

Figure 6.6 E-field polar plot based on azimuth rotation, $10^{\circ}$ step at X-Y plane for EUT P-T at $200 \mathrm{MHz}$ and $500 \mathrm{MHz}$

Even more interesting behavior-wise is the field at a frequency above $1.5 \mathrm{GHz}$, with the exception of $1 \mathrm{GHz}$ for EUT P-T, which has a very strong E-field of over $40 \mathrm{~V} / \mathrm{m}$. The next figures show the polar plot for EUT P-B, EUT P-T and EUT P-R for higher frequency points.

As can be seen in Figure 6.7, the field magnitude exceeds $10 \mathrm{~V} / \mathrm{m}$ for EUT P-T at several frequency points $(2.2 \mathrm{GHz}$ and $2.8 \mathrm{GHz})$. 

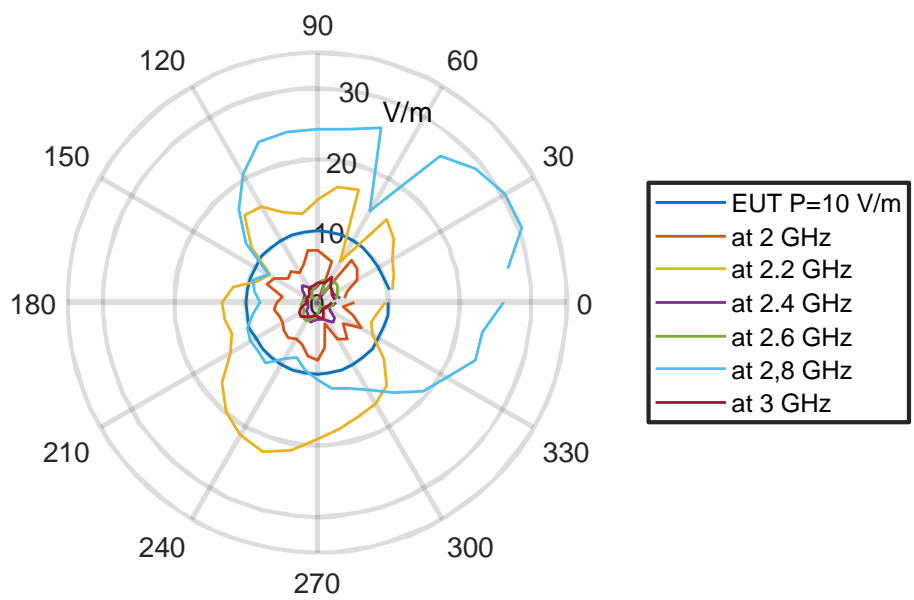

330

Figure 6.7 E-field polar plot based on azimuth rotation at X-Y plane for EUT P-T at 2, 2.2, 2.4, 2.6, $2.8,3 \mathrm{GHz}, 10^{\circ}$ rotation step

The next two figures are for the EUT P-B and EUT P-R shown in Figure 6.8 and Figure 6.9. The pattern similarities between the curves are obvious at high frequencies. For EUT P-R, due to many holes and slots, the induced voltage in the box happened more often, as clearly shown in the Figure 6.9.

EUT P-R was more susceptible to outside interference, due to more holes on the sides of the box. More frequency points are above $10 \mathrm{~V} / \mathrm{m}$, indicating the worst case for the EUT to have failed. At this point it is very important to mention that the EUTs were illuminated only from the sides, in the X-Y plane, without any change in elevation, which means that only a few possible coupling paths were covered. Changing the illumination angle from the X-Y plane could possibly create other coupling paths that could excite different cavity modes. As has been shown in this section, the resonances are the most serious threat to increasing the field strength inside the boxes. 

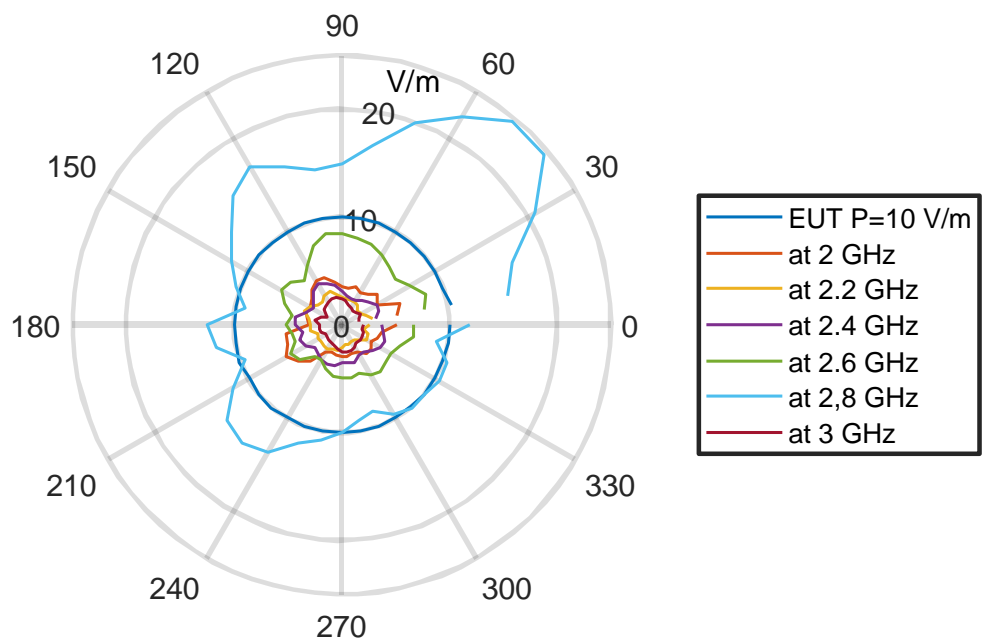

Figure 6.8 E-field polar plot based on azimuth rotation at X-Y plane for EUT P-B at 2, 2.2, 2.4, 2.6, $2.8,3 \mathrm{GHz}, 10^{\circ}$ rotation increment
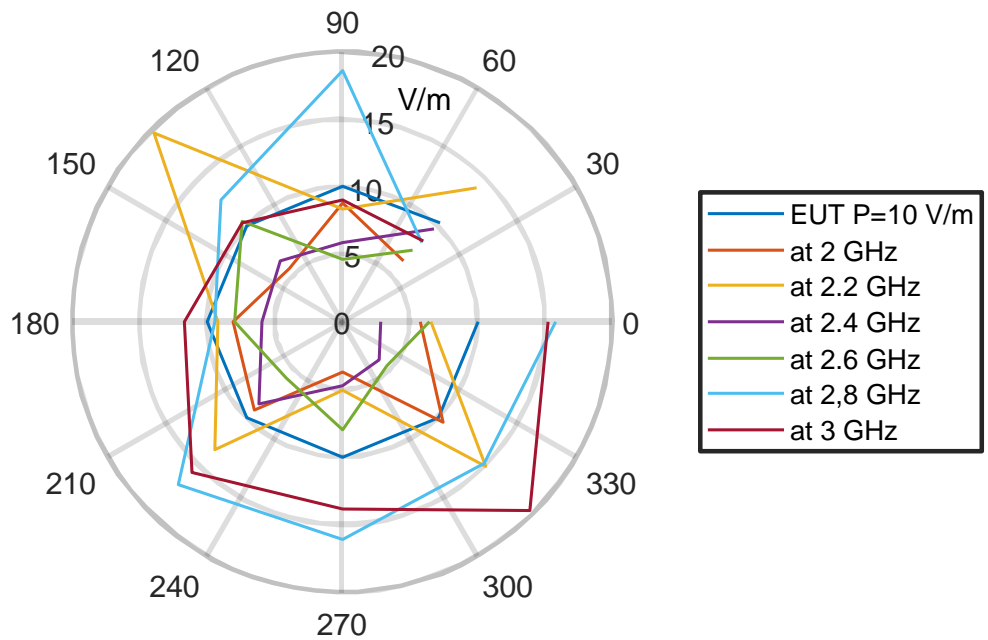

Figure 6.9 E-field polar plot based on azimuth rotation at X-Y plane for EUT P-R at 2, 2.2, 2.4, 2.6, $2.8,3 \mathrm{GHz}, 45^{\circ}$ rotation increment

\subsection{RS Test in VIRC}

A measurement was also carried out inside VIRC. The main objective was to understand how the EUT (probe) reacted to the field coming into the box. 
CHAPTER 6. GENERATING HIGH E-FIELD STRENGTH FOR RS MEASUREMENT

Table 6.3 Test setup inside the VIRC

\begin{tabular}{|l|l|}
\hline Frequency range & $300 \mathrm{MHz}-3 \mathrm{GHz}$ \\
\hline Transmitting transducer & DRGH \\
\hline Generator & Signal generator \\
\hline Frequency steps & $\begin{array}{l}50 \mathrm{MHz}, \text { from } 300 \mathrm{MHz} \text { to } 1 \mathrm{GHz} \\
200 \mathrm{MHz}, \text { from } 1 \mathrm{GHz} \text { to } 3 \mathrm{GHz}\end{array}$ \\
\hline Power input & $0-10 \mathrm{dBm}$ \\
\hline Receiver & $\begin{array}{l}\text { 3-axis fast and sensitive field probe with a } \\
\text { measurement system }\end{array}$ \\
\hline Received signal & 3-orthogonal $x, y, z$ axis \\
\hline Data samples & 100 k per frequency point \\
\hline EUT P & The probe without a box \\
\hline EUT P-B & The box with one hole and probe inside \\
\hline EUT P-T & The box with a tube and probe inside \\
\hline EUT P-R & The box with random slots and probe inside \\
\hline
\end{tabular}

Similar to the previous analysis in the FAR described in the previous subsection, the objective of this experiment was to analyze and investigate the behavior of the field reading by the field probe inside the boxes in VIRC.

\subsubsection{Measurement Setup}

The measurement was carried out from $300 \mathrm{MHz}$ to $3 \mathrm{GHz}$. The same EUT's were used here as were used for the measurement inside the FAR (see Chapter 6.1.1), except that the VIRC is ideally used above the lowest usable frequency and does not work very well below $300 \mathrm{MHz}$, which was used in the FAR setup. The equipment used for this method is described in Table 6.3. From the measurement, $100 \mathrm{kS}$ was collected for each frequency point. The test setup inside VIRC can be seen in Figure 6.10. 


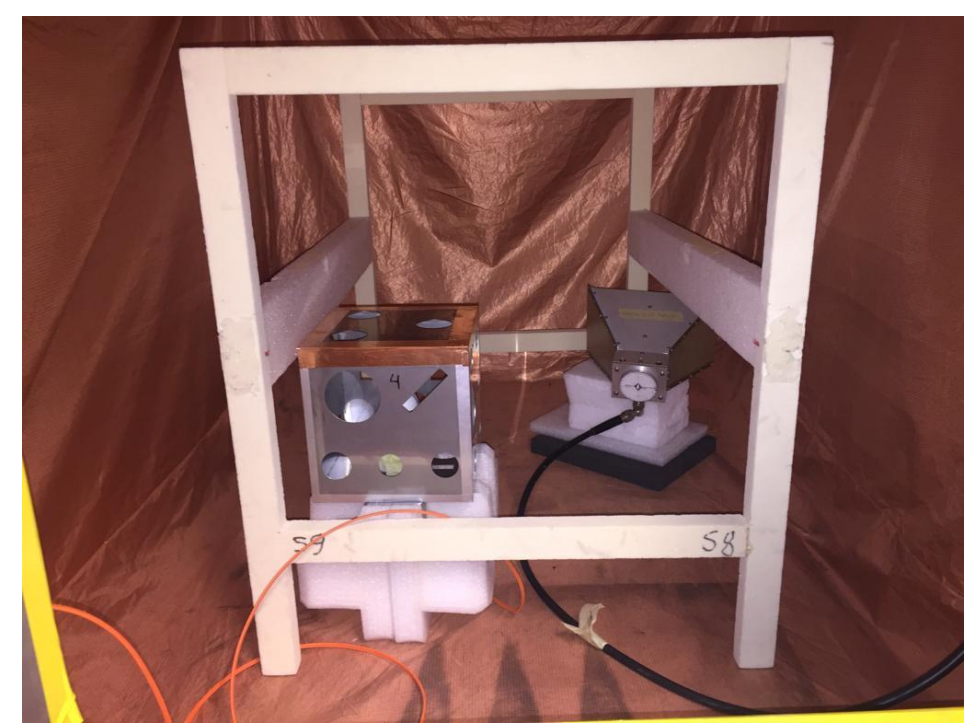

Figure 6.10 Measurement test setup inside VIRC, EUT P-R with fast-sensitive E-field probe inside

\subsubsection{Results and Discussion}

The field received by the probe inside the VIRC and outside the box (EUT P) is shown in Figure 6.11. This is the field behavior inside the empty chamber for 3-axis $\mathrm{x}, \mathrm{y}, \mathrm{z}$ components from $300 \mathrm{MHz}$ to $3 \mathrm{GHz}$.

Figure 6.11 shows the maximum E-field for each axis component. The black line is the max value for all axes. This value was obtained inside the VIRC by transmitting $10 \mathrm{dBm}$ power from the generator to the DRGH antenna. As can be seen here, in the lower frequency range the field is relatively small compared to the frequency above $1 \mathrm{GHz}$ due the strong antenna mismatch. From $500 \mathrm{MHz}$, the field magnitude for each component slowly increases to $1 \mathrm{GHz}$. 


\section{CHAPTER 6. GENERATING HIGH E-FIELD STRENGTH FOR RS}

MEASUREMENT

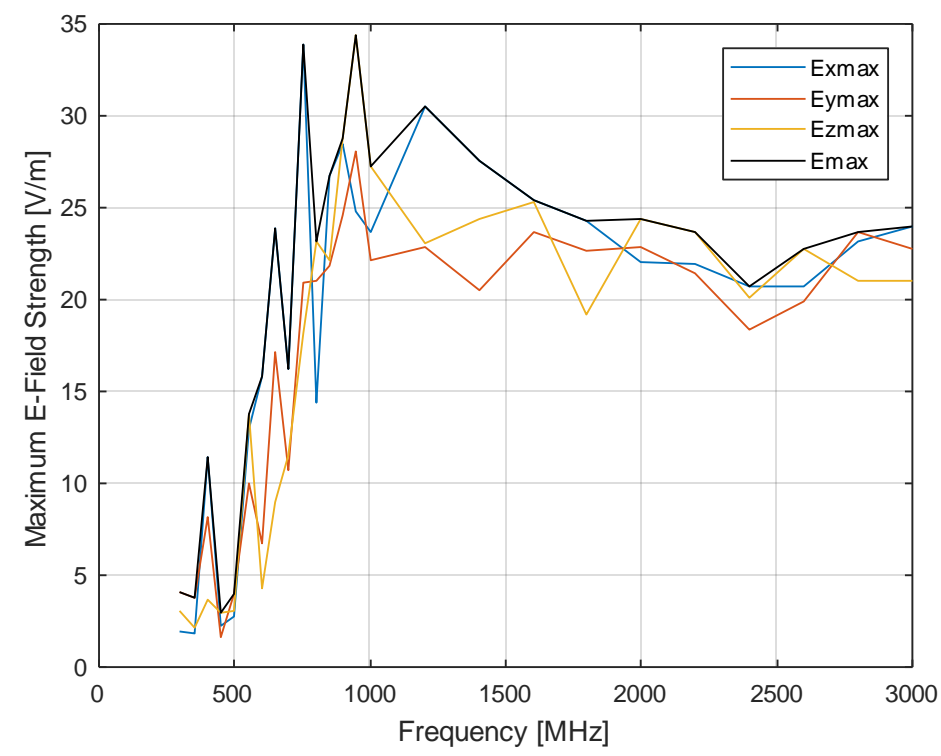

Figure 6.11 E-field maximum 3-axis component inside the VIRC

The field coupling into EUT P-B and EUT P-R has been plotted in Figure 6.12 and Figure 6.13. This is the E-field magnitude reading by the field probe inside the box. The transmit power (Pin) was set to $0-10 \mathrm{dBm}$ and delivered to the DRGH antenna from $300 \mathrm{MHz}$ to $3 \mathrm{GHz}$, as describe in Table 6.3.

In general, the box with a hole showed that there are many frequency points with good coupling of the field. Starting around $1 \mathrm{GHz}$, the probe started to capture some field inside the box, while the box with a tube indicating the similar behavior starting around $2 \mathrm{GHz}$. The reason is that a tube more likely became a shield for EM going in and out the box, particularly below $1.5 \mathrm{GHz}$. Increasing more than $2 \mathrm{GHz}$, it can be seen that both graphs have a relatively similar pattern with different E-field magnitude. 


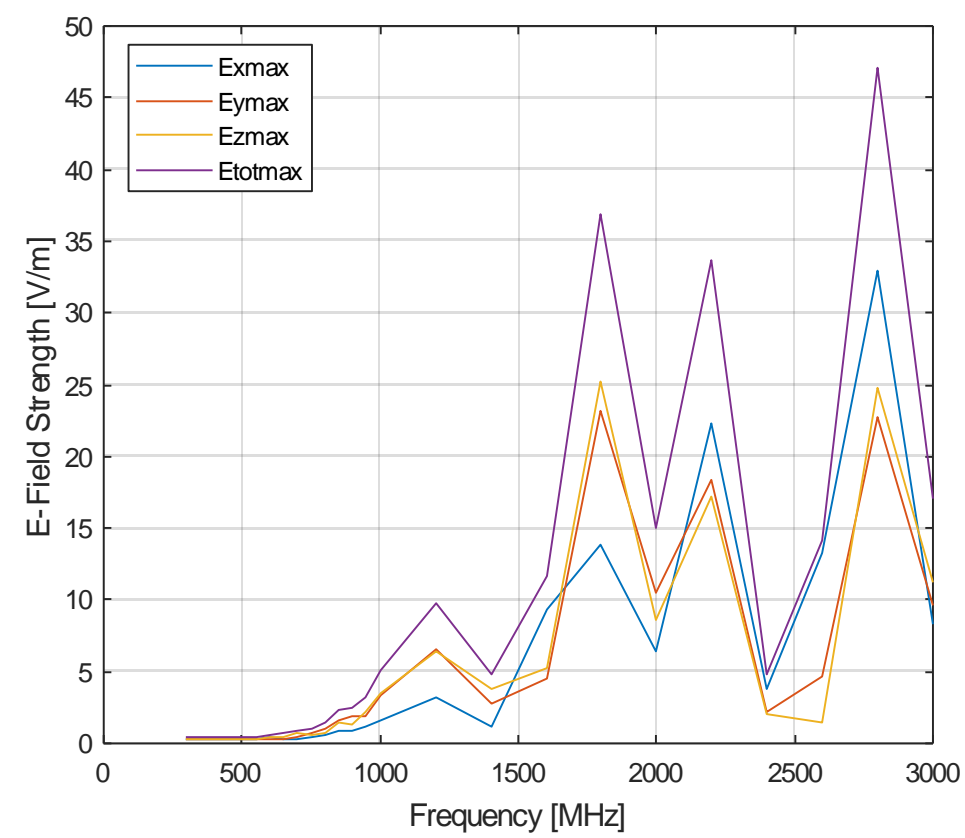

Figure 6.12 Maximum E-field for $x-y-z$ component and total E-field inside the EUT P-B

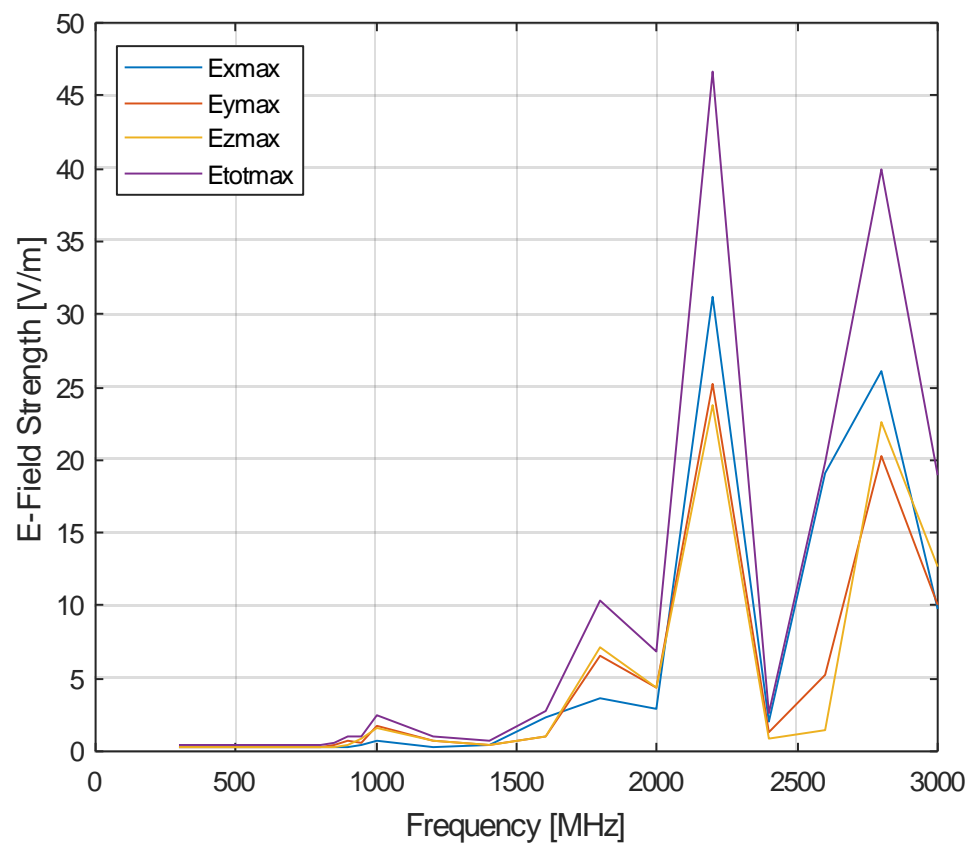

Figure 6.13 Maximum E-field for $x-y-z$ component and total E-field inside the EUT P-T 


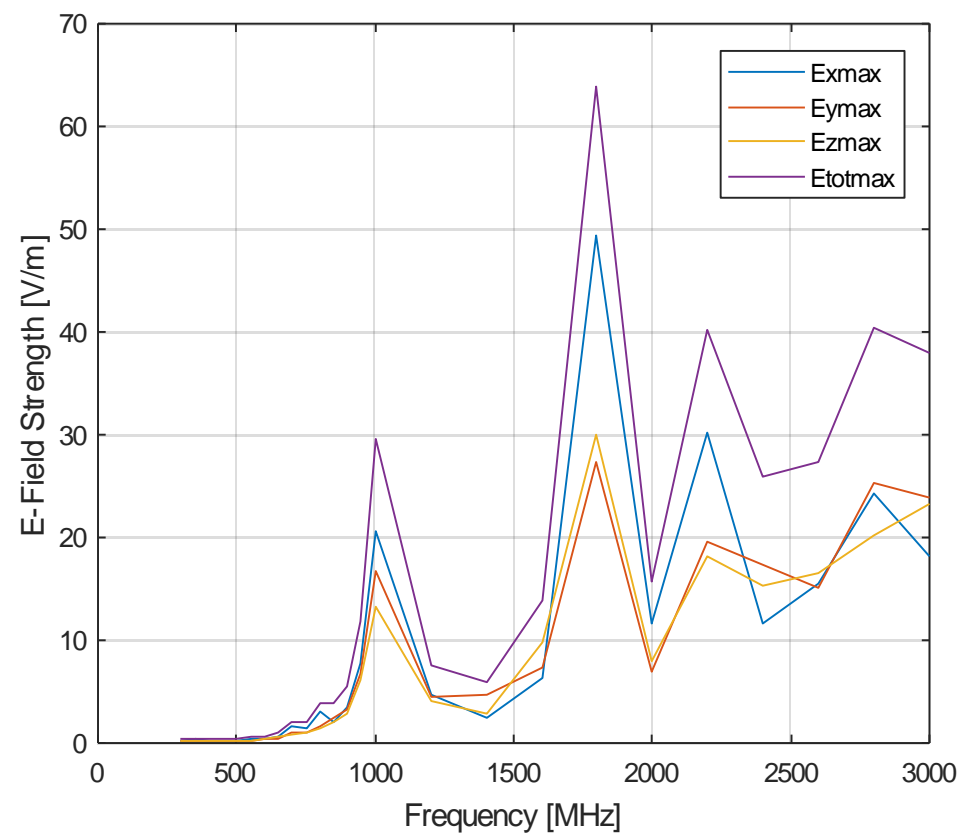

Figure 6.14 Maximum E-field for $x$-y-z component and total E-field inside EUT-R

Figure 6.14 shows the maximum E-field inside EUT P-R, the field in the higher frequency is obvious and flatter than the previous results inside the EUT-P-B and EUT-P-T. As expected, EUT-P-R has more holes and slots, so it is obvious that more outside fields from many angles are coupled into the box

\subsection{FAR vs VIRC Test Comparison}

In order to find a correlation between two different test techniques (FAR and VIRC) the box with random holes (EUT P-R) was used as the comparison example, as depicted in Figure 6.15.

In the VIRC, the devices were exposed to an omnidirectional un-polarized stochastic EM perturbation, while in FAR the devices were exposed to a directional perturbation. The failure field level corresponded to a deterministic field predetermined by a calibration or pre-calibration procedure. In this case, in FAR, the target test was $10 \mathrm{~V} / \mathrm{m}$. 


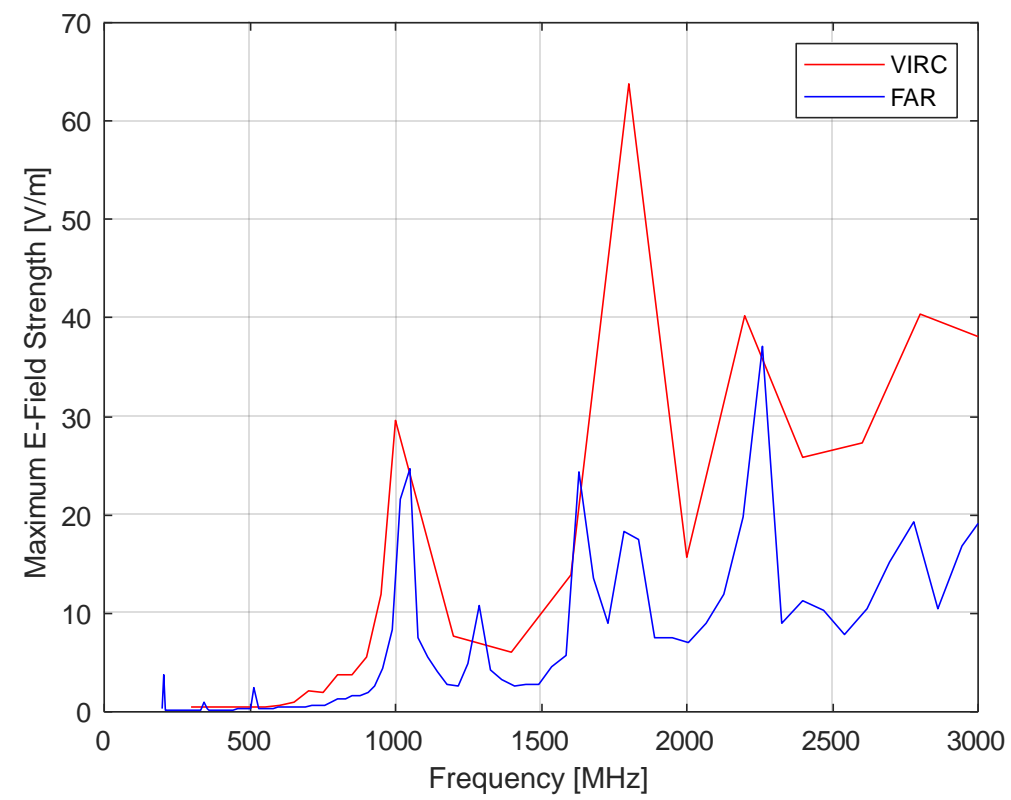

Figure 6.15 The maximum E-Field inside the box with random holes inside the FAR and VIRC

Despite having a different power input to the antenna as well as using different antennas for both the VIRC and FAR measurements, the graphs show that the line patterns are similar with some peaks approximately at the same frequency points. This curve also indicates that VIRC has the ability to demonstrate much less power needed, a more efficient measurement time (no need for EUT rotation), and comparable results to the conventional FAR technique.

\subsection{Conclusion}

Different methods for RS EMC testing were compared in this thesis. As an EUT, we used a fast and very sensitive E-field probe (EUT P) which we placed inside a box with a hole (EUT P-B), a tube (EUT P-T) and with random holes (EUT P-R). As RS test aims to investigate on how the EUT reacts to an electromagnetic field coming from outside, i.e. how the EUT is susceptible to an incident field, therefore this EUT is a perfect example, to detect fast and random E-field coming from all directions.

The correlation of AC and RC RS results were addressed in this study. The two testing approaches are clearly different in nature. The $\mathrm{AC}$ is strongly dependent on the radiation pattern of the EUT, while the omnidirectional RC testing is transparent to the radiation pattern. Consequently, a correlation between single direction tests in $\mathrm{AC}$ and $\mathrm{RC}$ testing is not possible without some test improvements. However, assuming that we have a linear system, we can adjust the power required in both 
cases to generate comparable E-field results. Additionally, by having more FAR data and thirty-six points in rotation increments, we can approximate the worst-case scenario by hitting the most susceptible part of the EUT. This, however, was not included in the standard RS test method! In other words, following the conventional RS methods using a FAR can result in under-testing an EUT and missing susceptibility problems. The RC or VIRC method is a potential and promising technique for RE as well as RS testing, particularly for generating high field strength with a low P2E. 


\section{Conclusions}

EMC testing has gained importance due to the technological improvements in modern life. Better test techniques are needed to cope with rapidly changing and new challenges. Enhanced EMC tests aim at shorter test times and cost-efficient test techniques, which resemble actual use conditions. This thesis investigated different test techniques for a better P2E ratio, in order to achieve high-field strength at a lower cost.

The first sub-research aimed to gain a better understanding of the conventional techniques inside anechoic chambers using different types of antennas to create high field strength. The investigation focused on and compared different antennas for generating high field strength with respect to the power required and the E-field produced, as well as the FU in the test area. The DRGH antenna showed a promising and optimum field with less power; however, when working in the lower frequency band, a larger antenna was desired. Therefore, going deeper into the antenna development utilized inside $\mathrm{AC}$ requires further research in order to achieve a better antenna design and test technique regarding the required power and FU.

In the second section, additional research was presented with different conventional RS EMC test techniques inside a SAC. The results revealed that large EUTs and vertical cables have a big impact on the E-field reading of probes.

In the next step, an empty RC and an empty VIRC was analyzed using a simultaneous multi-probe system. The RC with similar dimensions as the VIRC can be used from much higher frequencies. In other words, the VIRC operates at much lower frequencies compared to a conventional $\mathrm{RC}$ of the same size. The use of the multi-probe system also generated much more uncorrelated results than what can be obtained using a mode-stirred technique. It is also much faster than a mode-stirred technique. The FU with different stirrer shapes and the number of independent samples were investigated as well. In general it can be said that the bigger the stirrer, the better the results.

The next section compared EMC test techniques in different sites from an emissions perspective. Using dummy EUTs, ranging from simple to complex EUTs, a radiated field emission was carried out in different environments. Furthermore numerical 3D simulations were also done. The results revealed that the RC and VIRC were better at spotting the maximum RE from the EUT. This also proves that a basic correction factor to compare results obtained via various test techniques is 
nearly impossible; there will always be some uncertainty due to the test technique and type of EUT.

The objective of this study was to develop a test technique with a better P2E ratio to reduce costs. Therefore dummy EUTs were designed and built with very sensitive field probes inside. This emulated actual equipment over a broad frequency range. The RS tests were performed in a FAR, using the antenna technique, and in a VIRC. The experimental results found that the VIRC generated comparable results to the FAR, but had a much better P2E, i.e. is able to create a high field strength with less power. It was also shown that the worst case susceptibility is found by rotating the EUT, as then the susceptible part of the EUT could be hit. This is not covered by conventional RS standards using a FAR which can result in under-testing an EUT, and missing susceptibility problems. 


\section{Future Research and Potential Work}

The future research and potential work suggestions are listed below.

1. Antenna design and development for RS EMC application in AC, which could work at lower frequency, smaller, lighter, higher gain, requiring lower power and producing good FU.

2. Deeper investigation of the E-field behaviour and ergodicity inside RC and VIRC by applying a simultaneous multi-probe system measurement, as it delivers an extensive measurement data of 36 samples at the same frequency and time, by using 9 probes (positions) with 3 polarizations.

3. The comparison between test techniques is also another interesting topic to be researched in the future. A lot of previous research regarding correlation between various technique mostly ends up with large uncertainty and corrections due to test technique itself (equipment, calibration, test method, etc.) and EUT characteristic. However, based on this thesis and the concept of reciprocity, susceptibility tests with a real EUT is of interest for future research.

4. Continue the ongoing research to obtain a cost-efficient RS EMC technique in RC. Further research can focus on the RS test technique of real EUTs in FAR and RC. Additional research on the applicability of the antenna technique for complex and semi-enclosed and reverberant environment is recommended, as it is expected that EUTs with a directional pattern can be under-tested when using the antenna technique. Also, more in-depth behavioral analyses of the induced voltage or E-field coupled inside the EUT are needed. Some EUTs might react to the peak field strength, while others need a longer dwell time and might react to the average, or the demodulation.

5. And last but not least, a recommendation and suggestion of installing an RC in an existing shielded room to provide a cost-effective alternative to RS testing in Indonesia. This investigation is particularly relevant in an Indonesian environment where EMC awareness is increasing, but the cost involved in establishing new facilities to provide for these new environments is very high. The use of RCs could fulfill this requirement. 


\section{References}

[1] C. R. Paul, Introduction to Electromagnetic Compatibility. 2006.

[2] I. E. Commission, IEC 61000-4-3, Part-4: Testing and measurement techniques - Radiated, radio-frequency, electromagnetic field immunity test. 2006.

[3] D. of Defense, "MIL-STD-461F : DoD Interface Standard Requirements for the Control of Electromagnetic Interference Characteristics of Subsystems and," August, 1999.

[4] NATO Standard, AECTP-500 : NATO STANDARD ELECTROMAGNETIC ENVIRONMENTAL EFFECTS TESTS, January. 2016.

[5] D. Morgan, A Handbook for EMC Testing and Measurement. 2011.

[6] International Electrotechnical Commission, "CISPR 16-1, Part 1: Radio disturbance and immunity measuring apparatus," no. 918034377. 1999.

[7] M. Bäckström, O. Lundén, and P. S. Kildal, "Reverberation chambers for EMC susceptibility and emission analyses," Rev. Radio Sci., vol. 2002, no. January 2003, pp. 429-452, 1999.

[8] International Electrotechnical Commission, IEC 61000-4-21: Testing and measurement techniques - Reverberation chamber test methods Part 4-21, 2011th ed. IEC, 2011.

[9] F. Leferink, "High field strength in a large volume: The intrinsic reverberation chamber," in International Symposium on Electromagnetic Compatibility - EMC Europe, 1998.

[10] M. L. Crawford and G. H. Koepke, "Design, evaluation, and use of a reverberation chamber for performing electromagnetic susceptibility/Vulnerability Measurements." 1986.

[11] F. Leferink and D. J. G. Boerle, "High field strength in a large volume : the extended double ridged guide vs. the biconical and log-periodic antenna," in International Symposium on Elecromagnetic Compatibility, EMC Europe 1998, 1998, pp. 339-344.

[12] D. Mandaris and F. Leferink, "Simulation and measurement of log-periodic antenna and double ridged guide horn antenna for optimised field uniformity," in 2017 International Symposium on Electromagnetic Compatibility - EMC EUROPE 2017, EMC Europe 2017, 2017. 
[13] D. Mandaris, N. Moonen, J. Schuurmans, and F. Leferink, "Comparison of log-periodic, dual-stacked log-periodic, and horn antenna on the field uniformity and power efficiency from $80 \mathrm{MHz}$ to $1 \mathrm{GHz}$," in 2017 AsiaPacific International Symposium on Electromagnetic Compatibility, APEMC 2017, 2017.

[14] C. A. Balanis, Antenna Theory - Analysis and Design, vol. Third Edit. 2005.

[15] F. Leferink, "High field strength in a large volume: the balanced stripline TEM antenna," in International Symposium on Electromagnetic Compatibility, EMC Europe 1998, 1998, pp. 350-354.

[16] M. L. Crawford, "Generation of Standard EM Fields Using TEM Transmission Cells," IEEE Trans. Electromagn. Compat., vol. EMC-16, no. 4, pp. 1-7, 1974.

[17] IEC 61000-4-20, Electromagnetic compatibility (EMC) - Part 4-20: Testing and measurement techniques - Emission and immunity testing in transverse electromagnetic (TEM) waveguides, no. July. 2006.

[18] C. Bruns, "Three-Dimensional Simulation and Experimental Verification of a Reverberation Chamber," Swiss Federal Institute of Technology Zurich, 2005.

[19] D. A. Hill, "Electromagnetic Theory of Reverberation Chambers," NIST Techical Note 1506. 1998.

[20] R. Serra, "Introduction of Randomness in Deterministic, PhysicallyConsistent Descriptions of Verificatio, Reverberation Chambers and Experimental," POLITECNICO DI TORINO, 2010.

[21] F. Leferink, J.-C. Boudenot, and W. van Etten, "Experimental results obtained in the vibrating intrinsic reverberation chamber," IEEE Int. Symp. Electromagn. Compat. Symp. Rec. (Cat. No.00CH37016), vol. 2, pp. 639644, 2000.

[22] F. Leferink, "Using reverberation chambers for EM measurements," SoftCOM 2010 - Int. Conf. Software, Telecommun. Comput. Networks, pp. $1-5,2010$.

[23] P. Wilson, G. Koepke, J. Ladbury, and C. L. Holloway, "Emission and immunity standards: replacing field-at-a-distancelnmeasurements with totalradiated-power measurements," 2001 IEEE EMC Int. Symp. Symp. Rec. Int. Symp. Electromagn. Compat. (Cat. No.01CH37161), vol. 2, pp. 964-969, 2001.

[24] C. L. Holloway, H. A. Shah, R. J. Pirkl, W. F. Young, D. A. Hill, and J. 
Ladbury, "Reverberation chamber techniques for determining the radiation and total efficiency of antennas," IEEE Trans. Antennas Propag., vol. 60, no. 4, pp. 1758-1770, 2012.

[25] S. van de Beek, R. Vogt-Ardatjew, H. Schipper, and F. Leferink, "Vibrating Intrinsic Reverberation Chambers for shielding effectiveness measurements," IEEE Int. Symp. Electromagn. Compat., pp. 8-13, 2012.

[26] R. Serra et al., "Reverberation chambers a la carte: An overview of the different mode-stirring techniques," IEEE Electromagn. Compat. Mag., vol. 6, no. 1, pp. 63-78, 2017.

[27] R. Serra, "Reverberation chambers through the magnifying glass: An overview and classification of performance indicators," IEEE Electromagn. Compat. Mag., vol. 6, no. 2, pp. 76-88, 2017.

[28] D. Mandaris et al., "Comparison of active levelling and precalibrating/substitution method for radiated immunity testing of large equipment," in 2016 International Symposium on Electromagnetic Compatibility, 2016.

[29] Andrew S. Podgorski, "Dual Polarization BGF Emis Suscept Test Principles and Application," in Proceedings of International Symposium on EMC, 1996.

[30] F. B. J. Leferink, "Using reverberation chambers for EM measurements," SoftCOM 2010 - Int. Conf. Software, Telecommun. Comput. Networks, pp. $1-5,2010$.

[31] F. Leferink, "High Intensity Electromagnetic Field Generation using a Transportable Reverberation Chamber," in URSI General Assembly of the International Symposium, 2008.

[32] D. Mandaris, R. Vogt-Ardatjew, E. Suthau, and F. Leferink, "Simultaneous multi-probe measurements for rapid evaluation of reverberation chambers," 2018 IEEE Int. Symp. Electromagn. Compat. 2018 IEEE Asia-Pacific Symp. Electromagn. Compat. EMC/APEMC 2018, pp. 590-594, 2018.

[33] D. Mandaris, R. Vogt-Ardatjew, M. Zaher Mahfouz, E. Suthau, and F. Leferink, "Time Efficient Reverberation Chamber Performance Analysis Using Simultaneous Multiprobe Measurement Technique," IEEE Int. Symp. Electromagn. Compat., vol. 2018-Augus, pp. 689-693, 2018.

[34] V. Rodriguez, "Recent improvements to dual ridge waveguide horn antennas: The $200 \mathrm{MHz}$ to $2000 \mathrm{MHz}$ and $18 \mathrm{GHz}$ to $40 \mathrm{GHz}$ models," IEEE Int. Symp. Electromagn. Compat., pp. 24-27, 2009. 
[35] C. Bruns, P. Leuchtmann, and R. Vahldieck, "Analysis and simulation of a 1-18-GHz broadband double-ridged horn antenna," IEEE Trans. Electromagn. Compat., vol. 45, no. 1, pp. 55-60, 2003.

[36] M. Abbas-Azimi, F. Arazm, and J. Rashed-Mohassel, "Design of a new broadband EMC double ridged guide horn antenna," Eur. Sp. Agency, (Special Publ. ESA SP, vol. 626 SP, no. November, 2006.

[37] W. Liu and X. Xi, "Design and simulation of TEM double ridge guide horn antenna," 2007 8th Int. Conf. Electron. Meas. Instruments, ICEMI, no. November, pp. 1703-1706, 2007.

[38] M. J. Windler and S. Urbanski, "A Radiated Immunity Uniform Field Over a Ground Plane," vol. 000, pp. 669-673, 2003.

[39] A. S. Podgorski and J. Baran, "New concept of emission and susceptibility testing," IEEE 1997, EMC, Austin Style. IEEE 1997 Int. Symp. Electromagn. Compat. Symp. Rec. (Cat. No.97CH36113), no. September 1997, pp. 497499, 1997.

[40] Y.-F. Chau, Z.-H. Jiang, H.-Y. Li, G.-M. Lin, F.-L. Wu, and W.-H. Lin, “A Proposed method for Quantifying uncertainty in RF immunity testing due to EUT presence," Prog. Electromagn. Res. B, Vol. 28, 183-199, 2011, vol. 28, no. January, pp. 183-199, 2011.

[41] B. Audone and I. Marziali, "Repeatability and Reproducibility of Radiated Immunity Tests," in International Symposium on Electromagnatic Compatibility - EMC Europe, 2011, no. 1, pp. 394-399.

[42] R\&S, "Manual Specification ® HL046E High Gain Dual Stacked Log Periodic Antenna." pp. 2017-2018, 2018.

[43] T. B.V, THALES Manual Specification of Ext-DRGH Antenna. 1998.

[44] R. Carrel, "The Design of Log-Periodic Dipole Antennas," in IRE national Convention, 1958, pp. 61-75.

[45] European Commission, NATO STAGNAG 4370 AECTP 501, Edition E Test Method, NRSO2 - Radiated Susceptibility, Electric Field $50 \mathrm{kHz}$ to $40 \mathrm{GHz}$. 2016.

[46] MIL-STD-461G, "Requirements for the Control of Electromagnetic Interference Characteristics of Subsystems and Equipment," Measurement, no. March, pp. MIL-STD, 2015.

[47] MIL-STD-461, Electromagnetic Interference Characteristics Requirements for Equipment, vol. 85498, no. June. 2004, pp. 1-16. 
[48] D. S. 59-411, ELECTROMAGNETIC COMPATIBILITY PART 4: LARGE EQUIPMENT TESTING, vol. 41, no. 3. 1996.

[49] RTCA/DO-160, "Environmental Conditions and Test Procedures for Airborne Equipment.” 2011.

[50] I. E. Commission, "IEC 803-1: Electromagnetic Compatibility - Generic Immunity Standrad, Part 1 : Residential, commercial and light industry," no. January. 1992.

[51] The European Parliament and the Council of the European Union, "Directive 89/336/EEC relating to Electromagnetic Compatability," Off. J. Eur. Communities, vol. L 139/19, no. 23.05.1989, pp. 1-8, 1989.

[52] J. D. P. Jr., "ELECTROMAGNETIC COMPATIBILITY (EMC) REQUIREMENTS FOR MILITARY AND COMMERCIAL EQUIPMENT," Naval Postgraduate School, 2009.

[53] European Commission, EMC Directive 2014-30-EU, vol. 2014, no. February. 2014, pp. 79-106.

[54] S. Çakır, O. Şen, M. Çınar, A. Ayaydın, M. Çetintaş, and F. Üstüner, "Effects of Sensor Positions on Military Radiated Susceptibility Tests," pp. 584-585, 2014.

[55] F. B. J. Leferink, "Preventing Electromagnetic Interference from Integrated Circuits and Printed Circuit Boards using Computer Simulation.” 1992.

[56] F. Leferink, "Effect conducting plane nearby," PATO EMC Course - Univ. Eindhoven, 2015.

[57] D. A. Hill, Electromagnetic Fields in Cavities, IEEE Press., vol. 43, no. 08. IEEE Press Series on Electromagnetic Wave Theory, 2009.

[58] D. A. Hill, "Electromagnetic theory of reverberation chambers," NIST Technical Note 1506, 1998.

[59] J. Ladbury, G. Koepke, and D. Camell, "Evaluation of the NASA Langley Research Center Mode-Stirred Chamber Facility," NIST Tehcnical Note 1508, 1999.

[60] R. Vogt-ardatjew, Electromagnetic fields in reverberant environments. Ph.D Theses, University of Twente - the Netherlands, 2017.

[61] G. Andrieu, "Calibration of Reverberation Chambers from S21 Measurements," in IEEE International Symposium on Electromagnetic Compatibility, 2017, pp. 675-680. 
[62] F. Leferink, "Fast, Broadband, and High-Dynamic Range 3-D Field Strength Probe," IEEE Trans. Electromagn. Compat., vol. 55, no. 6, pp. 1015-1021, 2013.

[63] R. Vogt-Ardatjew, R. Serra, L. G. Hiltz, and F. Leferink, "Response time of electromagnetic field strength probes," 2013 Asia-Pacific Symp. Electromagn. Compat. APEMC 2013, pp. 1-6, 2015.

[64] Y. Huang and J. . Zhang, "Field Measurement inside A Reverberation Chamber," in IEEE International Symposium on Antenna and Propagation, 2004.

[65] R. Vogt-Ardatjew, R. Serra, L. G. Hiltz, and F. Leferink, "Response time of electromagnetic field strength probes," 2013 Asia-Pacific Symp. Electromagn. Compat. APEMC 2013, 2015.

[66] L. Gmbh, “Lumiloop Laser-powered sensor systems ; User manual.” 2018.

[67] V. Rajamani, C. F. Bunting, and J. C. West, "Stirred-mode operation of reverberation chambers for EMC testing," IEEE Trans. Instrum. Meas., vol. 61, no. 10, pp. 2759-2764, 2012.

[68] G. Andrieu, N. Ticaud, F. Lescoat, and L. Trougnou, "Fast and Accurate Assessment of the 'Well Stirred Condition' of a Reverberation Chamber From S1 1 Measurements," IEEE Trans. Electromagn. Compat., vol. PP, pp. $1-9,2018$.

[69] N. K. Kouveliotis, P. T. Trakadas, and C. N. Capsalis, "Reverberation Chamber," Prog. Electromagn. Res. PIER 39, pp. 47-59, 2003.

[70] J. Aditia Nur Bakti, Park and S. Park, "Design and Measurement of The KRISS Reverberation Chamber 1," in 2016 URSI Asia-Paciifc Radio Science Conference, 2016, no. 1, pp. 1765-1768.

[71] R. Alizada, Characterization of Vibrating Intrinsic Reverberation Chamber and Comparison with Classical Reverberation Chamber for Antenna Efficiency Measurements. Master Thesis, University of Twente - the Netherlands, 2018.

[72] F. Leferink, D. J. G. Boerle, and F. A. G. Sogtoen, "In-situ EMI Measurements Using a Vibrating Intrinsic Reverberation Chamber," in Internatioanl Sympoisium on EMC Europe, 2000.

[73] F. Leferink, "In-situ high field strength testing using a transportable reverberation chamber," 2008 Asia-Pacific Symp. Electromagn. Compat. 19th Int. Zurich Symp. Electromagn. Compat., no. May, pp. 379-382, 2008. 
[74] R. Vogt-Ardatjew, S. Van De Beek, and F. Leferink, "Influence of reverberation chamber loading on extreme field strength," IEEE Int. Symp. Electromagn. Compat., vol. 2014-Decem, pp. 685-688, 2014.

[75] R. Vogt-Ardatjew, S. Van De Beek, and F. Leferink, "Experimental extreme field strength investigation in reverberant enclosures," IEEE Int. Symp. Electromagn. Compat., pp. 332-336, 2014.

[76] R. Serra and F. Leferink, "Statistical measurements of fast changing electromagnetic fields," in International Symposium on Elecromagnetic Compatibility - EMC Europe, 2010.

[77] G. Andrieu, "Calibration of reverberation chambers from S21measurements," IEEE Int. Symp. Electromagn. Compat., pp. 675-680, 2017.

[78] G. Andrieu, "Calibration of Reverberation Chambers From S11 Measurements," in IEEE International Symposium on Electromagnetic Compatibility, 2017, pp. 1-6.

[79] A. Ubin, R. Vogt-Ardatjew, F. Leferink, M. Z. Mohd Jenu, and S. Van De Beek, "Statistical analysis of three different stirrer designs in a reverberation chamber," 2015 Asia-Pacific Int. Symp. Electromagn. Compat. APEMC 2015, pp. 604-607, 2015.

[80] S. Pfennig, "A General Method for Determining the Independent Stirrer Positions in Reverberation Chambers: Adjusting the Correlation Threshold," IEEE Trans. Electromagn. Compat., vol. 58, no. 4, pp. 1252-1258, 2016.

[81] S. Pfennig, "An evaluation of the independent stirrer positions in the Dresden Reverberation Chamber based on field homogeneity within a defined test volume," IEEE Int. Symp. Electromagn. Compat., vol. 2015-Septm, pp. 396401, 2015.

[82] S. Pfennig, H. G. Krauth, and H. Georgkrauthaeusertu-dresdende, "Comparison of Methods for Determining the Number of Independent Stirrer Positions in Reverberation Chambers," in IEEE International Symposium on Electromagnetic Compatibility, 2013, pp. 431-436.

[83] F. Leferink, G. Hilverda, D. G. Boerle, and W. van Etten, "Radiated electromagnetic fields of actual devices measured in different test environments," Int. Symp. Elecromagnetic Compat. - EMC Eur., pp. 558$563,2003$.

[84] G. Hilverda, F. Leferink, D. G. Boerle, and W. van Etten, "Correlation between Simulated and Measured Radiated Electromagnetic Fields in Different Test Environmnets," in International Symposium on 
Electromagnetic Compatibility - EMC Europe, 2002.

[85] P. Wilson, "Emission and immunity testing: test object electrical size and its implication," in Internartional Symposium on Electromagnetic Compatibility, EMC Europe, 2004, pp. 349-352.

[86] P. Wilson, C. L. Holloway, and G. Koepke, "A Review of Dipole Models for Correlating Emission Measurements made at Various EMC Test Facilities," vol. 2, no. 2, pp. 898-901, 2004.

[87] R. De Leo and V. M. Primiani, "Radiated immunity tests: Reverberation chamber vs. anechoic chamber results," Conf. Rec. - IEEE Instrum. Meas. Technol. Conf., vol. 1, no. May, pp. 17-19, 2005.

[88] G. J. Freyer and M. G. Backstrom, "Comparison of anechoic and reverberation chamber coupling data as a function of directivity pattern," in Internatioanl Sympoisium on EMC Europe, 2000, pp. 615-620.

[89] G. J. Freyer and M. G. Backstrom, "Comparison of anechoic and reverberation chamber coupling data as a function of directivity pattern. II," in Internatioanl Sympoisium on EMC Europe, 2001, pp. 286-291.

[90] L. Jansson and M. Bäckström, "Directivity of equipment and its effect on testing in mode-stirred and anechoic chamber," IEEE Int. Symp. Electromagn. Compat., vol. 1, pp. 17-22, 1999.

[91] H. Streitwolf, R. Heinrich, H. G. Behnke, L. Dallwitz, and U. Karsten, "Comparison of radiated immunity tests in different EMC test facilities," Proc. 18th Int. Zurich Symp. Electromagn. Compat. EMC, pp. 229-232, 2007.

[92] B. Menssen, D. Hamann, and H. Garbe, "Predicting the maximum radiated electric field strength from unintentional radiators," 2015 Asia-Pacific Int. Symp. Electromagn. Compat. APEMC 2015, pp. 456-459, 2015.

[93] B. Menssen, F. Burghardt, and H. Garbe, "Simulation Objects to be used as Unintentional Radiators," in 2014 Asia-Pacific International Symposium on Electromagnetic Compatibility - APEMC, 2014, pp. 37-40.

[94] B. Menssen, D. Hamann, and H. Garbe, "Extension of the emission measurements for alternative test methods above $1 \mathrm{GHz}$ for unintentional electromagnetic radiators," IEEE Int. Symp. Electromagn. Compat., vol. 2015-Septm, pp. 444-449, 2015.

[95] X. Wang and R. Vick, "Determination of radiated emissions of an electrically large EUT: Simulation and experiment," IEEE Electromagn. Compat. Mag., vol. 6, no. 2, pp. 32-35, 2017. 
[96] D. Hu, G. Wei, X. Pan, and K. Ji, "Investigation of the Radiation Immunity Testing Method in Reverberation Chambers," IEEE Trans. Electromagn. Compat., vol. 59, no. 6, pp. 1791-1797, 2017. 


\section{List of Publications}

1. D. Mandaris et al., "Different Test Site Analysis of Radiated Field Measurements of a Complex EUT", in International Symposium on Electromagnetic Compatibility, EMC Europe 2019, 2019.

2. D. Mandaris, R. Vogt-Ardatjew, M. Zaher Mahfouz, E. Suthau, and F. Leferink, "Time Efficient Reverberation Chamber Performance Analysis Using Simultaneous Multiprobe Measurement Technique," IEEE Int. Symp. Electromagn. Compat., EMC Europe 2018, vol. 2018-Augus, pp. 689-693, 2018.

3. D. Mandaris, R. Vogt-Ardatjew, E. Suthau, and F. Leferink, "Simultaneous multi-probe measurements for rapid evaluation of reverberation chambers," 2018 IEEE Int. Symp. Electromagn. Compat. 2018 IEEE Asia-Pacific Symp. Electromagn. Compat. EMC/APEMC 2018, pp. 590-594, 2018.

4. D. Mandaris, N. Moonen, J. Schuurmans, and F. Leferink, "Comparison of logperiodic, dual-stacked log-periodic, and horn antenna on the field uniformity and power efficiency from $80 \mathrm{MHz}$ to $1 \mathrm{GHz}$," in 2017 Asia-Pacific International Symposium on Electromagnetic Compatibility, APEMC 2017, 2017.

5. D. Mandaris and F. Leferink, "Simulation and measurement of log-periodic antenna and double ridged guide horn antenna for optimised field uniformity," in International Symposium on Electromagnetic Compatibility - EMC EUROPE 2017, EMC Europe 2017, 2017.

6. D. Mandaris et al., "Comparison of active levelling and precalibrating/substitution method for radiated immunity testing of large equipment," in International Symposium on Electromagnetic Compatibility, EMC Europe 2016, 2016.

7. D. Mandaris et al., "Validation of a Fully Anechoic Chamber", in 2016 AsiaPacific International Symposium on Electromagnetic Compatibility, APEMC 2016, 2016.

8. D. Mandaris, F. Buesink, F. Leferink, A. Munir, "Design and Realization of Planar Reflector Based on Artificial Magnetic Conductor at S-Band Frequency " , 2016 Asia-Pacific International Symposium on Electromagnetic Compatibility, APEMC 2016, 2016. 
9. E. Tas, ..., D. Mandaris, et al., "Proficiency Testing for Conducted Immunity with a new Round Robin Test Device", in International Symposium on Electromagnetic Compatibility, EMC Europe 2016, 2016.

10. W. Ardiatna, D. Mandaris, S. W. Hidayat, A. Nurbakti, F. Leferink, "EMI Risk Analysis via Dedicated Evaluation of the Susceptibility of Medical Devices", in IEEE Int. Symp. Electromagn. Compat. 2018 IEEE Asia-Pacific Symp. Electromagn. Compat. EMC/APEMC 2018, 2018.

11. H. Hardiles, ..., D. Mandaris, et al., "Implementation of IEC 61000-4-2 standard testing under tropical humidity for recommendation to Amendment of International Standards", in International Symposium on Electromagnetic Compatibility, EMC Europe 2018, 2018. 


\section{List of Abbreviations}

4G

$5 \mathrm{G}$

$\mathrm{AC}$

AECTP

$\mathrm{AF}$

AM

BFG

CEN

CISPR

CLT

CVF

DRGH

DUT

EC

EMC

EME

EMI

EMRP

EU

EUT

Ext-DRGH
Fourth Generation (Technology)

Fifth Generation (Technology)

Anechoic Chamber

Allied Environmental Conditions and Tests

Publication (Standard)

Antenna Factor

Amplitude Modulation

Dual Polarized Broadband Field Generator

Comité Européen de Normalisation

International Special Committee for Radio Protection

Central Limit Theorem

Chamber Validation Factor

Double Ridged Guide Horn

Device Under Test

European Commission

Electromagnetic Compatibility

Electromagnetic Environments

Electromagnetic Interference

European Metrology Research Programme

European Union

Equipment Under Test

Extended Double Ridged Guide Horn 


\begin{tabular}{|c|c|}
\hline FAR & Fully Anechoic Room \\
\hline FDTD & Finite Difference Time Domain \\
\hline FM & Frequency Modulation \\
\hline FU & Field Uniformity \\
\hline GTEM & GigaHertz Transverse Electromagnetic \\
\hline $\mathrm{HF}$ & High Frequency \\
\hline IEC & International Electro-technical Commission \\
\hline LOS & Line of Sight \\
\hline LPDA & Log-Periodic Dipole Array \\
\hline MIL-STD & Military Standards \\
\hline MoM & Method of Moment \\
\hline NATO & North Atlantic Treaty Organization \\
\hline NBS & National Bureau of Standard \\
\hline NRS02 & $\begin{array}{l}\text { Radiated Susceptibility, Electric Field, } 50 \mathrm{kHz} \text { to } 40 \\
\mathrm{GHz}\end{array}$ \\
\hline NSA & Normalized Site Attenuation \\
\hline OATS & Open Area Test Site \\
\hline OIML & International Organization of Legal Metrology \\
\hline PA & Power Amplifier \\
\hline $\mathrm{P} 2 \mathrm{E}$ & Power-to-Field-Strength \\
\hline PCC & Pearson Correlation Coefficient PCC \\
\hline PDF & Probability Density Function \\
\hline PSG & Programmable Signal Generator \\
\hline QAS & Quasi Active Shielding \\
\hline $\mathrm{RC}$ & Reverberation Chamber \\
\hline
\end{tabular}




$\begin{array}{ll}\text { RE } & \text { Radiated Emission } \\ \text { RF } & \text { Radio Frequency } \\ \text { RI } & \text { Radiated Immunity } \\ \text { RS } & \text { Radiated Susceptibility } \\ \text { RTCA } & \text { Radio Technical Commission for Aeronautics } \\ \text { sVSWR } & \text { Site-Voltage Standing Wave Ratio } \\ \text { SAC } & \text { Semi Anechoic Chamber } \\ \text { SG } & \text { Signal Generator } \\ \text { SHF } & \text { Super-High Frequency } \\ \text { SPA } & \text { Spectrum Analyzer } \\ \text { STANAG } & \text { NATO Standardization Agreement } \\ \text { TEM } & \text { Transverse Electromagnetic } \\ \text { TIRC } & \text { Tunable Intrinsic Reverberation Chamber } \\ \text { TV } & \text { Television } \\ \text { UFA } & \text { Uniform Field Area } \\ \text { VIRC } & \text { Vibrating Intrinsic Reverberation Chamber } \\ \text { VSWR } & \text { Voltage Standing Wave Ratio } \\ \text { WSN } & \text { Wireless Sensor Networks }\end{array}$




\section{List of Figures}

Figure 1.1 Generating high field strength (a) inside a fully anechoic chamber and (b) inside a reverberation chamber .................................................... 3

Figure 1.2 An example of a diagram in generating high E-field strength ..............3

Figure 1.3 Side view of GTEM working volume points [17] .............................6

Figure 2.1 The radiation pattern of a double LPDA (HL 046) at $500 \mathrm{MHz}$ [42] 13

Figure 2.2 Extended double-ridged guide horn (Ext-DRGH) antenna [43] ........14

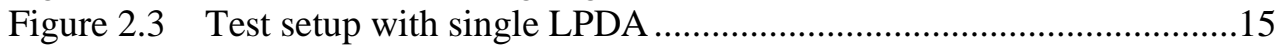

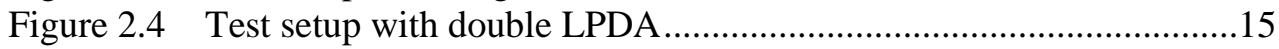

Figure 2.5 Test setup with Ext-DRGH.......................................................16

Figure 2.6 Power required for $10 \mathrm{~V} / \mathrm{m}$, biconical, single LPDA, double LPDA (HL046) and Ext-DRGH, horizontal and vertical polarization, at $3 \mathrm{~m}$

Figure 2.7 FU generated by single LPDA, double LPDA and Ext-DRGH Antenna, horizontal and vertical polarization, $3 \mathrm{~m}$.........................................18

Figure 2.8 Measured field strength distribution, biconical and single LPDA, double LPDA and Ext-DRGH antenna, horizontal polarization........19

Figure 2.9 Calculated E-field strength, forward power and theoretical/manufactured gain of single LPDA, double LPDA, ExtDRGH antenna, horizontal and vertical polarization. 20

Figure 2.10 Measured field strength generated by biconical, single LPDA, double LPDA and Ext-DRGH antennas at constant power $(100 \mathrm{~W})$, vertical

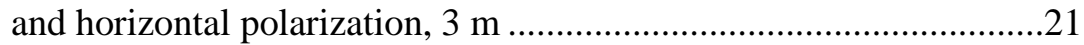

Figure 2.11 The schematic diagram of LPDA [14] ..........................................22

Figure 2.12 Single LPDA antenna (MWS model) for $150 \mathrm{MHz}-1 \mathrm{GHz}$............24

Figure 2.13 Double LPDA antenna (MWS model) for $80 \mathrm{MHz}-1 \mathrm{GHz}$............24

Figure 2.14 Model of E-field measurement at a distance of $3 \mathrm{~m}$ in CST ..............25

Figure 2.15 The Ext-DRGH antenna (MWS model) for $80 \mathrm{MHz}-1 \mathrm{GHz} \ldots \ldots \ldots . .25$

Figure 2.16 Simulated $S_{11}$ of single LPDA $150 \mathrm{MHz}-1 \mathrm{GHz} \ldots \ldots \ldots \ldots \ldots \ldots \ldots \ldots . . .26$

Figure 2.17 The radiation pattern of the LPDA at $300 \mathrm{MHz}$..............................26

Figure 2.18 The polar plot of radiation pattern for the LPDA at $1 \mathrm{GHz}$.............27

Figure 2.19 Simulated E-field probe value of a single LPDA, 16 points, at $3 \mathrm{~m} .27$

Figure 2.20 The typical gain of a double LPDA $0.8-1 \mathrm{GHz}$ (manual specification)

Figure 2.21 Simulated Gain of double LPDA $80 \mathrm{MHz}-1 \mathrm{GHz} \ldots \ldots \ldots \ldots \ldots \ldots \ldots \ldots . . .28$

Figure 2.22 Simulation result; $S_{11}$-parameter of double LPDA ...........................29

Figure 2.23 Simulated E-field distribution of double LPDA, 16 points at $3 \mathrm{~m}$....29

Figure 2.24 Simulated FU of E-field for single LPDA and double LPDA ............30

Figure 2.25 Simulated result: S-parameter of Ext-DRGH antenna .........................30

Figure 2.26 Simulation result: Gain of Ext-DRGH antenna ...............................31 
Figure 2.27 Simulated E-field distribution of Ext-DRGH antenna, 16 points at $3 \mathrm{~m}$

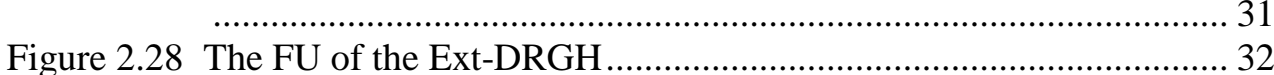

Figure 3.1 QAS effect due to nearby conducting plane [56] ............................ 35

Figure 3.2 Coupling caused by induced current on the large metal plane.......... 36

Figure 3.3 Reduction of E-field strength as a function of frequency ................. 36

Figure 3.4 Effect of the field sensor on top of EUT ……................................. 37

Figure 3.5 Test setup with vertical grounded wire measurement ........................ 38

Figure 3.6 Measured electric field intensity at the vertical grounded wire ........ 39

Figure 3.7 Simulated electric field intensity at the vertical grounded wire........ 39

Figure 3.8 Electric field intensity along the grounded wire ............................. 40

Figure 3.9 (a) AECTP 500 NRS02 test equipment configuration (b) Pre-

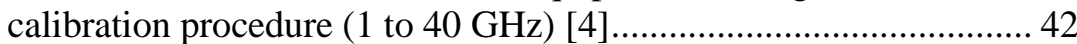

Figure 3.10 Dummy EUT (inside view and side view) .................................... 45

Figure 3.11 Dummy EUT (front view)............................................................. 45

Figure 3.12 Measurement at $3 \mathrm{~m}$ (a) free space (b) with dummy EUT ................ 46

Figure 3.13 Pre-calibration FU test method .................................................... 47

Figure 3.14 Active leveling test method............................................................ 47

Figure 3.15 Test setup for active leveling method (INTA) .................................. 48

Figure 3.16 Comparison of RS test methods at $3 \mathrm{~m}$ with the standard method (precalibration) at $3 \mathrm{~m}$ (with large EUTs) (a) E-field calibration, (b) forward power, (c) E-field outside EUT, (d) induced voltage (e) normalized induced voltage ............................................................ 51

Figure 3.17 External E-field @ 30 V/m for different sized EUTs, horizontal

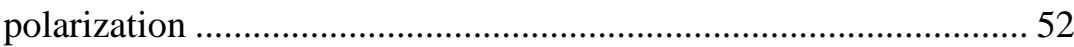

Figure 3.18 External E-Field @ $30 \mathrm{~V} / \mathrm{m}$ for different size of EUT, vertical

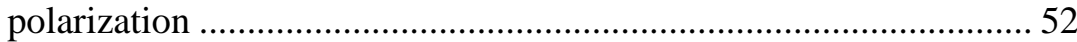

Figure 3.19 Input power antenna for leveling for different EUTs........................ 53

Figure 3.20 The E-field reading, antenna input power and susceptibility level for $100 \mathrm{~V} / \mathrm{m}$ for a medium-size EUT .................................................... 54

Figure 3.21 The E-field reading, antenna input power, susceptibility level for 200

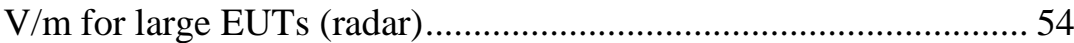

Figure 4.1 Three axis(x-y-z) small antennas inside field probe [64]................. 60

Figure 4.2 Schematic diagram of multi-probe system on classical RC / VIRC .61

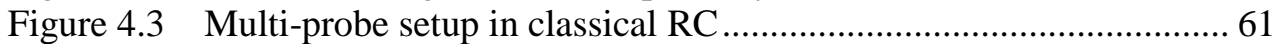

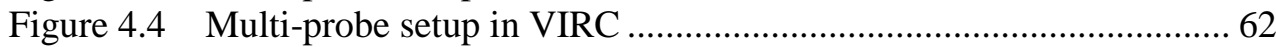

Figure 4.5 Field behavior over time inside classical RC .....................................63

Figure 4.6 Field behavior over time inside VIRC ...........................................63

Figure 4.7 Normalized field strength deviation to the mean at 9 positions, classical

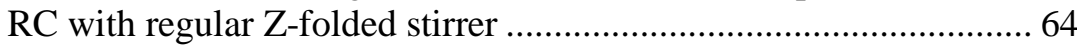

Figure 4.8 Normalized field strength deviation to the mean at 9 positions, classical

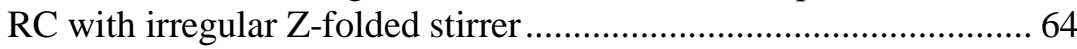


Figure 4.9 Normalized field strength deviation to the mean at 9 positions, VIRC

Figure 4.10 Small classical RC, dimension $1.5 \mathrm{~m} \times 1.3 \mathrm{~m} \times 1 \mathrm{~m}$, the motor is connected to the stirrer inside the RC

Figure 4.11 Three different shapes of stirrers. Stirrer 1 (irregular Z-folded) in the middle, stirrer 2 (flat panel) on the left side, stirrer 3 (asymmetrical irregular folded) on the right side .68

Figure 4.12 Test setup of nine multi-probe system in classical RC ....................69

Figure 4.13 FU inside RC with stirrer 1 (irregular Z-folded) ..............................70

Figure 4.14 FU inside RC with stirrer 2 (flat panel) .........................................70

Figure 4.15 FU inside RC with stirrer 3 (asymmetric irregular folded)................71

Figure 4.16 Number of independent samples for three different stirrers based on standard method [8]

Figure 4.17 Number of independent samples for three different stirrers with general

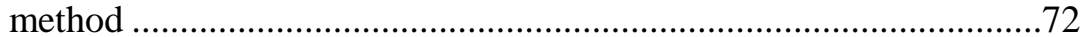

Figure 5.1 The monopole antenna model in CST (a) and radiation pattern at (b)

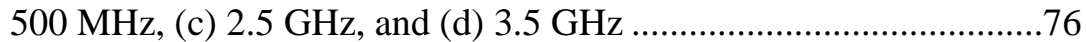

Figure 5.2 The coefficient reflection of monopole antenna ...............................77

Figure 5.3 (a) The box with hole model and radiation pattern at (b) $1 \mathrm{GHz}$, (c) 2.5

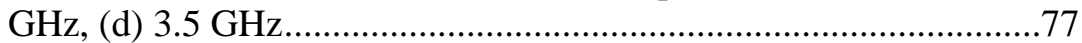

Figure 5.4 (a) The box with tube model and radiation pattern at (b) $500 \mathrm{MHz}$, (c)

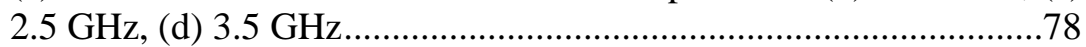

Figure 5.5 (a) The box with random holes model and radiation pattern at (b) 500

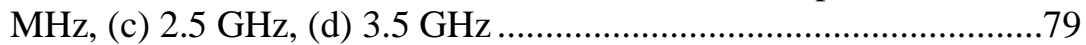

Figure 5.6 The simulated E-field results of the EUTs.......................................8

Figure 5.7 (a) The small LPDA and (b) the monopole antenna ..........................81

Figure 5.8 Measurement setup diagram inside FAR [82] ................................82

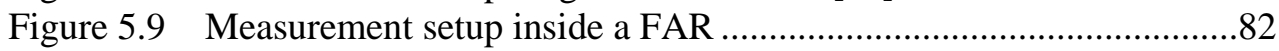

Figure 5.10 Measurement setup diagram inside SAC [82] .................................83

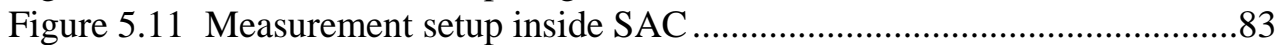

Figure 5.12 Measurement diagram inside the classical RC ….............................85

Figure 5.13 Measurement setup inside the classical RCs ..................................85

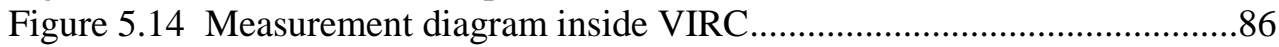

Figure 5.15 Measurement setup inside VIRC …………..................................86

Figure 5.16 Simulation and measurement result in FAR: monopole antenna.......88

Figure 5.17 Comparison of simulation and FAR: Box with hole ........................89

Figure 5.18 Comparison of simulation and FAR: Box with tube .........................90

Figure 5.19 Comparison of simulation and FAR : Random box..........................90

Figure 5.20 Simulated and measured E-field strength of a monopole antenna at different test sites (FAR, SAC, RC, VIRC)

Figure 5.21 Simulated and measured E-field strength of a box with a hole at different test sites (FAR, SAC, RC, VIRC) 
Figure 5.22 Simulated and measured E-field strength of a box with tube at different test sites (FAR, SAC, RC, VIRC)....

Figure 5.23 Simulated and measured E-field strength of a box with random holes at different test sites (FAR, SAC, RC, VIRC) …………................... 93

Figure 5.24 The E-field strength of monopole in the RC and VIRC ................... 94

Figure 5.25 The E-field strength inside the box with hole in the RC and VIRC using different reference antenna.......................................................... 95

Figure 5.26 The E-field strength inside the box with tube in the RC and VIRC using different reference antenna............................................................ 95

Figure 5.27 The E-field strength inside the box with random holes in the RC and VIRC using different reference antenna ........................................ 96

Figure 6.1 The E-field pre-calibration measurement inside the FAR using E-field targeted as EUT P at $3 \mathrm{~V} / \mathrm{m}$ and $10 \mathrm{~V} / \mathrm{m}$....................................... 100

Figure 6.2 RS test setup inside FAR, E-field inside the box ........................... 100

Figure 6.3 Power required for pre-calibration 10 V/m E-field targeted ........... 101

Figure 6.4 E-field received by EUT P (pre-calibration targeted E-field, $10 \mathrm{~V} / \mathrm{m}$ ), (a) EUT P-B and (b) EUT P-T, (c) EUT P-R with $10^{\circ}$ rotation increment for EUT P, EUT P-T and $45^{\circ}$ for EUT P-R................... 102

Figure 6.5 Comparison of maximum E-field received by the probe inside the box in EUT P-B, EUT P-T and EUT P-R. Targeted field, $10 \mathrm{~V} / \mathrm{m}$ at EUT P 103

Figure 6.6 E-field polar plot based on azimuth rotation, $10^{0}$ step at X-Y plane for EUT P-T at $200 \mathrm{MHz}$ and $500 \mathrm{MHz}$ 104

Figure 6.7 E-field polar plot based on azimuth rotation at X-Y plane for EUT P-T at $2,2.2,2.4,2.6,2.8,3 \mathrm{GHz}, 10^{0}$ rotation step 105

Figure 6.8 E-field polar plot based on azimuth rotation at X-Y plane for EUT P$\mathrm{B}$ at $2,2.2,2.4,2.6,2.8,3 \mathrm{GHz}, 10^{0}$ rotation increment ................ 106

Figure 6.9 E-field polar plot based on azimuth rotation at X-Y plane for EUT P$\mathrm{R}$ at $2,2.2,2.4,2.6,2.8,3 \mathrm{GHz}, 45^{0}$ rotation increment ................ 106

Figure 6.10 Measurement test setup inside VIRC, EUT P-R with fast-sensitive Efield probe inside....................................................................... 108

Figure 6.11 E-field maximum 3-axis component inside the VIRC .................... 109

Figure 6.12 Maximum E-field for $x-y-z$ component and total E-field inside the EUT P-B

Figure 6.13 Maximum E-field for $x-y-z$ component and total E-field inside the EUT P-T

Figure 6.14 Maximum E-field for $\mathrm{x}-\mathrm{y}-\mathrm{z}$ component and total E-field inside EUT-R 111

Figure 6.15 The maximum E-Field inside the box with random holes inside the FAR and VIRC 112 


\section{Acknowledgement}

First of all, I would give thanks and gratitude to God Almighty through his grace I'm able to complete this long, hardest and steep journey. Without his blessings this achievement would not be possible. Believe, God doesn't letting us down, He is letting us learn.

Then I would like to express my great appreciation and deeply grateful to my main supervisor, Prof. dr. ir. Frank Leferink. Frank, you're the best mentor I've ever had. Our first meeting was in Surabaya, and you're one of the keynote speakers for our national conferences at the end of 2014. I thought that was the first time I would have a life-changing moment. Frank, thank you for all your efforts in accompanying me through this struggle, I would not accomplish all this work without your guidance, your endless motivation, your relentless support as well as your scientific intuitive solutions. Your high-quality standard on academic research has brought me deeper into the research. I enjoyed our discussion related to the research as well as many things about collaboration. Every time we have a meeting, you will end up with your famous encouragement, "success", to motivate $\mathrm{PhD}$, and it works. You are strict about the research job but you really humble and show kindness or empathy about every days life, like family's life, especially talks about home-made Indonesian food during break time or coffee morning. Again, thanks a lot for your trust, your constructive and positive advice, your immense support during my $\mathrm{PhD}$ time.

I also would like to thank dr. Robert Vogt, a mysterious and helpful man, he is 'officially' my co-supervisor. Robert, thanks for fruitful discussion and sharing about dark side stuff, RC. Your knowledge and scientific experience is really help to push me forward to have better understanding. My knowledge and skills on RC have enhanced significantly ever since. I thank for your support and 'destructive' advice. (:)

Thanks also to all my committee members who are involved in my defense, Prof. Mark Bentum, Prof. V.M Primiani, Dr. Stefan, Dr. Andres, Prof. Kees Slump, and Prof. N. Kok. All of you have enriched my theses materials.

Lilian, you're the best secretary I've ever met. You're not only my co-worker but also my best friend ever during this PhD time. Special thanks to you, you always ready and willing to help for everyone in the group, especially me (-). You always come not only with solutions but also offered ideas and suggestions. Thanks for your help and assist me in administrative issues, sometimes you also have to listen about personal problem. Hope to see you soon in Bali, Lillian, for chilling out, enjoy the nice sunshine, delicious food, hot weather and of course beautiful beaches and other Balinese culture. Thanks a lot Lilian. 
For all the group friends, it is my pleasure to gratitude the Telecommunication Engineering (TE, it was) group. Frits, Olga, Bart, Cees, Alex, Stefan, Robert, Peter, Ibrahim, Niek, Iwan, Arjan, Zaher, Jesper, Koos, Bas, Tom, Warren, Mohammad, Alireza, Wibi, Imam, Daria, Alex, Denys, Mumpy, Nancy, Marco, Roelof, Wei, Evelina, Vasso, Tara, thanks for our friendship. Special thanks for Evelina for her contribution in this work. This group is amazing with nice cultural mixing. Keep moving.

Niek, you have been my longest colleagues in the group. Thanks for the friendship, stays healthy with football exercise, not with watery cucumber juice. And also congratulation to your marriage, God bless both of you. Stefan, thanks also for the great time at the group, although we met for short time but your presence always make the group smile and happier and forget a terrible PhD life for a while...success for your next carrier, send my best regards to Gisette and also congratulation with her pregnancy. Cees, get the thesis done and grab your victorious crown, and see you in Bali next year. Frits, thanks for your talks and discussion on some occasion, despite people thought it's not important, honestly you just want to help others. Zaher, finish your work and get married. Koos, your learning spirit always inspire me, you proved ages is nothing. Bas and Tom, thanks also for our friendship, you're team-working as $\mathrm{PhD}$ researcher, most of the time you're working a lot together although sometimes you're like Tom and Jerry, nice collaboration. (:). Warren, my Malaysian team-mate, please keep healthy, stay away from the snacks on your desk :- Don't forget you owe me Malaysian food, and keep practicing to beat my Indonesian meal. Alireza, it's nice to know you, you're an open-minded and religious person, it's always nice talks something with you, you're very friendly but too bad time very short for us. Alex, Denys, nice to know you before I left UT. You're such a good friend, always smile and spread positive mind. Daria, Mumpy, Nancy, you're though and smart women in the group, thumbs up for you. For Indonesian friends at the group, Imam and Wibi, good luck with your $\mathrm{PhD}$ journey, keep going and focus, make many friends and network to broaden your knowledge, and don't forget to come back, Indonesia still needs more talented people. I will surely miss the group atmosphere, especially the group outing and the Christmas dinner.

Thanks also for friends from Thales, Hans Schipper, Patrick, Remy, Hans Bergsma, and Casper which has given me many opportunities to work at the EMC lab as well as for open discussion and share experiences regarding EMC issues.

Many thanks also for friends outside the Netherlands, who have worked together and collaborated in some projects. Prof. Dave Thomas and his group from Nottingham University, UK and Dr. Zbigniew from Wrocław University of Science and Technology, Poland, thank you for your help and kindness during the last part of my thesis project. Soydan and Osman from Tubitak - Turkey, Emrah Tas from METAS - Switzerland, friends from INTA - Spain and CMI - Cezch Republic as 
well as the EMC team from Politechnica de Catalunya, UPC, Barcelona - Spain, Prof. Ferran Silva, Marco and Marc Pous, thanks for our friendship, it's been such great time to work and spent time with you all, hope to see you again. And I think Wroclaw and Barcelona are coincidently the most visited cities during my $\mathrm{PhD}$ life there, because of the famous beer and beautiful city.

Life is also enjoyable outside from the scientific environment as we have many Indonesian friends and comunity. I would like to thank to all friends in persatuan pelajar Indonesia di Enschede (Indonesian Student Association in Enschede, NL/PPIE) as a big family in NL. The list will be exhaustive which I couldn't mention one by one. Akbar, pak Helmy, mas Hero, Nico, pak Dadang, Pak Rizal, Aji, Fajar, mas Andri, Kamia, mbak Lulu, Dwi Cui, Chritoforus Dimas, Okky, Giri, Ihrom, Patrick, Arie, Kevin, Thomas, and others. Thanks for sharing and supporting each other when we have the hardest time in our study. My LIPI friend's, Pesi, Nova and mbak Dyah, good luck with your PhD journey. Thanks also to my junior classmate in bachelor degree, Dr. David Marpaung and his family. Thanks for our friendship and many success for your academic carrier.

My very nice neighbor, Rene and Appie, thanks for being family in NL, for having nice time together and discuss about many cultural knowledge.

This research was possible due to funding from RISETPro, Ministry of Research, Technology and Higher Education of Indonesia, supported by University of Twente (UTwente), and Lembaga Ilmu Pengetahuan Indonesia (LIPI). My sincere thanks for supporting me, giving permission and opportunity to pursue doctoral degree.

And last but not least, finally, I dedicated this work to my beloved family, parents, my wife and my precious and amazing two children, Arya and Indira. Bapak dan mamah, thank for who I am now, your endless love and care, make me feel so blessed until this achievement. To my wife, Patricia, you are the reason I dare to go out the comfort zone in Indonesia, live together as a family with a completely different environment. You sacrifice your settle work there to move out with me abroad, at Enschede-NL. Your commitment to walk through side by side and to take care of our children give me more strength to overcome the life difficulties in Enschede. Thanks for everything you did during living at the Netherlands for 4.5 years. You always made me feel like at the home town with your delicious traditional Indonesia food every day!! I really grateful having you in my life. Indira and Arya, you're such diamonds in my life and you all always give cherish and make my day when life is so shit to be confronted. Put your dream so high when you're falling down, the stars will keep you up.

God is good all the time...

Enschede, the Netherlands - November 2019 


\section{Biography}

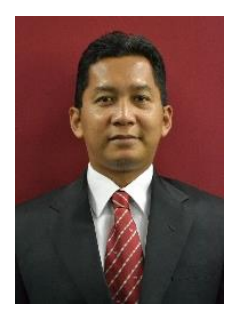

Dwi Mandaris was born in Bandung, Indonesia, in 1977. He received his M.S degree in electrical engineering at 2012 from Bandung Institute of Technology (ITB), Indonesia. Since 2005, he has been working for research center for Quality System and Testing Technology, P2SMTP - LIPI.

In 2008, he has been a junior researcher at LIPI and during period 2007 to 2009, he involved and became a member of Electromagnetic Compatibility (EMC) testing laboratory. At the end of 2013, his last position was head of electrical safety testing laboratory, P2SMTP - LIPI.

Currently, in 2015 he started a P.hD. degree in Telecommunication Engineering (TE) department - in 2020, became Power Electronics and EMC (PE \& EMC) - and joined the EMC Research group, Univ. of Twente, Netherlands. In particular, he has been involved in studies EMC emission and immunity measurement of audio-video, radio receivers, ITE equipment and household appliances. His main research interests include the area of design and development of EMC testing method, antenna for generating high field strength for RS EMC application, alternative for non-standard EMC measurement, EMC measurement in Reverberation Chamber and EM simulation for EMC application. 